UNIVERSIDADE DE SÃO PAULO

ESCOLA DE ENGENHARIA DE SÃO CARLOS

FIAZ AHMAD

PRODUÇÃO DE METANO EM RESPOSTA AO PRÉ-TRATAMENTO HÍDROTERMICO COM ÁCIDO SULFÚRICO E PERÓXIDO DE HIDROGÊNIO DO BAGAÇO DE CANA-DE-AÇUCAR

METHANE PRODUCTION IN RESPONSE TO SULFURIC ACIDIC AND HYDROGEN PEROXIDE ASSISTED HYDROTHERMAL PRETREATMENT OF SUGARCANE BAGASSE 
FIAZ AHMAD

\title{
METHANE PRODUCTION IN RESPONSE TO SULFURIC ACID AND HYDROGEN PEROXIDE ASSISTED HYDROTHERMAL PRETREATMENT OF SUGARCANE BAGASSE
}

\begin{abstract}
Thesis submitted to Engineering School of São Carlos - University of São Paulo as a partial requirement to obtain the title of Doctor of Science: Hydraulics Engineering and Sanitation
\end{abstract}

Area of Study: Hydraulics and Sanitation

Supervisor: Prof. Assoc. Maria Bernadete Amâncio Varesche

\section{Corrected version}

São Carlos/SP

2017 


\section{AUTORIZO A REPRODUÇÃO TOTAL OU PARCIAL DESTE TRABALHO, POR QUALQUER MEIO CONVENCIONAL OU ELETRÔNICO, PARA FINS DE ESTUDO E PESQUISA, DESDE QUE CITADA A FONTE.}

\footnotetext{
Ahmad, Fiaz

A286p PRODUÇÃO DE METANO EM REPOSTA AO PRÉ-TRATAMENTO HÍDROTERMICO COM ÁCIDO SULFÚRICO E PERÓXIDO DE HIDROGÊNIO DO BAGAÇO DE CANA-DE-AÇUCAR / Fiaz Ahmad; orientadora Maria Bernadete Amâncio Varesche; coorientador Edson Luiz Silva. São Carlos, 2017.

Tese (Doutorado) - Programa de Pós-Graduação em Engenharia Hidráulica e Saneamento e Área de Concentração em Hidráulica e Saneamento -- Escola de Engenharia de São Carlos da Universidade de São Paulo, 2017 .

1. Biogás. 2. Comunidade microbiana. 3. Lignina. I. Título.
} 


\section{FOLHA DE JULGAMENTO}

Candidato: Bacharel FIAZ AHMAD.

Título da tese: "Produção de metano em resposta ao pré-tratamento hidrotérmico com ácido sulfúrico e peróxido de hidrogênio do bagaço de cana de açúcar".

Data da defesa: 09/06/2017.

\section{Comissão Julgadora:}

Resultado:

Profa. Associada Maia Bernadełe Amâncio Varesche (Orientadora)

(Escola de Engenharia de São Carlos/EESC)

Prof. Titular Marcelo Zaiat

(Escola de Engenharia de São Carlos/EESC)

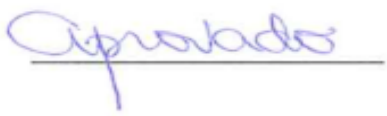

Profa. Dra. Sandra Imaculada Maintinguer

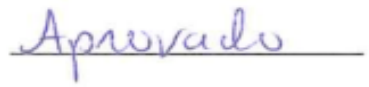

(Universidade Estadual Paulista "Júlio de Mesquita Filho"/UNESP- Rio Claro)

Profa. Dra. Katia Sivieri

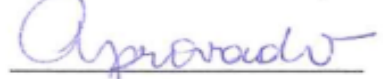

(Universidade Estadual Paulista "Júlio de Mesquita Filho"/UNESP-Araraquara)

Prof. Dr. Antonio José Gonçalves da Cruz

(Universidade Federal de São Carlos/UFSCar)

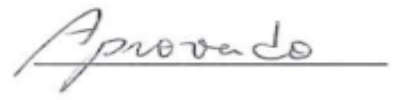

Coordenadora do Programa de Pós-Graduação em Engenharia Hidráulica e Saneamento:

Profa. Associada Maria Bernadete A. Varesche Silva

Presidente da Comissão de Pós-Graduação:

Prof. Associado Luis Fernando Costa Alberto 


\section{ACKNOWLEDGEMENTS}

This work has been conducted in the Laboratorio de Processos Biológicos, Engineering School of Sao Carlos - University of Sao Paulo for the duration 2014-2017. First of all, I would like to thank my supervisor Prof. Dr. Maria Bernadete Amâncio Varesche for giving me this opportunity and for all his invaluable advice during these years. Besides, I am very grateful to my co-supervisor, Prof. Dr. Edson Luiz Silva for all the conversations, statistical design of my experiments, and guidance. Moreover, I have been lucky to have fellow-researchers standing by me and sharing all the good and bad moments with experimental devices as well as during courses and seminars.

I am grateful to Dr. Isabel Kimiko Sakamoto, who helped me with the molecular biology experiments and her valuable time and suggestions for the write up of molecular biology. Without her sincere efforts, I could not have come this long. I also extend my gratitude to Dr. Eloisa Pozzi Gianotti for her help in preparation of Electron microscopy samples, Dr. Carolina Sabatini for her valuable help in sample analysis, Juliana for her kind assistance in 'monitoramento PAE', and Dr. Maria Angela Talarico who performed HPLC analyses and assist in GC analysis of methane measurement.

I humbly thankful to Vanessa Cristina da Silva, Kiemi Murata, Clara Faria for their invaluable company during my stay in Brazil; hanging out and festas $(-)$. I would like to extend my gratitude to Dr. Marcus Vinicius F Andrade for his kind help, share good and bad moments in and outside of the laboratory.

I am thankful for Dr. Maria Angela Talarico and Dr. Fabrício Montteran for their suggestion in qualification presentation.

I am humbly thankful for all my lab fellows at laboratorio de processos biologicos; Carla Diniz, Lívia Botta, Lucas Fuess, Clara Faria, Kiemi Murata, Vanessa Silva, Dagoberto Okada, Tiago Palladino, Thais Zaninetti, Rodrigo Carneiro, Adriana Maluf, Juliana Kawanishi, Fabrício Montteran, Raíssa Mazzareli, Alejandra Vila, Leonardo Gerosa, Alana Moura, Vinicius Masquetti, Carol Granatto and Leandro.

I am thankful for CAPES to fund this study, USP, EESC, SHS, and LPB.

Finally, family member; Riaz Ahmad, Ejaz Ahmad, lovely sisters; Khizra, Sidra and Iqra. Finally yet importantly, Mom and Dad, you all are my sunshine!

São Carlos, 2017

Fiaz Ahmad 
Ahmad, F. Produção de metano em reposta ao pré-tratamento hídrotermico com ácido sulfúrico e peróxido de hidrogênio do bagaço de cana-de-açucar. 2017. 224 p. Tese (Doutorado) - Escola de Engenharia de São Carlos, Universidade de São Paulo, São Carlos, 2017.

O objetivo deste estudo foi otimizar a produção de metano investigando as condições do prétratamento hidrotérmico assistido do bagaço da cana de açúcar sob impregnação de ácido $\left(\mathrm{H}_{2} \mathrm{SO}_{4}\right)$ e álcali $\left(\mathrm{H}_{2} \mathrm{O}_{2}\right)$ utilizando-se a razão substrato $\left(\mathrm{g} \mathrm{kg}^{-1}\right)$ - inóculo $\left(\mathrm{g} \mathrm{kg}^{-1}\right)$ de 1:2. Os reatores em batelada foram mantidos em condições mesofílicas $\left(37^{\circ} \mathrm{C}\right)$. Para otimizar as condições de prétratamento hidrotérmico, o design de composto central rotacional (DCCR) foi realizado utilizando três fatores: temperatura $\left({ }^{\circ} \mathrm{C}\right)$, tempo (min) e concentração do composto químico $\left(\mathrm{H}_{2} \mathrm{O}_{2}(\% \mathrm{v} / \mathrm{v})\right.$ e $\mathrm{H}_{2} \mathrm{SO}_{4}(\% \mathrm{p} / \mathrm{v})$ ). Trinta e dois pré-tratamentos hidrotérmicos foram realizados de acordo com a concepção do DCCR. O pré-tratamento hidrotérmico assistido do bagaço, com $\mathrm{H}_{2} \mathrm{O}_{2}$ resultou em maior recuperação de sólidos $(93,13 \%)$, elevado percentual de glicana $(139,52 \%)$ e menor recuperação de lignina $\left(76,48 \%\right.$ ) da fração sólida pré-tratada, se comparada aquele com $\mathrm{H}_{2} \mathrm{SO}_{4}$. Nesse último caso, observou-se menor rendimento de sólidos $(12,27 \%)$ e glucanas $(187,01 \%)$ e maior recuperação de lignina $(358,85 \%)$. No líquido hidrolisado do pré-tratamento hidrotérmico assistido do bagaço com $\mathrm{H}_{2} \mathrm{SO}_{4}$ foi observada elevada solubilização de DQO $\left(25,20 \mathrm{~g} \mathrm{~L}^{-1}\right)$, menor teor de fenóis totais $\left(658,13 \mathrm{mg} \mathrm{L}^{-1}\right)$, elevado sulfato $\left(7240 \mathrm{mg} \mathrm{L}^{-1}\right)$, furfural $(925,77$ - 2216,47 $\mathrm{mg}$ $\mathrm{L}^{-1}$ e 5-hidroximetilfurfural $\left(70,95-970,08 \mathrm{mg} \mathrm{L}^{-1}\right)$. Enquanto, foi registrado menor solubilização de DQO $\left(17,27 \mathrm{~g} \mathrm{~L}^{-1}\right)$, maior teor de fenóis totais $(3005,63 \mathrm{ppm})$, e menor concentração de furfural $\left(0\right.$ - $\left.56.91 \mathrm{mg} \mathrm{L}^{-1}\right)$, 5-hidroximetilfurfural $\left(2,56-50,60 \mathrm{mg} \mathrm{L}^{-1}\right) \mathrm{com}_{2} \mathrm{O}_{2}$. Em relação ao a produção de metano nas condições com $\mathrm{H}_{2} \mathrm{O}_{2}$, observou-se $5.59 \mathrm{Nmmol} \mathrm{g}^{-1} \mathrm{STV}\left(2 \% \mathrm{v} / \mathrm{v} \mathrm{H}_{2} \mathrm{O}_{2}\right)$ a $13.49 \mathrm{Nmmol} \mathrm{g}^{-1}$ STV (6\% v/v $\left.\mathrm{H}_{2} \mathrm{O}_{2}\right)$. No tratamento com $7.36 \%$ de $\mathrm{H}_{2} \mathrm{O}_{2}$ observou-se 14,43 Nmmol g ${ }^{-1}$ STV que foi $118.16 \%$ maior se comparado com o bagaço não-tratado (6,60 Nmmol g ${ }^{-}$ $\left.{ }^{1} \mathrm{STV}\right)$. Inibição metanogênica foi observada na maioria dos reatores pré-tratados com $\mathrm{H}_{2} \mathrm{SO}_{4}(1$ $-3 \% \mathrm{p} / \mathrm{v}$ ), e a produção mínima observada foi de $0.58 \mathrm{Nmmol} \mathrm{g}^{-1} \mathrm{TVS}$ no pré-tratamento com $2 \%$ $\mathrm{p} / \mathrm{v}$ de $\mathrm{H}_{2} \mathrm{SO}_{4}$. Ácido acético foi o principal ácido orgânico volátil observado somente no reatores por tratamento de $\mathrm{H}_{2} \mathrm{O}_{2}$. Por meio da A análise da comunidade microbiana, para o domínio Bacteria, foi observado prevalência dos gêneros AUTHM297, Clostridium e Treponema nos reatores cujo substrato foi pré-tratado $\operatorname{com~} \mathrm{H}_{2} \mathrm{O}_{2}$. Gêneros relacionados à degradação de compostos aromáticos foram identificados e estiveram em maior abundância nos reatores cujo substrato foi pré-tratado com $\mathrm{H}_{2} \mathrm{SO}_{4}$. Methanolinea, Methanobacterium, e Methanosaeta foram os microrganismos do domínio Archaea mais abundantes e identificados em ambos os prétratamentos. $\mathrm{O}$ pré-tratamento hidrotérmico assistido $\mathrm{com}_{2} \mathrm{H}_{2}$ foi a melhor opção em relação ao $\mathrm{H}_{2} \mathrm{SO}_{4}$, devido a maior solubilização de lignina, maior recuperação de glucano e baixa produção de compostos furânicos.

Palavras-chave: biogás, comunidade microbiana, lignina 
Ahmad, F. Methane production in response to acidic and alkaline hydrogen peroxide assisted hydrothermal pretreatment of sugarcane bagasse. 2017. 224 p. Thesis (PhD) - Engineering School of Sao Carlos, University of Sao Paulo, Sao Carlos, 2017.

The aim of this study was to optimize methane production by investigating hydrothermal pretreatment of sugarcane bagasse impregnated with acid $\left(\mathrm{H}_{2} \mathrm{SO}_{4}\right)$ and alkaline $\mathrm{H}_{2} \mathrm{O}_{2}$ using substrate $\left(\mathrm{g} \mathrm{kg}^{-1}\right)$-inoculum $\left(\mathrm{g} \mathrm{kg}^{-1}\right)$ ratio of 1:2. Batch reactors were realized under mesophilic conditions $\left(37^{\circ} \mathrm{C}\right)$. A central composite design $(\mathrm{CCD})$ involving three factors; temperature $\left({ }^{\circ} \mathrm{C}\right)$, time (min), and chemical compound concentration $\left(\mathrm{H}_{2} \mathrm{O}_{2}(\% \mathrm{v} / \mathrm{v})\right.$ and $\left.\mathrm{H}_{2} \mathrm{SO}_{4}(\% \mathrm{w} / \mathrm{v})\right)$ was utilized to optimize hydrothermal pretreatment. Thirty-two hydrothermal pretreatments were conducted according to CCD. $\mathrm{H}_{2} \mathrm{O}_{2}$ assisted hydrothermal pretreatment resulted in higher solid recovery (93.13\%), higher percent glucan increase $(139.52 \%)$, and lower lignin recovery $(76.48 \%)$ in pretreated solid fraction in comparison to $\mathrm{H}_{2} \mathrm{SO}_{4}$ impregnated hydrothermal pretreatment. In the latter case, lower solid yield (12.27\%), glucan recovery (187.01\%) and higher lignin recovery (358.85\%) was recorded. Higher COD solubilization $\left(25.20 \mathrm{~g} \mathrm{~L}^{-1}\right)$, lower total phenolic (content $658.13 \mathrm{ppm})$, higher sulfate $\left(7240 \mathrm{mg} \mathrm{L}^{-1}\right)$, furfural $\left(925.77-2216.47 \mathrm{mg} \mathrm{L}^{-1}\right)$ and 5hydroxymehtylfurfural (70.95-970.08 $\mathrm{mg} \mathrm{L}^{-1}$ ) were observed in liquid hydrolysate of $\mathrm{H}_{2} \mathrm{SO}_{4}$ assisted hydrothermal pretreatment. While lower COD solubilization $\left(17.75 \mathrm{mg} \mathrm{L}^{-1}\right)$, higher total phenolic content $(3005.63 \mathrm{ppm})$, lower concentration of furfural $\left(0-56.91 \mathrm{mg} \mathrm{L}^{-1}\right)$ and 5hydroxymethylfurfural $\left(2.56-56.60 \mathrm{mg} \mathrm{L}^{-1}\right)$ was recorded with $\mathrm{H}_{2} \mathrm{O}_{2}$ assisted hydrothermal pretreatment. Concerning methane production for $\mathrm{H}_{2} \mathrm{O}_{2}$ assisted conditions, $5.59 \mathrm{Nmmol} \mathrm{g}{ }^{-1}$ TVS $\left(2 \% \mathrm{H}_{2} \mathrm{O}_{2}\right)$ to $13.49 \mathrm{Nmmol} \mathrm{g}^{-1}$ TVS $\left(6 \% \mathrm{H}_{2} \mathrm{O}_{2}\right)$ was recorded. However, pretreatment with $7.36 \%$ $\mathrm{H}_{2} \mathrm{O}_{2}$ resulted in $14.43 \mathrm{Nmmol} \mathrm{g}^{-1}$ TVS, which was $118.16 \%$ higher comparing to untreated sugarcane bagasse $\left(6.60 \mathrm{Nmmol} \mathrm{g}^{-1} \mathrm{TVS}\right)$. Methanogenic inhibition was recorded for most of the $\mathrm{H}_{2} \mathrm{SO}_{4}$.pretreated reactor $\left(1-3 \% \mathrm{w} / \mathrm{v} \mathrm{H}_{2} \mathrm{SO}_{4}\right)$. Minimum $\mathrm{CH}_{4}$ production observed was 0.58 Nmmol g ${ }^{-1}$ TVS in pretreatment O-HSO $\left(2 \% \mathrm{w} / \mathrm{v}_{2} \mathrm{SO}_{4}\right)$. Acetic acid was the predominant volatile fatty acid observed in digestion process of $\mathrm{H}_{2} \mathrm{O}_{2}$ treated batch reactor however was not recorded in $\mathrm{H}_{2} \mathrm{SO}_{4}$ treated batch reactors. Microbial community analysis indicated the prevalence of unclassified AUTHM297, Clostridium, and Treponema related genera in $\mathrm{H}_{2} \mathrm{O}_{2}$ treated reactors. Genera related aromatic compound degradation were identified and abundant in $\mathrm{H}_{2} \mathrm{SO}_{4}$ treated reactors. Methanolinea, Methanobacterium, and Methanosaeta were abundant methanogens in both pretreatments. Hydrogen peroxide assisted hydrothermal pretreatment was verified as a better choice for methane production comparing to sulfuric acid assisted hydrothermal pretreatment primarily on account of higher lignin solubilization, higher glucan recovery, and lower furanic compounds production

Keywords: biogas, microbial community, lignin 


\section{LIST OF FIGURES}

Figure 3.1 - The components and structure of lignocellulosic biomass (modified after (Edward, 2008)) . 10 Figure 3.2 - Mechanism of inhibitory compounds production during hydrothermal pretreatment modified after (Jönsson and Martín, 2016)

Figure 3.3 - Schematic conversion of macromolecules into biomethane in anaerobic digestion process

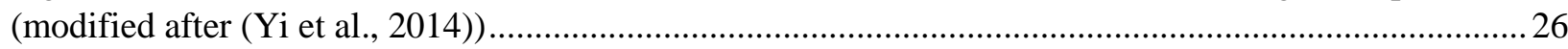

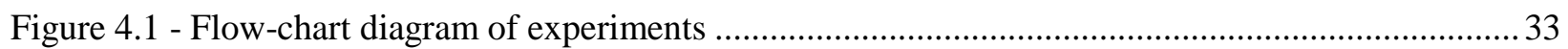

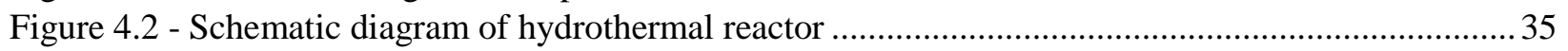

Figure 5.1 - Comparison of SEM images; Raw (A), B-HO (B), and K-HO (C) ....................................56

Figure 5.2 - SEM images of B-HO indicating pseudo-lignin droplets on cell wall surface.......................57

Figure 5.3 - SEM images of K-HO indicating porous surface due to lignin removal ............................58

Figure 5.4 - Impact of $\mathrm{H}_{2} \mathrm{O}_{2}$ assisted hydrothermal pretreatment on visual appearance of sugarcane bagasse; (A) Highest studied temperature (pretreatment run $\mathrm{O}-\mathrm{HO}-213.6{ }^{\circ} \mathrm{C}$ ), (B) Lowest studied

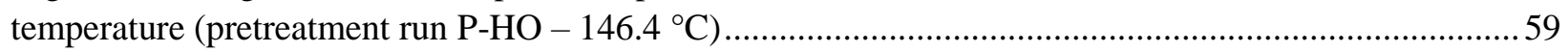

Figure 5.5 - Time-course profile of cumulative methane production for solid fraction of $\mathrm{H}_{2} \mathrm{O}_{2}$ impregnated

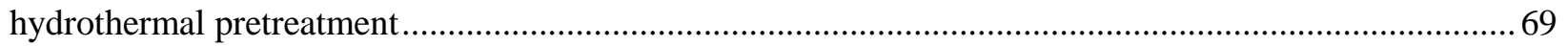

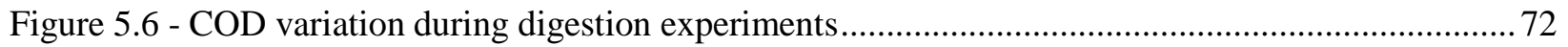

Figure 5.7 - Total carbohydrates consumption during digestion experiments ........................................ 75

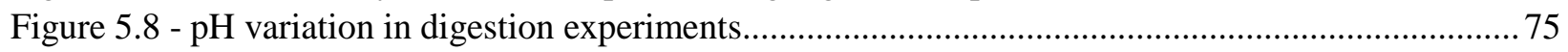

Figure 5.9 - Organic acids at three selected position on methane production curve; A (Initial stage of reactor), B (approx. exponential phase), C (reactor termination) .......................................................... 76

Figure 5.10 - Interaction between temperature $\left({ }^{\circ} \mathrm{C}\right)$ and time $(\mathrm{min})$ on the methane concentration........... 79 Figure 5.11 - Interaction between temperature $\left({ }^{\circ} \mathrm{C}\right)$ and hydrogen peroxide $(\% \mathrm{v} / \mathrm{v})$ on methane

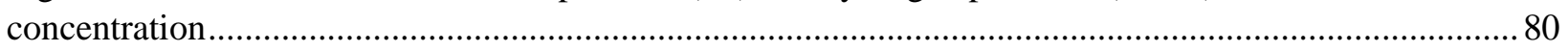

Figure 5.12 - Interaction between hydrogen peroxide $(\% \mathrm{v} / \mathrm{v})$ and time $(\mathrm{min})$ on the methane yield ........ 81

Figure 5.13 - Pearson Similarity Coefficient $\left(\mathrm{S}_{\mathrm{c}}\right)$ of DGGE band patterns for bacterial communities....... 83

Figure 5.14 - Pearson Similarity Coefficient $\left(\mathrm{S}_{\mathrm{c}}\right)$ of DGGE band patterns for archaeal communities ....... 86 Figure 5.15 - Bacterial community classification at Phylum level. Relative abundance (RA\%) less than 1 in the samples was accumulated and presented as Others.

Figure 5.16 - Bacterial community classification at Family-level. Relative abundance (RA\%) less than 1

in the samples was accumulated and presented as Others ................................................................ 91

Figure 5.17 - Bacterial community classification at Genus-level. Relative abundance less than 1 in the samples was accumulated and presented as 'Others'.

Figure 5.18 - Archaeal community classification for selected $\mathrm{H}_{2} \mathrm{O}_{2}$ pretreated samples at Class-level. All taxonomic groups with relative abundance less than $1 \%$ are accumulated and presented as others ..........96 Figure 5.19 - Archaeal community classification for selected $\mathrm{H}_{2} \mathrm{O}_{2}$ samples at Family-level. All taxonomic groups with relative abundance less than $1 \%$ are accumulated and presented as others ..........97 Figure 5.20 - Archaeal community classification for selected $\mathrm{H}_{2} \mathrm{O}_{2}$ samples at Genus-level. All taxonomic groups with relative abundance less than $1 \%$ are accumulated and presented as others. ........................97 Figure 5.21 - Comparison between SEM images of untreated sugarcane bagasse (A) and O-HSO (B, C)

Figure 5.22 - Impact of $\mathrm{H}_{2} \mathrm{SO}_{4}$ assisted hydrothermal pretreatment on visual appearance of sugarcane bagasse; (A) Highest studied temperature (pretreatment run O-HSO $-213.6^{\circ} \mathrm{C}$ ), (B) Lowest studied

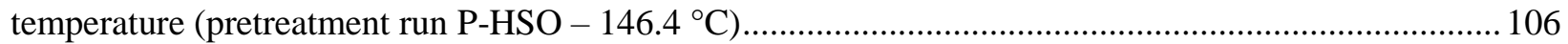
Figure 5.23 - Time-course profile of Methane production for solid fraction of $\mathrm{H}_{2} \mathrm{SO}_{4}$-catalyzed hydrothermal pretreatment. 
Figure 5.24 - Relationship between klason lignin (\%) and methane production 116

Figure 5.25 - $\mathrm{COD}\left(\mathrm{mg} \mathrm{L}^{-1}\right)$ variation during digestion process of $\mathrm{H}_{2} \mathrm{SO}_{4}$ pretreated samples ..... 118 Figure 5.26 - Total carbohydrate content $\left(\mathrm{mg} \mathrm{L}^{-1}\right)$ during digestion process of $\mathrm{H}_{2} \mathrm{SO}_{4}$ pretreated samples

Figure 5.27 - $\mathrm{pH}$ variation during digestion process..................................................................... 120 Figure 5.28 - Interaction between temperature $\left({ }^{\circ} \mathrm{C}\right)$ and time $(\mathrm{min})$ variable on Methane (Nmmol g$\left.{ }^{-1} \mathrm{TVS}\right)$

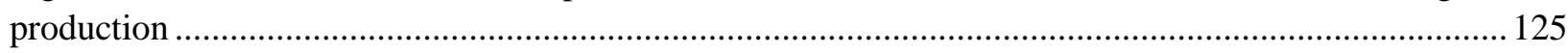
Figure 5.29 - Interaction between temperature $\left({ }^{\circ} \mathrm{C}\right)$ and $\mathrm{H}_{2} \mathrm{SO}_{4}(\% \mathrm{w} / \mathrm{v})$ variable on Methane $\left(\mathrm{Nmmol} \mathrm{g}^{-1}\right.$

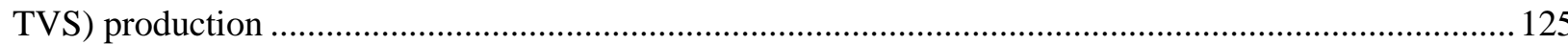
Figure 5.30 - Interaction between Time ( $\mathrm{min}$ ) and $\mathrm{H}_{2} \mathrm{SO}_{4}(\% \mathrm{w} / \mathrm{v})$ variable on Methane (Nmmol g${ }^{-1}$ TVS) production 126

Figure 5.31 - PCR-DGGE band profile for bacterial community structure for $\mathrm{H}_{2} \mathrm{SO}_{4}$ impregnated anaerobic reactors

Figure 5.32 - PCR-DGGE band profile for archaeal community of $\mathrm{H}_{2} \mathrm{SO}_{4}$ impregnated anaerobic reactors

Figure 5.33 - Bacterial community classification at Phylum-level. Relative abundance less than $1 \%$ of the samples was accumulated and presented as 'Others'. 133

Figure 5.34 Bacterial community classification for $\mathrm{H}_{2} \mathrm{SO}_{4}$ pretreated samples at Genus-level. Relative abundance less than $1 \%$ of the samples was accumulated and presented as 'Others' ............................136 Figure 5.35 - Archaeal community classification for selected $\mathrm{H}_{2} \mathrm{SO}_{4}$ pretreated samples at Class-level. 137 Figure 5.36 - Archaeal community classification for $\mathrm{H}_{2} \mathrm{SO}_{4}$ pretreated samples at Family-level. Relative abundance less than $1 \%$ of the samples was accumulated and presented as 'Others' 138 Figure 5.37 - Archaeal community classification for $\mathrm{H}_{2} \mathrm{SO}_{4}$ pretreated samples at Genus-level. Relative abundance less than $1 \%$ of the samples was accumulated and presented as 'Others' 139 Figure 5.38 - Microbial community structure of positive control at Genus-level for bacteria (A) and archaea (B). All the taxonomic groups less than 1\% are accumulated and represented as 'Others' ......... 142 Figure 5.39 - Microbial community structure of bacteria (upper row) and archaea (lower row) at Genuslevel for selected $\mathrm{H}_{2} \mathrm{O}_{2}$ treated batch digestion reactors. All the taxonomic groups less than $1 \%$ are accumulated and represented as 'Others'

Figure 5.40 - Microbial community structure of bacteria (upper row) and archaea (lower row) at Genuslevel for selected $\mathrm{H}_{2} \mathrm{SO}_{4}$ treated batch digestion reactors. All the taxonomic groups less than $1 \%$ are accumulated and represented as 'Others'

Figure 9.1 - Cumulative methane (Nmmol g-1 TVS) production with Modified Gompertz fit for A-HO 191 Figure 9.2 - Cumulative methane (Nmmol g${ }^{-1}$ TVS) production with Modified Gompertz fit for B-HO 191 Figure 9.3 - Cumulative methane (Nmmol g-1 TVS) production with Modified Gompertz fit for C-HO 192 Figure 9.4 - Cumulative methane (Nmmol g-1 TVS) production with Modified Gompertz fit for D-HO 192 Figure 9.5 - Cumulative methane (Nmmol g-1 TVS) production with Modified Gompertz fit for E-HO 193 Figure 9.6 - Cumulative methane (Nmmol g ${ }^{-1}$ TVS) production with Modified Gompertz fit for F-HO. 193 Figure 9.7 - Cumulative methane (Nmmol g${ }^{-1}$ TVS) production with Modified Gompertz fit for G-HO 194 Figure 9.8 - Cumulative methane (Nmmol g ${ }^{-1}$ TVS) production with Modified Gompertz fit for H-HO 194 Figure 9.9 - Cumulative methane (Nmmol g ${ }^{-1}$ TVS) production with Modified Gompertz fit for I-HO .195 Figure 9.10 - Cumulative methane (Nmmol g${ }^{-1}$ TVS) production with Modified Gompertz fit for J-HO195 Figure 9.11 - Cumulative methane (Nmmol g${ }^{-1}$ TVS) production with Modified Gompertz fit for K-HO

Figure 9.12 - Cumulative methane (Nmmol g${ }^{-1} \mathrm{TVS}$ ) production with Modified Gompertz fit for L-HO 
Figure 9.13 - Cumulative methane (Nmmol g-1 TVS) production with Modified Gompertz fit for M-HO

Figure 9.14 - Cumulative methane (Nmmol g-1 TVS) production with Modified Gompertz fit for N-HO

Figure 9.15 - Cumulative methane (Nmmol g-1 TVS) production with Modified Gompertz fit for O-HO

Figure 9.16 - Cumulative methane (Nmmol g ${ }^{-1}$ TVS) production with Modified Gompertz fit for P-HO 198

Figure 9.17 - Cumulative methane (Nmmol g ${ }^{-1}$ TVS) production with Modified Gompertz fit for A-HSO

Figure 9.18 - Cumulative methane (Nmmol g ${ }^{-1}$ TVS) production with Modified Gompertz fit for B-HSO 199

Figure 9.19 - Cumulative methane (Nmmol g-1 TVS) production with Modified Gompertz fit for C-HSO

Figure 9.20 - Cumulative methane (Nmmol g ${ }^{-1}$ TVS) production with Modified Gompertz fit for D-HSO

Figure 9.21 - Cumulative methane (Nmmol g ${ }^{-1}$ TVS) production with Modified Gompertz fit for E-HSO

Figure 9.22 - Cumulative methane (Nmmol g-1 TVS) production with Modified Gompertz fit for F-HSO

201

Figure 9.23 - Cumulative methane (Nmmol g-1 TVS) production with Modified Gompertz fit for G-HSO

Figure 9.24 - Cumulative methane (Nmmol g ${ }^{-1}$ TVS) production with Modified Gompertz fit for H-HSO

Figure 9.25 - Cumulative methane (Nmmol g ${ }^{-1}$ TVS) production with Modified Gompertz fit for I-HSO

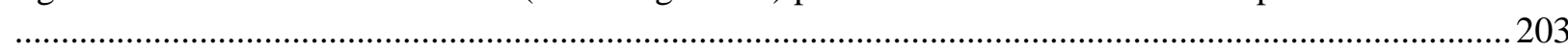

Figure 9.26 - Cumulative methane (Nmmol g-1 TVS) production with Modified Gompertz fit for J-HSO

Figure 9.27 - Cumulative methane ( $\mathrm{Nmmol} \mathrm{g}^{-1} \mathrm{TVS}$ ) production with Modified Gompertz fit for K-HSO

Figure 9.28 - Cumulative methane (Nmmol g-1 TVS) production with Modified Gompertz fit for L-HSO

Figure 9.29 - Cumulative methane (Nmmol g-1 TVS) production with Modified Gompertz fit for M-HSO

Figure 9.30 - Cumulative methane (Nmmol g ${ }^{-1}$ TVS) production with Modified Gompertz fit for N-HSO

Figure 9.31 - Cumulative methane (Nmmol g ${ }^{-1}$ TVS) production with Modified Gompertz fit for O-HSO

Figure 9.32 - Cumulative methane (Nmmol g ${ }^{-1}$ TVS) production with Modified Gompertz fit for P-HSO 


\section{LIST OF TABLES}

Table 3.1 - Composition of agricultural and other lignocellulosic residues on dry matter basis (Saini et al., 2015)

Table 3.2 - Chemical composition of sugarcane bagasse on DM basis ................................................. 9

Table 3.3 - Hydrolysate composition in response to hydrothermal pretreatment of various feedstocks .... 22

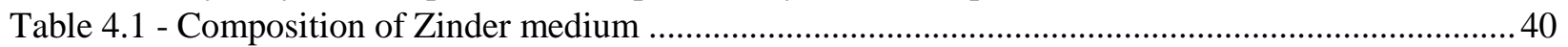

Table 4.2 - Composition of trace metal solution and vitamin solution - Zinder medium ..........................41

Table 4.3 - Coded and uncoded values for central composite design for $\mathrm{H}_{2} \mathrm{SO}_{4}$ and $\mathrm{H}_{2} \mathrm{O}_{2}$ assisted

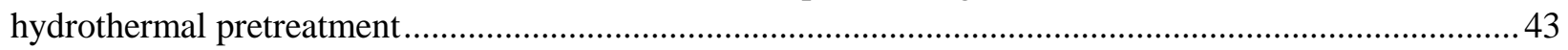

Table 4.4 - Central composite design matrix for $\mathrm{H}_{2} \mathrm{O}_{2}$ assisted hydrothermal pretreatment .................... 44

Table 4.5 - Central composite design matrix for $\mathrm{H}_{2} \mathrm{SO}_{4}$ assisted hydrothermal pretreatment .................. 44

Table 4.6 - Bacterial and Archaeal primers and sequences for Illumina MiSeq Sequencing .....................46

Table 5.1 - Compositional analysis of sugarcane bagasse ................................................................ 47

Table 5.2 - Chemical characterization of solid fraction of $\mathrm{H}_{2} \mathrm{O}_{2}$ pretreated sugarcane bagasse; Solid yield (\%), Glucan (g $100 \mathrm{~g}^{-1} \mathrm{TS}$ ), Xylan (g $100 \mathrm{~g}^{-1} \mathrm{TS}$ ), Klason lignin (\%), Glucan increase \%), Xylan removal

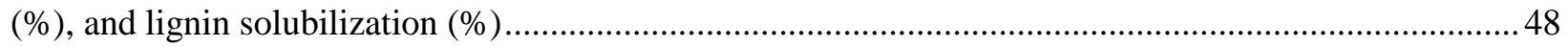

Table 5.3 - Analysis of variance (ANOVA) for glucan content ( $100 \mathrm{~g}^{-1} \mathrm{TS}$ ) in pretreated solids

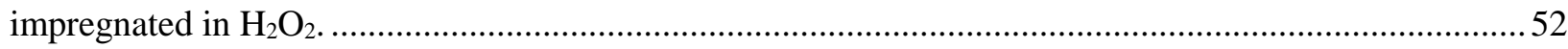

Table 5.4 - Analysis of variance (ANOVA) for xylan content (g $100 \mathrm{~g}^{-1} \mathrm{TS}$ ) in pretreated solids

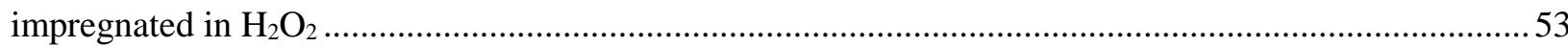

Table 5.5 - Analysis of variance (ANOVA) for percent lignin dissolution in pretreated solids impregnated

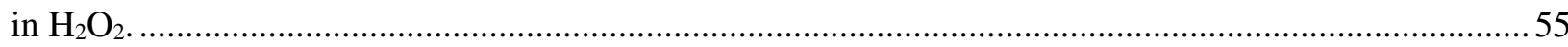

Table 5.6 - Characterization of liquid hydrolysate obtained from $\mathrm{H}_{2} \mathrm{O}_{2}$ assisted hydrothermally pretreated

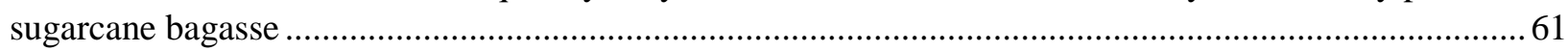

Table 5.7 - Selected organic acids, furanic compounds, and sugar monomers in liquid hydrolysate obtained from $\mathrm{H}_{2} \mathrm{O}_{2}$ assisted hydrothermal pretreatment of sugarcane bagasse .................................... 64

Table 5.8 - Regression analysis for the experimental methane production for quadratic response surface

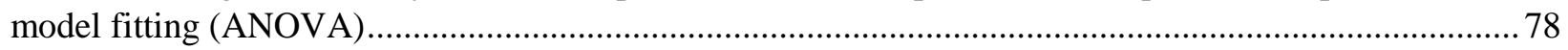

Table 5.9 - Kinetic parameters of methane production from $\mathrm{H}_{2} \mathrm{O}_{2}$ pretreated sugarcane bagasse ............. 82 Table 5.10 - Microbial diversity (Shannon-Wiener and Dominance) for Bacteria and Archaea of $\mathrm{H}_{2} \mathrm{O}_{2}$

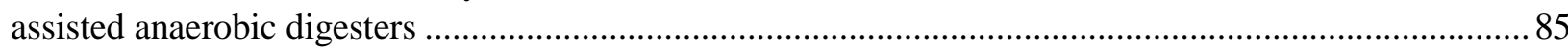

Table 5.11 - Impact of $\mathrm{H}_{2} \mathrm{SO}_{4}$ impregnation of sugarcane bagasse before hydrothermal pretreatment on Solid yield (\%), Glucan (g $100 \mathrm{~g}^{-1}$ TVS), Xylan (g $100 \mathrm{~g}^{-1}$ TVS), Klason Lignin (\%), Glucan increase (\%), xylan removal (\%), and Lignin Recovery (\%) ................................................................................ 98 Table 5.12 - Analysis of variance (ANOVA) for glucan content $\left(\mathrm{g} 100 \mathrm{~g}^{-1} \mathrm{TS}\right)$ in pretreated solids

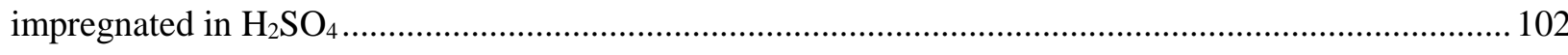
Table 5.13 - Analysis of variance for percent lignin recovery in pretreated solids impregnated in $\mathrm{H}_{2} \mathrm{SO}_{4}$

Table 5.14 - Characterization of liquid hydrolysate obtained from $\mathrm{H}_{2} \mathrm{SO}_{4}$ aided hydrothermal pretreatment

Table 5.15 - Selected organic acid and furanic compounds in liquid hydrolysate obtained from $\mathrm{H}_{2} \mathrm{SO}_{4}$ assisted hydrothermal pretreatment of sugarcane bagasse .................................................................. 111 Table 5.16 - Experimental value of methane (Nmmol $\mathrm{g}^{-1} \mathrm{TVS}$ ) and kinetic analysis data obtained from

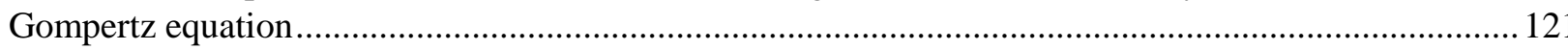

Table 5.17 - Multiple-regression analysis for experimental methane production for quadratic response methodology 
Table 5.18 - Microbial diversity (Shannon-Wiener and Dominance) for Bacteria and Archaea of $\mathrm{H}_{2} \mathrm{SO}_{4}$ assisted anaerobic reactors..... 130

Table 9.1 - Batch reactor composition of $\mathrm{H}_{2} \mathrm{O}_{2}$ assisted hydrothermal pretreatment for anaerobic digestion 189

Table 9.2 -Batch reactor composition of $\mathrm{H}_{2} \mathrm{SO}_{4}$ assisted hydrothermal pretreatment for anaerobic digestion 190 


\section{LIST OF ABBREVIATIONS}

31-PNMR Phosphorus-31 nuclear magnetic resonance

AD

AIL

Aka

ARDRA

ASL

ATR-FTIR

BMP

CAPES

CCD

COD

CTC

DGGE

DM

DNA

DP

FISH

FTIR

5-HMF

HPLC

$\mathrm{H}_{2} \mathrm{SO}_{4}$

$\mathrm{H}_{2} \mathrm{O}_{2}$

$\mathrm{K}_{\mathrm{w}}$

LPB

NCBI

NMR

NREL
Anaerobic digestion

Acid insoluble lignin

Also known as

Amplified ribosomal DNA restriction analysis

Acid soluble lignin

Attenuated total reflectance Fourier transform spectroscopy

Biomethane potential

Coordenação de Aperfeiçoamento de Pessoal de Nível Superior

Central composite design

Chemical oxygen demand

Cane technology center

Denaturing gradient gel electrophoresis

Dry matter

Deoxyribonucleic acid

Degree of polymerization

Fluorescence in situ hybridization

Fourier transform infrared spectroscopy

5-hydroxymethylfurfural

High performance liquid chromatography

Sulfuric acid

Hydrogen peroxide

Water autohydrolysis constant

Laboratório de processos Biológicos

National center for biotechnology information

Nuclear magnetic resonance

National renewable energy laboratory 
OTU

PCR

$\mathrm{pH}$

RISA

RNA

SCB

SEM

SRB

SUS

TCD

TEM

TGGE

TPC

TRFLP

TS

UNICA

VFA

TVS

USP

WIS

XRD
Operational taxonomic unit

Polymerase chain reaction

Potential of hydrogen

Ribosomal intergenic spacer analysis

Ribonucleic acid

Sugarcane bagasse

Scanning electron microscopy

Sulfate reducing bacteria

Steel used stainless

Thermal conductivity detector

Transmission electron microscopy

Temperature gradient gel electrophoresis

Total phenolic content

Terminal restriction fragment length polymorphism

Total solids

Brazilian sugarcane industry association

Volatile fatty acids

Total volatile solids

University of São Paulo

Water insoluble solid

X-ray powder diffraction 


\section{LIST OF SYMBOLS}

$\begin{array}{ll}\% & \text { Percentage } \\ { }^{\circ} \mathrm{C} & \text { Degree Celsius } \\ \mathrm{D} & \text { Dominance } \\ \mathrm{g} \mathrm{L}^{-1} & \text { Gram per liter } \\ \mathrm{g} 100 \mathrm{~g}^{-1} \mathrm{TS} & \text { Gram per hundred gram of total solids } \\ \mathrm{h} & \text { Hour } \\ \mathrm{H}^{\prime} & \text { Shannon-Wiener index } \\ \mathrm{HT}^{\circ} & \text { Hydrothermal pretreatment } \\ \mathrm{min} & \text { Minute } \\ \mathrm{mg} \mathrm{L}^{-1} & \text { Milligram per liter } \\ \mathrm{Nmmol} \mathrm{g}^{-1} \mathrm{TVS}^{-1} & \text { Normal millimoles per gram of total volatile solids } \\ \mathrm{Nmmol} \mathrm{g}^{-1} \mathrm{TVS} \mathrm{h}^{-1} & \text { Normal millimoles per gram of total volatile solids per hour }\end{array}$




\section{TABLE OF CONTENTS}

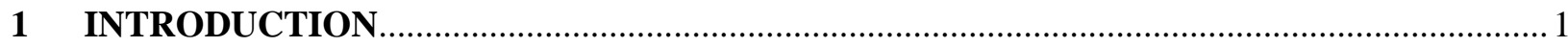

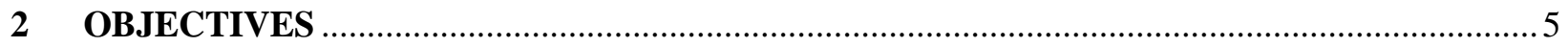

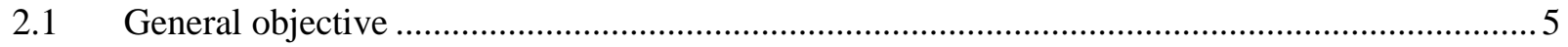

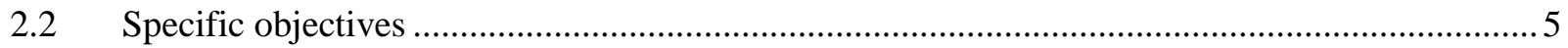

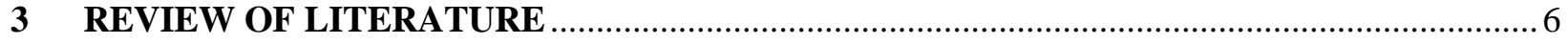

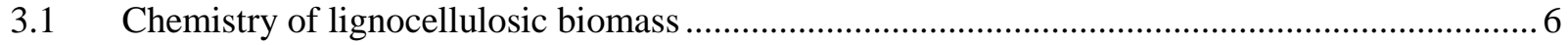

$3.2 \quad$ Hydrothermal pretreatment mechanism ........................................................................... 11

3.3 Impact of hydrothermal pretreatment on the lignocellulosic biomass composition on solid

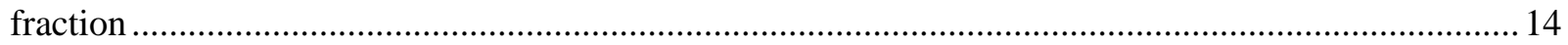

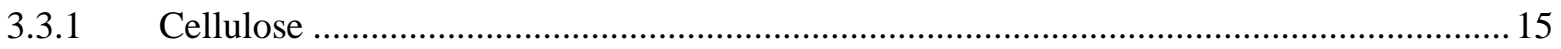

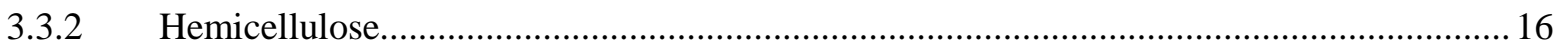

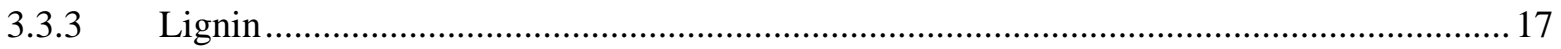

3.4 Impact of hydrothermal pretreatment on hydrolysate on liquid fraction …………………….... 19

3.5 Impact of hydrothermal pretreatment on morphological structure of biomass ............................2 23

3.6 Anaerobic Digestion: process and affecting parameters .......................................................2.

3.7 Hydrothermal pretreatment in relation to subsequent methanogenesis .....................................2. 28

3.8 Microbial community structure of anaerobic digestion and molecular fingerprinting techniques 31

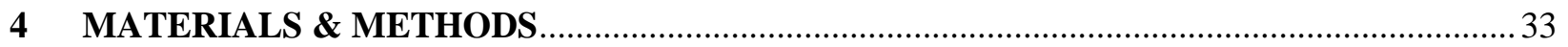

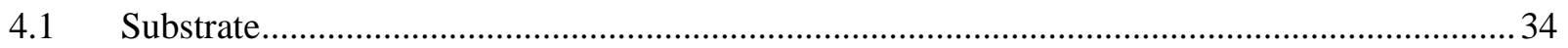

4.2 Hydrothermal pretreatment ............................................................................................. 34

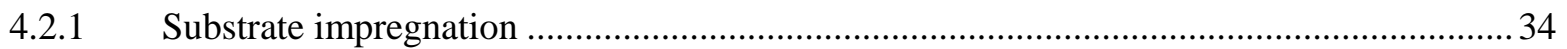

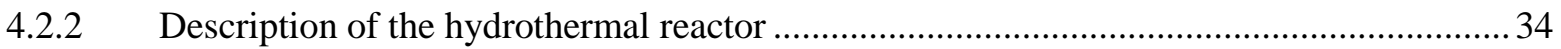

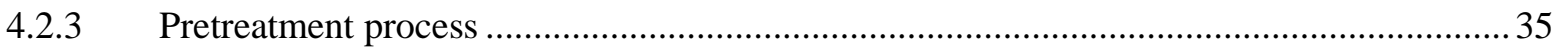

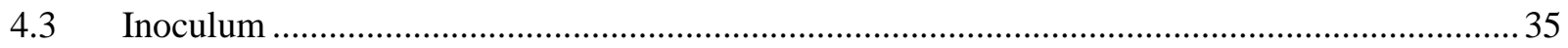

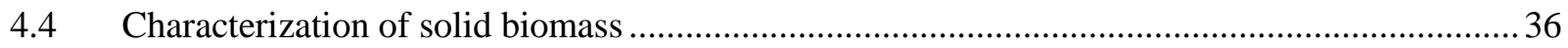

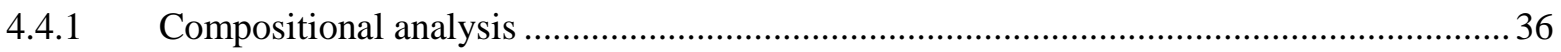

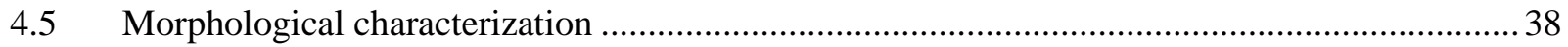

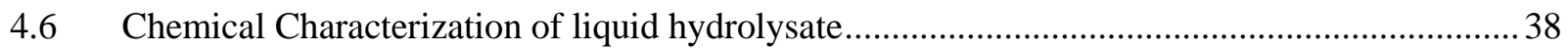

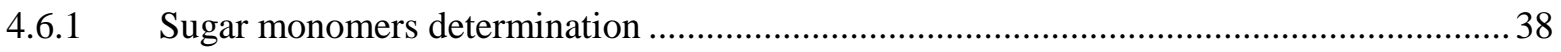

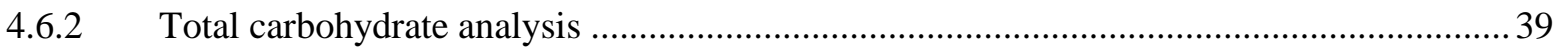

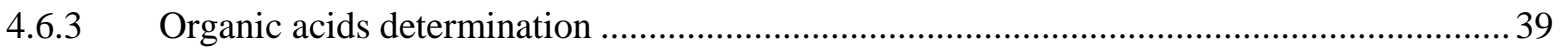

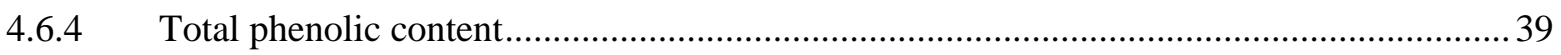

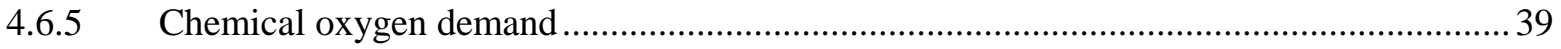




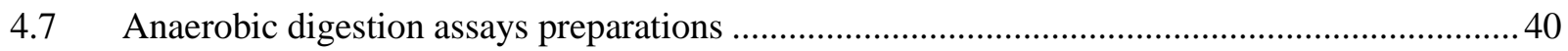

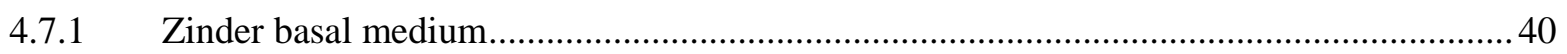

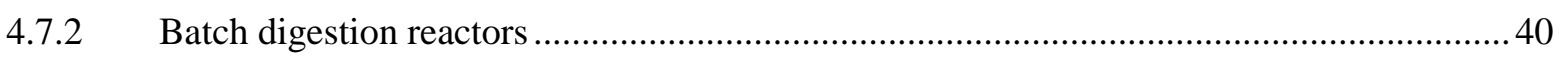

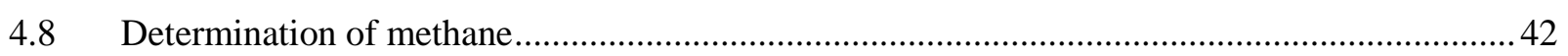

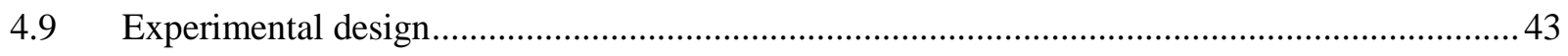

4.10 Microbial community characterization by molecular techniques ..........................................45

4.10.1 Sample collection and DNA extraction....................................................................... 45

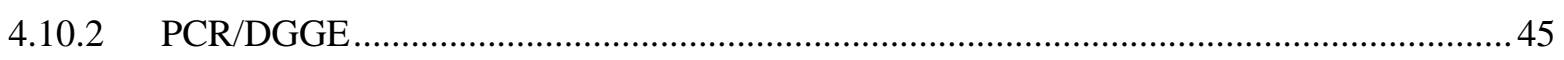

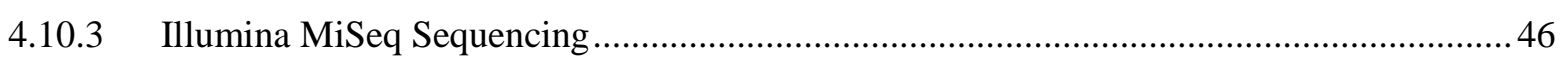

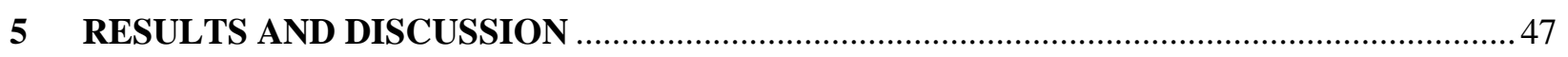

5.1 Compositional analysis of untreated sugarcane bagasse ......................................................4 47

5.2 Impact of $\mathrm{H}_{2} \mathrm{O}_{2}$ assisted hydrothermal pretreatment on chemical composition of sugarcane

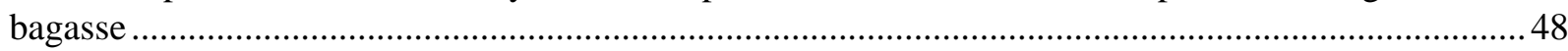

5.2.1 Morphological characteristics of $\mathrm{H}_{2} \mathrm{O}_{2}$ assisted hydrothermally pretreated solid fraction .55

5.3 Chemical composition of liquid hydrolysate obtained from $\mathrm{H}_{2} \mathrm{O}_{2}$ assisted hydrothermal

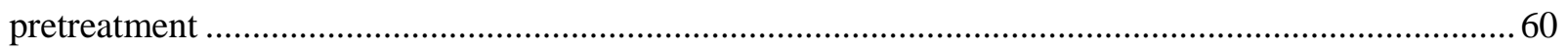

5.4 Methane production from solid fractions of $\mathrm{H}_{2} \mathrm{O}_{2}$ assisted hydrothermal pretreatment ............66

5.5 Statistical methane optimization with $\mathrm{H}_{2} \mathrm{O}_{2}$ assisted HT pretreatment .................................. 77

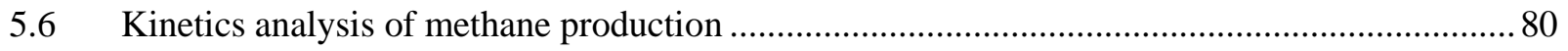

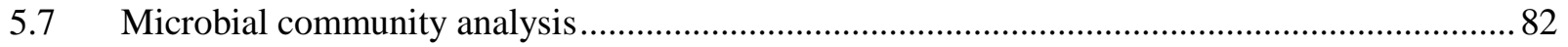

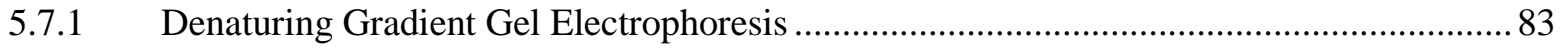

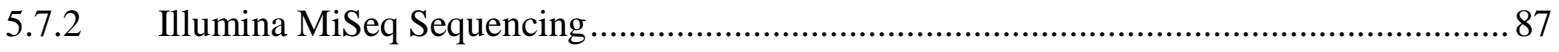

5.8 Impact of sugarcane bagasse impregnation in $\mathrm{H}_{2} \mathrm{SO}_{4}$ before hydrothermal pretreatment on

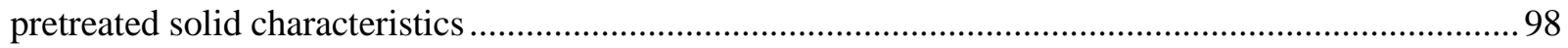

5.8.1 Morphological characteristics of $\mathrm{H}_{2} \mathrm{SO}_{4}$ assisted hydrothermally pretreated solid fraction 104

5.9 Chemical composition of liquid hydrolysate obtained from $\mathrm{H}_{2} \mathrm{SO}_{4}$ assisted Hydrothermal

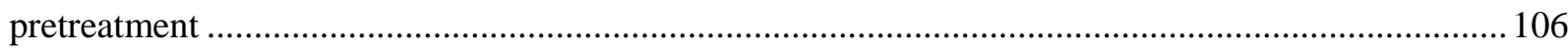

5.10 Impact of $\mathrm{H}_{2} \mathrm{SO}_{4}$ impregnation before hydrothermal pretreatment on methane production ......... 112

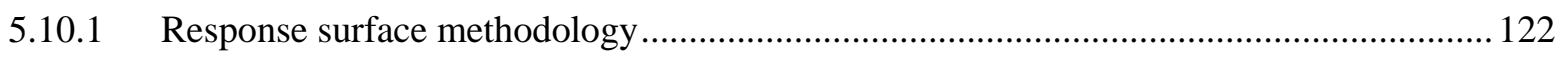

5.11 Microbial community Structure of $\mathrm{H}_{2} \mathrm{SO}_{4}$ impregnated sugarcane bagasse ......................... 126

5.11.1 Denaturing gradient gel electrophoresis for $\mathrm{H}_{2} \mathrm{SO}_{4}$ impregnated anaerobic reactors ....... 126

5.12 Illumina MiSeq Sequencing of selected $\mathrm{H}_{2} \mathrm{SO}_{4}$ pretreatments ......................................... 130

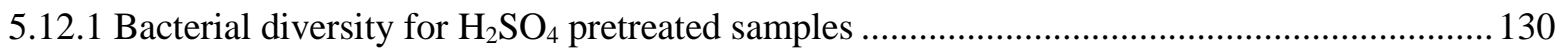

5.12.2 Archaeal diversity in selected $\mathrm{H}_{2} \mathrm{SO}_{4}$ pretreated samples .......................................... 136

5.13 Microbial community structure difference between positive control and pretreated samples ...... 139 
6 COMPARISON BETWEEN SULFURIC ACID AND HYDROGEN PEROXIDE ASSISTED

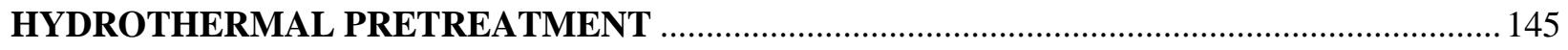

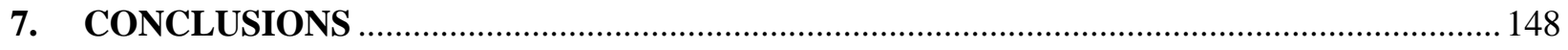

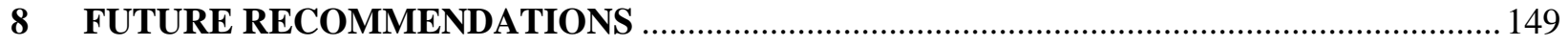

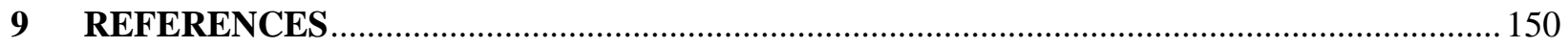

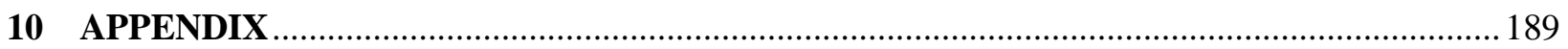




\section{INTRODUCTION}

Industrial revolution after Second World War, the rapid increase in world population, urbanization, and lavish lifestyle triggered the fossil fuel consumption worldwide in the twentieth century. Nowadays, fossil fuels serve up to $80 \%$ of world's energy demand (Braun et al., 2010). United States, China, and Japan consume ca. 40\% of world's total oil consumption (DOE, 2006). Fossil fuels are finite, nonrenewable, and potential source of environmental pollution even though a global certainty has not yet been established between fossil fuel usage and environmental quality but it is certain that fossil fuel consumption, in metropolitan cities, is a source of localized air pollution, global climate change, and greenhouse effect (Ramanathan and Feng, 2009). In addition, waste production and its accumulation is an irrefutable fact in human society. Consequently, its safe disposal is one of the great challenges to cope with in the 21 st century (Taherzadeh and Keikhosro, 2008).

In view of these challenges, global research theme has been shifted in the last couple of decades to seek biotechnological routes that could deal with waste stabilization issue, even, make them available to renewable and clean energy carriers (biofuels). Besides, interest in biofuels production is increasing due to expected shortage of conventional fuels, emission of greenhouse gasses, increased energy demand for transportation, electricity, industrial processes, and an upsurge in oil prices. It could safely be assumed that in a couple of decades, wind energy, solar energy, and bioenergy i.e., biogas, ethanol, and butanol would be in our energy portfolio. World Wildlife Fund reported that by 2050 world would be fueled $100 \%$ by renewable energy (WWF, 2011)

Lignocelluloses, carbon-based-polymers, are attaining global attraction owing to mass availability, low cost, easy transportation, high quantity, and renewable nature (Kaparaju et al., 2009). Lignocellulosics produce in enormous amount, ca. $2 \times 10^{11}$ tons annually in comparison to $1.5 \times 10^{8}$ tons of synthetic polymers (Mohanty et al., 2000). Furthermore, with the agricultural advancement, millions of tons of agricultural residues are available every year (Somerville et al., 2010). Moreover, it is the only feedstock that could be biologically transformed into liquid and gaseous fuels, ethanol and biogas, respectively by exploiting simple microbial routes (Hatti-Kaul

et al., 2007) and could replace the petroleum-based fuels utilizing the same infrastructure. The 
potential lignocellulosic feedstocks comprise on agricultural residues including sugarcane bagasse (SCB), wheat straw and corn stover, forest residues, dedicated energy crops, waste sludge from pulp and paper industry, switch grass and algae (Sims and Bassam, 2004; Sjöde et al., 2007; Sassner et al., 2008; Vergara-Fernández et al., 2008; Wingren et al., 2008).

Lignocellulosic material is composed predominantly of carbohydrate fractions (cellulose, hemicellulose) and non-carbohydrate fractions (lignin, pectin, protein, extractives and ash (Henning et al., 2007; Ahmad, 2013). Cellulose, a glucose polysaccharide, forms highly dense and ordered groups with a degree of polymerization (DP) in the 10,000s (before any treatment). Hemicellulose is a mixture of hexoses and pentoses with a much lower degree of polymerization (100-200), but can physically prohibit enzymatic access to the cellulose. Lignin is the largest noncarbohydrate portion of plant matter. Composition and quantification of bio-fibers are dependent primarily on plant age, plant type, cultivation practices, growth conditions, soil type, soil conditions, and environmental conditions (Henning et al., 2007). In native lignocellulose, cellulose and hemicellulose are cemented together by lignin, which is responsible for the integrity, structural rigidity, and prevention of fiber swelling (Ramirez et al., 2013).

Sugarcane (Saccharum spp.) is an indigenous crop that originates from New Guinea (southeast Asia) and is grown in tropical and subtropical regions, on both sides of the equator (Lisboa et al., 2011). Sugarcane, $\mathrm{C}_{4}$ plant, is very efficient in converting solar radiation into biomass with unique ability within the Poaceae family to accumulate up to $60 \%$ of its mature stem dry weight (Casu et al., 2007; Anuj et al., 2012)

Brazil is the world leader in sugarcane production. The Cane Technology Center (CTC) in consultation with The Brazilian Sugarcane Industry Association (UNICA) speculated that sugarcane harvest in Brazil could reach up to 590 million tons (UNICA, 2015). According to Ministry of Agriculture, livestock and farming of Brazil (MAPA, 2016) sugar export of Brazil may reach up to 32.6 million tons.

Sugarcane bagasse is the most abundant lignocellulosic residue among agricultural residues in tropical countries. Sugarcane bagasse (SCB) is a valuable byproduct of ethanol distilleries and sugar mills with ca. 270-280 kg (50\% moisture content) per metric ton of sugarcane (Karp et al., 2013) with a global production of 250 million tons per year (Kanokratana et al., 2013). Around $5.4 \times 10^{8}$ tons of dry sugarcane bagasse is a processed annually worldwide. It usually 
finds its way (50\%) in boilers to satisfy the energy requirements of the distilleries (Aita and Kim, 2010) due to its higher (1800 kcal kg-1) calorific value (Zanin et al., 2000). It is an inexpensive carbohydrate source (60-70\%) and a potential feedstock for anaerobic digestion to produce biogas (Badshah et al., 2012), and ethanol (Rabelo et al., 2011). In addition, based on lower ash content (2-3\%) it offers advantages over the wheat straw and rice straw (Basso et al., 2013). However, being a recalcitrant material its utilization as a feedstock for anaerobic digestion is a challenging task.

Anaerobic digestion (AD) has been recognized as the most efficient technology for waste stabilization with associated benefits of clean energy (Muhammad et al., 2012). Anaerobic digesters were primarily designed to digest sewage sludge and animal excreta. However, substrates are of less biodegradable potential in comparison to agricultural residues, food wastes, and municipal solid wastes (Forster-Carneiro et al., 2012). It is a less energy demanding rather energy generating process. The major obstacle in the successful operation of AD process is inefficient hydrolysis, a rate-limiting step in digestion process, owing to recalcitrant nature of lignocellulosic material (Valo et al., 2004; Fernandes et al., 2009) as in the case of sugarcane bagasse, whilst methanogenesis is considered a rate-limiting step for easily degradable compounds (Gavala et al., 2003; Skiadas et al., 2005). In order to disrupt the bio-fibers arrangement, enhancing enzymatic attack of fermentative bacteria of microbial consortium, thus overcoming hydrolysis rate-limiting step, a pretreatment step is inevitable. Pretreatment constitutes $30 \%$ of overall processing cost (Aita and Kim, 2010).

With technological advancement, a number of pretreatment strategies have been developed to unlock the lignocellulosic complex in the last couple of decades. However, due to intrinsic variety in lignocellulosics chemical composition owing to aforementioned factors, not a single pretreatment method can be recommended for different biofuels. In addition, every pretreatment has its own pros and cons. A suitable pretreatment process should be of following characteristics: (a) simple; (b) cost effective; (c) highly efficient in terms of sugar release; (d) less energy intensive; (e) non-corrosive to reactor material; (f) minimum process side products; and (g) minimal inhibitory product formation (Taherzadeh and Keikhosro, 2008).

Sugarcane bagasse is a coherent lignocellulosic feedstock; efficient utilization of this feedstock for anaerobic digestion necessitates a pretreatment step. Hydrolysis is considered a 
bottleneck owing to lignocellulosic feedstock recalcitrance (Wang et al., 2015). It is further enhanced by macroscopic factors; tissue compositional heterogeneity, mass transfer limitations, and microscopic factors; cellulose crystallinity, criss-cross nature of lignin-carbohydrate complex (Chundawat et al., 2011). Acid pretreatment has been reported to increase the hemicellulose solubilization (Yi et al., 2014) while, alkaline oxidative pretreatment proved to be a good option for lignin removal (Zheng et al., 2010). Hydrothermal pretreatment has been reported to open up the lignocellulosic structure and higher temperature and sudden release of pressure further break down the structural components. In the present study, an attempt is made to combine the three processes; acid, alkaline and hydrothermal processing. Sugarcane bagasse was impregnated in dilute $\mathrm{H}_{2} \mathrm{SO}_{4}$ and alkaline $\mathrm{H}_{2} \mathrm{O}_{2}$ separately in two phases before introduction to the hydrothermal reactor.

The current study focused on a promising pretreatment, hydrothermal processing, to pretreat sugarcane bagasse, to rupture its complex structure, as a tool to enhance methane production. To best of our knowledge, no work has been reported on a comparison of acidic (sulfuric acid) and alkaline oxidative (hydrogen peroxide) assisted hydrothermal pretreatment of sugarcane bagasse for anaerobic digestion. Furthermore, microbial consortium was studied in response to pretreatment effect by state of the art denaturing gradient gel electrophoresis (DGGE) and Illumina MiSeq Sequencing 


\section{OBJECTIVES}

\subsection{General objective}

The general objective of this study was to evaluate the methane production of sugarcane bagasse after hydrothermal pretreatment assisted with dilute $\mathrm{H}_{2} \mathrm{SO}_{4}$ and alkaline $\mathrm{H}_{2} \mathrm{O}_{2}$ impregnation

\subsection{Specific objectives}

The specific objectives of the research were:

a) To analyze sugarcane bagasse morphologically and physicochemically for anaerobic digestion;

b) To correlate pretreatment severity factor with inhibitory products (furfural and 5hydroxymethylfurfural) formation;

c) To compare both pretreatments for highest methane and organic acids yield in batch reactors under mesophilic conditions $\left(37^{\circ} \mathrm{C}\right)$;

d) To evaluate the impact of pretreatments on the microbial community structure. 


\section{REVIEW OF LITERATURE}

To design an optimum pretreatment process for anaerobic digestion, fundamental knowledge of lignocellulosic material, impact of pretreatment on structural and chemical composition of lignocellulosic substrate, biochemistry and microbiology of digestion process, processes understanding of inhibitory product formation during pretreatment, and microbial response to pretreatment side products in terms of kinetics, is an imperative to adopt a pretreatment on industrial scale. Pretreatment is the primary step to open up the coherent lignocellulosic structure, making the components accessible to enzymatic action of microorganisms for the release of monomeric sugars (Mosier et al., 2005). Furthermore, it has a pervasive impact on downstream processing.

In this chapter, a brief review of the chemical composition of lignocellulosic biomass is presented supported with references from the literature. Hydrothermal pretreatment mechanism, its impact on the chemical composition of solid and liquid fractions, a brief overview of anaerobic digestion process and impact of hydrothermal pretreatment on subsequent digestion process are discussed.

\subsection{Chemistry of lignocellulosic biomass}

To obtain desired results and optimum pretreatment efficiency, it is important to get a clear picture of the lignocellulosic composition to visualize what is going on with lignocellulosic components during pretreatment. 31 P NMR ( phosphorus 31 - Nuclear Magnetic Resonance) is a direct analysis tool to quantify hydroxyl groups in lignin (El Hage et al., 2010). Real-time monitoring of lignocellulosic components during pretreatment may pave the way to understand pretreatment impact better and to optimize maximum sugar recovery. Physical properties of the lignocellulosic material; water-holding capacity, specific porosity, specific surface area and crystallinity index" change with each kind of pretreatment applied but to a different extent depending on pretreatment type, severity, and lignocellulosic composition.

Lignocellulosic biomass irrespective of their physical appearance shares the same chemical make-ups; cellulose (30-70\%), hemicellulose (15-30\%), and lignin (10-25\%), and minute quantity of extractives (Monlau et al., 2013). Extractives are those compounds that are not accounted for integral parts of biomass structure. Common components encountered in the lignocellulosic 
composition of different feedstocks are presented in Table 3.1. While chemical composition of sugarcane bagasse by various researchers is given in Table 3.2. Graphical representation of the various components of lignocellulosic biomass originating from plant biomass is shown in Fig 3.1. Lignocellulosic composition, structural features and factors affecting recalcitrance have been reviewed elsewhere (Himmel et al., 2007; Zhao et al., 2012).

Cellulose was first separated in 1839 by Anselme Payen (Chen, 2014). Cellulose, $\left[\mathrm{C}_{6 n} \mathrm{H}_{10 \mathrm{n}+2} \mathrm{O}_{5 \mathrm{n}+1}, \mathrm{n}\right.$ - degree of polymerization of glucose] the most abundant polysaccharide, is a constituent of anhydro-glucan units linked together by $\beta, 1-4$ glycosidic linkages in a linear fashion (Edward, 2008). A number of glucan units in a polymeric chain terms into the degree of polymerization (DP). Chain length ranges from hundreds to over tenths of thousands. The hydrogen bonds between glucan units determine cellulose crystallinity. Furthermore, some chains are irregularly arrayed rendering amorphous regions intertwined with crystalline cellulose (Taherzadeh and Keikhosro, 2008). Chain length is inversely proportional to hydrolysis efficiency (Karimi and Taherzadeh, 2016). It is insoluble in water and dilute acids and alkaline solutions at room temperature. Cellulose in its amorphous form is most susceptible to microbial degradation (Monlau et al., 2013).

Hemicellulose $\left(\mathrm{C}_{5} \mathrm{H}_{8} \mathrm{O}_{4}\right)_{n}$ is a linear and highly branched-heteropolymer composed primarily of D-xylose, L-arabinose (members of $\mathrm{C}_{5}$ sugar family), D-glucose, D-mannose, Dgalacturonic acid, D-galactose, and glucuronic acid (members of $\mathrm{C}_{6}$ sugar family) and $\mathrm{C}_{7}$ sugar 4O-methyl glucuronic acid (Soccol et al., 2011 b). Individual sugars may be methylated or acylated. This group contains three pentoses (D-xylose, L-arabinose, and D-ribose) and two pentitols (Darabitol, and ribitol) (Singh and Mishra, 1995). The composition is heavily dependent upon the source whether it is derived from angiosperm (hardwood) or gymnosperm (softwood). Xylose is the principle sugar for angiosperms and agricultural wastes while glucomannan for softwood (Ebringerová and Heinze, 2000). Hemicelluloses have lower molecular weight, lower DP, and less crystallinity with random amorphous structure compared to highly packed cellulose rendering it more susceptible to hydrolysis than cellulose (Yoshida et al., 2008; Heather and Charles, 2013). 
Table 3.1 - Composition of agricultural and other lignocellulosic residues on dry matter basis (Saini et al., 2015)

\begin{tabular}{|c|c|c|c|c|c|}
\hline Feedstock & $\begin{array}{c}\text { Cellulose } \\
(\%)\end{array}$ & $\begin{array}{c}\text { Hemicellulose } \\
(\%)\end{array}$ & $\begin{array}{c}\text { Lignin } \\
(\%)\end{array}$ & $\begin{array}{l}\text { Ash } \\
(\%)\end{array}$ & $\begin{array}{c}\text { Extractives } \\
(\%)\end{array}$ \\
\hline Algae (green) & $20-40$ & $20-50$ & - & - & - \\
\hline Cotton, flax & $80-95$ & $5-20$ & - & - & - \\
\hline Grasses & $25-40$ & $25-50$ & $10-30$ & - & - \\
\hline Hardwoods & $45 \pm 2$ & $30 \pm 5$ & $20 \pm 4$ & $0.6 \pm 0.2$ & $5 \pm 3$ \\
\hline Hardwood barks & $22-40$ & $20-38$ & $30-55$ & $0.8 \pm 0.2$ & $6 \pm 2$ \\
\hline Softwoods & $42 \pm 2$ & $27 \pm 2$ & $28 \pm 3$ & $0.5 \pm 0.1$ & $3 \pm 2$ \\
\hline Softwood barks & $18-38$ & $15-33$ & $30-60$ & $0.8 \pm 0.2$ & - \\
\hline Cornstalk & $39-47$ & $26-31$ & $3-5$ & $12-16$ & - \\
\hline Wheat straw & $37-41$ & $27-32$ & $13-15$ & $11-14$ & - \\
\hline Newspaper & $40-55$ & $25-40$ & $18-30$ & - & - \\
\hline Chemical pulp & $60-80$ & $20-30$ & $2-10$ & - & - \\
\hline Sorghum stalks & 27 & 25 & 11 & - & - \\
\hline Corn stover & $38-40$ & 28 & $7-21$ & $3.6-7.0$ & - \\
\hline Coir & $36-43$ & $0.15-0.25$ & $41-45$ & $2.7-10.2$ & - \\
\hline Sugarcane Bagasse & $32-48$ & $19-24$ & $23-32$ & $1.5-5$ & - \\
\hline Rice straw & $28-36$ & $23-28$ & $12-14$ & $14-20$ & - \\
\hline Wheat straw & $33-38$ & $26-32$ & $17-19$ & $6-8$ & - \\
\hline Barley straw & $31-45$ & $27-38$ & 14-19 & $2-7$ & - \\
\hline Sorghum straw & 32 & 24 & 13 & 12 & - \\
\hline $\begin{array}{c}\text { Sweet sorghum } \\
\text { bagasse }\end{array}$ & $34-45$ & $18-28$ & $14-22$ & - & - \\
\hline
\end{tabular}

Lignin, the most abundant highly branched natural non-carbohydrate polymer next to cellulose and hemicellulose; $40 \%$ of dry biomass weight (Effendi et al., 2008), is an important component in plant cell wall providing structural strength. Moreover, to counter it from biotic and abiotic stresses (Weng and Chapple, 2010). It is composed of phenylpropane alcohols; coniferyl, 
sinapyl, and to a lesser extent $p$-coumaryl which form guaiacyl (G), sinapyl (S), and $p$ hydroxyphenyl units linked through the ( $\beta$-O-4) $\beta$-aryl ether and 5-O-4 (biphenyl ether). C-C ("condensed") bonds such as 5-5 (biphenyl) linkages or a combination of C-C and ether linkages (Adler, 1977; Boerjan et al., 2003; Rowel, 2005; Zeng et al., 2014). Furthermore, lignin frequently forms a covalent bond with surrounding carbohydrate mainly hemicellulose (Saake and Lehnen, 2007).

Table 3.2 - Chemical composition of sugarcane bagasse on DM basis

\begin{tabular}{|c|c|c|c|c|}
\hline $\begin{array}{c}\text { Cellulose } \\
(\%)\end{array}$ & $\begin{array}{c}\text { Hemicellulose } \\
(\%)\end{array}$ & $\begin{array}{l}\text { Lignin } \\
(\%)\end{array}$ & $\begin{array}{l}\text { Ash } \\
(\%)\end{array}$ & References \\
\hline 45.5 & 27 & 21.1 & 2.2 & $\begin{array}{c}\text { (De Moraes et } \\
a l ., 2011)\end{array}$ \\
\hline 41.1 & 22.7 & 31.4 & 2.4 & (Pitarelo, 2007) \\
\hline 38.8 & 26 & 32.4 & 2.8 & $\begin{array}{c}\text { (da Silva et al., } \\
\text { 2010) }\end{array}$ \\
\hline 45.0 & 25.8 & 19.1 & 1.0 & $\begin{array}{c}\text { (Canilha et al., } \\
\text { 2011) }\end{array}$ \\
\hline 42.4 & 25.2 & 19.6 & 1.6 & $\begin{array}{c}\text { (Brienzo } \text { et al. } \\
\text { 2009) }\end{array}$ \\
\hline 38.4 & 23.2 & 25.0 & 1.5 & $\begin{array}{l}\text { (Rabelo } \text { et al., } \\
\text { 2011) }\end{array}$ \\
\hline $32-44$ & $27-32$ & $19-24$ & $4.5-9$ & $\begin{array}{c}\text { (Soccol et al., } \\
2010)\end{array}$ \\
\hline 30.2 & 56.7 & 13.4 & 1.9 & $\begin{array}{c}\text { (Bharathiraja et } \\
\text { al., } 2014\end{array}$ \\
\hline
\end{tabular}

$\mathrm{DM}=$ Dry matter 


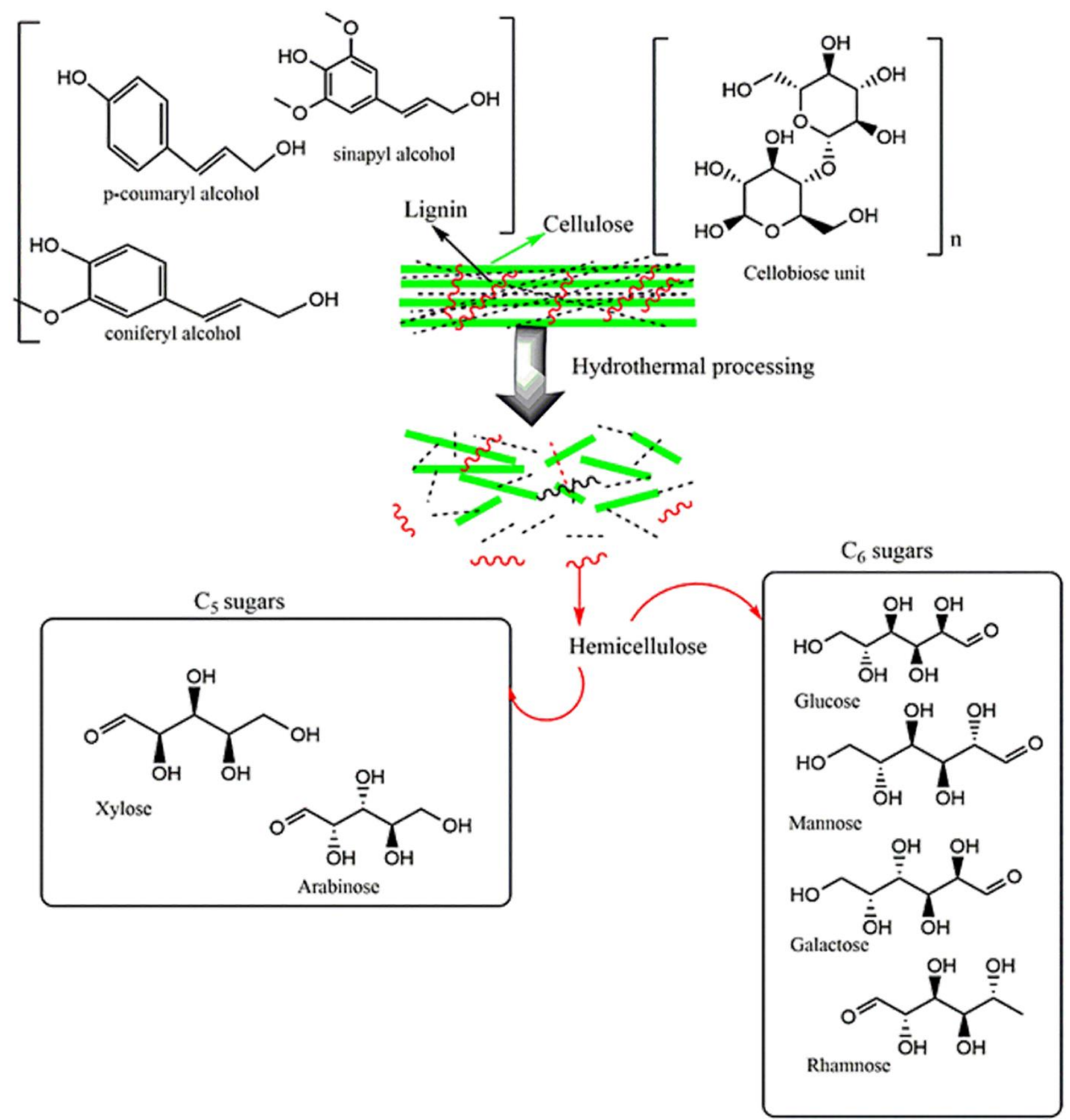

Figure 3.1 - The components and structure of lignocellulosic biomass (modified after (Edward, 2008))

The relative portion of each component varies by plant species. Coniferyl alcohol is the principal monomer in softwood lignin while both sinapyl and coniferyl monomers are the building blocks for hardwood lignin. Others "non-canonical" aromatic monomers also known to be incorporated into lignin framework (Ralph et al., 2004; Bonawitz and Chapple, 2010). It provides the protective cover around the cellulose and hemicellulose as a hydrophobic sheet and has high 
significance for anaerobic digestion since lignin concentration varies inversely to methane production (Kobayashi et al., 2004; Ahring et al., 2015). While lignin's role in cell wall recalcitrance is universally accepted, the precise set of factors that contribute to this recalcitrance is not generally acknowledged.

Factors specific to lignin's role in recalcitrance have been proposed to include the total lignin abundance (Soest, 1994; Chen and Dixon, 2007; Studer et al., 2011), lignin location within the cell wall (Yang and Wyman, 2004), and the properties of lignin such as hydrophobicity (Nakagame et al., 2011), as well as indirect impacts such as lignin's ability to bind enzymes (Rahikainen et al., 2011).

\subsection{Hydrothermal pretreatment mechanism}

Pretreatment is the initial step to overcoming the recalcitrance property of lignocellulosic material. Pretreatment techniques are divided into four broad categories; physical, physicochemical, chemical and biological. There are several methods within each category. A bunch of reviews in the literature can be found specifically on pretreatment of lignocellulosic biomass for biogas production (Yi et al., 2014; He et al., 2015), biological pretreatment (white rot fungi) (Rouches et al., 2016), and pretreatments used for high-fat cattle slaughterhouse wastewater (Harris and McCabe, 2015). Understanding the pretreatment process itself is as important as its impact on the lignocellulosic biomass composition.

Hydrothermal pretreatment (aka., liquid hot water pretreatment, hot compressed water pretreatment, hydrothermolysis, un-catalyzed solvolysis, aqueous fractionation or aquasolv, hydrothermal carbonization or wet torrefaction (Lynam et al., 2014) is a process in which lignocellulosic biomass is cooked with water in liquid state at higher temperature $\left(140-300{ }^{\circ} \mathrm{C}\right)$ with corresponding pressure for several minutes to few hours. Water at high-temperature acts as an acid owing to autoionization with hydrogen ions generation (Equation 3.1), thus significantly reduces the $\mathrm{pH}$ to an acidic level.

$$
K_{w}=\frac{\left[\mathrm{H}^{+}\right]\left[\mathrm{OH}^{-}\right]}{\left[\mathrm{H}_{2} \mathrm{O}\right]}
$$

Where; $\mathrm{K}_{\mathrm{w}}=$ water autohydrolysis constant 


$$
\begin{aligned}
& {\left[\mathrm{H}^{+}\right]=\text {Hydrogen ion }} \\
& {\left[\mathrm{OH}^{-}\right]=\text {Hydroxyl ion }} \\
& {\left[\mathrm{H}_{2} \mathrm{O}\right]=\text { Water }}
\end{aligned}
$$

Pure water exhibits $\mathrm{pH}$ of 5 at $250^{\circ} \mathrm{C}$ that enhances the catalytic ability of water 25 times to room temperature conditions (Lloyd and Wyman, 2004). In this process, water (subcritical state) enters the lignocellulosic biomass to hydrate cellulose, solubilize a significant portion of hemicellulose and partly remove lignin (Pérez et al., 2007; Chandra et al., 2012). Higher kinetic energy available in the system at high temperature increases the rate of polymerization reactions, thereby, increasing the breakdown of cell wall polymers. Furthermore, it causes swelling (nonchemical) of cellulose, thereby, increasing the surface area of cellulose, essential for enzymatic action.

Water, under pressure, helps in cleaving the acetyl and uronic acid groups of hemicellulose producing acetic acid and other organic acids making oligosaccharides further solubilize (Garrote et al., 1999; Aita and Kim, 2010). Hydronium ions generated by acetic acid are of greater importance than of water as indicated by Garrote et al. (Garrote et al., 1999). It results in opening up the structure, expansion of specific surface area, and pore size of lignocellulosic biomass (Zakaria et al., 2015). Since water is the reaction medium, it voids neutralization step afterward for bioethanol production due to lower inhibitory products formation.

The effectiveness of the pretreatment is a function of substrate composition and $\mathrm{pH}$ in addition to temperature employed and retention time (Taherzadeh and Keikhosro, 2008; Hendriks and Zeeman, 2009). Hydrothermal pretreatment has been reported a better choice for biomasses with higher acetyl content (Nitsos et al., 2013). Hydrothermal pretreatment is aimed to balance the fermentable sugar yield delivered by acid pretreatment with lower operational cost (Eggeman and Elander, 2005).

Hydrothermal pretreatment is carried out in three types of reactors; cocurrent (biomass and liquid water cooked together), counter current (movement of biomass and liquid water in the opposite direction), and flow-through reactors (hot water flow over a stationary bed of biomass) (Liu and Wyman, 2005). Hydrothermal pretreatment combat against recalcitrance of 
lignocellulosic biomass under heat and pressure at different reactor configurations to break strong bonding between carbohydrate-lignin matrix (Guilliams et al., 2016).

Hydrothermal processing is a thermochemical conversion process. It is further categorized into three processes depending upon the severity conditions applied; hydrothermal carbonization $\left(<247{ }^{\circ} \mathrm{C}\right)$, hydrothermal liquefaction $\left(247-373^{\circ} \mathrm{C}\right)$, and hydrothermal gasification $\left(>373{ }^{\circ} \mathrm{C}\right)$. Each process results in a distinct main product. Hydrochar is the main product of hydrothermal carbonization which has properties similar to low-rank coal (Heilmann et al., 2011). Biocrude, liquid fuel, is the product of hydrothermal liquefaction. Synthetic fuel gas is the product of hydrothermal gasification. Hydrothermal liquefaction followed by gasification results into higher carbon efficiencies (Brown et al., 2010).

The severity factor is a measure of the pretreatment intensity in hydrothermal processes and it allows comparing the results of experiments carried out under different conditions (Rocha et al., 2013). It has extensively been used to report pretreatment severity in the literature (Overend et al., 1987; Chum et al., 1990; Bouchard et al., 1991; Abatzoglou et al., 1992; Jollez et al., 1994; Montané et al., 1994; van Walsu, 2001; Yourchisin and Peter Van Walsum, 2004; Kabel et al., 2007; Pedersen and Meyer, 2010; Agbor et al., 2011; Lee and Jeffries, 2011; Temiz and Akpinar, 2016). The generalized impact of pretreatment time and temperature on lignocellulosic composition is first proposed by Overend et al (Overend et al., 1987) in terms of severity factor (Equation 3.2).

$$
\log R_{0}=\log \left\{t \cdot \exp \left(\frac{T-100}{14.75}\right)\right\}
$$

Where

$t=$ the holding time

$T=$ the reaction temperature

$100=$ the reference temperature

The fitted value (14.75) is based on activation energy, assuming pseudo first order kinetics (Carvalheiro et al., 2009). The Equation 3.2 is not valid under variable $\mathrm{pH}$ conditions, therefore, to understand the influence of $\mathrm{pH}$ on pretreatment severity, Equation 3.3 has been derived by 
having acidic and alkaline pretreatment impact on biomass digestibility (Pedersen and Meyer, 2010).

The severity factor is quite important in modeling individual stages of the processing; (a) to describe the behavior of xylan removal during reactions (Overend and Chornet, 1989; Heitz et al., 1991; Saska and Ozer, 1995), (b) biomass solubilization (Bouchard et al., 1991; Abatzoglou et al., 1992), and c) lignin removal (Bouchard et al., 1991; Montané et al., 1994; Trajano et al., 2013).

$$
\log R_{0}{ }^{\prime}=\log R_{0}-p H
$$

Where

$\log R_{0}{ }^{\prime}=$ Severity factor at variable $\mathrm{pH}$

$\log R_{0}=$ Severity factor without considering $\mathrm{pH}$

$\mathrm{pH}=$ Potential of hydrogen

\subsection{Impact of hydrothermal pretreatment on the lignocellulosic biomass composition on solid fraction}

Hydrothermal pretreatment has a significant impact on solid yield predominantly due to hemicellulose solubilization and partial lignin dissociation. Furthermore, solid recovery indicates extraction pattern of components into the liquid stream based on chemical composition of lignocellulosics. Since hemicellulose solubilization is in direct relation to temperature, therefore, solid yield has a direct link, in decreasing order, with an increase in temperature (Yang et al., 2004). Organic matter solubilization at higher temperature mainly targets carbohydrates followed by protein in the lignocellulosic structure. Mendez et al. (Mendez et al., 2014) reported a 4-6-fold increase in carbohydrate dissolution in comparison to 1-2 fold for protein.

The solid yield of Eucalyptus camaldulensis declined to $54.2 \%$ from $72.7 \%$ when ammonium chloride catalyzed hydrothermal pretreatment temperature increased from 140 to 180 ${ }^{\circ} \mathrm{C}$ (Shen et al., 2016). Similarly, Deng et al. (Deng et al., 2015) reported a decrease in the solid residue of corncob from $96.5 \%$ to $60.67 \%$ when pretreatment temperature was increased from 170 ${ }^{\circ} \mathrm{C},(0 \mathrm{~min})$ to $190{ }^{\circ} \mathrm{C}(60 \mathrm{~min})$. Sun et al. (Sun et al., 2014) reported a progressive decrease in 
solid residues of corncob $69.4 \%$ to $48.7 \%$ when temperature increased from $170{ }^{\circ} \mathrm{C}$ to $190{ }^{\circ} \mathrm{C}$. Further, it reached to the lowest value of $47.0 \%$ at $200{ }^{\circ} \mathrm{C}$.

Hydrothermal pretreatment optimization was carried out by $\mathrm{Lu}$ et al (Lu et al., 2009) to evaluate the impact of $\mathrm{H}_{2} \mathrm{SO}_{4}$ addition, pretreatment time and solid content on rapeseed straw, solid recoveries were in the range of $55 \%$ to $88 \%$, the lowest recovery was obtained at highest acid concentration studied (2\%), at 5\% solid loading for a retention time of $20 \mathrm{~min}$. Moutta et al. (Moutta et al., 2013) reported recovery of $24.5 \mathrm{~g}, 22.0 \mathrm{~g}$, and $20.8 \mathrm{~g}$ of insoluble solid on the introduction of $30.0 \mathrm{~g}$ bagasse, straw and mixture of bagasse and straw (1:1), respectively. Ko et al. (Ko et al., 2015) reported a decrease in solid recovery up to $71.1 \%$ from $93.9 \%$ in response to increasing the temperature from $180{ }^{\circ} \mathrm{C}$ to $210^{\circ} \mathrm{C}$.

Perez et al. (Pérez et al., 2007) reported lower solid recovery on wheat straw within the range of $57.5 \%$ to $90 \%$ depending upon pretreatment severity. The lowest value was indicated at $200{ }^{\circ} \mathrm{C}$ and 40 min. Li et al. (Li et al., 2013) performed liquid hot water pretreatment at different severities on suspended and precipitated solid of Miscanthus lutarioriparious and reported lowest solid recovery at high severity $(4.71) ; 65.46 \% \pm 0.16$ and $64.85 \pm 0.46$ for suspended and precipitated solid, respectively. Solid yield is an important parameter for consideration with reference to anaerobic digestion; higher pretreatment temperature leads to an increase in lignin content in the solid fraction thus resulting in lower overall methane yield as reported by Fernandez et al. (Fernandez-Cegri et al., 2012).

\subsubsection{Cellulose}

Hydrothermal pretreatment has a minimal direct impact on cellulose dissolution in comparison to hemicellulose and lignin due to its thermal stability, highly packed structure, and encapsulation by the lignin sheath (Mosier et al., 2005). Cellulose structural rearrangements can occur at high pretreatment temperature (Mok et al., 1992). C-O-C bond cleavage mechanism in cellulose involves protonation of glycoside bonds. The proton can attack the oxygen bond in between two glucose monomers or cyclic oxygen. The mechanism involves the rapid formation of an intermediate complex with the oxygen and proton followed by slow splitting of glycosidic bonds by water molecules (Fan et al., 1987). 
Cellulose undergoes crystalline to amorphous transformation at $320^{\circ} \mathrm{C}, 25 \mathrm{MPa}$ (Deguchi et al., 2006). In contrast, Sakaki et al. (Sakaki et al., 2002) reported degradation of cellulose started into hexoses and oligosaccharides above $230{ }^{\circ} \mathrm{C}$ and almost all decomposition at $295{ }^{\circ} \mathrm{C}$. Since cellulose has a high degree of polymerization (DP); higher hydrogen bonding within cellulose fibers resists its breakdown and pose a major hindrance to hydrolyze the biomass (Karimi and Taherzadeh, 2016). Lower DP may increase the susceptibility of cellulose hydrolysis (Zhang and Lynd, 2005), a clear-cut relationship between DP and hydrolysis has not yet been established (Yang et al., 2011). Though having little impact on cellulose dissolution, hydrothermal pretreatment substantially increases cellulose reactivity with hydrolytic enzymes, predominantly, due to hemicellulose removal and disruption of lignin-hemicellulose-cellulose meshwork thus making cellulose accessible.

Lignocellulosic solubilization has been reported to increase in direct relation to an increase in temperature (Ruiz et al., 2012). Cellulose content, as a whole, tends to increase after hydrothermal pretreatment owing to the dissolution of hemicellulose and lignin. Nitsos et al. (Nitsos et al., 2013) reported an increase in cellulose content up to $63 \% \mathrm{w} / \mathrm{w}$ in comparison to an untreated sample, $42 \% \mathrm{w} / \mathrm{w}$. In similar fashion, $83 \%$ increase in glucan yield reported by Lilis et al. (Lilis et al., 2009) in a pretreated solid fraction of switchgrass. Ruiz et al. (Ruiz et al., 2012) reported $63.7 \%$ cellulose on glucan content basis in the pretreated solid fraction. In another study, Fang et al. (Fang et al., 2015) reported $31.63 \%$ increase in glucan content of date palm leaflet at $210{ }^{\circ} \mathrm{C}$ while $60.12 \%$ increase in pretreated rachis at $200{ }^{\circ} \mathrm{C}$. Sun et al. (Sun et al., 2014) reported an increase in cellulose content from $45.01 \%$ to $59.69 \%$. Perez et al. (Pérez et al., 2007) reported $45 \%$ to $65 \%$ increase in the cellulose in a pretreated solid fraction on a dry weight basis in comparison to untreated wheat straw (37.4\%). Pretreated solid obtained from hydrothermal pretreatment of Eucalyptus globulus reported containing almost $98.5 \%$ cellulose (Romaní et al., 2010).

\subsubsection{Hemicellulose}

Liquid hot water pretreatment primarily makes available hydronium ions by water fractionation at elevated temperature. Hydronium ions are highly reactive, having a significant impact on xylan depolymerization and acetyl group cleavage from hemicellulose backbone (Rocha 
et al., 2013). It has shown to solubilize hemicellulose up to $89 \%$ as reported by Xiao et al. (Xiao et al., 2011) at $200{ }^{\circ} \mathrm{C}$ for $3 \mathrm{~h}$. on woody biomass Tamarix ramosissima.

Temperature is an important parameter with respect to hemicellulose dissolution; lower temperature has no impact on hemicellulose solubilization as Nitsos et al. (Nitsos et al., 2013) reported on beech wood that hydrothermal pretreatment has virtually no impact on hemicellulose dissolution at a mild temperature $\left(130{ }^{\circ} \mathrm{C}, 15 \mathrm{~min}\right)$. Removal of hemicellulose began at $\left(150{ }^{\circ} \mathrm{C}\right.$, $15 \mathrm{~min}$ ) with almost complete removal at $220{ }^{\circ} \mathrm{C}$ for $15 \mathrm{~min}$ corresponding to $\log \mathrm{R}_{0} 4.69$. Similar results are reported by (Hendriks and Zeeman, 2009; Fernandez-Cegri et al., 2012).

Senila and fellows (Senila et al., 2014) reported complete hemicellulose solubilization of silver fir wood at $200{ }^{\circ} \mathrm{C}$ with a holding time of $10 \mathrm{~min}$. Sun et al. (Sun et al., 2014) reported a significant decrease in hemicellulose from $19.51 \%$ to $1.69 \%$ with a corresponding increase in pretreatment temperature from $100{ }^{\circ} \mathrm{C}$ to $180{ }^{\circ} \mathrm{C}$ for $60 \mathrm{~min}$. Perez et al. (Pérez et al., 2007) reported a decrease in xylan content in the wheat straw by reporting a recovery of xylan content in the water-insoluble solid fraction in the range of $0.3 \%$ to $25.4 \%$ depending upon conditions studied comparing to $26.3 \%$ hemicellulose in the untreated sample.

Hydrothermal pretreatment has been proven to be of lower impact when applied to softwood materials owing to lower acetyl content of softwood (Alvira et al., 2010). On the other hand, Nitsos et al. (Nitsos et al., 2013) reported hydrothermal pretreatment as a viable option for lignocellulosics having higher acetyl content.

\subsubsection{Lignin}

It is generally believed that hydrothermal pretreatment increases the lignin content in solid fraction primarily due to solubilization of hemicellulose in the liquid fraction. Long pretreatment time is another significant factor to increase klason lignin in the solid fraction due to recombination reaction between lignin and holocellulose (Kobayashi et al., 2004). Lignin recovery is in direct proportion to the pretreatment temperature (Hansen et al., 2004). The process could solublize, depending upon pretreatment severity, all hemicellulose in addition to 4-22\% cellulose and 3560\% lignin (Aita and Kim, 2010). In contrast Iwona et al. (Iwona et al., 2013) reported minimal removal of lignin due to subsequent repolymerization on cellulose fibers. Lignin, hydrophobic in nature, on exposure to biomass surface, contributes in two ways to biomass recalcitrance; (a) 
impedes cellulases accessibility to biomass, (b) unproductive diffusion of cellulose enzymes to active sites on a biomass surface. The process sufficiently changes the lignin structure by melting and coagulation. Syringil units have been reported the most susceptible to hydrothermal degradation (Garrote et al., 1999).

Lignin solubilization involves the breaking of lignin-carbohydrate bonds and depolymerization reactions (Garrote et al., 1999). The fraction of solubilized lignin depends upon the raw material (Wallis and Wearne, 1985) and operational conditions (Shimizu et al., 1989). Lignin during hydrothermal pretreatment undergoes various chemical reactions, phase transitions; solid and liquid phase, and morphological changes. Various researchers observed droplets on cellulose in response to pretreatment.

It determined to be lignin as a result of phase transition; glassy to a rubbery state, coalescence, and extrusion from cell wall (Donaldson et al., 1988; Donohoe et al., 2008). Repolymerization counteracts lignin removal, although ether bonds cleaved, delignification rate was reported close to zero (Li et al., 2007). In addition, an increase in molecular weight of lignin after pretreatment is a clear indication of repolymerization of lignin (Li et al., 2007). Furthermore, sugar oligomers and solubilized lignin are reported to inhibit cellulose digestion by reattaching to the surface of pretreated fibers. (Liu and Charles, 2005).

Garrote and co-workers (Garrote et al., 2007) reported an increase in lignin content at high temperature owing to a combination of lignin and protein. The higher pretreatment severity led to an increase in lignin recovery yield, which might be caused by the condensation reactions of lignin with other degradation products. Hydrothermal pretreatment of date palm leaflets and rachis substantially increase lignin content up to $64.95 \%$ and $49.45 \%$, respectively, at $210^{\circ} \mathrm{C}$. Sun et al. (Sun et al., 2014) reported an increase in lignin from 25.84\% to 54.35. Mittal et al. (Mittal et al., 2009) reported an initial solubilization of lignin (15\%), thereafter, on prolonged pretreatment (175 ${ }^{\circ} \mathrm{C}, 8 \mathrm{~h}$ ) lignin value reached a maximum value of $103 \%$ on initial lignin content basis.

Romani and colleagues (Romaní et al., 2010) reported recovery of $85.4 \%$ lignin on average in the pretreated solid of Eucalyptus globulus while studying autohydrolysis at 195, 205, 220 and $230{ }^{\circ} \mathrm{C}$. Nitsos and fellows (Nitsos et al., 2013) reported 26\%-35\% increase in lignin content in pretreated beach wood comparing to native at the severity of $\log \mathrm{R}_{0} 4.69$. Ko et al. (Ko et al., 2015) studied the fate of lignin on hardwood chips and reported an increase in lignin from $29.3 \%$ to 
$40.3 \%$ for a severity range of 8.25 to 12.51 with a maximum of $90 \%$ recovery at severity $\log \mathrm{R}_{0}>$ 11.39. Authors observed a change in the ratio of acid insoluble lignin (AIL) to acid-soluble lignin (ASL), reporting that higher severity lead to increase in acid insoluble lignin with the corresponding decrease in acid soluble lignin.

The percentage of lignin increased from 29.3 to $40.3 \%$ with increasing pretreatment severity mainly due to the solubilization of xylan while the cellulose and lignin remain in the solids recovered after pretreatment. In the range of pretreatment severity of $\log R_{0} 1 / 48.25-12.51,75-$ $85 \%$ of the lignin initially present was recovered in pretreated solids. However, at the severity of $\log R_{0}>11.39$, the apparent lignin recovery increased to $90 \%$ (Ko et al., 2015).

Kristensen et al. (Kristensen et al., 2008) reported re-localization of lignin in response to hydrothermal pretreatment that subsequently makes cellulose susceptible to enzymatic hydrolysis. Fernandez et al. (Fernandez-Cegri et al., 2012) indicated that lignin tends to concentrate in the pretreated solid primarily owing to solidification and re-deposition on cooling, authors observed $33 \%$ lignin in pretreated solid at severing pretreatment conditions of $200{ }^{\circ} \mathrm{C}$ in comparison to $14 \%$ of untreated sunflower oil cake. Sun et al. (Sun et al., 2014) reported an increase in klason lignin up to a maximum value of $41.7 \%$ in a corncob.

\subsection{Impact of hydrothermal pretreatment on hydrolysate on liquid fraction}

Thermal and thermochemical pretreatment of lignocellulosic biomass results into two fractions: (a) solid fraction rich in cellulose, lignin, and residual organic acids and (b) liquid fraction mainly containing xylose, organic acids released, phenolic compounds; vanillin, syringaldehyde and other lignin derived phenolics, and furanic compounds; furfural, 5hydroxymethylfurfural (5-HMF) (Hendriks and Zeeman, 2009; Du et al., 2010; GonzálezFernández et al., 2012; Sambusiti et al., 2013). Furanic compounds are known to be detrimental for archaea and bacteria by inhibiting cell growth, damaging DNA, and inhibiting enzymes of glycolysis pathway. (Palmqvist and Hahn-Hägerdal, 2000; Almeida et al., 2009). Furfural found to be more toxic than 5-HMF owing to its lower molecular weight that facilitates easy penetration into microbial cell membrane (Quéméneur et al., 2012). Toxicity of Lignin-derived phenolic inhibitors directly related to molecular weight; low molecular weight phenolic compounds are more lethal than high molecular weight phenolics (Jönsson and Martín, 2016). 
The degradation products; furfural, 5-HMF (5-hydroxymethylfurfural), acetic acid, and formic acid are an undeniable fact during chemical or physicochemical pretreatment; hydrothermal pretreatment is not an exception. Furfural is a pentose, while 5-HMF is a hexose dehydration product. Former can be converted to 2-furoic acid through hydraulic fission of aldehyde groups, while latter can be transformed to equimolar amounts of levulinic acid and formic acid under acid conditions at elevated temperatures (Clark and Mackie, 1984; Ulbricht et al., 1984; Nitsos et al., 2013).

Mechanism of inhibitory products formation during hydrothermal pretreatment is presented in Fig. 3.2. 5-HMF and furfural, under anaerobic fermentation condition, are mainly converted to their corresponding alcohols, furan dimethanol, and furfuryl alcohol, respectively, while aerobic metabolism in Saccharomyces cerevisiae converts furfural to furoic acid (Sárvári Horváth et al., 2003; Liu et al., 2004).

A lower concentration of 5-HMF has been reported in hydrolysate due to limited hexose degradation in comparison to furfural (Chandel et al., 2011). Phenolic compounds production is related mostly to lignin degradation. Production of these undesirable compounds may be prevented by careful optimization of process parameters of pretreatments. Maintaining $\mathrm{pH}$ between $4-7$ minimizes the risk of inhibitory products formation (Hendriks and Zeeman, 2009). Production of these undesirable inhibitory products is widely dependent upon nature of lignocellulosic biomass, reaction conditions, and reaction time of hydrolysis (Palmqvist and Hahn-Hägerdal, 2000). El Hage et al. (El Hage et al., 2010) studied autohydrolysis on Miscanthus x giganteus, reported that furans increase steadily at mild conditions (130-140 ${ }^{\circ} \mathrm{C}$ ), while the substantial increase was observed to a maximum of $5.5 \%$ at $150{ }^{\circ} \mathrm{C}$ for $20 \mathrm{~h}$.

Hydrothermal pretreatment of sweet sorghum was conducted by Sun and colleagues (Sun et al., 2015). The authors reported that the concentrations of acetic acid $\left(4.03 \mathrm{~g} \mathrm{~L}^{-1}\right)$ and furfural (4.53 $\left.\mathrm{g} \mathrm{L}^{-1}\right)$ were significantly higher in the severest pretreatment condition $\left(230{ }^{\circ} \mathrm{C}, 30 \mathrm{~min}\right)$. Furthermore, it was noted that degradation products closely associated with pretreatment temperature and time; increasing temperature at a constant time or vice versa. The authors observed lower 5-HMF concentration in comparison to furfural indicating limited cellulose solubilization and consequent glucose formation. Table 3.3 presents various possibilities of hydrolysate composition in response to hydrothermal pretreatment of various feedstocks. 
Hexose sugars

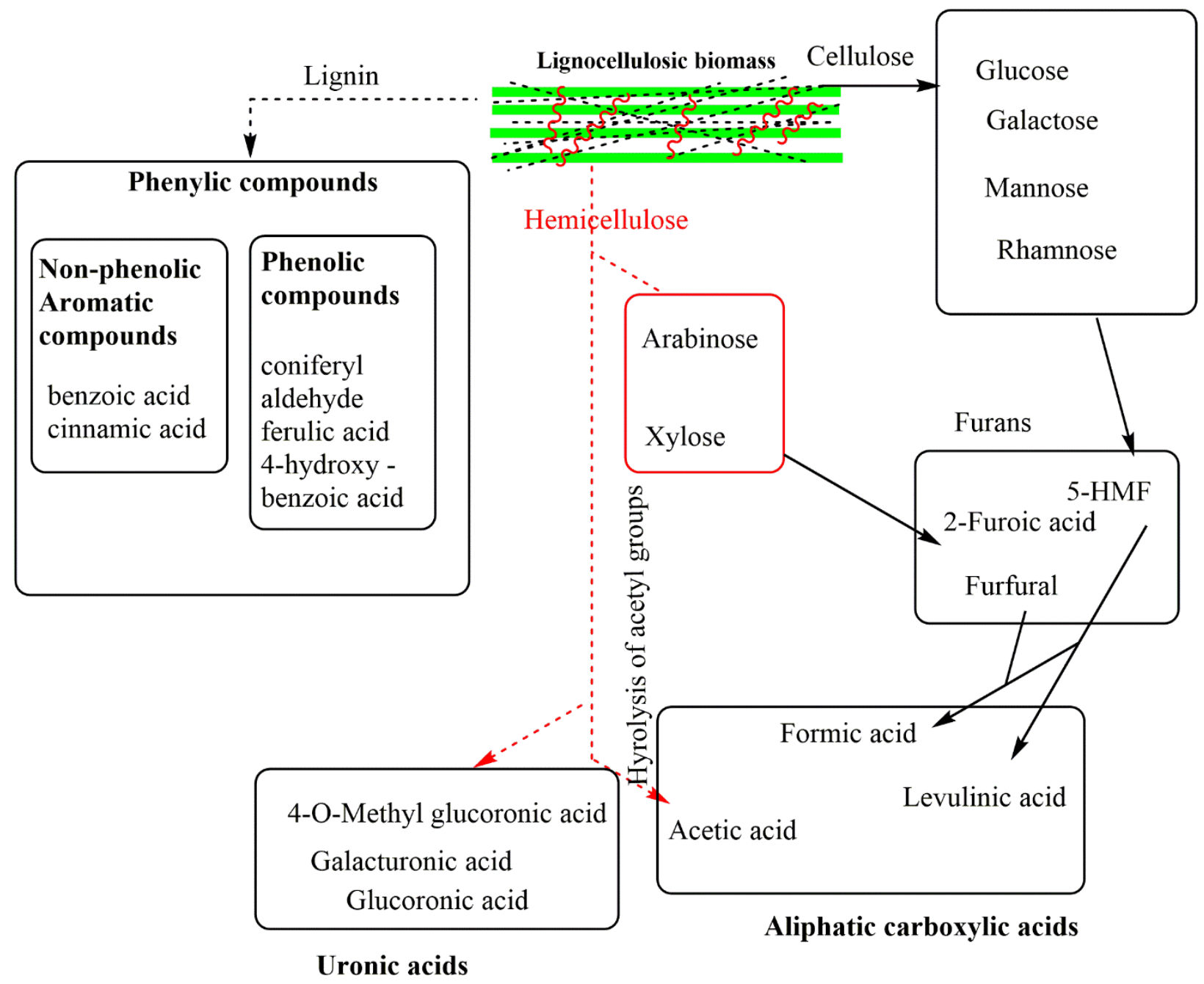

Figure 3.2 - Mechanism of inhibitory compounds production during hydrothermal pretreatment modified after (Jönsson and Martín, 2016) 
Table 3.3 - Hydrolysate composition in response to hydrothermal pretreatment of various feedstocks

\begin{tabular}{|c|c|c|c|c|c|c|}
\hline Feedstock & $\begin{array}{l}\text { Chemical } \\
\text { addition }\end{array}$ & $\begin{array}{l}\text { Pretreatment } \\
\text { conditions }\end{array}$ & $\begin{array}{l}\text { Furfural } \\
g^{-1}\end{array}$ & $\begin{array}{l}\text { 5- } \\
\text { Hydroxymethylfurfural } \\
\qquad \mathrm{g} \mathrm{L} \mathrm{L}^{-1}\end{array}$ & $\begin{array}{l}\text { Acetic } \\
\text { acid } \\
\text { g L L }\end{array}$ & Reference \\
\hline $\begin{array}{l}\text { Sugarcane } \\
\text { bagasse }\end{array}$ & - & $\begin{array}{c}195^{\circ} \mathrm{C}, 10 \\
\min \end{array}$ & $\begin{array}{c}0.59 \\
\pm 0.10\end{array}$ & $0.03 \pm 0.01$ & $2.03 \pm 0.40$ & $\begin{array}{l}\text { (de Moutta } \\
\text { et al., 2013) }\end{array}$ \\
\hline Straw & - & $\begin{array}{c}195^{\circ} \mathrm{C}, 10 \\
\min \end{array}$ & $0.81 \pm 0.15$ & $0.33 \pm 0.01$ & $1.93 \pm 0.10$ & $\begin{array}{l}\text { (de Moutta } \\
\text { et al., 2013) }\end{array}$ \\
\hline Yard waste & - & $\begin{array}{l}\mathrm{WS}^{\mathrm{a}}, \mathrm{AIS}^{\mathrm{b}} \\
\mathrm{AcS}^{3} 180^{\circ} \mathrm{C} \\
\quad 30 \mathrm{~min}\end{array}$ & $\begin{array}{c}0.08,0.00 \\
0.87 \\
\left(\mathrm{mg} \mathrm{mL}^{-1}\right)\end{array}$ & $0.09,0.00,0.90$ & $\begin{array}{c}2.75,2.35 \\
1.80 \\
\left(\mathrm{mg} \mathrm{mL} \mathrm{mL}^{-1}\right. \\
\text { ) }\end{array}$ & $\begin{array}{l}\text { (Wangliang } \\
\text { et al., 2014) }\end{array}$ \\
\hline Beach wood & - & $\begin{array}{c}130^{\circ} \mathrm{C}- \\
220^{\circ} \mathrm{C}, 15- \\
180 \mathrm{~min}\end{array}$ & $\begin{array}{c}0.03- \\
2.73(\mathrm{mg} \\
\left.\mathrm{mL}^{-1}\right)\end{array}$ & $0.03-0.84$ & $\begin{array}{c}0.08- \\
3.41(\mathrm{mg} \\
\left.\mathrm{mL}^{-1}\right)\end{array}$ & $\begin{array}{l}\text { (Nitsos et } \\
\text { al., 2013) }\end{array}$ \\
\hline Corn stover & - & $\begin{array}{l}200^{\circ} \mathrm{C}, 5 \mathrm{~min} \\
-60 \mathrm{~min}\end{array}$ & $\begin{array}{c}4.8-21.5 \\
\mathrm{mg} \mathrm{g}^{-1}\end{array}$ & $\begin{array}{c}0.42-3.2 \\
\mathrm{mg} \mathrm{g}^{-1}\end{array}$ & - & $\begin{array}{l}\text { (Saha et al., } \\
\text { 2013) }\end{array}$ \\
\hline Wheat straw & - & $\begin{array}{c}170^{\circ} \mathrm{C}- \\
200^{\circ} \mathrm{C} \\
0 \min -40 \\
\min \end{array}$ & $\begin{array}{l}<0.1- \\
3.32 \mathrm{~g} 100^{-1} \\
\mathrm{~g}^{-1} \\
\text { untreated } \\
\text { material }\end{array}$ & $\begin{array}{c}<0.1-0.50{\mathrm{~g} 100 \mathrm{~g}^{-1}} \\
\text { untreated material }\end{array}$ & $\begin{array}{l}0.51- \\
3.86 \mathrm{~g} 100 \\
\mathrm{~g}^{-1} \\
\text { untreated } \\
\text { material }\end{array}$ & $\begin{array}{l}\text { (Pérez et } \\
\text { al., 2007) }\end{array}$ \\
\hline $\begin{array}{l}\text { Eucalyptus } \\
\text { urophylla }\end{array}$ & - & $\begin{array}{c}100^{\circ} \mathrm{C}- \\
240^{\circ} \mathrm{C} \\
15 \min -60 \\
\min \end{array}$ & $\begin{array}{c}\mathrm{ND}^{\mathrm{d}}- \\
1.45\end{array}$ & $\mathrm{ND}-1.27$ & $\mathrm{ND}-3.28$ & $\begin{array}{l}\text { (Sun et al., } \\
\text { 2014) }\end{array}$ \\
\hline Switchgrass & - & $\begin{array}{c}190^{\circ} \mathrm{C}- \\
210^{\circ} \mathrm{C} \\
10 \min -20 \\
\min \end{array}$ & $\begin{array}{c}<0.2- \\
0.91\end{array}$ & $<0.15-0.79$ & - & $\begin{array}{l}\text { (Lilis et al., } \\
\text { 2009) }\end{array}$ \\
\hline $\begin{array}{l}\text { Sugarcane } \\
\text { bagasse }\end{array}$ & - & $\begin{array}{c}180^{\circ} \mathrm{C}- \\
295^{\circ} \mathrm{C}\end{array}$ & $2.8-18.2$ & $0.9-3.9$ & $1.1-2.6$ & $\begin{array}{l}\text { (Rocha } e t \\
\text { al., 2013) }\end{array}$ \\
\hline Corn Stover & $\begin{array}{l}\text { Acetic } \\
\text { Acid }(0- \\
400 \mathrm{~g} \mathrm{Kg}^{-} \\
\left.{ }^{1} \mathrm{DM}\right)\end{array}$ & $\begin{array}{l}195^{\circ} \mathrm{C} \\
15 \mathrm{~min}\end{array}$ & $\begin{array}{c}0.19- \\
1.74\end{array}$ & $0.02-0.23$ & - & $\begin{array}{c}\text { (Xu et al., } \\
\text { 2009) }\end{array}$ \\
\hline $\begin{array}{l}\text { Sugarcane } \\
\text { press mud }\end{array}$ & - & $\begin{array}{c}140-210{ }^{\circ} \mathrm{C} \\
2-23 \mathrm{~min}\end{array}$ & 1.21 & $0.034-0.362$ & $\begin{array}{c}6132 \mathrm{mg} \\
\mathrm{L}^{-1}\end{array}$ & $\begin{array}{c}\text { (González } \\
\text { et al., 2014) }\end{array}$ \\
\hline Corn cob & - & $170-230{ }^{\circ} \mathrm{C}$ & 5.13 & 1.27 & - & $\begin{array}{l}\text { (Sun et al., } \\
\text { 2014) }\end{array}$ \\
\hline $\begin{array}{c}\text { Eucalyptus } \\
\text { camaldulensis }\end{array}$ & $\begin{array}{c}\text { Aqueous } \\
\mathrm{AlCl}_{3} \\
(0.02 \mathrm{M})\end{array}$ & $\begin{array}{c}140-180{ }^{\circ} \mathrm{C} \\
1 \mathrm{~h}\end{array}$ & $\begin{array}{l}1.31- \\
3.05\end{array}$ & $0.53-1.53$ & $\begin{array}{c}2.63- \\
5.23\end{array}$ & $\begin{array}{l}\text { (Shen et al., } \\
\text { 2016) }\end{array}$ \\
\hline
\end{tabular}




\subsection{Impact of hydrothermal pretreatment on morphological structure of biomass}

Morphological structure of lignocellulosic biomass is an important aspect of studying the chemical components distribution and their inter-linkages (Hon and Shiraishi, 2001). The in-depth morphological study would help to broaden the knowledge about physiochemical properties of lignocellulosics in question. Furthermore, it would help to enhance lignocellulosic bioconversion and understand enzyme accessibility during downstream processing

A number of techniques have widely been employed to visualize structural changes, including Fourier transform infrared spectroscopy (FTIR), nuclear magnetic resonance (NMR), Xray powder diffraction (XRD), scanning electron microscopy (SEM), and transmission electron microscopy (TEM). The collective use of FTIR and NMR can provide detailed structural elucidation of pretreatment impacts on lignocellulosic, SEM is used to visualize morphological changes (Wi et al., 2015), while XRD is used to estimate crystallinity index (Zhang et al., 2014).

Structural disruption of the lignocellulosic matrix is a complex process to understand at the molecular level. Xylan dissolution mechanism during hydrothermal pretreatment has recently been reported by transmission electron microscopy at a ultra-structural level that will advance our understanding of reaction mechanisms impact on the structural morphology of biomass (Ma et al., 2015).

Amorphous cellulose is relatively easy to solubilize than of crystalline cellulose. Deconstruction of cellulose involves swelling under concentrated acid condition and breakage of glycosidic bonding. Cellulose chain cleavage started when temperature slightly exceeds to $150^{\circ} \mathrm{C}$ during hydrothermal pretreatment (Ma et al., 2013). Decomposition of cellulose occurs within a temperature range of $250-400{ }^{\circ} \mathrm{C}$ with maxima at $334^{\circ} \mathrm{C}$, while hemicellulose and lignin have maximum deconstruction rate at $375^{\circ} \mathrm{C}$ and $296^{\circ} \mathrm{C}$, respectively (Nitsos et al., 2013). Moreover, authors reported that at mild temperature conditions no significant morphological changes were observed while at higher severity $\log \mathrm{R}_{0} \geq 3.5$ significant morphological changes were observed under SEM microimages indicating lignin removal and recondensation in droplets forms on the surface of particles. 
To visualize the impact of hydrothermal pretreatment on ultrastructure and molecular organization of biomass, Kristensen et al. (Kristensen et al., 2008) reported studies on wheat straw in comparison to $\mathrm{SO}_{2}$ impregnated steam explosion.

A hypothesis was put forward by Donohoe et al. (Donohoe et al., 2008) for the appearance of lignin droplets on the surface of cell wall after hydrothermal pretreatment based on their study on corn stover after comparing several techniques; FTIR, NMR analysis, antibody labeling, and cytochemical staining. The authors hypothesized that whenever thermochemical pretreatment temperature goes above the lignin phase transition temperature range, it causes lignin to coalesce into larger molten bodies and make it migrate within and out of the cell wall and it can redeposit on the surface of the cell wall. Kumar et al. (Kumar et al., 2013) proposed another hypothesis that spherical droplets are pseudo-lignin derived from carbohydrate like xylan components at high severity hydrothermal pretreatments.

The degree of polymerization and chain break in bamboo as a result of hydrothermal pretreatment were studied by Ma et al. (Ma et al., 2013). The authors observed that cellulose degradation is favored at a higher temperature as indicated by Xiang and co-workers (Xiang et al., 2003). Hardwood was pretreated hydrothermally at different severities by Ko et al. (Ko et al., 2015) to study its impact on enzymatic cellulose hydrolysis and lignin properties. The authors compared SEM micro images of the untreated and pretreated sample and observed fragmentation and disruption in the morphology of treated samples as compared to the flat and smooth surface of untreated hardwood. Spherical droplets of lignin were noticed on the surface even on the corners of the disrupted cell thus might be a source of a physical barrier for impeding cellulose hydrolysis.

Date palm (Phoenix dactylifera L.) leaflets and rachis were pretreated with hydrothermal pretreatment at four temperature levels; $180,190,200$, and $210^{\circ} \mathrm{C}$ for a holding time of 10 min to evaluate pretreatment impact on enzymatic digestibility and bioethanol potential in addition to assessing pretreatment severity effect on morphological changes (Fang et al., 2015). By SEM images, a significant difference between untreated and pretreated samples was observed. Rachis surface was found to be more irregular in contrast to leaflets at same severity condition. Furthermore, the structure of leaflets and rachis showed a variety of smaller fragments in response to hydrothermal pretreatment. Pretreatment at $210{ }^{\circ} \mathrm{C}$ depicted significant morphological and structural changes than $180{ }^{\circ} \mathrm{C}$ for both leaflets and rachis. High severity results in significant cell 
wall destruction thereby increasing surface area for enzymatic hydrolysis and improve lignocellulosic bio-convertibility (Ding et al., 2012; Li et al., 2014).

Untreated and liquid hot water pretreated $\left(170-230{ }^{\circ} \mathrm{C}\right)$ corncob samples were visualized for SEM images to look into morphological characteristics. A substantial cell wall disruption was observed for pretreated samples comparative to compact surface structure and intact morphology of untreated ones. Authors noted minimal structural disruption at lower temperature $(170-180$ ${ }^{\circ} \mathrm{C}$ ), fiber length reduction at moderate temperature $\left(190^{\circ} \mathrm{C}\right)$ while complete cell wall disruption at high temperature (above $190{ }^{\circ} \mathrm{C}$ ), lignin droplets were also observed on cell wall surface for samples pretreated at $220^{\circ} \mathrm{C}$ (Sun et al., 2014)

A comparison of hydrothermal and wet explosion pretreatment was studied to map and characterize changes in lignin by Kaparaju and Felby (Kaparaju and Felby, 2010) with the help of microscopy (atomic force microscopy, scanning electron microscopy), and ATR-FTIR (Attenuated Total Reflectance Fourier Transform Infrared Spectroscopy). The authors reported substantial removal of hemicellulose in both pretreatments, but the values observed slightly higher for hydrothermal than wet explosion pretreatment. This might be due to the combined effect of counter-current water flow system and partial hydrolysis of cellulose during hydrothermal pretreatment

\subsection{Anaerobic Digestion: process and affecting parameters}

Anaerobic digestion is a series of processes governed by several bacterial and archaeal guilds to break down organic matter in the absence of oxygen to produce clean energy, methane, along with carbon dioxide plus hydrogen, hydrogen sulfide and new bacterial biomass (Kavuma, 2013; De Vrieze and Verstraete, 2016). A comprehensive review of the biochemical reactions and microbiological perspective of the digestion process is beyond the scope of this text.

The readers are referred to Adekunle and Okolie (Adekunle and Okolie, 2015) for in-depth study of the biochemical process of anaerobic digestion and to Vrieze and Verstraete (De Vrieze and Verstraete, 2016) for microbiological perspectives. A brief overview of anaerobic digestion process and affecting parameters is presented in this text. Hydrolysis, acidogenesis, acetogenesis, and methanogenesis (Fig 3.3) are the key steps of the digestion process, based on the chemical reactions undertaken by various obligatory and facultative anaerobes (Yi et al., 2014). The 
products of one-step are taken up as substrate by microbial community of the subsequent step. Therefore, the imbalance between chemical reactions of microbes will influence microbial kinetics, substrate consumption rate, final product formation, and finally could lead to system failure (Franke-Whittle et al., 2014; Adekunle and Okolie, 2015).

Several factors including physical, chemical, and biological could affect the digestion process. Alteration in substrate characteristics, organic loading rate, temperature fluctuation, $\mathrm{pH}$, nutrients, and mixing conditions can have an influencing impact on biodegradation rate, biogas compositions, substrate utilization, and specific microbial growth rate.

The biogas yield, composition, and success of digestion process are strongly dependent upon the feed characteristics in terms of its constituents protein, fat (Schnürer and Jarvis, 2010), and carbohydrates; cellulose, hemicellulose, and lignin (Hartmann and Ahring, 2006). Moreover, substrate particle size, biodegradability, total solids, and volatile solids play a vital part in anaerobic digestion.

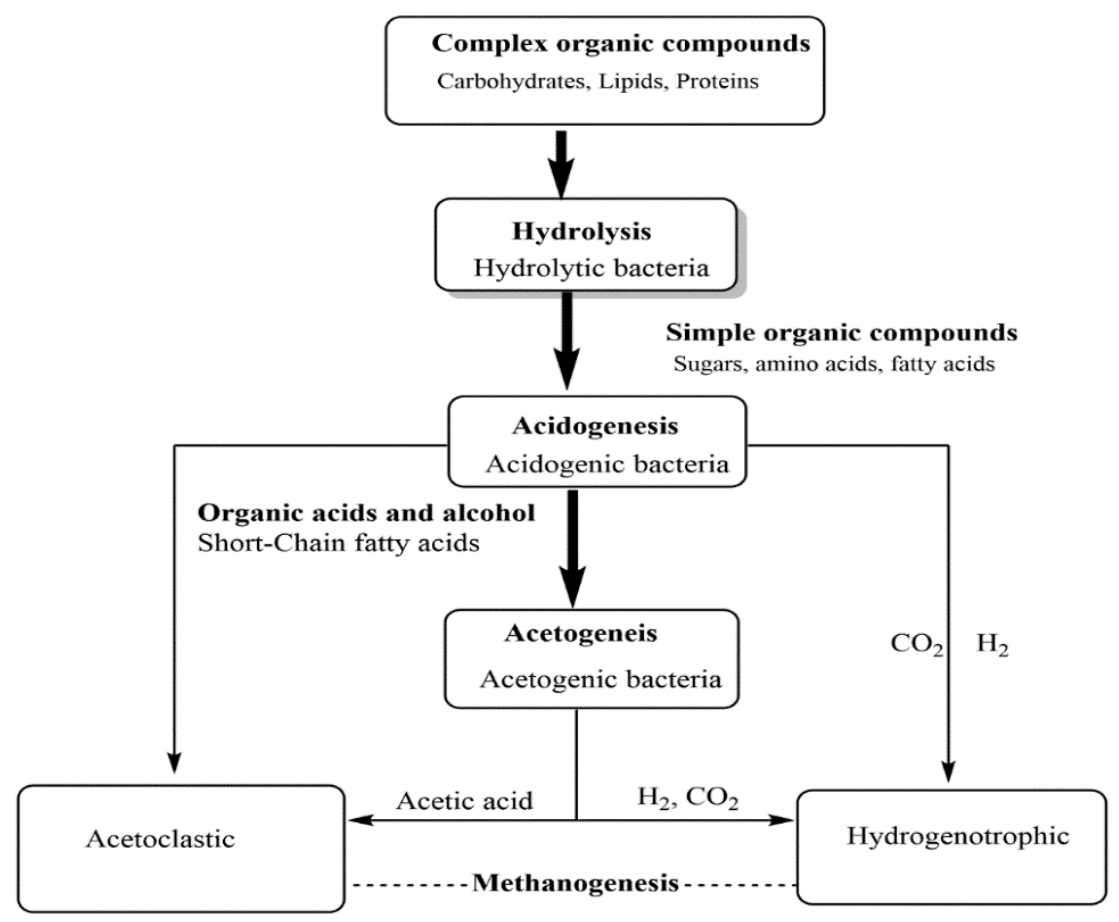

Figure 3.3 - Schematic conversion of macromolecules into biomethane in anaerobic digestion process (modified after (Yi et al., 2014))

The $\mathrm{pH}$ value is an important parameter and indicator of process stability. It has a significant impact on the microbial growth (Yadvika et al., 2004). Since a consortium of 
microorganisms is involved in biogas production, their $\mathrm{pH}$ requirements vary widely. Microorganisms can be divided into two groups based on $\mathrm{pH}$ optima for anaerobic digestion. Acidogenic bacteria prefer a $\mathrm{pH}$ range of $5.5-6.5$, while methanogens thrive best at $7.8-8.2$ (Khanal, 2008). However, methanogens have been reported to remain active outside this range (Whitman et al., 2006). $\mathrm{pH}$ control is vital to the bacterial growth and conversion processes in digestion.

In single stage digestion reactors, $\mathrm{pH}$ is maintained at neutral since methanogens are very susceptible to $\mathrm{pH}$ change since microorganisms of both groups are present at this stage. Methane generation rate may decrease if $\mathrm{pH}$ is lower than 6.3 or higher than 7.8 (Stronach et al., 1986). However, studies are reported for acidophilic (Bräuer et al., 2006) and alkaliphilic methanogens (Sorokin et al., 2015).

Microorganisms, like other organisms, require nutrients for their growth, activity, and to perform metabolic processes. A balanced anaerobic digestion system necessitates mix of nutrients, both macro and micro, to fulfill the microbial needs involved in the process (Goodwin et al., 1990; Takashima et al., 1990). Nutrients fall into two categories based on their requirement; a) macronutrients, required in substantial amount, carbon, nitrogen, hydrogen, phosphorus, potassium, and sulphur (Kayhanian and Rich, 1995), and micronutrients; cobalt, zinc, molybdenum, nickel, iron, copper, selenium, and tungsten and also vitamins, required in minute quantities but essential for growth (Rivard et al., 1989; Kayhanian and Rich, 1995). The trace elements requirement by methanogens, both acetoclastic and hydrogenotrophic, is not entirely understood. Therefore, it presents toxic or inhibitory effects during digestion if exceed a threshold level of microbial requirement.

The anaerobic process requires lower macronutrients than aerobic process owing to lower biomass yield while degrading equal amount of waste. A single nutrient recipe is not available, as substrates having different chemical composition require specific nutrients for the digestion process. Nutrient requirements can be determined with COD (Chemical Oxygen Demand) of the substrate, COD:N ratio. A COD:N ratio of 350:7 and 1000:7 is recommended for highly and low loaded system (Henze and Harremoës, 1983). Most authors prefer to cite as C/N ratio in literature. $\mathrm{C} / \mathrm{N}$ ratio lies in the range of 10-30 with an optimum value of 25-30:1 for the digesters to work at full potential (Mital, 1996; Yadvika et al., 2004). In the case of high $\mathrm{C} / \mathrm{N}$ ratio digester will be 
deficient in nitrogen impeding microbial growth (Alvarez and Lidén, 2008) while in the other circumstances degradation leads to ammonia inhibition (Hartmann and Ahring, 2006), VFA (Volatile Fatty Acids) accumulation, and ultimately reactor failure (Franke-Whittle et al., 2014).

\subsection{Hydrothermal pretreatment in relation to subsequent methanogenesis}

Hydrothermal pretreatment parameters; temperature, reaction time, total solids, and $\mathrm{pH}$ are aspects of paramount importance in relation to pretreatment efficiency and subsequently on anaerobic digestion. Furanic (sugar monomers degradation products) and phenolic compounds (lignin degradation products) are undeniable products during pretreatment. These products are toxic and can possibly inhibit growth mechanism of bacteria and methanogenic archaea (Ghasimi et al., 2016). Whereas Barakat et al. (Barakat et al., 2012) reported contradictory results by demonstrating the adaptability of microbial consortia to phenolic and furanic compounds. Ligninderived phenolics specifically inhibit hydrolytic enzymes cellulase, glucanase, and xylanase (Berlin et al., 2006).

Massive volatile fatty acids, ammonia nitrogen and amino acids released into liquid hydrolysate at a higher severity. Higher VFAs; propionic acid $900 \mathrm{mg} \mathrm{L}^{-1}$ could stop the methanogenesis (Wang et al., 2009). Pretreatment parameters can be optimized to a lower production of inhibitory compounds, maximizing sugar yield, and ultimately higher digestion efficiency.

Hydrothermal pretreatment recently gets more attraction in lignocellulosic pretreatment as it did not require particle size reduction resulting in cost reduction at large scale (Weil et al., 1997; Taherzadeh and Keikhosro, 2008). Use of hydrothermal pretreatment for biogas production is not only limited to energy crops (Koponen, 2010) and agricultural residues (Grimaldi et al., 2015), but also expands to algal biomass (Passos and Ferrer, 2015). Qiao et al. (Qiao et al., 2011) reported an increase of $67.8,18.5,13.3$, and $7.8 \%$ biogas in hydrothermally pretreated $\left(170^{\circ} \mathrm{C}, 1 \mathrm{~h}\right)$ municipal sewage sludge, fruit/vegetable waste, cow manure, and pig manure, respectively. The authors also observe $3.5 \%$ decrease in biogas with $6.9 \%$ reduction in methane content for food waste under same pretreatment conditions; this might be a result of valorization of readily degradable feedstock during hydrothermal pretreatment. 
In another study, hydrothermal pretreatment was carried out on sugar beet pulp to enhance biogas production. Zieminski et al. (Zieminski et al., 2014) investigated the pretreatment of sugar beet pulp (100 g TS) conducted at 120, 130, 140, 150, 160, 170, and $200{ }^{\circ} \mathrm{C}$ in a $600 \mathrm{~mL}$ thermostatic reactor for $20 \mathrm{~min}$ under varying pressure range. Batch digestion experiments of pretreated hydrolysate were carried out in glass chambers of $1 \mathrm{~L}$ working volume. The authors observed the highest cumulative methane yield of $502.50 \mathrm{~L} \mathrm{CH}_{4} \mathrm{~kg}^{-1} \mathrm{VS}$ from $160{ }^{\circ} \mathrm{C}$ pretreated pulp. The highest free glucose release of $3.29 \mathrm{mg} \mathrm{mL}^{-1}$ was observed at $160{ }^{\circ} \mathrm{C}, 4$ folds higher than $120^{\circ} \mathrm{C}$.

Rice straw, a potential AD (Anaerobic Digestion) feedstock, was studied by Chandra et al. (Chandra et al., 2012) using two different pretreatments: (1) $\mathrm{NaOH}$, and (2) hydrothermal followed by $\mathrm{NaOH}$ addition. $\mathrm{NaOH}$ pretreatment was given at $3 \% \mathrm{NaOH}$ for $120 \mathrm{~h}$ at $37^{\circ} \mathrm{C}$ in a temperature controlled incubator at $10 \%$ TS (20 g). Hydrothermal pretreatment was conducted at $200{ }^{\circ} \mathrm{C}$ with a residence time of $10 \mathrm{~min}$ under pressure of $1.55 \mathrm{MPa}$ in a SUS (Steel Used Stainless) 316 austenitic steel reactor followed by $5 \% \mathrm{NaOH}$ to adjust the $\mathrm{pH}$ of pretreated slurry for subsequent $\mathrm{AD}$ experiments. The pretreated material with both pretreatments was subjected to digestion for 60 days under mesophilic conditions $\left(37^{\circ} \mathrm{C}\right)$ with a $\mathrm{C} / \mathrm{N}$ ratio of 25 . The study results revealed a biogas production of 140 , and $184 \mathrm{~L} \mathrm{~kg}^{-1} \mathrm{VS}$ a for untreated and $3 \% \mathrm{NaOH}$ pretreated, wheat straw while highest biogas production $\left(315.9 \mathrm{~L} \mathrm{~kg}^{-1} \mathrm{VSa}\right)$ was observed for hydrothermal pretreatment followed by $5 \% \mathrm{NaOH}$ addition.

Poplar leaves, considering yard waste, were primarily screened to remove plastics, sticks, and metals. These were then hydrothermally pretreated using three catalysts; hot compressed water, acidic solution, and alkaline solution, to investigate the effect on anaerobic digestion in batch reactors. The batch reactors were maintained at mesophilic conditions $\left(37^{\circ} \mathrm{C}\right)$ with an inoculum to substrate ratio of $1 \mathrm{~mL} \mathrm{~g}^{-1}$ for a period of 32 days. The highest concentration of glucose and xylose were observed in the acidic pretreated sample. Biogas yield for samples pretreated with an alkaline solution, acidic solution, and hot compressed water was increased by 364, 107, and $79 \%$, respectively in comparison to the untreated sample. Furthermore, authors noted a decrease in the COD in liquid phase followed the same order as of biogas yield (Wangliang et al., 2014).

Sunflower oil cake was studied by Fernandez et al. (Fernandez-Cegri et al., 2012) for hydrothermal pretreatment. The study was aimed at to elucidate the impact of different 
temperatures $\left(25,100,150\right.$, and $\left.200^{\circ} \mathrm{C}\right)$ of hydrothermal pretreatment on the chemical composition of cake and subsequent biomethane potential tests. Batch digestion reactors were conducted for pretreated solids and hydrolysate samples obtained after separation of pretreatment slurry at inoculum to substrate ratio of 2 ( $2 \mathrm{~g}$ inoculum / $1 \mathrm{~g}$ substrate) on VS basis at mesophilic conditions $\left(35 \pm 1{ }^{\circ} \mathrm{C}\right)$. The authors reported hemicellulose decrease in solid content from 13 to $6 \%$ while an increase was observed in lignin content by $16 \%$, for pretreatment temperature range of $25-200$ ${ }^{\circ} \mathrm{C}$. The pretreatment conducted at $100{ }^{\circ} \mathrm{C}$ reported representing highest methane yield, $6.5 \%$ higher, based on combined methane yields from solid and hydrolysate.

A dedicated crop Giant reed (Arundo donax) was subjected to a hydrothermal pretreatment by Giuseppe and co-workers (Giuseppe et al., 2013) to evaluate its potential for biogas production. Three conditions were tested for hydrothermal pretreatment; uncatalyzed, $24 \mathrm{~h}$ impregnation of the substrate with $2 \%(\mathrm{w} / \mathrm{w}) \mathrm{H}_{2} \mathrm{SO}_{4}$, and immediate addition of $2 \%(\mathrm{w} / \mathrm{w}) \mathrm{H}_{2} \mathrm{SO}_{4}$ before steam cooking for pretreatment parameters; temperature $\left(150\right.$ and $\left.180{ }^{\circ} \mathrm{C}\right)$ and time (10 and $\left.20 \mathrm{~min}\right)$. Results of subsequent batch digestion tests, conducted with $4 \mathrm{~g} \mathrm{VS} \mathrm{L}^{-1}$ under thermophilic conditions $\left(53^{\circ} \mathrm{C}\right)$ for a period of 39 days, revealed into methane yield of $273 \mathrm{~mL} \mathrm{~g}^{-1}$ VS added for untreated biomass. Reactors with uncatalyzed biomass achieved a yield of $23 \%$ at temperature/time combination of $180{ }^{\circ} \mathrm{C} / 10 \mathrm{~min}$. Conversely, the reactors fed with catalyzed biomass were observed methanogenic inhibition. The inhibition might be due to competition with sulfate reducing bacteria (SRB) as sulfate concentration was observed in the hydrolysates of acidcatalyzed pretreatments.

Jorn and his team (Jörn et al., 2014) conducted thermobarical pretreatment on solid cattle manure and liquid cattle manure obtained from two different location in Germany to evaluate its efficiency on the biomethanation. Pretreatment was performed in a mini reactor $(600 \mathrm{~mL})$ at a temperature range of $140,160,180,200 \& 220{ }^{\circ} \mathrm{C}$ for a retention time of $5 \mathrm{~min}$. The authors observed the high concentration of inhibitory compounds (furfural, 5-HMF, and phenolic compounds) at a temperature of $220{ }^{\circ} \mathrm{C}$; resulting into lower degradability and lower methane output. Authors claimed 58\% increase in the methane yield with pretreatment conducted at 180 ${ }^{\circ} \mathrm{C}$. Furthermore, reported an optimum temperature of $164{ }^{\circ} \mathrm{C}$ based on regression analysis of methane generation rate and methane yield. 


\subsection{Microbial community structure of anaerobic digestion and molecular fingerprinting}

techniques

Anaerobic digestion is a microbial mediated process involving bacterial and archaeal communities working in close relation, as both communities need each other to degrade the complex organic compounds and for their own survival. The process is initiated by the hydrolytic bacteria by converting complex organic compounds into simpler ones. Carbohydrates, proteins and lipids are converted into simple sugars, amino acids and fatty acids, respectively as depicted in Fig 3.3. Input material dictates the bacterial community composition within the reactor for the hydrolytic stage, whilst, the temperature is the key driver for microbial community diversity and evenness (Leven et al., 2007). Digesters treating cellulosic material are dominant with Clostridium spp. along with Bacteroidetes and Proteobacteria but at lower abundance (Carballa et al., 2015). Clostridium spp. and other members of Firmicutes are abundant in lipid-rich digesters (Zakrzewski et al., 2012). Whilst, Bacillus spp. Clostridia spp., and representatives of Proteobacteria were found in protein-rich reactors (Kovács et al., 2015).

Identification of specific organism about specific biochemical-stage of digestion process has been a challenging task due to culture restraints. It is quite impossible to generate a pure culture from syntrophic interactions. Recent advancements in the molecular biology, specifically regarding DNA sequencing technology has made an in-depth study of microbial community structure possible. Furthermore, microbial community characterization and monitoring is currently the theme of research to increase methane output and capacity of digesters (Vanwonterghem et al., 2014).

The emergence of $16 \mathrm{~S}$ rRNA as universal target led to a new era in taxonomic classification of microorganisms based on DNA sequencing information (Woese and Fox, 1977). Sequence divergence of the ribosomal small subunit RNA (16S rRNA) is the basis for culture-independent techniques (Nayak et al., 2009). This approach classified methanogens into a new Archaeal Domain. Recently, other universal targets have also been developed based on bacterial type I cpn60 (Hill et al., 2004) and archaeal type II thermosome chaperonins (Chaban and Hill, 2012). These chaperone proteins are highly conserved for both archaea and bacteria and help in protein folding (Hemmingsen et al., 1988). Groups of microorganisms with a similar taxonomic relationship based 
on DNA sequences put together in an operational taxonomic unit (OTU). Phylogenetically, OTU permits greater resolution of closely related microorganisms (Links et al., 2012).

A number of fingerprinting techniques have been developed to study the microbial diversity and structure; amplified ribosomal DNA restriction analysis (ARDRA), single strand conformation polymorphism (SSCP), denaturing gradient gel electrophoresis (DGGE), temperature gradient gel electrophoresis (TGGE), terminal restriction fragment length polymorphism (TRFLP), and ribosomal intergenic spacer analysis (RISA). Fluorescence in situ hybridization (FISH), DNA microarray, and sequencing are the tools for microbial identification. DGGE could give a snapshot of microbial community, but it is not suitable to identify changes in microbial community at specie level (Ercolini, 2004)

DGGE technique is generally applied to separates complex mixtures of 16S rRNA gene amplicons of the same length having different sequences. The mixture of $16 \mathrm{~S}$ rRNA amplicons is applied on a polyacrylamide gel with a linearly increasing gradient of denaturant (formamide or urea). An electric current is applied and the amplicons migrate though the gel. First, the fragments travel according to their molecular weight and as they are exposed to the increasing concentration of denaturant, the DNA strands begin to denature. At their specific melting point their migration stops. Therefore, separation of the fragments is the consequence of different melting temperatures according to their DNA sequence variations. The separated strands could be excised and directly utilize for sequencing after following proper protocol. 
The Study was planned according to the following flow-chart diagram Fig 4.1

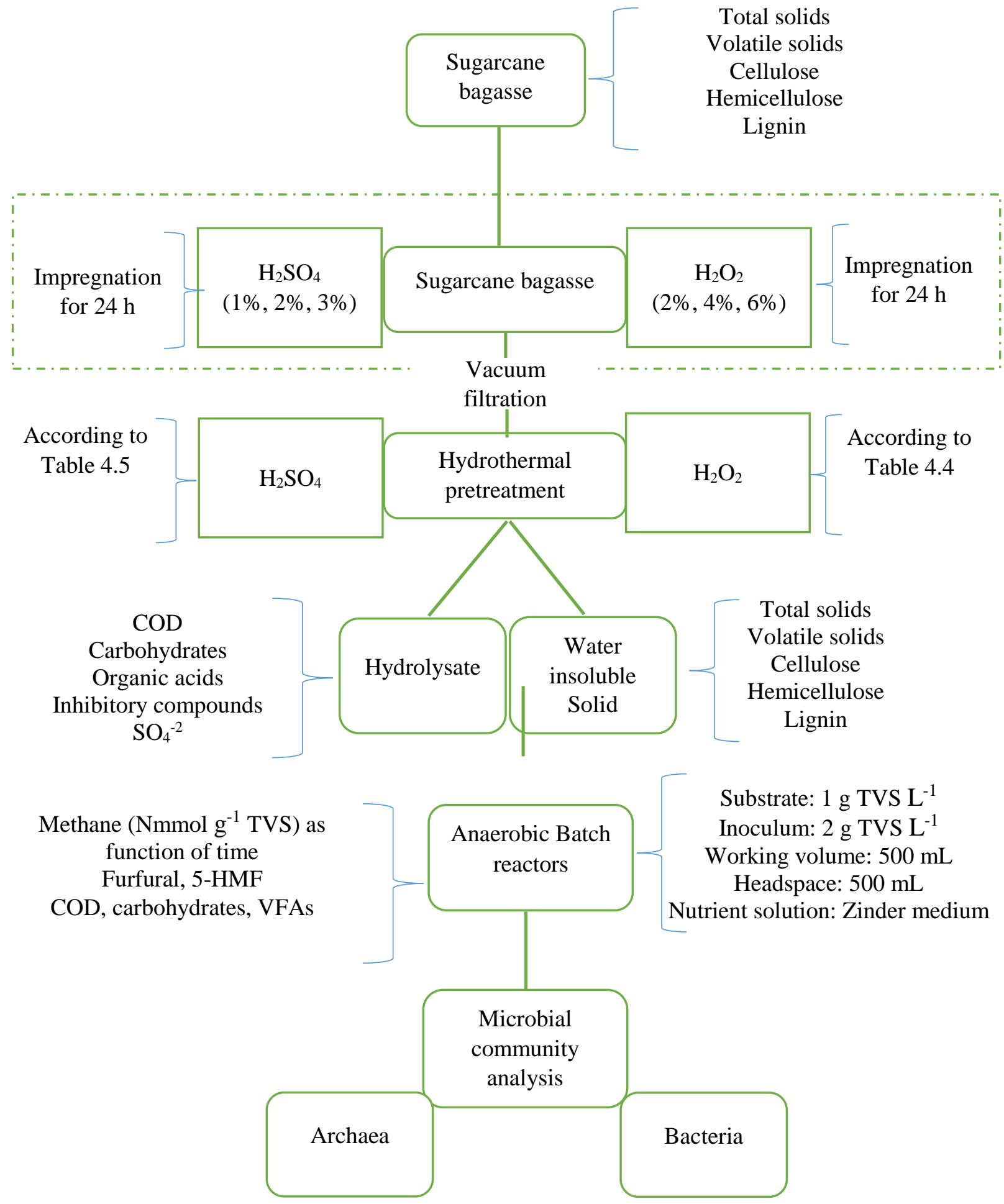

Figure 4.1 - Flow-chart diagram of experiments 


\subsection{Substrate}

Sugarcane bagasse was generously provided by Laboratório Nacional de Ciência e Tecnologia do Bioetanol, Campinas - Brazil. It was dried at $37^{\circ} \mathrm{C}$ in an incubator and afterward stored in plastic bags at ambient temperature until further use for pretreatment and compositional analysis.

\subsection{Hydrothermal pretreatment}

\subsubsection{Substrate impregnation}

Sugarcane bagasse was impregnated with sulfuric acid and hydrogen peroxide at solid to liquid ratio of 1:10 in plastic beakers according to pretreatment index presented in Table 4.4 and 4.5. The beakers were sealed with paper film strengthened by rubber wires. The beakers were left for $24 \mathrm{~h}$ at room temperature under static conditions. Sugarcane bagasse was separated by vacuum filtration, afterward. In the case of hydrogen peroxide, $\mathrm{pH}$ was raised to 11.0 with $5 \mathrm{M} \mathrm{NaOH}$ before impregnation. Acid pretreatment will be indexed as A-HSO, B-HSO, C-HSO, and so on till P-HSO. On the other hand, hydrogen peroxide pretreatment will be indexed as A-HO, B-HO, C$\mathrm{HO}$, and so on till P-HO".

\subsubsection{Description of the hydrothermal reactor}

The hydrothermal reactor was built in-house by Departamento de Engenharia de Mecânica, Universidade de São Paulo, São Carlos - Brazil. A brief description of the reactor is presented as follow: The reactor was made of steel with a capacity of $150 \mathrm{~mL}$. The reactor (Fig 4.2) consists of a temperature control panel, pressure gauge to measure the inside reactor pressure, pressure valve to release the pressure, and a cyclone-shaped receiver to receive the pretreated biomass. 


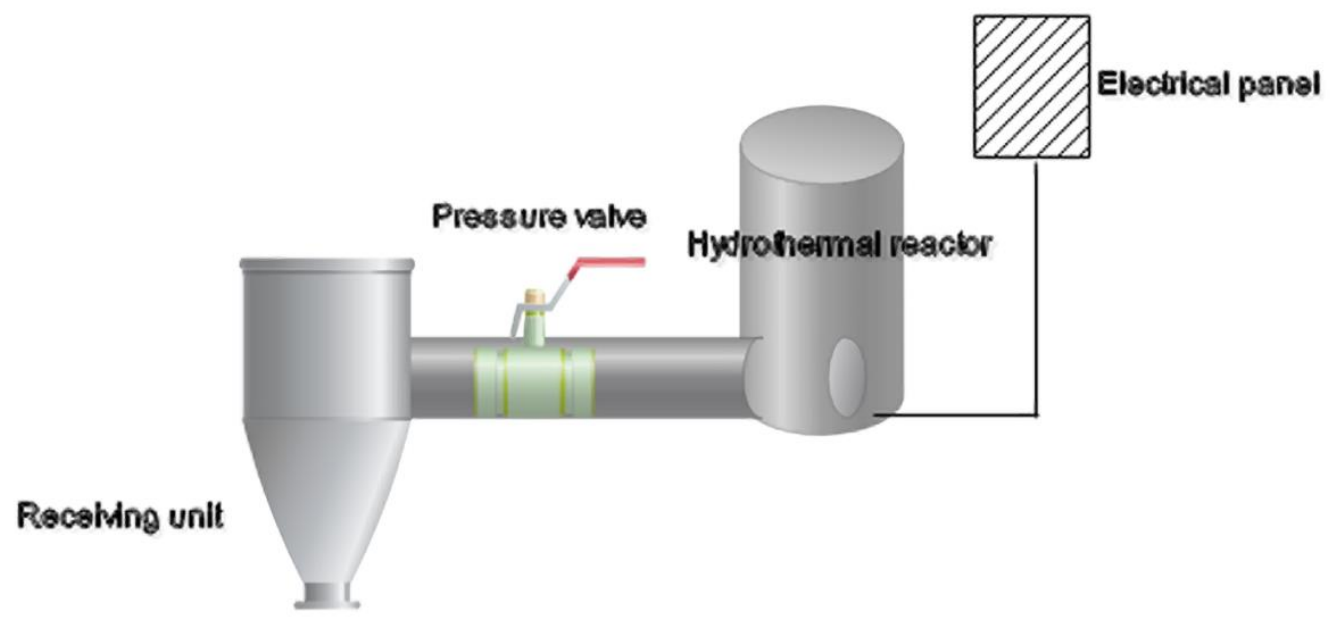

Figure 4.2 - Schematic diagram of hydrothermal reactor

\subsubsection{Pretreatment process}

Before each pretreatment, the reactor was flushed with water and preheated. Approx $12 \mathrm{~g}$ of impregnated bagasse was loaded to hydrothermal reactor according to the Tables 4.4 and 4.5 with $110 \mathrm{~mL}$ distilled water. After substrate loading, the heating system was initiated. The countdown started after the temperature was reached to required pretreatment temperature of 160, 180, 200, 146.4 and $213.6{ }^{\circ} \mathrm{C}$ (Table $4.4 \& 4.5$ ). Pressure (bar) was recorded. At the same time, the countdown started. After defined time of 5, 12, 19, 0.24, and $23.76 \mathrm{~min}$ for different pretreatments (Table $4.4 \& 4.5$ ), the heating system was switched off and pressure valve was released at once to sudden decrease the pressure inside the reactor that further dismantle the lignocellulosic structure. Pretreated biomass was recovered from the wall of the cyclone while hydrolysate was obtained from the plastic basket placed under the cyclone. Furthermore, the solid fraction was separated from the liquid (hydrolysate) via filter paper. A part of the solid fraction was transferred to pre-weighed crucibles to dry at room temperature for structural analysis. Total recovered solid fraction after each pretreatment was recorded to calculate solid recovery. Both fractions were stored at $4{ }^{\circ} \mathrm{C}$ until further analysis and batch digestion.

\subsection{Inoculum}

The inoculum was granular sludge obtained from Upflow Anaerobic Sludge Blanket (UASB) reactor treating poultry wastewater - Dacar, Tiete, São Paulo. Inoculum was transported 
from the facility to Laboratório de Processos Biológicos (LPB) USP Campus 2 in 30 L plastic bottles and subsequently stored in cold storage room, temperature maintained at $4{ }^{\circ} \mathrm{C}$. Inoculum was macerated in household juicer followed by TS and VS characterization.

\subsection{Characterization of solid biomass}

Pretreated solid recovered after filtration of pretreatment slurry was equilibrated to moisture content $(4.2-6.6 \%)$, and solid recovery $(\%)$ was determined by equation 4.1 according to de Vasconcelos et al. (de Vasconcelos et al., 2013)

Solid recovery $(\%)=($ Solid recovery $(g)$ after pretreatment on dry matter basis $) /$ (Raw bagasse $(g)$ on DM bais) $\times 100$

Total solids and volatile solids of untreated bagasse and WIS (water insoluble solid) fraction of pretreatment slurry were determined according to Standard Methods procedures 2540 B and 2540 E (APHA et al., 2005).

\subsubsection{Compositional analysis}

Chemical characterization of biomass (sugarcane bagasse) is very important in order to determine its biomethane potential. Sugarcane bagasse was milled using household juice maker and passed through $2.5 \mathrm{~mm}$ sieve for compositional analysis. Cellulose (glucan) and hemicellulose (xylan+arabinan) were determined following Sluiter protocol (Sluiter et al., 2008) available online (http://www.nrel.gov/docs/gen/fy08/42623.pdf). Briefly, 0.16 g solid was mixed with $1.5 \mathrm{~mL}$ $\mathrm{H}_{2} \mathrm{SO}_{4}\left(72 \%\right.$ w/w) in digestion tube placed in a water bath pre-adjusted to $30{ }^{\circ} \mathrm{C}$ for $1 \mathrm{~h}$. The contents were mixed at intervals of 0,20 , and $40 \mathrm{~min}$. The reaction was terminated by adding 42 $\mathrm{mL}$ distilled water to make $\mathrm{H}_{2} \mathrm{SO}_{4}$ concentration to $4 \% \mathrm{w} / \mathrm{w}$. The contents of the tube were autoclaved for $1 \mathrm{~h}$ at $120^{\circ} \mathrm{C}$. Afterwards, the contents were filtered through $0.2 \mu \mathrm{m}$ glass fiber filter (Sartorius stedim Biotech ${ }^{\circledR}$ ) in pre-ashed porcelain crucibles. The solids obtained were dried at $105^{\circ} \mathrm{C}$ and reported as \% Klason lignin (Equation 4.6) corrected to ash $\left(550{ }^{\circ} \mathrm{C}, 3 \mathrm{~h}\right)$. The filtrate obtained was stored at $-20{ }^{\circ} \mathrm{C}$ after neutralization with $\mathrm{CaCO}_{3}$ for $\mathrm{HPLC}$. Glucose and xylose were separated on Aminex HPX-87H (Bio-Rad, Hercules, USA) column (300 mm × $7.8 \mathrm{~mm}$ ). All samples were passed through Sep-Pak C18 cartridges and filtered through $0.2 \mu \mathrm{m}$ syringe filter. Ultrapure water with $0.005 \mathrm{~N} \mathrm{H}_{2} \mathrm{SO}_{4}$ was used as mobile phase with a flow rate of $0.5 \mathrm{~mL} / \mathrm{min}$, and the oven temperature was maintained at $43{ }^{\circ} \mathrm{C}$. 
Glucan, xylan, and arabinan in the untreated and pretreated solid fraction were determined according to formulas described in NREL protocol. Sugar recovery standards after dilute acid hydrolysis was calculated according to Equation 4.2

$\% R_{-}$sugar $=$(concentration detected by HPLC, $\mathrm{mg} / \mathrm{L}$ ) /

(known concentration of sugar before hydrolysis $\times 100$ )

Sugars in hydrolyzed samples were calculated using the Equation 4.3

$$
C_{-} X=\left(C_{-} H P L C \times \text { Dilution factor }\right) /\left(\% R_{-} \text {sugar } / 100\right)
$$

Where

C_HPLC $=$ Concentration of sugars determined by HPLC

$\% R_{-}$sugar $=$Recovery of specific sugar component

C_X $X=$ Concentration of sugar $\left(\mathrm{mg} \mathrm{L}^{-1}\right)$ in hydrolyzed sample after correction for loss on $4 \%$ hydrolysis

Polymeric sugars concentrations were determined using anhydro correction factor; 0.88 for xylan and arabinan while 0.90 for glucose, as indicated by Equation 4.4

$$
C_{\text {anhydro }=C_{X} \times \text { Anhydro Correction }}
$$

Where

$C_{\text {anhydro }}=$ Concentration of polymeric sugar $\mathrm{mg} \mathrm{L}^{-1}$

$C_{X}=$ Sugar concentration after $4 \%$ hydrolysis

Anhydro Correction $=$ Correction factor

Ash was determined based on Equation 4.5

$$
\% \text { Ash }=\text { Weight }_{\text {Crucible plus ash }}-\text { Weight }_{\text {Crucible }} / \text { Oven Dry Weight } \text { Sample } \times 100
$$

Klason lignin was determned according to Equation 4.6

$$
\begin{gathered}
\% \text { Klason lignin }= \\
\left(\text { Weight }_{\text {Acid insoluble residue }}-\text { Weight }_{\text {Ash }}\right) / \text { Oven dry weight of sample } \\
\times 100
\end{gathered}
$$


Recovery and removal for sugar monomers were determined by following formulas equation 4.7, and 4.8, respectively according to (Su et al., 2015). While delignification was determined by equation 4.9

Recovery $(\%)=$ Weight $(g)$ pretreated solid/Initial weight $(g)$ in raw biomass $\times 100$

Removal $(\%)=1-($ weight $(g)$ pretreated solid/initial weight $(g)$ in raw biomass $) \times$ $100 \quad(4.8)$

Delignification $(\%)=$ Initial lignin $(g)-$ residual lignin $(g) /$ Initial lignin $(g) \times 100$

\subsection{Morphological characterization}

Morphology of raw and selected pretreated solid fractions was visualized with field emission Zeiss sigma ${ }^{\mathrm{TM}}$ scanning electron microscope at Instituto de Física de São Carlos, Universidade de São Paulo, São Carlos - SP, Brazil. The samples were mounted on aluminum stubs and coated with gold prior to analysis.

\subsection{Chemical Characterization of liquid hydrolysate}

Liquid hydrolysate obtained from pretreatment slurry was characterized for sugar monomers, organic acids, total phenolic content, total carbohydrate, and chemical oxygen demand (COD)

\subsubsection{Sugar monomers determination}

Briefly, $20 \mathrm{~mL}$ liquid sample was taken in digestion tubes followed by addition of predetermined amount of $\mathrm{H}_{2} \mathrm{SO}_{4}(72 \% \mathrm{w} / \mathrm{w})$ based on $\mathrm{pH}$ value. The tubes were then submitted to the autoclave for $1 \mathrm{~h}$. Liquid aliquots obtained were neutralized with $\mathrm{CaCO}_{3}$ and stored at -20 ${ }^{\circ} \mathrm{C}$ until further analysis. Samples were extracted with Sep-Pak C-18 cartridges following $0.2 \mu \mathrm{m}$ glass filters before submitted to HPLC. HPLC analysis was conducted as described in section 4.4.1. 


\subsubsection{Total carbohydrate analysis}

Total carbohydrate analysis of the hydrolysate fraction was determined by the phenolsulfuric acid method proposed by (DuBois et al., 1956). Briefly, $1 \mathrm{~mL}$ of sample was transferred to $10 \mathrm{~mL}$ glass vials followed by $1 \mathrm{~mL}$ of $5 \%$ (w/w) phenol solution and $5 \mathrm{~mL} 96 \%$ (w/w) $\mathrm{H}_{2} \mathrm{SO}_{4}$. Glass vials were screw capped and slightly inverted twice and left for $10 \mathrm{~min}$ at room temperature. Afterward, placed in cold water for $15 \mathrm{~min}$. The total carbohydrates $\left(\mathrm{mg} \mathrm{L}^{-1}\right)$ were determined using spectrophotometer (Hach® model no. DR-14000) at $420 \mathrm{~nm}$. The analysis was performed under a fume hood.

\subsubsection{Organic acids determination}

Organic acids in liquid hydrolysate produced during hydrothermal pretreatment and during digestion process were determined using high performance liquid chromatography (HPLC) equipped with a UV diode array detector (SPD-M10Avp), a refraction index detector (RID-10A), a CTO-20A oven, a LC-10ADvp Pump, a SCL10 Avp controller and Aminex HPX-87H column, $300 \mathrm{~mm} \times 7.8 \mathrm{~mm}(\mathrm{BioRad})$. The mobile phase consisted of $\mathrm{H}_{2} \mathrm{SO}_{4}(0.01 \mathrm{~N})$ at $0.5 \mathrm{~mL} / \mathrm{min}$ flow rate (Penteado et al., 2013). Samples were passed through $0.2 \mu \mathrm{m}$ glass filter before introduction to HPLC.

\subsubsection{Total phenolic content}

Total phenolic content in the hydrolysate was determined with protocol explained by Caza et al . (Caza et al., 1999). Briefly, $2 \mathrm{~mL}$ sample was supplemented with $2 \mathrm{~mL}$ deionized water, 200 $\mu \mathrm{l}$ ferricyanide solution and $200 \mu \mathrm{l}$ 4-aminoantipyrine solution. The contents were mixed and left for 7 minutes afterward absorbance was detected at $500 \mathrm{~nm}$ against predetermined calibration curve.

\subsubsection{Chemical oxygen demand}

Chemical oxygen demand of hydrolysate fraction was determined by potassium dichromate-ferrous ammonium sulfate method according to Standards Methods (APHA et al., 2005). 


\subsection{Anaerobic digestion assays preparations}

\subsubsection{Zinder basal medium}

To avoid inhibition owing to the nutritional requirement, Zinder basal medium (Zinder $e t$ al., 1984) was employed as a medium of batch reactors instead of distilled water. The medium was prepared according to chemicals presented in Table 4.1 in ultrapure water.

Table 4.1 - Composition of Zinder medium

\begin{tabular}{lc}
\hline Chemical & $\begin{array}{c}\text { Quantities - q.s.p. } \\
\text { water }\end{array}$ \\
\hline $\mathrm{NH}_{4} \mathrm{Cl}$ & $0.5 \mathrm{~g}$ \\
\hline $\mathrm{KH}_{2} \mathrm{PO}_{4}$ & $0.4 \mathrm{~g}$ \\
\hline $\mathrm{MgCl}_{2} \cdot 6 \mathrm{H}_{2} \mathrm{O}$ & $0.1 \mathrm{~g}$ \\
\hline $\mathrm{CaCl}_{2} \cdot 2 \mathrm{H}_{2} \mathrm{O}$ & $0.05 \mathrm{~g}$ \\
\hline Trace metal solution & $10 \mathrm{~mL}$ \\
\hline Vitamin solution & $0.1 \mathrm{~mL}$ \\
\hline${ }^{a}$ quantity of solute per volume &
\end{tabular}

Trace metal solution and vitamin solution were prepared according to Table 4.2. The both solutions were vacuum filtered through $0.22 \mu \mathrm{m}$ glass filter, subsequently flushed with $\mathrm{N}_{2}$ (100\%) gas for 20 min via gas distribution system to provide anaerobic conditions and stored in a refrigerator at $4{ }^{\circ} \mathrm{C}$ under dark conditions.

\subsubsection{Batch digestion reactors}

Digestion experiments for the pretreatments (in duplicate reactors) were conducted in three sets. Batch experiments were conducted in $1000 \mathrm{~mL}$ glass bottles with a working volume of 500 $\mathrm{mL}$ and $500 \mathrm{~mL}$ of headspace. Defined amount of substrates (solid fraction of pretreatment A-HO, $\mathrm{B}-\mathrm{HO}, \ldots, \mathrm{P}-\mathrm{HO}$, and A-HSO, B-HSO, ..., P-HSO) on $\left(1 \mathrm{~g} \mathrm{~kg}^{-1}\right)$ TVS basis were introduced into glass reactor followed by zinder nutrient solution. Reactor composition for each pretreatment is presented in Table 9.1 and 9.2 (Appendix). The inoculum was introduced on $2 \mathrm{~g} \mathrm{~kg}^{-1} \mathrm{TVS}_{\text {basis. }}$ The $\mathrm{pH}$ of reactors was adjusted to around neutrality $(7.0-7.1)$ with $5 \mathrm{M} \mathrm{NaOH}$ and where necessary with $1 \mathrm{M} \mathrm{H}_{2} \mathrm{SO}_{4}$. Thereafter, reactors were flushed with pure $\mathrm{N}_{2}(100 \%)$ gas for 10 min 
via gas distribution system to ensure anaerobic conditions and immediately sealed with rubber septum followed by plastic caps. The reactors were placed in an incubator programmed at $37^{\circ} \mathrm{C}$.

Three points were selected for COD, carbohydrates, and volatile fatty acids determination; a) time zero (reactor initiation), b) approximate exponential phase, c) reactor terminations. Each time $10 \mathrm{~mL}$ sample was collected into $13 \mathrm{~mL}$ plastic vials. The vials were stored in a freezer until further analysis. All experiments were performed in duplicate except blank and positive control (glucose). The results presented are the average values of duplicate reactors.

Table 4.2 - Composition of trace metal solution and vitamin solution - Zinder medium

\section{Trace Metal Solution}

\begin{tabular}{lc} 
Chemical & $\begin{array}{c}\text { Quantities - q.s.p. 1000 } \mathbf{~ L L} \text { of ultrapure } \\
\text { water }\end{array}$ \\
\hline Tritriplex III & $4.5 \mathrm{~g}$ \\
\hline $\mathrm{FeSO}_{4} \cdot 7 \mathrm{H}_{2} \mathrm{O}$ & $0.556 \mathrm{~g}$ \\
\hline $\mathrm{MnSO}_{4} \cdot \mathrm{H}_{2} \mathrm{O}$ & $0.086 \mathrm{~g}$ \\
\hline $\mathrm{CoCl}_{2} \cdot 6 \mathrm{H}_{2} \mathrm{O}$ & $0.17 \mathrm{~g}$ \\
\hline $\mathrm{ZnSO}_{4} \cdot 7 \mathrm{H}_{2} \mathrm{O}$ & $0.21 \mathrm{~g}$ \\
\hline $\mathrm{H}_{3} \mathrm{BO}_{3}$ & $0.19 \mathrm{~g}$ \\
\hline $\mathrm{NiCl}_{2}$ & $0.02 \mathrm{~g}$ \\
\hline $\mathrm{Na}_{2} \mathrm{MoO}_{4}$ & $0.01 \mathrm{~g}$ \\
\hline Vitamin Solution & \\
\hline Biotin & $0.002 \mathrm{~g}$ \\
\hline Folic Acid & $0.002 \mathrm{~g}$ \\
\hline Thiamin & $0.005 \mathrm{~g}$ \\
\hline Riboflavin & $0.005 \mathrm{~g}$ \\
\hline Nicotinic acid & $0.005 \mathrm{~g}$ \\
\hline Calcium pentothenate & $0.005 \mathrm{~g}$ \\
\hline Pyridoxin.HCl & $0.010 \mathrm{~g}$ \\
\hline
\end{tabular}




\subsection{Determination of methane}

The reactors were manually shaken for approx. $1 \mathrm{~min}$ to avoid thermal stratification, before taking a gas sample. The pressure in the reactors was recorded by inserting syringe into the septum, linked with a pressure transducer (T\&S equipamentos electronicos). Each time $0.5 \mathrm{~mL}$ gas sample was taken for GC analysis. Methane content was determined via Shimadzu® gas chromatography (GC-2010) equipped with thermal conductivity detector (TCD). The column was Carboxen 1010 PLOT, $30 \mathrm{~m}$ x $0.53 \mathrm{~mm}$. Injector temperature, oven temperature, and detector temperature were $220^{\circ} \mathrm{C}, 130{ }^{\circ} \mathrm{C}$, and $230{ }^{\circ} \mathrm{C}$, respectively. Argon gas was used as carrier gas with a flow rate of $5.66 \mathrm{~mL} / \mathrm{min}$ with makeup volume of $12 \mathrm{~mL} / \mathrm{min}$ according to Motteran e al. (Motteran et al., 2014). $\mathrm{CH}_{4}$ concentration is reported in this text in normal mmol - $\mathrm{Nmmol} \mathrm{g}^{-1} \mathrm{TVS}$, i.e., at standard temperature and pressure conditions $(273 \mathrm{~K}, 101.325 \mathrm{KPa})$. The cumulative methane content (Nmmol g- $\mathrm{TVS}^{-1}$ ) as a function of time was determined according to Equation 4.5

$$
X_{S T P}=X_{m} \cdot \frac{T_{\text {Standard }} \cdot P_{m}}{T_{m} \cdot P_{\text {Standard }}}
$$

Where

$X_{S T P}=$ Methane content at standard temperature and pressure

$X_{m}=$ Methane content at room temperature and pressure

$T_{\text {Standard }}=$ Standard temperature $-273 \mathrm{~K}$

$P_{m}=$ Pressure of the reactor determined

$T_{m}=$ Actual temperature $-37^{\circ} \mathrm{C}$

$P_{\text {Standard }}=$ Standard pressure $-101.325 \mathrm{KPa}$

Assuming $\mathrm{CH}_{4}$ production is proportional to microbial activity. The experimental data (average values of duplicate reactors) obtained was adjusted using modified Gompertz equation 4.6 (Zwietering et al., 1990) with Origin software package version

$$
H=P \cdot \exp \left\{-\exp \left[\frac{R_{m} \cdot e}{P}(\lambda-t)+1\right]\right\}
$$

Where

$P=\mathrm{CH}_{4}$ production potential $\left(\mathrm{Nmmol} \mathrm{g}^{-1} \mathrm{TVS}\right)$ 
$R_{m}=\mathrm{CH}_{4}$ production rate $\left(\mathrm{Nmmol} \mathrm{g}{ }^{-1} \mathrm{TVS} / \mathrm{h}\right)$

$t=$ incubation time of reactors $(\mathrm{h})$

$\mathrm{e}=$ Euler number $(2.71828)$

$\lambda=$ lag phase before $\mathrm{CH} 4$ production starts $(\mathrm{h})$

\subsection{Experimental design}

A $3^{3}$ full factorial design was selected to optimize the hydrothermal pretreatment in order to test the pretreatment time, temperature and concentration of sulphuric acid $\left(\mathrm{H}_{2} \mathrm{SO}_{4}\right)$ and Hydrogen peroxide $\left(\mathrm{H}_{2} \mathrm{O}_{2}\right)$. Coded values and real values for central composite design are presented in Table 4.3. The matrix of factors and levels of pretreatments applied to sugarcane bagasse for $\mathrm{H}_{2} \mathrm{O}_{2}$ and $\mathrm{H}_{2} \mathrm{SO}_{4}$ are presented in Table 4.4 and Table 4.5, respectively.

Table 4.3 - Coded and uncoded values for central composite design for $\mathrm{H} 2 \mathrm{SO} 4$ and $\mathrm{H} 2 \mathrm{O} 2$ assisted hydrothermal pretreatment

\begin{tabular}{|c|c|c|c|}
\hline Coded values & $\begin{array}{c}X 1 \\
\left(\text { temperature, }{ }^{\circ} \mathbf{C}\right)\end{array}$ & $\begin{array}{c}X 2 \\
\text { (time, } \min \text { ) }\end{array}$ & $\begin{array}{c}X 3 \\
\left(\mathrm{H}_{2} \mathrm{SO}_{4} \% \mathrm{w} / v\right)\end{array}$ \\
\hline+1.68 & 213.6 & 23.76 & 3.68 \\
\hline 1 & 200 & 19 & 3 \\
\hline 0 & 180 & 12 & 2 \\
\hline-1 & 160 & 5 & 1 \\
\hline-1.68 & 146.4 & 0.24 & 0.32 \\
\hline Coded values & $\begin{array}{c}X 1 \\
\left(\text { temperature, }{ }^{\circ} \mathrm{C}\right)\end{array}$ & $\begin{array}{c}X 2 \\
\text { (time, } \min \text { ) }\end{array}$ & $\begin{array}{c}X 3 \\
\left(\mathrm{H}_{2} \mathrm{O}_{2}, \% \mathrm{v} / \mathrm{v}\right)\end{array}$ \\
\hline+1.68 & 213.6 & 23.76 & 7.36 \\
\hline 1 & 200 & 19 & 6 \\
\hline 0 & 180 & 12 & 4 \\
\hline-1 & 160 & 5 & 2 \\
\hline-1.68 & 146.4 & 0.24 & 0.64 \\
\hline
\end{tabular}


Table 4.4 - Central composite design matrix for $\mathrm{H}_{2} \mathrm{O}_{2}$ assisted hydrothermal pretreatment

\begin{tabular}{cccc|ccc}
\hline \multicolumn{5}{c}{ Coded values } & \multicolumn{3}{c}{ Real values } \\
\hline Pretreatment & Temperature & Time & $\mathbf{H}_{2} \mathbf{S O}_{4}$ & Temperature & Time & $\mathbf{H}_{2} \mathbf{O}_{2}$ \\
run & $\mathbf{X} 1$ & $\mathbf{X 2}$ & $\mathbf{X 3}$ & $\boldsymbol{X}_{\mathbf{1}}$ & $\boldsymbol{X}_{2}$ & $\boldsymbol{X}_{\mathbf{3}}$ \\
\hline A-HO & 1 & 1 & 1 & 200 & 19 & 6 \\
\hline B-HO & 1 & 1 & -1 & 200 & 19 & 2 \\
\hline C-HO & 1 & -1 & 1 & 200 & 5 & 6 \\
\hline D-HO & 1 & -1 & -1 & 200 & 5 & 2 \\
\hline E-HO & -1 & 1 & 1 & 160 & 19 & 6 \\
\hline F-HO & -1 & 1 & -1 & 160 & 19 & 2 \\
\hline G-HO & -1 & -1 & 1 & 160 & 5 & 6 \\
\hline H-HO & -1 & -1 & -1 & 160 & 5 & 2 \\
\hline I-HO & 0 & 0 & 0 & 180 & 12 & 4 \\
\hline J-HO & 0 & 0 & 0 & 180 & 12 & 4 \\
\hline K-HO & 0 & 0 & 1.68 & 180 & 12 & 7.36 \\
\hline L-HO & 0 & 0 & -1.68 & 180 & 12 & 0.64 \\
\hline M-HO & 0 & 1.68 & 0 & 180 & 23.76 & 4 \\
\hline N-HO & 0 & -1.68 & 0 & 180 & 0.24 & 4 \\
\hline O-HO & 1.68 & 0 & 0 & 213.6 & 12 & 4 \\
\hline P-HO & -1.68 & 0 & 0 & 146.4 & 12 & 4 \\
\hline
\end{tabular}

Table 4.5 - Central composite design matrix for $\mathrm{H}_{2} \mathrm{SO}_{4}$ assisted hydrothermal pretreatment

\begin{tabular}{cccc|ccc}
\hline & \multicolumn{3}{c|}{ Coded values } & \multicolumn{3}{c}{ Real values } \\
\hline Pretreatment & Temperature & Time & $\mathbf{H}_{\mathbf{2}} \mathbf{S O}_{\mathbf{4}}$ & Temperature & Time & $\mathbf{H}_{\mathbf{2}} \mathbf{S O}_{\mathbf{4}}$ \\
run & $\mathbf{X 1}$ & $\mathbf{X 2}$ & $\mathbf{X 3}$ & $\boldsymbol{X}_{\boldsymbol{I}}$ & $\boldsymbol{X}_{\mathbf{2}}$ & $\boldsymbol{X}_{\mathbf{3}}$ \\
\hline A-HSO & 1 & 1 & 1 & 200 & 19 & 3 \\
\hline B-HSO & 1 & 1 & -1 & 200 & 19 & 1 \\
\hline C-HSO & 1 & -1 & 1 & 200 & 5 & 3 \\
\hline D-HSO & 1 & -1 & -1 & 200 & 5 & 1 \\
\hline E-HSO & -1 & 1 & 1 & 160 & 19 & 3 \\
\hline F-HSO & -1 & 1 & -1 & 160 & 19 & 1 \\
\hline G-HSO & -1 & -1 & 1 & 160 & 5 & 3 \\
\hline H-HSO & -1 & -1 & -1 & 160 & 5 & 1 \\
\hline I-HSO & 0 & 0 & 0 & 180 & 12 & 2 \\
\hline J-HSO & 0 & 0 & 0 & 180 & 12 & 2 \\
\hline K-HSO & 0 & 0 & 1.68 & 180 & 12 & 3.68 \\
\hline L-HSO & 0 & 0 & -1.68 & 180 & 12 & 0.32 \\
\hline M-HSO & 0 & 1.68 & 0 & 180 & 23.76 & 2 \\
\hline N-HSO & 0 & -1.68 & 0 & 180 & 0.24 & 2 \\
\hline O-HSO & 1.68 & 0 & 0 & 213.6 & 12 & 2 \\
\hline P-HSO & -1.68 & 0 & 0 & 146.4 & 12 & 2 \\
\hline
\end{tabular}




\subsection{Microbial community characterization by molecular techniques}

Samples for microbial community characterization were taken at the end of batch digestion reactors. Samples were analyzed by denaturing gradient gel electrophoresis for the relative similarity of bacterial and archaeal domains. PCR/DGGE analysis was conducted for all the batch reactors of both pretreatments except pretreatment $15\left(213.6^{\circ} \mathrm{C}\right)$ and $16\left(146.4{ }^{\circ} \mathrm{C}\right)$ in both cases $\left(\mathrm{H}_{2} \mathrm{O}_{2}\right.$ and $\left.\mathrm{H}_{2} \mathrm{SO}_{4}\right)$ due to extreme temperature conditions applied.

Selected samples were characterized by bacterial and chemical community structure using next-gen Illumina MiSeq Sequencing. Seven samples were sent for next gen Illumina MiSeq Sequencing; 3 from $\mathrm{H}_{2} \mathrm{O}_{2}$ impregnated and 3 from $\mathrm{H}_{2} \mathrm{SO}_{4}$ impregnated pretreatments. Samples selected from $\mathrm{H}_{2} \mathrm{O}_{2}$ pretreatments were B-HO, K-HO and P-HO. While D-HSO, I-HSO and N$\mathrm{HSO}$ were chosen from $\mathrm{H}_{2} \mathrm{SO}_{4}$ assisted pretreatments. Sample from positive control (glucose) was also characterized to determine the difference in archaeal and bacterial diversity in digestion reactors of pretreated lignocellulose substrate and pure glucose.

\subsubsection{Sample collection and DNA extraction}

Samples were collected by centrifugation at $4{ }^{\circ} \mathrm{C}$ at $6000 \mathrm{rpm}$ for $10 \mathrm{~min}$ followed by cleaning with phosphate buffer, thereafter were stored at $-20{ }^{\circ} \mathrm{C}$. Genomic DNA was collected by cell lysis with glass beads (Sigma) followed by a phenol-chloroform method utilizing modified Griffith's protocol (Griffiths et al., 2000).

\subsubsection{PCR/DGGE}

Polymerase chain reaction (PCR) was conducted with bacterial primer set 968FGC (5'CGCCCGGGGCGCGCCCCGGGCGGGGCGGGGGCACGGGGGGAACGCGAAGAACCTT AC-3') /1401R (5'-CGGTGTGTACAAGACCC-3') (Nubel et al., 1996) and archaeal primer set 1100FGC (5'-AACCGTCGACTCAGGYAACGAGCGAG-3') and 1400R (5' CGGCGAATTCGTGCAAGGAGCAGGGGA3') (Kudo et al., 1997). The PCR products were checked for purity by $1.2 \%$ agarose gel electrophoresis. In the current study, DGGE was conducted under denaturants $45 \%$ and 65\% (100\% denaturant - 7M Urea and 40\% (v/v) deionized formamide) for bacterial and archaeal domains. Running conditions of the apparatus DCode ${ }^{\mathrm{TM}}$ Universal Mutation Detection System (Bio-Rad Laboratories, Hercules, CA, USA) were; 75V, 16 
$\mathrm{h}$ at a constant temperature of $60{ }^{\circ} \mathrm{C}$ (Muyzer et al., 1993). Ethidium bromide was utilized as a fluorescent solution. Gels were visualized with Foto documentation L. PixTouch (Loccus Biotechnology) under $254 \mathrm{~nm}$ UV exposure.

Multivariate analysis of DGGE band profiles was conducted using BioNumerics 3.5 software package (Applied Maths, Belgium) with Pearson correlation. Dendrograms were constructed with UPMA method. The Shannon-Wiener diversity index (H), and Dominance (D) were calculated with Past 3.0 software package.

\subsubsection{Illumina MiSeq Sequencing}

The V4 variable region of 16S rRNA gene was PCR amplified with a barcoded 515F/806R primer set (Table 4.6); universal for bacteria and archaea (Table 4.6) (Walters et al., 2011). HotStarTaq Plus Master Mix Kit (Qiagen, USA) was used for amplification by PCR. Amplicons were checked for the success of amplification and relative intensity of bands with $2 \%$ agarose gel electrophoresis. Multiple samples were pooled based on their molecular weight and DNA concentration and were purified using calibrated Ampure XP beads. Purified amplicons were used to prepare Illumina DNA library. Sequencing was performed at MR DNA (Shallowater, TX USA) on a MiSeq following manufacturer's protocol.

Table 4.6 - Bacterial and Archaeal primers and sequences for Illumina MiSeq Sequencing

\begin{tabular}{lll}
\hline Primers & Sequences $\mathbf{5}^{\prime}-3^{\prime}$ & References \\
\hline $\mathbf{5 1 5 F}$ & 5'-GTGCCAGCMGCCGCGGTAA-3' $^{\text {(Wolters } \text { et al., 2011) }}$ \\
\hline $\mathbf{8 0 6 R}$ & 5'-GGACTACHVHHHTWTCTAAT-3' $^{\prime}$ & \\
\hline
\end{tabular}

MR DNA pipeline was used to process sequence data using three steps;

a) Joining of paired-end reads.

b) Removal of barcodes and sequences $<150 \mathrm{bp}$ were depleted in addition to sequences with ambiguous base calls.

c) Operational taxonomic units (OUTs) were assigned to a most relevant taxonomic level based on BLASTn similarity percentage $(97 \%)$.

Final OTUs were taxonomically classified using BLASTn against a curated database derived from RDPII and NCBI (http://rdp.cme.msu.edu, www.ncbi.nlm.nih.gov). 


\section{RESULTS AND DISCUSSION}

\subsection{Compositional analysis of untreated sugarcane bagasse}

The composition of lignocellulosic biomass is important to determine the potential for methane production. Polymeric and non-polymeric compounds encountered in raw sugarcane bagasse are presented in Table 5.1

Table 5.1 - Compositional analysis of sugarcane bagasse

\begin{tabular}{cc}
\hline Composition & \%DM basis* \\
\hline Glucan & 31.4 \\
\hline Xylan & 36.6 \\
\hline Arabinan & 5.0 \\
\hline Lignin & 24.8 \\
\hline Ash & 1.2
\end{tabular}

* On percent Dry Matter (DM) basis

As indicated in Table 5.1, sugarcane bagasse was characterized for sugar monomers; glucan (cellulose), xylan and arabinan (hemicellulose), Klason lignin, and ash content according to equations mentioned in section 4.4.1. Glucan, xylan, arabinan, and lignin content of sugarcane

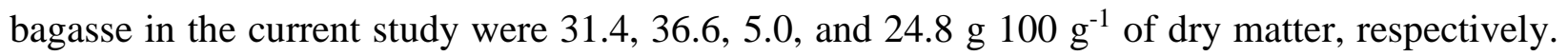
Other researchers documented approx. similar results for sugarcane bagasse; Da Silva et al. (da Silva et al., 2010) reported 38.8, 26 and $32.4 \%$ cellulose, hemicellulose and lignin content on percent dry matter basis. While De Moraes et al. (De Moraes et al., 2011) reported slightly different composition of sugarcane bagasse; $45.5 \%$ cellulose, $27 \%$ hemicellulose, and $21.1 \%$ lignin on dry matter basis. In another study, Bharathiraja et al (Bharathiraja et al., 2014) reported 56.7\% hemicellulose content, $30.2 \%$ cellulose and $13.4 \%$ lignin in sugarcane bagasse.

Ash content $(1.2 \%)$ was also in accordance with other reported studies for sugarcane bagasse; $1 \%$ (Canilha et al., 2011), 1.5\% (Rabelo et al., 2011) and 1.6\% (Brienzo et al., 2009). Lower ash content is desirable for biofuels production and directly affects the heating value of the plant biomass (Demirbas, 2009). The compositional analysis of sugarcane bagasse in the current study is in confirmation with already reported studies. Differences in composition among reported studies and current results are due to cultivar type, soil characteristics, and process differences of processing plants where sugarcane is being processed. 


\subsection{Impact of $\mathrm{H}_{2} \mathrm{O}_{2}$ assisted hydrothermal pretreatment on chemical composition of sugarcane}

bagasse

Impact of $\mathrm{H}_{2} \mathrm{O}_{2}(0.64-7.36 \% \mathrm{v} / \mathrm{v})$ impregnation for $24 \mathrm{~h}$ was observed in 16 pretreatment runs of HT pretreatment according to CCD matrix (Table 4.4). Solid yield, glucan, xylan, klason lignin $(\%)$, and lignin solubilization (\%) in raw sugarcane bagasse and pretreated solid residues are presented in Table 5.2

Table 5.2 - Chemical characterization of solid fraction of $\mathrm{H}_{2} \mathrm{O}_{2}$ pretreated sugarcane bagasse; Solid yield (\%), Glucan (g $100 \mathrm{~g}^{-1} \mathrm{TS}$ ), Xylan (g $100 \mathrm{~g}^{-1} \mathrm{TS}$ ), Klason lignin (\%), Glucan increase \%), Xylan removal (\%), and lignin solubilization (\%)

\begin{tabular}{|c|c|c|c|c|c|c|c|c|}
\hline Run & Designation & $\begin{array}{l}\text { Solid } \\
\text { yield } \\
(\%)\end{array}$ & $\begin{array}{l}\text { Glucan } \\
\text { (g 100 } \\
\mathrm{g}^{-1} \text { TS) }\end{array}$ & $\begin{array}{c}\text { Xylan } \\
(\text { g 100 } \\
\text { g }^{-1} \\
\text { TS) }\end{array}$ & $\begin{array}{c}\text { Klason } \\
\text { lignin } \\
(\mathrm{g} 100 \\
\left.\mathrm{g}^{-1} \mathrm{TS}\right)\end{array}$ & $\begin{array}{c}\text { Glucan } \\
\text { increase } \\
(\%)\end{array}$ & $\begin{array}{l}\text { Xylan } \\
\text { removal } \\
(\%)\end{array}$ & $\begin{array}{c}\text { Lignin } \\
\text { solubilization } \\
(\%)\end{array}$ \\
\hline 1 & A-HO & 54.41 & 68.20 & 10.12 & 9.60 & 117.19 & 72.36 & 61.39 \\
\hline 2 & B-HO & 62.55 & 55.52 & 16.74 & 23.2 & 76.81 & 54.28 & 6.86 \\
\hline 3 & C-HO & 59.36 & 63.21 & 15.60 & 7.4 & 101.31 & 57.39 & 70.33 \\
\hline 4 & D-HO & 71.58 & 49.15 & 28.63 & 16.2 & 56.53 & 21.81 & 34.97 \\
\hline 5 & E-HO & 58.26 & 47.50 & 12.74 & 9.3 & 51.27 & 65.21 & 62.51 \\
\hline 6 & F-HO & 74.21 & 42.61 & 29.64 & 15.0 & 35.70 & 19.05 & 39.72 \\
\hline 7 & G-HO & 66.98 & 45.75 & 18.39 & 10.2 & 45.70 & 49.78 & 58.82 \\
\hline 8 & $\mathrm{H}-\mathrm{HO}$ & 89.20 & 39.65 & 32.18 & 14.9 & 26.27 & 12.11 & 40.08 \\
\hline 9 & I-HO & 71.08 & 50.02 & 25.60 & 11.9 & 59.29 & 30.08 & 52.00 \\
\hline 10 & $\mathrm{~J}-\mathrm{HO}$ & 73.11 & 49.15 & 26.60 & 12.8 & 56.52 & 27.35 & 48.55 \\
\hline 11 & K-HO & 64.99 & 60.42 & 8.85 & 6.7 & 92.42 & 75.83 & 73.09 \\
\hline 12 & L-HO & 93.13 & 39.17 & 31.41 & 22.4 & 24.74 & 14.22 & 9.93 \\
\hline 13 & M-HO & 49.75 & 56.19 & 24.33 & 12.9 & 78.94 & 33.55 & 48.02 \\
\hline 14 & N-HO & 73.30 & 46.14 & 29.14 & 10.6 & 46.94 & 20.42 & 57.47 \\
\hline 15 & O-HO & 36.57 & 75.21 & 18.74 & 19.0 & 139.52 & 48.82 & 23.52 \\
\hline 16 & $\mathrm{P}-\mathrm{HO}$ & 76.49 & 33.12 & 27.15 & 12.0 & 5.47 & 25.85 & 51.62 \\
\hline
\end{tabular}

As indicated in Table 5.2, the lowest solid yield (36.57 \%) was observed at pretreatment OHO $\left(213.60{ }^{\circ} \mathrm{C}, 12\right.$ min, $\left.4 \% \mathrm{H}_{2} \mathrm{O}_{2}\right)$, while the highest solid yield of $93.13 \%$ was observed at pretreatment $\mathrm{L}-\mathrm{HO}\left(180{ }^{\circ} \mathrm{C}, 12 \mathrm{~min}, 0.32 \% \mathrm{H}_{2} \mathrm{O}_{2}\right)$. Solid yield increased $(9.09 \%)$ from $54.41 \%$ to 
$59.6 \%$ when pretreatment time was decreased from $19 \mathrm{~min}$ (PRT A-HO) to $5 \mathrm{~min}$ (PRT C-HO) at a temperature of $200{ }^{\circ} \mathrm{C}$ and $\mathrm{H}_{2} \mathrm{O}_{2}$ concentration of $6(\% \mathrm{v} / \mathrm{v})$. However, $14.43 \%$ increase was observed in solid yield from $62.55 \%$ (PRT B-HO) to $71.58 \%$ (PRT D-HO) when the reaction time was $5 \mathrm{~min}$ at conditions of $200{ }^{\circ} \mathrm{C}$ and $2 \% \mathrm{H}_{2} \mathrm{O}_{2}$. A reduction in pretreatment temperature to 160 ${ }^{\circ} \mathrm{C}$ favored an increase in solid yield of $7.07 \%$ and $18.64 \%, 14.43 \%$, and $24.61 \%$ in pretreatment E-HO, F-HO, G-HO, and H-HO in comparison to pretreatment A-HO, B-HO, C-HO, and D-HO, respectively at similar pretreatment conditions. At pretreatment temperature of $180{ }^{\circ} \mathrm{C}$, an increase in $\mathrm{H}_{2} \mathrm{O}_{2}$ concentration from $4 \%$ (PRT I-HO) to 7.36\% (PRT K-HO) at pretreatment time of 12 min resulted in a $9.3 \%$ decrease in solid yield. While, at the similar condition $\left(180{ }^{\circ} \mathrm{C}, 12 \mathrm{~min}\right)$, a decrease in $\mathrm{H}_{2} \mathrm{O}_{2}$ concentration from $7.3 \%$ to $0.64 \%$ resulted in $43.29 \%$ increase in solid yield. On the other hand, a decrease in pretreatment time from $23.7 \mathrm{~min}$ to $0.24 \mathrm{~min}$ did not show a significant difference in solid yield at similar $\mathrm{H}_{2} \mathrm{O}_{2}$ concentration and pretreatment temperature.

Hydrothermal pretreatment has a significant impact on solid yield predominantly due to hemicellulose solubilization and partial lignin dissociation. Since hemicellulose solubilization is in direct relation to temperature, therefore, solid yield has a direct relation, in decreasing order, with an increase in temperature (Yang et al., 2004). The solid yield of Eucalyptus camaldulensis declined to $54.2 \%$ from $72.7 \%$ when ammonium chloride catalyzed hydrothermal pretreatment for temperature increased from 140 to $180^{\circ} \mathrm{C}$ (Shen et al., 2016). Similarly, Deng et al (Deng et al., 2015 ) reported a decrease in the solid residue of corncob from $96.5 \%$ to $60.67 \%$ when pretreatment temperature was increased from $170{ }^{\circ} \mathrm{C},(0 \mathrm{~min})$ to $190{ }^{\circ} \mathrm{C}(60 \mathrm{~min})$. In similar fashion, Sun and his team (Sun et al., 2014) reported successive decrease in solid residues of corncob $69.4 \%$ to $48.7 \%$ when temperature increased from $170{ }^{\circ} \mathrm{C}$ to $190{ }^{\circ} \mathrm{C}$, further it reached to the lowest value of $47.0 \%$ at $200{ }^{\circ} \mathrm{C}$. In the current study, solid yield increased with a decrease in $\mathrm{H}_{2} \mathrm{O}_{2}$ concentration applied as evidenced in pretreatment L-HO where a maximum solid yield of $93.13 \%$ was observed with lowest $\mathrm{H}_{2} \mathrm{O}_{2}(0.64 \%$ v/v) was studied. An increase in solid yield with a decrease in reaction temperature under similar reaction time is in line with the already reported studies

Glucan and xylan content in the pretreated solid fraction indicated proportional increase and decrease, respectively, in response to pretreatment conditions applied. Glucan content in literature is reported to increase in the pretreated solid fractions due to the removal of hemicellulose content and partial lignin solubilization to liquid stream. Glucan content was 


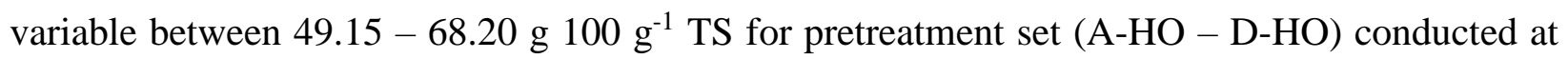
$200{ }^{\circ} \mathrm{C}$. Higher glucan content was noted for higher $\mathrm{H}_{2} \mathrm{O}_{2}$ loading. A decrease in glucan content

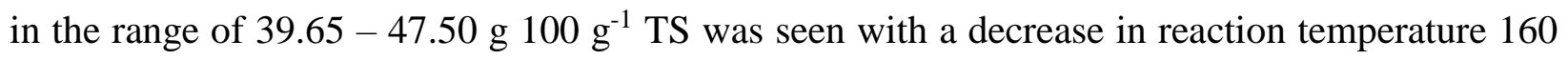
${ }^{\circ} \mathrm{C}$ (pretreatment set $\mathrm{E}-\mathrm{HO}-\mathrm{H}-\mathrm{HO}$ ) in comparison to pretreatment temperature $200{ }^{\circ} \mathrm{C}$. Although similar $\mathrm{H}_{2} \mathrm{O}_{2}$ loading was applied to this pretreatment set (E-HO - H-HO), however, glucan increase was not as consistent as was seen at $200{ }^{\circ} \mathrm{C}$, indicating that reaction temperature played a significant role.

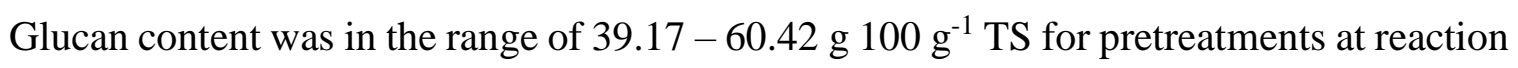
temperature $180{ }^{\circ} \mathrm{C}$. Lowest glucan content (33.12) was seen at lowest reaction temperature studied (pretreatment run P-HO, $146.4^{\circ} \mathrm{C}$ ). Percent glucan increase in solid fraction was in the range of $5.47-139.52 \%$ in the pretreatments conducted in this phase of the study. The percent glucan increase was quite higher in the current study than in comparison to Zhao et al. (Zhao et $a l ., 2016)$. The authors reported up to $97.6 \%$ glucan in $\mathrm{H}_{2} \mathrm{O}_{2}$-ammonia fiber explosion for corn stalk, with lignin removal in the range of $2.4-28.8 \%$. However, authors reported results for an $\mathrm{H}_{2} \mathrm{O}_{2}$ loading of $0.1-0.7 \mathrm{~g} \mathrm{~g}^{-1}$ dry biomass and lower reaction temperature range $90-130{ }^{\circ} \mathrm{C}$.

Shao and co-workers reported (Shao et al., 2013) $1.5 \%$ glucan increase after hydrogen peroxide $(0.7 \%)$ ammonia fiber explosion at reaction temperature of $150{ }^{\circ} \mathrm{C}$. Shen et al (Shen et $a l ., 2011)$ reported an increase in reducing sugars up to $347.2 \%$ after enzymatic hydrolysis of tobacco stem that could indirectly relate to higher glucan recovery after pretreatment with $\mathrm{H}_{2} \mathrm{O}_{2}$ $(0.6 \%)$ for $9 \mathrm{~h}$ at $60{ }^{\circ} \mathrm{C}$. Higher percent glucan increase in current study could relate to (Yu et al., 2013). The authors reported that hydrogen peroxide combined with sodium carbonate and sodium hydroxide (green liquor) resulted in the selective removal of lignin leaving behind approx. complete glucan for higher enzymatic hydrolysis.

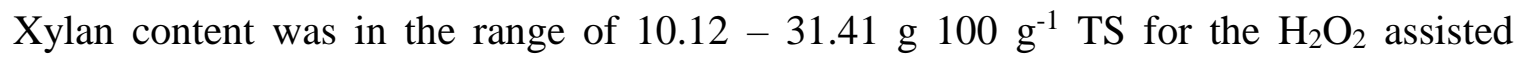
hydrothermal pretreatments corresponding to xylan recovery in pretreated solid fractions in the range of $24.17-85.78 \%$. Zhao et al. (Zhao et al., 2016) reported maximum of $97.4 \%$ xylan recovery in their study for corn stalk employing $\mathrm{H}_{2} \mathrm{O}_{2}$ in the range of $0.1-0.7 \%$ at reaction temperature in the range of $90-130 \mathrm{C}$. Xylan removal in the current study were in the range of $12.11-75.83 \%$, respectively. Arabinan recovered in the solid fraction was in the range of $0.46-$ 
$3.97 \%$. The results of the current study could not be compared to the literature owing to different pretreatments, pretreatment conditions and variability in the feedstock.

Second-order polynomial equation was derived from the experimental data of glucan and xylan contents to determine the impact of pretreatment parameters; reaction temperature, reaction time, and $\mathrm{H}_{2} \mathrm{O}_{2}$ concentration on their availability in the solid fraction in response to $\mathrm{H}_{2} \mathrm{O}_{2}$ assisted hydrothermal pretreatment. Equation 5.1 and 5.2 represent the second order polynomial equations, respectively, for glucan and xylan.

$$
\begin{array}{rr}
\text { Glucan }\left(\mathrm{g} 100 \mathrm{~g}^{-1} \mathrm{TS}\right)=49.62-9.62 X_{1}+2.41 X_{2}+5.38 X_{3}+1.53 X_{1}{ }^{2}+0.47 X_{2}{ }^{2}- \\
0.02 X_{3}{ }^{2}+0.83 X_{1} X_{2}+1.97 X_{1} X_{3}-0.32 X_{2} X_{3} & \text { Equation } 5.1
\end{array}
$$

It was observed that all the studied parameters; temperature $\left(X_{1}\right)$, time $\left(X_{2}\right)$ and $\mathrm{H}_{2} \mathrm{O}_{2}$ concentration $\left(X_{3}\right)$ showed significant impact on the glucan (g $100 \mathrm{~g}^{-1}$ TS) content. The model described that all the linear model terms $X_{1}, X_{2}$, and $X_{3}$ showed the significant positive impact on the glucan content with magnitude values of 9.62, 2.41, and 5.38, respectively. It indicated that temperature $\left(X_{1}\right)$ had a higher positive impact followed by $\mathrm{H}_{2} \mathrm{O}_{2}$ concentration $\left(X_{3}\right)$, and reaction time $\left(X_{2}\right)$ implying that reaction temperature is an important parameter for glucan recovery under the studied conditions.

The interaction of studied parameters revealed that not a single interaction among three parameters was significant. One-way analysis of variance (Table 5.3) indicated that interaction of parameters was insignificant i.e., $p$-value for the interaction of all the parameters; $X_{1} X_{2}, X_{1} X_{3}$, and $X_{2} X_{3}$ was more than 0.05 .

Equation 5.2 indicates the second-order polynomial equation for xylan (g $\left.100 \mathrm{~g}^{-1} \mathrm{TS}\right)$ content. The model equation showed that all the three linear terms of temperature $\left(X_{1}\right)$, time $\left(X_{2}\right)$, and $\mathrm{H}_{2} \mathrm{O}_{2}$ concentration $\left(X_{3}\right)$ were significant with magnitude values of $2.63,2.46$, and 6.46, respectively. However, it can be observed that all the linear terms are negative significant. Furthermore, temperature and time had approx. similar negative impact while $\mathrm{H}_{2} \mathrm{O}_{2}$ concentration had higher negative impact implying that $\mathrm{H}_{2} \mathrm{O}_{2}$ concentration was more important in xylan content as indicated in one-way analysis of variance (Table 5.4)

$$
\begin{array}{rr}
\text { Xylan }\left(\mathrm{g} 100 \mathrm{~g}^{-1} \mathrm{TS}\right)=26.35-2.63 X_{1}-2.46 X_{2}-6.46 X_{3}-1.72 X_{1}{ }^{2}-0.38 X_{2}{ }^{2}- \\
2.71 X_{3}{ }^{2}-1.15 X_{1} X_{2}+1.38 X_{1} X_{3}+0.41 X_{2} X_{3} & \text { Equation } 5.2
\end{array}
$$


Table 5.3 - Analysis of variance (ANOVA) for glucan content (g 100 g-1 TS) in pretreated solids impregnated in $\mathrm{H} 2 \mathrm{O} 2$.

\begin{tabular}{|c|c|c|c|c|c|}
\hline Source & Sum of square & Degree of freedom & Mean Square & F-value & P-value $($ prob $>$ F $)$ \\
\hline$X_{1}(\mathrm{~T})^{\alpha}$ & 1263.437 & 1 & 1263.437 & 3338.451 & $0.011017 *$ \\
\hline$X_{1}^{2}$ & 21.651 & 1 & 21.651 & 57.209 & 0.083683 \\
\hline$X_{2}(\mathrm{t})^{\beta}$ & 79.616 & 1 & 79.616 & 210.375 & $0.043822 *$ \\
\hline$X_{2}^{2}$ & 2.032 & 1 & 2.032 & 5.369 & 0.259371 \\
\hline $\begin{array}{c}X_{3} \\
\left(\mathrm{H}_{2} \mathrm{O}_{2} \text { Conc. }\right)^{¥}\end{array}$ & 395.227 & 1 & 395.227 & 1044.332 & $0.019693^{*}$ \\
\hline$X_{3}^{2}$ & 0.002 & 1 & 0.002 & 0.006 & 0.948823 \\
\hline$X_{1} X_{2}$ & 5.528 & 1 & 5.528 & 14.606 & 0.162922 \\
\hline$X_{1} X_{3}$ & 31.008 & 1 & 31.008 & 81.934 & 0.070047 \\
\hline$X_{2} X_{3}$ & 0.839 & 1 & 0.839 & 2.216 & 0.376598 \\
\hline Lack of fit & 93.100 & 5 & 18.620 & 49.200 & 0.107800 \\
\hline Pure Error & 0.378 & 1 & 0.378 & & \\
\hline
\end{tabular}

Total SS $1895.691 \quad 15$

$\mathrm{R}$-square $=0.9506$, Adjusted R-square $=0.876, \mathrm{MS}$ pure error $=0.37,{ }^{*}$ represents significant factors, ${ }^{\alpha}(\mathrm{T})$ represents Temperature, ${ }^{\beta}(\mathrm{t})$ represents time, and ${ }^{¥}$ represents $\mathrm{H}_{2} \mathrm{O}_{2}$ concentration

Sugarcane bagasse impregnation into $\mathrm{H}_{2} \mathrm{O}_{2}$ before introduction to hydrothermal pretreatment resulted in significant decrease in Klason lignin as shown in Table 5.2. Klason lignin

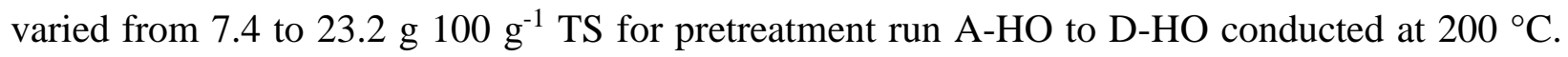
While, a decrease in temperature to $160{ }^{\circ} \mathrm{C}$ indicated a relative decrease in Klason lignin in the

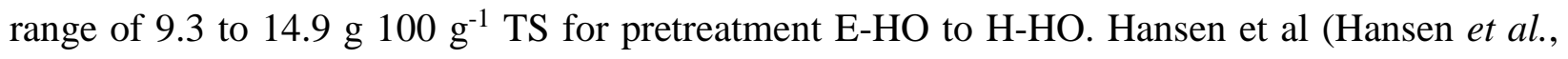
2004) reported that lignin recovery is in direct relation to pretreatment temperature. Pretreatment

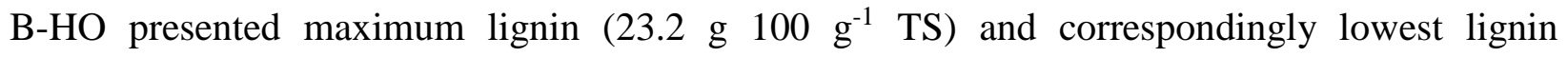
solubilization (6.86\%) in the pretreated solid possibly due to lower $\mathrm{H}_{2} \mathrm{O}_{2}(2 \%)$, higher temperature

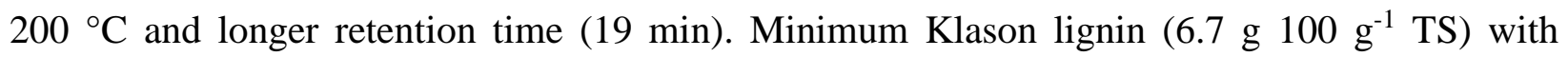
correspondent highest lignin dissolution (73.09\%) was observed in pretreatment K-HO conducted at $7.36 \% \mathrm{H}_{2} \mathrm{O}_{2}, 180{ }^{\circ} \mathrm{C}$, and $12 \mathrm{~min}$. Complete degradation of lignin during the hydrothermal process is not possible due to recondensation process (Alvira et al., 2010). 
Table 5.4 - Analysis of variance (ANOVA) for xylan content (g 100 g-1 TS) in pretreated solids impregnated in $\mathrm{H} 2 \mathrm{O} 2$

\begin{tabular}{cccccc}
\hline Source & Sum of square & Degree of freedom & Mean Square & F-value & P-value (prob > F) \\
\hline$X_{1}(\mathrm{~T})^{\alpha}$ & 94.9178 & 1 & 94.9178 & 189.836 & $0.046124^{*}$ \\
\hline$X_{1}^{2}$ & 27.3930 & 1 & 27.3930 & 54.786 & 0.085492 \\
\hline$X_{2}(\mathrm{t})^{\beta}$ & 82.9096 & 1 & 82.9096 & 165.819 & $0.049339^{*}$ \\
\hline$X_{2}{ }^{2}$ & 1.3349 & 1 & 1.3349 & 2.670 & 0.349638 \\
$X_{3}$ & 570.6716 & 1 & 570.6716 & 1141.343 & $0.018838^{*}$ \\
$\left(\mathrm{H}_{2} \mathrm{O}_{2} \text { Conc. }\right)^{\ddagger}$ & & 1 & & & 0.054346 \\
\hline$X_{3}^{2}$ & 68.2786 & 1 & 10.5341 & 21.068 & 0.136563 \\
\hline$X_{1} X_{2}$ & 10.5341 & 1 & 15.2352 & 30.470 & 0.114092 \\
\hline$X_{1} X_{3}$ & 15.2352 & 1 & 1.3612 & 2.722 & 0.346871 \\
\hline$X_{2} X_{3}$ & 1.3612 & 5 & 8.7590 & 17.518 & 0.179350 \\
\hline Lack of fit & 43.7950 & 1 & 0.5000 & & \\
\hline Pure Error & 0.5000 & 15 & & & \\
\hline
\end{tabular}

Total SS $\quad 902.7186 \quad 15$

R-square $=0.9509$, Adjusted R-square $=0.877$, MS pure error $=0.5,{ }^{*}$ represents significant factors, ${ }^{\alpha}(\mathrm{T})$ represents Temperature, ${ }^{\beta}(\mathrm{t})$ represents time, and ${ }^{¥}$ represents $\mathrm{H}_{2} \mathrm{O}_{2}$ concentration

Degradation mechanism of lignin with $\mathrm{H}_{2} \mathrm{O}_{2}$ during hydrothermal pretreatment could be explained with Equations 5.3 and 5.4 proposed by Gould (Gould, 1985). Kadla and Chang (Kadla and Chang, 2001) reported that hydrogen peroxide reacts readily with lignin to produce low molecular weight degradation compounds.

$$
\begin{gathered}
\mathrm{H}_{2} \mathrm{O}_{2} \rightarrow \mathrm{H}^{+}+\mathrm{HOO}^{-} \\
\mathrm{H}_{2} \mathrm{O}_{2}+\mathrm{HOO}^{+} \rightarrow . \mathrm{OH}+\mathrm{O}_{2} \cdot-+\mathrm{H}_{2} \mathrm{O}
\end{gathered}
$$

Hydroxyl radical acts as a powerful lignin oxidant, which lead to delignification of lignocellulosic biomass by oxidation and degradation. While perhydroxy anion cleaves the diferulate linkages which cross-link polysaccharides resulting in depolymerization of polysaccharides (Kim and Lee, 1996).

Zhao et al (Zhao et al., 2016) studied the impact of $\mathrm{H}_{2} \mathrm{O}_{2}(0.1,0.4$, and 0.7 mass ratios to dry biomass) presoaking before ammonia fiber expansion on physical and chemical characteristics 
of the corn stalk. The authors observed $2.4-28.8 \%$ lignin removal that increased with increase in pretreatment temperature and $\mathrm{H}_{2} \mathrm{O}_{2}$ loading. In another study, Shen et al (Shen et al., 2011) reported $66.5 \pm 1.6 \%$ lignin removal for tobacco stem pretreated with $\mathrm{H}_{2} \mathrm{O}_{2}(01.2 \% \mathrm{w} / \mathrm{v})$ at $90{ }^{\circ} \mathrm{C}$ for $24 \mathrm{hrs}$. Song et al (Song et al., 2013) reported 12.5\% decrease in lignin content of rice straw after pretreatment with $\mathrm{H}_{2} \mathrm{O}_{2}(1,2,5$ and $4 \%)$ at $25 \pm 2{ }^{\circ} \mathrm{C}$ for 7 days. Higher lignin dissolution (74.2\%) in the current study was might be due to direct introduction of impregnated bagasse into the hydrothermal reactor after $\mathrm{H}_{2} \mathrm{O}_{2}$ removal whereas Shen et al (Shen et al., 2011) dried tobacco after $\mathrm{H}_{2} \mathrm{O}_{2}$ impregnation pretreatment. Another reason for higher lignin removal is higher $\mathrm{H}_{2} \mathrm{O}_{2}$ (v/v \%) loading.

A Second-order polynomial equation (Equation 5.5) was derived from the experimental data of lignin solubilization (\%) to explain the impact of studied factors. It was observed that all the studied parameters; temperature $\left(X_{1}\right)$, time $\left(X_{2}\right)$ and $\mathrm{H}_{2} \mathrm{O}_{2}$ concentration $\left(X_{3}\right)$ showed significant impact on lignin dissolution. The model described that linear model terms $X_{1}$ and $X_{2}$ showed the significant negative impact on lignin dissolution with magnitude values of 5.48 and 3.63, respectively, while $X_{3}$ showed the highest positive significant impact on lignin dissolution with magnitude value of 17.40 . It implied that $\mathrm{H}_{2} \mathrm{O}_{2}$ concentration proved to be a parameter of significant interest for lignin dissolution.

The interaction of studied parameters indicated that $X_{1} X_{2}$ showed a negative impact on magnitude value of 5.05 while $X_{1} X_{3}$ showed a positive impact on magnitude value of 6.05 . It implied that to remove lignin content from sugarcane bagasse interaction between temperature $\left(X_{1}\right)$ and $\mathrm{H}_{2} \mathrm{O}_{2}\left(X_{3}\right)$ are more important than reaction time $\left(X_{2}\right)$. One-way analysis of variance (Table 5.5) indicated that $X_{1}, X_{2}, X_{3}, X_{1} X_{2}$, and $X_{1} X_{3}$ were significant with $p$-values of $0.009,0.047,0.000$, 0.038, and 0.019, respectively (Table 5.5).

$\%$ lignin dissolution $=49.96-5.48 X_{1}-3.63 X_{2}+17.40 X_{3}-3.72 X_{1}^{2}+1.64 X_{2}{ }^{2}-$ $2.34 X_{3}^{2}-5.05 X_{1} X_{2}+6.05 X_{1} X_{3}+2.90 X_{2} X_{3}$ 
Table 5.5 - Analysis of variance (ANOVA) for percent lignin dissolution in pretreated solids impregnated in $\mathrm{H}_{2} \mathrm{O}_{2}$.

\begin{tabular}{|c|c|c|c|c|c|}
\hline Source & Sum of square & Degree of freedom & Mean Square & F-value & P-value $($ prob > F) \\
\hline $\begin{array}{c}X_{1} \\
(\mathrm{~T})^{\alpha}\end{array}$ & 409.99 & 1.00 & 409.99 & 14.20 & $0.009 *$ \\
\hline$X_{1}^{2}$ & 128.70 & 1.00 & 128.70 & 4.46 & 0.079 \\
\hline $\begin{array}{l}X_{2} \\
(\mathrm{t})^{\beta}\end{array}$ & 180.15 & 1.00 & 180.15 & 6.24 & $0.047 *$ \\
\hline$X_{2}^{2}$ & 24.81 & 1.00 & 24.81 & 0.86 & 0.390 \\
\hline $\begin{array}{c}X_{3} \\
\left(\mathrm{H}_{2} \mathrm{O}_{2} \text { Conc. }\right)^{\ddagger}\end{array}$ & 4135.19 & 1.00 & 4135.19 & 143.23 & $0.000 *$ \\
\hline$X_{3}^{2}$ & 50.57 & 1.00 & 50.57 & 1.75 & 0.234 \\
\hline$X_{1} X_{2}$ & 203.82 & 1.00 & 203.82 & 7.06 & $0.038 *$ \\
\hline$X_{1} X_{3}$ & 292.43 & 1.00 & 292.43 & 10.13 & $0.019 *$ \\
\hline$X_{2} X_{3}$ & 67.37 & 1.00 & 67.37 & 2.33 & 0.177 \\
\hline Error & 173.22 & 6.00 & 28.87 & & \\
\hline Total SS & 5742.97 & 15.00 & & & \\
\hline
\end{tabular}

R-square $=0.969$, Adjusted R-square $=0.925$, MS error $=28.87, *$ represents significant factors, ${ }^{\alpha}(\mathrm{T})$ represents Temperature, ${ }^{\beta}(\mathrm{t})$ represents time, and ${ }^{\ddagger}$ represents $\mathrm{H}_{2} \mathrm{O}_{2}$ concentration

\subsubsection{Morphological characteristics of $\mathrm{H}_{2} \mathrm{O}_{2}$ assisted hydrothermally pretreated solid fraction}

Scanning electron microscopy is a well-documented technique to study the morphology of lignocellulosic biomass and has been proven useful to study structural characteristics at the molecular level (Trajano et al., 2013). Native sugarcane bagasse and solid fractions of selected pretreatments, based on $\mathrm{CH}_{4}$ yield, were compared for the ultrastructural differences by scanning electron microscopy. The impact of $\mathrm{H}_{2} \mathrm{O}_{2}$ assisted pretreatment on visual appearance of sugarcane bagasse at the lowest $\left(146.4{ }^{\circ} \mathrm{C}\right)$ and highest $\left(213.6{ }^{\circ} \mathrm{C}\right)$ studied temperature is depicted in Fig 5.4

The SEM micrographs of native Sugarcane bagasse and $\mathrm{BOH}$, and $\mathrm{KOH}$ pretreatments are shown in Fig 5.1 (A, B, and C). The SEM images show a distinct difference between the morphology of raw Fig 5.1 (A) and pretreated samples Fig 5.1 (B, C). Raw sample (Fig. 5.1 A) shows a smooth surface, rigid, and compact rather highly organized morphological structure. Cellulosic fibers Fig 5.1 (B) are present in stripes (higher magnification) as tightly packed 
structures and encapsulated within lignin sheath, in addition, covered with extractives, superficially. This kind of structure makes cellulosic microfibrils virtually inaccessible for enzymatic action, and poses challenges to hydrolysis process.

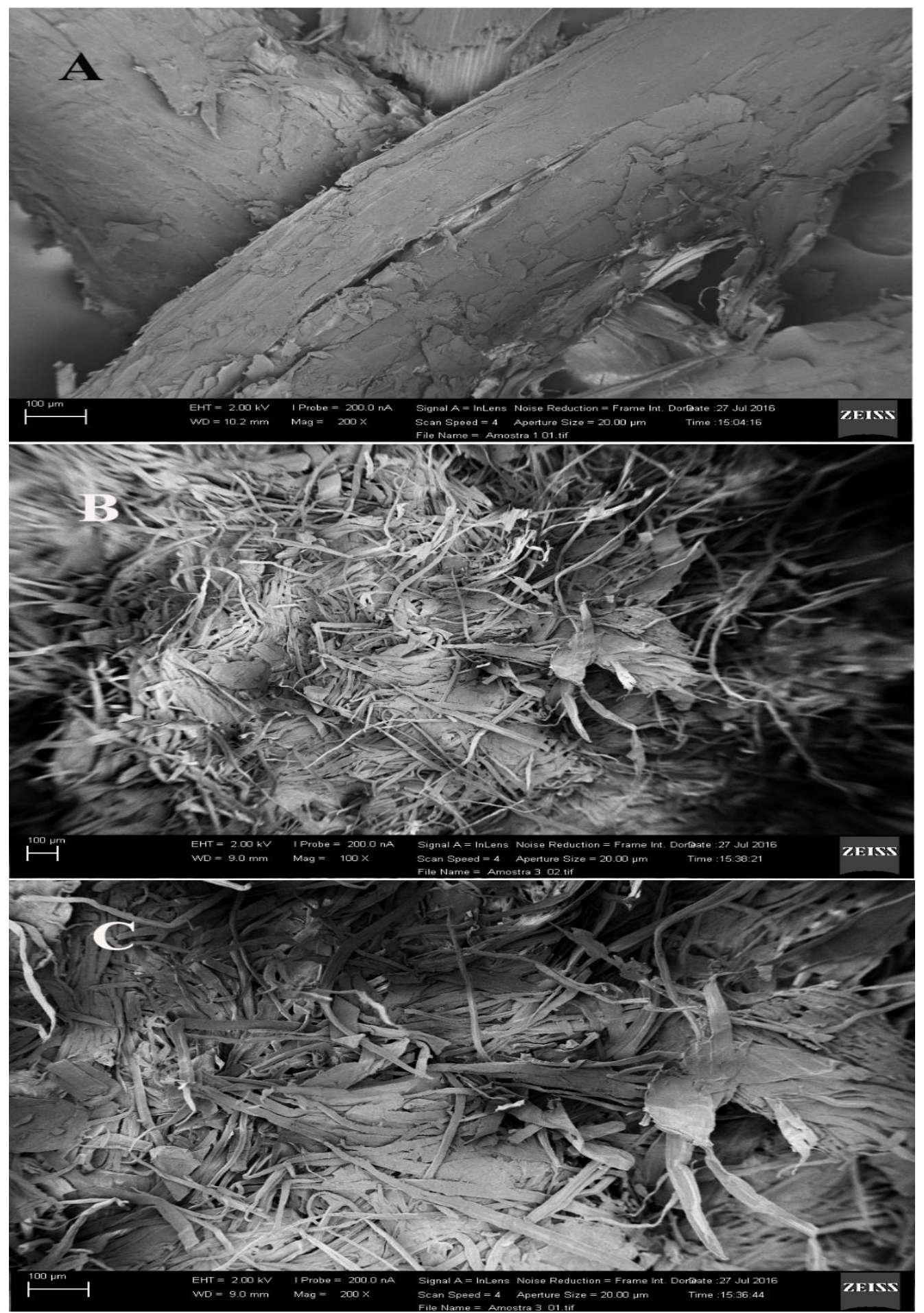

Figure 5.1 - Comparison of SEM images; Raw (A), B-HO (B), and K-HO (C) 

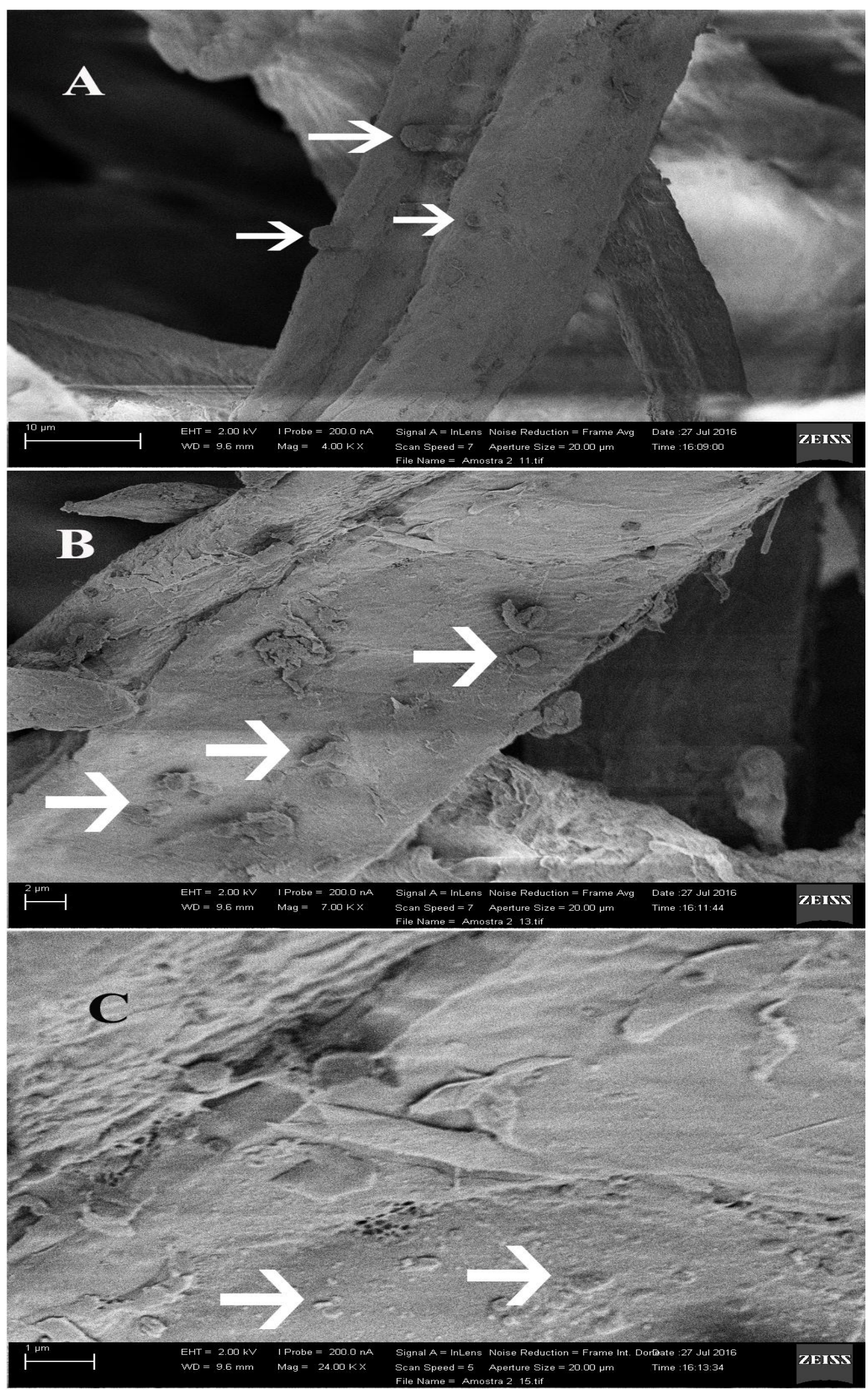

Figure 5.2 - SEM images of B-HO indicating pseudo-lignin droplets on cell wall surface 

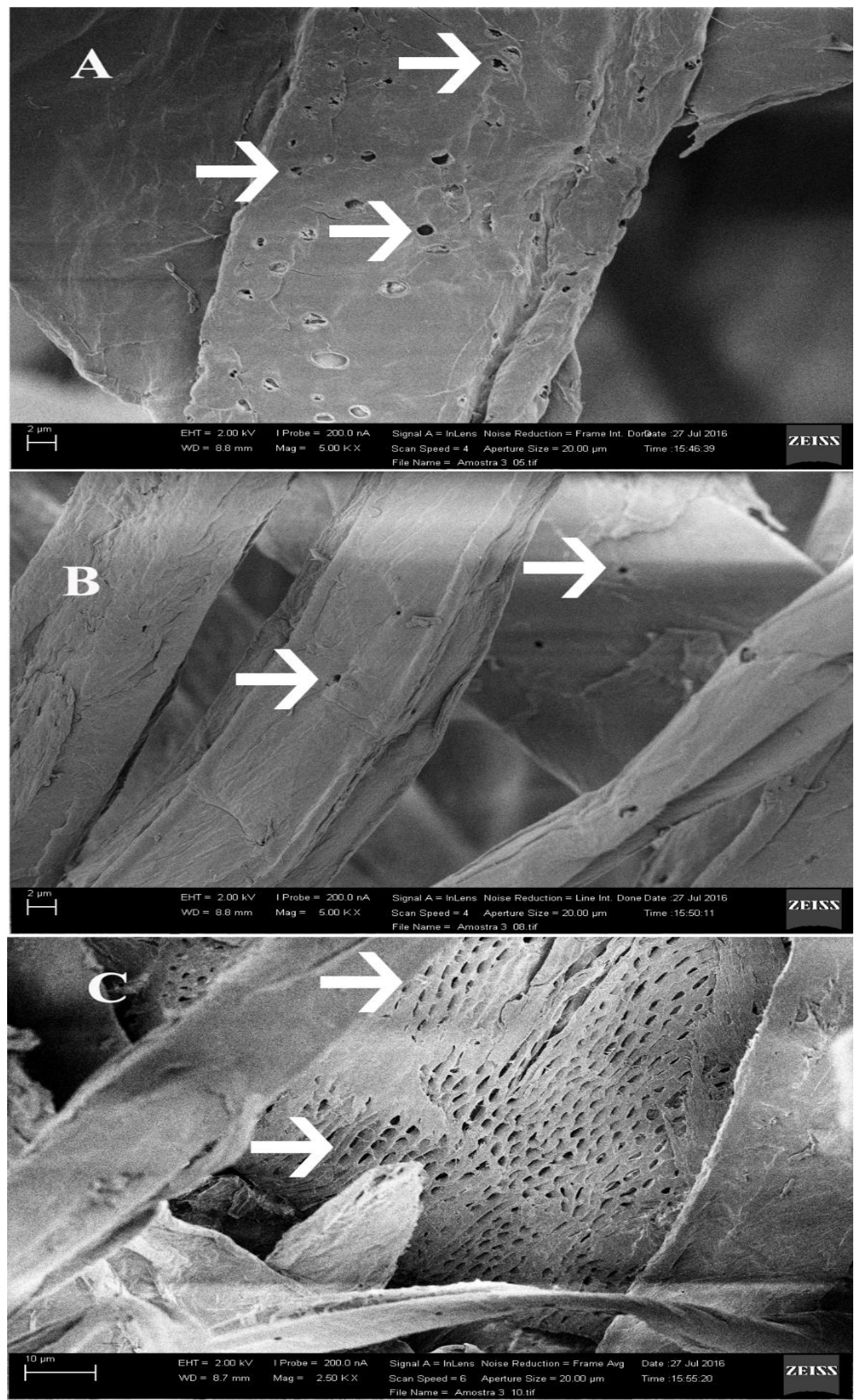

Figure 5.3 - SEM images of K-HO indicating porous surface due to lignin removal 

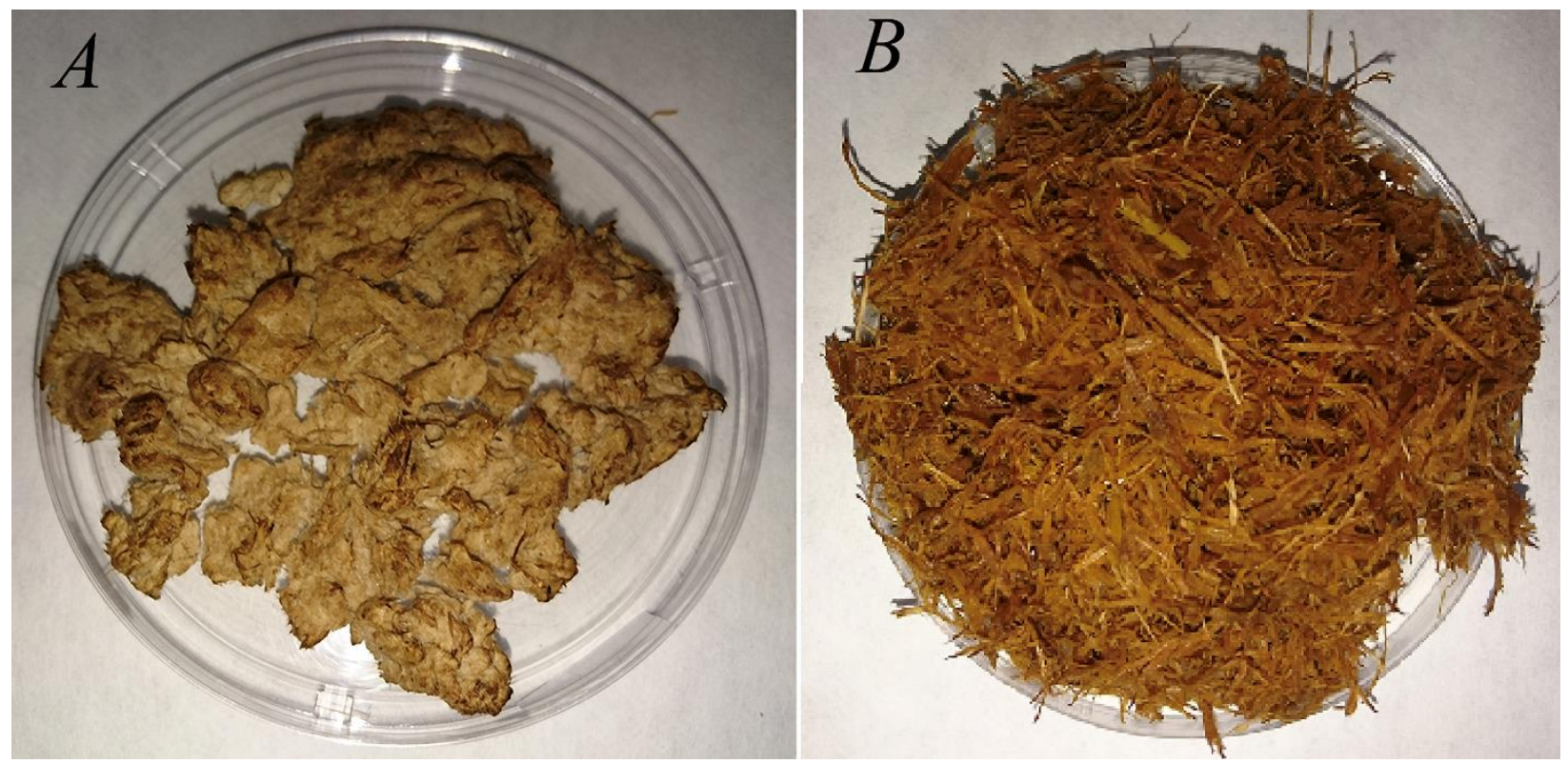

Figure 5.4 - Impact of $\mathrm{H}_{2} \mathrm{O}_{2}$ assisted hydrothermal pretreatment on visual appearance of sugarcane bagasse; (A) Highest studied temperature (pretreatment run $\mathrm{O}-\mathrm{HO}-213.6^{\circ} \mathrm{C}$ ), (B) Lowest studied temperature (pretreatment run $\mathrm{P}-\mathrm{HO}-146.4{ }^{\circ} \mathrm{C}$ )

A significant difference between pretreated samples cannot be seen at lower magnification, a distinct difference can be observed at a higher resolution (Fig 5.3 \& Fig 5.4 A, B, and C). Both pretreated samples showed disorganized structure, characterized with scattered microfibrils; bundles appear flexible because of twisted appearance (Fig. $5.1 \mathrm{~B}, \mathrm{C}$ ). Heather et al (Heather et $a l ., 2013$ ) reported that presence of carbohydrates in the biomass influence the solubility of lignin during pretreatment process. Cellulosic fibers are more exposed to the pretreated sample, which allows better access to enzymes for higher hydrolysis yield (Martín et al., 2012; Cao and Aita, 2013). Complex agglomerated structures appeared on the surface (Fig 5.2 A, B, C) in the form of droplets of varying sizes in B-HO. These structures have been reported as pseudo-lignin in several other studies (Donohoe et al., 2008; Kumar et al., 2013; Nitsos et al., 2013; Sun et al., 2014). It appeared that lower concentration of $\mathrm{H}_{2} \mathrm{O}_{2}(2 \% \mathrm{v} / \mathrm{v})$ did not help in removing the lignin, in spite higher temperature $\left(200^{\circ} \mathrm{C}\right)$ showed significant impact on lignin phase transition and coalescence and pseudo-lignin formation. Furthermore, pores were not visible on the surface that are characteristic to lignin removal. The higher lignin content $(23.2 \%)$ in B-HO solid fraction correlated well with the lower $\mathrm{CH}_{4}$ yield (5.59 $\mathrm{Nmmol} \mathrm{g}^{-1} \mathrm{TVS}$ ). Fig 5.3B depicts higher order dismantled surface of biomass for K-HO pretreatment. 
Impregnation of bagasse at $7.36(\% \mathrm{v} / \mathrm{v}) \mathrm{H}_{2} \mathrm{O}_{2}$ resulted in $73.09 \%$ delignification leading to the perforated surface (Fig $5.3 \mathrm{C}$ ). It demonstrated that impregnation in higher $\mathrm{H}_{2} \mathrm{O}_{2}$ concentration facilitated the degradation reactions, thereby, breaking down the lignin structure and evaporation of volatile compounds might have been resulted into the porous surface. The highly dispersed and porous surface represents a loss of physical and morphological integrity due to lignin removal owing to attack of degradation products; hydroxyl $\left(\mathrm{HO}^{-}\right)$and superoxide radical anions $\left(\mathrm{O}_{2}{ }^{-}\right)$of $\mathrm{H}_{2} \mathrm{O}_{2}$ on lignin (Damaurai et al., 2014). The porous surface structure might helpful for bacterial contact and further improve the degradation process during fermentation. Rezende et al (Rezende et al., 2011) observed that delignification increased the fragility and holes in the cell wall structure of sugarcane bagasse. Authors further observed detachment of fibers and dismantling of vascular bundles as an impact of $\mathrm{NaOH}$ pretreatment on sugarcane bagasse. Limiting residence time of depolymerized lignin moieties during pretreatment could significantly improve lignin removal. Delignification promotes biomass swelling, which increases internal surface area and median pore volume (Zhu et al., 2008).

Chandel and co-workers (Chandel et al., 2014) reported comparable results while studying sodium hydroxide pretreatment on cellulignin obtained after dilute acid hydrolysis. Authors reported substantial removal of lignin in response to alkali pretreatment and visibility of pores on the surface. The morphological structure of sugarcane bagasse in the current study is further strengthened by the finding of Corrales et al (Corrales et al., 2012) for the presence of round elongated shaped lignin particles on the biomass surface.

\subsection{Chemical composition of liquid hydrolysate obtained from $\mathrm{H}_{2} \mathrm{O}_{2}$ assisted hydrothermal pretreatment}

Liquid hydrolysate obtained from hydrothermal pretreatment was characterized by chemical oxygen demand (COD), total carbohydrate content, total phenolic content, organic acids and monomeric sugar compounds; glucose, and xylose.

Hydrothermal pretreatment results in breakage of chemical bonds within the lignincellulosic complex, thereby degrading structural compounds that make their route to liquid stream. Hence, resulted into increase in chemical oxygen demand and carbohydrate content. 
Table 5.6 - Characterization of liquid hydrolysate obtained from $\mathrm{H}_{2} \mathrm{O}_{2}$ assisted hydrothermally pretreated sugarcane bagasse

\begin{tabular}{ccccccc}
\hline Pretreatment & $\begin{array}{c}\text { Temperature } \\
\left({ }^{\circ} \mathbf{C}\right)\end{array}$ & $\begin{array}{c}\text { Time } \\
(\mathbf{m i n})\end{array}$ & $\begin{array}{c}\mathbf{H}_{2} \mathbf{O}_{2} \\
(\mathbf{v} / \mathbf{v} \\
\mathbf{\%})\end{array}$ & $\begin{array}{c}\text { COD } \\
\left(\mathbf{g ~ L ~ L}^{-1}\right)\end{array}$ & $\begin{array}{c}\text { Total } \\
\text { Carbohydrate } \\
\left(\mathbf{g ~ L}^{-1}\right)\end{array}$ & $\begin{array}{c}\text { Phenolic } \\
\text { content } \\
(\mathbf{p p m})\end{array}$ \\
\hline A-HO & 200 & 19 & 6 & 17.75 & 4.14 & $3,005.63$ \\
\hline B-HO & 200 & 19 & 2 & 9.98 & 3.17 & $1,578.75$ \\
\hline C-HO & 200 & 5 & 6 & 12.98 & 3.32 & $2,068.13$ \\
\hline D-HO & 200 & 5 & 2 & 12.53 & 3.99 & $1,316.25$ \\
\hline F-HO & 160 & 19 & 6 & 10.28 & 3.27 & $1,991.25$ \\
\hline G-HO & 160 & 19 & 2 & 10.10 & 2.48 & 941.25 \\
\hline H-HO & 160 & 5 & 6 & 13.49 & 2.24 & $1,316.25$ \\
\hline I-HO & 180 & 5 & 2 & 9.84 & 3.92 & 741.25 \\
\hline J-HO & 180 & 12 & 4 & 9.63 & 3.88 & $2,028.75$ \\
\hline K-HO & 180 & 12 & 7.36 & 17.21 & 4.18 & $1,468.13$ \\
\hline L-HO & 180 & 12 & 0.64 & 8.07 & 2.85 & $1,116.25$ \\
\hline M-HO & 180 & 23.76 & 4 & 13.44 & 3.35 & $1,411.88$ \\
\hline N-HO & 180 & 0.24 & 4 & 9.87 & 3.03 & $1,303.75$ \\
\hline O-HO & 213.6 & 12 & 4 & 12.84 & 1.96 & $1,828.75$ \\
\hline P-HO & 146.4 & 12 & 4 & 10.34 & 3.00 & $1,478.75$ \\
\hline & & & 4 & & & $2,053.75$ \\
\hline
\end{tabular}

As indicated in Table 5.6, approx. 2-fold decrease in chemical oxygen demand (COD) was observed when $\mathrm{H}_{2} \mathrm{O}_{2}$ was decreased from 6 to $2 \%$ under similar conditions of temperature (200 ${ }^{\circ} \mathrm{C}$ ) and time (19 min) for pretreatment A-HO and B-HO, respectively. On the other hand, 42\% decrease (17.75 to $10.28 \mathrm{~g} \mathrm{~L}^{-1}$ ) was noted when retention time (19 min) and $\mathrm{H}_{2} \mathrm{O}_{2}(6 \%)$ was held constant and pretreatment temperature was decreased from 200 to $160{ }^{\circ} \mathrm{C}$ for pretreatment A-HO and E-HO, respectively. A retention time of $5 \mathrm{~min}$ did not affect much on COD values with the decrease in $\mathrm{H}_{2} \mathrm{O}_{2}(6 \%$ to $2 \%)$ at $200{ }^{\circ} \mathrm{C}$, though it was higher from COD values at $160{ }^{\circ} \mathrm{C}$ except for pretreatment $\mathrm{G}-\mathrm{HO}$, where it was bit higher $\left(13.49 \mathrm{~g} \mathrm{~L}^{-1}\right)$, than pretreatment $\mathrm{C}-\mathrm{HO}$, under similar reaction time and $\mathrm{H}_{2} \mathrm{O}_{2}$ concentration. Pretreatment $\mathrm{K}-\mathrm{HO}$ and L-HO showed $53.11 \%$ decrease (17.21 to $8.07 \mathrm{~g} \mathrm{~L}^{-1}$ ) in COD with a decrease in $\mathrm{H}_{2} \mathrm{O}_{2}$ from 7.36 to $0.64 \%$ under similar 
conditions of temperature $\left(180{ }^{\circ} \mathrm{C}\right)$ and reaction time (12 min). It implicates that $\mathrm{H}_{2} \mathrm{O}_{2}$ applied had a notable impact on the release of organics into the liquid stream.

A maximum reaction time $(23.76 \mathrm{~min})$ studied in this study resulted in $26.56 \%$ decrease (13.44 to $\left.9.87 \mathrm{~g} \mathrm{~L}^{-1}\right)$ in COD when compared to lowest $(0.24 \mathrm{~min})$ reaction time at pretreatment temperature of $180{ }^{\circ} \mathrm{C}$ and $4(\% \mathrm{v} / \mathrm{v}) \mathrm{H}_{2} \mathrm{O}_{2}$. While only $19.47 \%$ decrease $\left(12.84\right.$ to $\left.10.34 \mathrm{~g} \mathrm{~L}^{-1}\right)$ was observed between pretreatments with highest $\left(213.6{ }^{\circ} \mathrm{C}\right)$ and lowest $\left(146.4{ }^{\circ} \mathrm{C}\right)$ studied temperature, keeping reaction time and $\mathrm{H}_{2} \mathrm{O}_{2}$ held constant. A decrease in COD solubilization at highest temperature could be due to the formation of humic substances or maximum achievable organic compounds degradation (Ahuja, 2015).

González-Fernández et al. (González-Fernández et al., 2012) reported that higher temperature results in more solubilization of organic matter into liquid stream than lower temperature. Hao et al (Hao et al., 2009) reported that COD of municipal solid waste increased from 1.8 to $7.5 \mathrm{~g} \mathrm{~L}^{-1}$ when temperature was increased from $90{ }^{\circ} \mathrm{C}$ to $190{ }^{\circ} \mathrm{C}$. Authors further observed substantial increase in COD from $5.9 \mathrm{~g} \mathrm{~L}^{-1}$ to $12 \mathrm{~g} \mathrm{~L}^{-1}$, when $\mathrm{NaOH}$ was incorporated

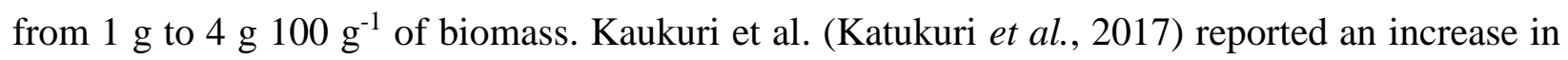
COD up to $6 \mathrm{~g} \mathrm{~L}^{-1}$ at $1 \% \mathrm{H}_{2} \mathrm{O}_{2}$ for $24 \mathrm{~h}$ pretreatment and speculated that increase in COD with an increase in $\mathrm{H}_{2} \mathrm{O}_{2}$ loading is a direct indication of degradation of organic compounds. Ana et al (Anna et al., 2010) reported $4.22 \mathrm{~g} \mathrm{~L}^{-1} \mathrm{COD}$ for paper tube residuals treated with $2 \% \mathrm{H}_{2} \mathrm{O}_{2}$ at 190 ${ }^{\circ} \mathrm{C}$ for $10 \mathrm{~min}$ in comparison to $0.026 \mathrm{~g} \mathrm{~L}^{-1}$ for untreated ones. Higher COD in the current study is a result of higher reaction temperature and higher $\mathrm{H}_{2} \mathrm{O}_{2}$ loading. The combination with treatments of temperatures, times and $\mathrm{H}_{2} \mathrm{O}_{2}$ should be assessed in further studies for optimum COD solubilization, however, was not the focus of this study.

Total carbohydrates content was in the range of 3.17 to $4.14 \mathrm{~g} \mathrm{~L}^{-1}$ at $200{ }^{\circ} \mathrm{C}$ for pretreatment A-HO - D-HO. The decrease in temperature to $160{ }^{\circ} \mathrm{C}$ under a similar condition of retention time and $\mathrm{H}_{2} \mathrm{O}_{2}$ resulted in a decrease in carbohydrate content in the range of 2.24-3.92 $\mathrm{g} \mathrm{L}^{-1}$ for pretreatment $\mathrm{E}-\mathrm{HO}-\mathrm{H}-\mathrm{HO}$. Lower total carbohydrates content in the liquid slurry is a result of dehydration reactions of sugars to acids at a higher temperature. The argument is supported with the lowest total carbohydrate content $\left(1.96 \mathrm{~g} \mathrm{~L}^{-1}\right)$ for the maximum temperature (pretreatment O$\left.\mathrm{HO}-213.6{ }^{\circ} \mathrm{C}\right)$ applied in this study. Maximum total carbohydrate content $\left(4.18 \mathrm{~g} \mathrm{~L}^{-1}\right)$ at maximum $\mathrm{H}_{2} \mathrm{O}_{2}$ applied $\left(180^{\circ} \mathrm{C}, 12 \mathrm{~min}, 7.36 \% \mathrm{H}_{2} \mathrm{O}_{2}\right)$ indicated maximum lignin removal 
(73.09\% solubilization) making cellulose and hemicellulose readily available thereby increasing overall carbohydrate content. Lucas et al (Lucas et al., 2012) reported that oxidative pretreatment like $\mathrm{H}_{2} \mathrm{O}_{2}$ results into the extreme degradation of hemicellulose thereby making it unavailable for the downstream fermentation process.

Since lignin is a complex phenolic polymer (Lange et al., 2013), alkaline oxidative $\mathrm{H}_{2} \mathrm{O}_{2}$ pretreatment resulted in the appreciable amount of phenolic components release into the liquid stream. As presented in Table 5.6, phenolic compounds decreased (47.47\%) with a decrease in $\mathrm{H}_{2} \mathrm{O}_{2}$ (6 to $2 \%$ ) from $3,005.63$ to $1,578.75 \mathrm{ppm}$ at the similar reaction temperature $\left(200{ }^{\circ} \mathrm{C}\right)$ and time $(19 \mathrm{~min})$. When reaction time $(19 \mathrm{~min})$ and $\mathrm{H}_{2} \mathrm{O}_{2}(6 \% \mathrm{v} / \mathrm{v})$ were held constant, a decrease in pretreatment temperature from 200 to $160{ }^{\circ} \mathrm{C}$ resulted in $33.74 \%$ decrease in phenolic content $(3,005.63$ to $1,991.25 \mathrm{ppm})$. A substantial decrease in phenolic contents was recorded at $160{ }^{\circ} \mathrm{C}$ with a decrease in $\mathrm{H}_{2} \mathrm{O}_{2}$; phenolic content decreased $52.73 \%$ (1,991.25 to 941.25 ppm) when $\mathrm{H}_{2} \mathrm{O}_{2}$ decreased from 6 to $2 \%$ at $19 \mathrm{~min}$ reaction time while at reaction time of $5 \mathrm{~min} 43.68 \%(1,316.25$ to $721.25 \mathrm{ppm}$ ) decrease was noted between pretreatment run 7 and 8 .

A $23.97 \%$ decrease in phenolic content was observed between pretreatments with maximum and minimum $\mathrm{H}_{2} \mathrm{O}_{2}$ employed at reaction temperature of $180{ }^{\circ} \mathrm{C}$ for $12 \mathrm{~min} .19 .4 \%$ difference in phenolic content was seen between pretreatments with highest and lowest temperature employed. The phenolic contents data in the hydrolysate indicated that pretreatment temperature and $\mathrm{H}_{2} \mathrm{O}_{2}$ concentration utilized had effectively broken down the ester linkages between lignin and hemicellulose thereby degrading lignin and release of phenolic monomers into liquid hydrolysate. Katukuri et al (Katukuri et al., 2017) reported an increase in total phenolic content with an increase in $\mathrm{H}_{2} \mathrm{O}_{2}$ concentration for Miscanthus floridulus (a perennial grass). Harmsen et al (Harmsen et al., 2010) reported that phenolic contents are more toxic to fermenting bacteria due to their capability to disintegrate microbial enzymes and speculated as more toxic than furfural and 5-hydroxymehtylfurfural. However, studies are available representing the consumption of phenolic compounds by several microbial guilds especially gut microbiota (Mosele et al., 2015). This indicates that impact of phenolic compounds on microbial communities is genera dependent.

Sugarcane bagasse was introduced to the hydrothermal reactor at approx. pH of 12 after discarding $\mathrm{H}_{2} \mathrm{O}_{2}$. $\mathrm{pH}$ values of resulting liquid streams of different pretreatments are presented in 
Table 5.7. The decrease in $\mathrm{pH}$ is a direct indication of production of organic acids during pretreatment due to degradation of structural components and break down of linkages within the lignin-carbohydrate complex. Lowest $\mathrm{pH} 4.66$ was noted for the pretreatment $\mathrm{B}-\mathrm{HO}\left(200{ }^{\circ} \mathrm{C}, 19\right.$ min, $2 \% \mathrm{H}_{2} \mathrm{O}_{2}$ ). However, a minimal decrease in $\mathrm{pH}(9.68)$ was observed for pretreatment $\mathrm{P}-\mathrm{HO}$ $\left(146.4{ }^{\circ} \mathrm{C}, 12 \mathrm{~min}, 4 \% \mathrm{H}_{2} \mathrm{O}_{2}\right)$.

Table 5.7 - Selected organic acids, furanic compounds, and sugar monomers in liquid hydrolysate obtained from $\mathrm{H}_{2} \mathrm{O}_{2}$ assisted hydrothermal pretreatment of sugarcane bagasse

\begin{tabular}{cccccccc}
\hline Pretreatment & $\mathbf{p H}$ & $\begin{array}{c}\text { Glucose } \\
\left(\mathrm{mg} \mathrm{mL}^{-1}\right)\end{array}$ & $\begin{array}{c}\text { Xylose } \\
\left(\mathrm{mg} \mathrm{mL}^{-1}\right)\end{array}$ & $\begin{array}{c}\text { Acetic } \\
\text { acid } \\
\left(\mathrm{mg} \mathrm{L}^{-1}\right)\end{array}$ & $\begin{array}{c}\text { Formic } \\
\text { acid } \\
\left(\mathrm{mg} \mathrm{L}^{-1}\right)\end{array}$ & $\begin{array}{c}\text { Furfural } \\
\left(\mathrm{mg} \mathrm{L}^{-1}\right)\end{array}$ & $\begin{array}{c}\text { 5-HMF } \\
\left(\mathrm{mg} \mathrm{L}^{-1}\right)\end{array}$ \\
\hline A-HO & 8.23 & 0.19 & 2.63 & 201.23 & 884.07 & 0.00 & 5.25 \\
\hline B-HO & 4.66 & 0.61 & 2.25 & 450.11 & 839.35 & 56.91 & 37.45 \\
\hline C-HO & 8.78 & 0.34 & 5.90 & 409.56 & 851.00 & 0.00 & 56.60 \\
\hline E-HO & 5.35 & 0.25 & 8.55 & 581.02 & 736.67 & 0.00 & 8.01 \\
\hline F-HO & 8.65 & 0.18 & 4.45 & 255.78 & 54.95 & 0.00 & 12.69 \\
\hline G-HO & 9.38 & 0.17 & 3.64 & 377.13 & 482.13 & 0.00 & 15.03 \\
\hline I-HO & 8.89 & 0.17 & 4.03 & 367.66 & 509.08 & 0.00 & 27.46 \\
\hline K-HO & 8.19 & 0.17 & 3.84 & 189.84 & 504.06 & 0.00 & 18.31 \\
\hline L-HO & 9.49 & 0.50 & 6.56 & 494.86 & 952.31 & 0.00 & 2.56 \\
\hline M-HO & 8.92 & 0.26 & 1.27 & 305.39 & 532.47 & 0.00 & 8.91 \\
\hline N-HO & 8.91 & 0.78 & 7.48 & 107.42 & 151.77 & 0.00 & 21.78 \\
\hline O-HO & 4.85 & 0.82 & 4.95 & 474.54 & 1108.02 & 27.46 & 46.44 \\
\hline P-HO & 9.68 & 0.38 & 7.92 & 339.90 & 416.76 & 0.00 & 23.74 \\
\hline
\end{tabular}

Low-molecular-weight carboxylic acids are produced during hydrothermal pretreatment due to degradation mechanism of polymeric carbohydrates at high temperature. Selected acids (Acetic and formic), furanic compounds (furfural and 5-hydroxymethylfurfural) as well as sugar monomers produced in the current study are presented in Table 5.7. Acetic acid released from Oacetyl groups in hemicellulose results into lowering the $\mathrm{pH}$ during hydrothermal pretreatment that 
further facilitates the removal of sugar monomers (Chen et al., 2010; Shen et al., 2016). Another possible reason for a decrease in $\mathrm{pH}$ during hydrothermal pretreatment could be hydrothermal oxidation of different minerals present in sugarcane bagasse (Chandra et al., 2012).

Acetic acid varied in the range of 107.42 to $581.02 \mathrm{mg} \mathrm{L}^{-1}$ for $\mathrm{H}_{2} \mathrm{O}_{2}$ pretreated samples. Concentration pattern of acetic acid in the liquid hydrolysate of sixteen pretreatments indicated that pretreatment parameters had an effect on its production in relation to $\mathrm{pH}$ of the liquid hydrolysate. Acetic acid is reported to be produced from the oxidation of levulinic and lactic acid during hydrothermal pretreatment (Jin et al., 2005; Fang et al., 2012). Lower acetic acid concentration could be attributed to its further degradation.

Quitain et al (Quitain et al., 2002) reported that formic and acetic acid are intermediate products before their complete degradation to volatile carbon and water. Higher concentrations of formic acid were observed at a higher temperature $\left(200{ }^{\circ} \mathrm{C}\right)$ irrespective of the reaction time and $\mathrm{H}_{2} \mathrm{O}_{2}$ concentration. However, Jin et al (Jin et al., 2008) reported that higher yields of formic acids could be attained by adding base catalyst or $\mathrm{H}_{2} \mathrm{O}_{2}$ during hydrothermal pretreatment. The current study revealed that formic acid could be produced in higher yields even at lower $\mathrm{H}_{2} \mathrm{O}_{2}$ at a higher temperature; however, higher formic acid at lower temperature required higher $\mathrm{H}_{2} \mathrm{O}_{2}$ (pretreatment $\left.\mathrm{K}-\mathrm{HO}-7.36 \% \mathrm{H}_{2} \mathrm{O}_{2}, 12 \mathrm{~min}, 180{ }^{\circ} \mathrm{C}\right)$. Highest formic acid $\left(1,108.02 \mathrm{mg} \mathrm{L}^{-1}\right)$ was observed in current study at pretreatment $\mathrm{O}-\mathrm{HO}\left(213.6{ }^{\circ} \mathrm{C}, 12 \mathrm{~min}, 4 \% \mathrm{H}_{2} \mathrm{O}_{2}\right)$.

$\mathrm{C}_{5}$ sugars degrade into furfural while decomposition of $\mathrm{C}_{6}$ sugars results into 5-HMF, both are further degraded into formic acid (Shen et al., 2016). Furfural was not observed in 13 of 16 pretreatments primarily due to higher $\mathrm{pH}$. Furfural can be degraded into formic acid via hydrolytic fission of aldehyde groups. Furfural was only observed in pretreatments where liquid hydrolysate pH was approx. closer to 5.

5-HMF concentrations were ranging from 2.56 to $56.60 \mathrm{mg} \mathrm{L}^{-1}$. The lower furanic compounds in $\mathrm{H}_{2} \mathrm{O}_{2}$ impregnated pretreatments are in agreement with Teixeira et al. (Teixeira et al., 2014). The authors suggested that $\mathrm{pH}$ of reaction mixture must be kept between 4-7 to avoid the formation of inhibitory compounds because this $\mathrm{pH}$ disfavors the formation of monomers, carbohydrates retained in oligomeric form resulting into lower furanic compounds production. However, Du et al (Du et al., 2010) presented another viewpoint that under alkaline conditions, degradation of sugars might occur through some alternate pathway. 
Glucose and xylose in the liquid fraction were determined after Sluiter protocol (Sluiter et al., 2011). Lower values of glucose were seen in liquid hydrolysate indicating that most of the cellulose was retained in the solid fraction. On the other hand, relatively higher values of xylose in the range of $1.27-9.60 \mathrm{mg} \mathrm{mL}^{-1}$ indicated removal of xylose as indicated by higher xylan removal (Table 5.2). Su et al. (Su et al., 2015) conducted fractional pretreatment on corncob with $\mathrm{H}_{2} \mathrm{O}_{2}$ to characterize its major components. Authors observed no xylose and arabinose in the liquid fraction. However, the pretreatment strategy was different comparing to the present study. The authors conducted pretreatment in a shaking water bath at $50{ }^{\circ} \mathrm{C}$ at $\mathrm{pH} 11$. However, the present study was realized in a hydrothermal reactor solubilizing xylan content leading to higher pentose sugars in the liquid hydrolysate. The authors speculated that hemicellulose removal during hydrogen peroxide is a dissolution mechanism and not reaction mechanism.

\subsection{Methane production from solid fractions of $\mathrm{H}_{2} \mathrm{O}_{2}$ assisted hydrothermal pretreatment}

Solid fractions of $\mathrm{H}_{2} \mathrm{O}_{2}$ impregnated hydrothermal pretreatments were tested for methane production. Batch reactors were set up based on total volatile solids (TVS) according to CCD matrix (Table 4.4). The composition of each reactor is presented in Table 9.1 (Appendix). Batch reactors were supplemented with $1 \mathrm{~g}$ TVS of the pretreated substrate and inoculated with $2 \mathrm{~g}$ TVS of inoculum. The actual substrate (g) and inoculum ( $\mathrm{g}$ ) values are presented in Table 9.1 (Appendix). The reactors were incubated in a neutral starting $\mathrm{pH}$.

Total time of incubation was variable (600 to $1200 \mathrm{~h}$ ) across different pretreatments based on stable methane production in different reactors. Sugarcane bagasse is a heterogeneous material, it requires a consortium of hydrolytic microorganisms to break down its polymeric structure for the release of fermentable sugars for fermenting microbial. Methane production data ( $\mathrm{Nmmol} \mathrm{g}^{-1}$ TVS) was processed with modified Gompertz model (Zwietering et al., 1990). Modified Gompertz

model has been utilized to describe the progress of cumulative $\mathrm{CH}_{4}$ production in batch experiments taking into account relationship between microbial growth and metabolism (Ghasemian et al., 2016; Siripatana et al., 2016; Li et al., 2017).

In the first set of experiments, six pretreatments were tested for digestion experiments; BHO, C-HO, D-HO, E-HO, F-HO and H-HO besides control without substrate addition i.e., only inoculum to subtract indigenous $\mathrm{CH}_{4}$. Pretreatment B-HO had presented longest lag phase of 88.45 
h (Table 5.9) before the methane production started. Higher lag phase in B-HO could be a result of higher lignin $(23.2 \%)$ content in the pretreated solid besides higher furanic compounds (furfural $0.06 \mathrm{~g} \mathrm{~L}^{-1}$ and $0.04 \mathrm{~g} \mathrm{~L}^{-1} 5-\mathrm{HMF}$ ) in the pretreatment slurry.

Lignin structure resulting due to hydrothermal pretreatment is inhibitory to microbial cellulase (Ko et al., 2015). Microorganisms need to acclimatize to the reactor conditions and inhibitory compounds like furfural and 5-HMF (Monlau et al., 2014). Anna et al (Anna et al., 2010) reported a lag phase of 5 days $\left(120 \mathrm{~h}\right.$ ) for paper tube residuals treated at $190{ }^{\circ} \mathrm{C}$ with $2 \%$ $\mathrm{H}_{2} \mathrm{O}_{2}$ for 10 min. Methane reached to a maximum level of $5.59 \mathrm{Nmmol} \mathrm{g}^{-1} \mathrm{TVS}$ in $250 \mathrm{~h}$ afterward its production started to decrease that could possible due to unavailability of fermentative products due to higher lignin $(23.2 \%)$ content in this pretreatment. Lignin makes it difficult for the microbial cellulases to degrade polysaccharides due to their unproductive adsorption.

For other pretreatments in this set, lag phase varied in the range of $37.32-86.80 \mathrm{~h}$. A rapid increment in $\mathrm{CH}_{4}$ was seen in $\mathrm{C}-\mathrm{HO}$ and $\mathrm{E}-\mathrm{HO}$ after the lag phase in comparison to other pretreatments. The $\mathrm{CH}_{4}$ value was 5.75 and $6.00 \mathrm{Nmmol} \mathrm{g}^{-1} \mathrm{TVS}$ for pretreatment $\mathrm{C}-\mathrm{HO}$ and E$\mathrm{HO}$, respectively while for B-HO, D-HO, F-HO and H-HO it was 1.67, 2.28, 4.52, $4.22 \mathrm{Nmmol} \mathrm{g}^{-}$ ${ }^{1}$ TVS, respectively at approx. $\log$ phase of $132 \mathrm{~h}$. Thereafter, $\mathrm{CH}_{4}$ production was observed in all the pretreatments at relatively lower rate until it reached to plateau at approx. $348 \mathrm{~h}$. Overall methane production rate for this set was in the range of $0.03-0.12 \mathrm{Nmmol} \mathrm{g}^{-1} \mathrm{TVS} \mathrm{h}^{-1}$ (Table 5.9). The reactors were terminated at $600 \mathrm{~h}$ assuming stable production. However, as appeared in Fig 5.5, if the reactors could let for further few days $\mathrm{CH}_{4}$ production might continue and there might be a higher value of $\mathrm{CH}_{4}$ in the first set of experiments documented in this text. Positive control (glucose) was also tested for methane production (Fig 5.5). Maximum methane 6.8 Nmmol was recorded in $288 \mathrm{~h}$ afterward its production decreased and reactor was terminated after $408 \mathrm{~h}$. As indicated in Fig 5.5, methane production rate was high enough that in $24 \mathrm{~h}$ of incubation methane production almost reached to its maximal point.

In the second set of experiments, I-HO, M-HO, N-HO, and O-HO were tested. The lag phase of $-35.73 \mathrm{~h}$ in $\mathrm{I}-\mathrm{HO}$ indicated an abrupt production of $\mathrm{CH}_{4}$ in this pretreatment while in other three pretreatments lag phase varied from 28.77 - $35.56 \mathrm{~h}$. In $108 \mathrm{~h}, \mathrm{CH}_{4}$ production reached to 5.9, 3.2, 3.06 and 4.21 Nmmol g ${ }^{-1}$ TVS (approx. log phase) for I-HO, M-HO, N-HO and O-HO, respectively. However, a rapid increase in $\mathrm{CH}_{4}$ was observed in $\mathrm{O}-\mathrm{HO}$ and $\mathrm{M}-\mathrm{HO}$ afterward. 
Methane production continued to increase at a lower rate until it reached to stable phase in $659 \mathrm{~h}$. The reactors were discarded after observing not a significant increase in $\mathrm{CH}_{4}$ at $779 \mathrm{~h}$. The overall methane production rate for this set of experiments was ranging from $0.03-0.04 \mathrm{Nmmol} \mathrm{g}^{-1} \mathrm{TVS}$ $\mathrm{h}^{-1}$.

In the third set of experiments, six pretreatments namely A-HO, G-HO, J-HO, K-HO, L$\mathrm{HO}$ and P-HO were set up for digestion. A lower lag phase was observed in pretreatment P-HO ($37.59 \mathrm{~h}$ ) followed by $\mathrm{G}-\mathrm{HO}(0.50 \mathrm{~h})$. While, for other pretreatments lag phase varied from 14.35 - $24.44 \mathrm{~h}$. After the lag phase, the instant increment in $\mathrm{CH}_{4}$ production was observed for A-HO, G-HO, J-HO, and K-HO. $\mathrm{CH}_{4}$ reached to 6.18, 4.51, 3.0 and $4.45 \mathrm{Nmmol} \mathrm{g}^{-1}$ TVS in $108 \mathrm{~h}$. On the other hand, a relatively slower increment was seen for L-HO and P-HO even though minimum lag phase was observed in P-HO. Relatively slower production of $\mathrm{CH}_{4}$ in $\mathrm{L}-\mathrm{HO}$ and $\mathrm{P}-\mathrm{HO}$ could be justified with the pretreatment conditions; L-HO was pretreated with lowest $\mathrm{H}_{2} \mathrm{O}_{2}(0.64 \% \mathrm{v} / \mathrm{v})$ at $180{ }^{\circ} \mathrm{C}$ and $12 \mathrm{~min}, \mathrm{P}-\mathrm{HO}$ was pretreated at lowest pretreatment temperature $146.4{ }^{\circ} \mathrm{C}$ for 12 min and $4 \%(\mathrm{v} / \mathrm{v}) \mathrm{H}_{2} \mathrm{O}_{2}$. These conditions might have not able to degrade sugarcane bagasse structure for the action of microbial enzymes thereby resulting in the slower activity of hydrolytic microbial consortia leading to a relatively slower increment in $\mathrm{CH}_{4}$.

As depicted in Fig 5.5, after a steep slope for $\mathrm{CH}_{4}$ around $108 \mathrm{~h}, \mathrm{CH}_{4}$ production continued to increase until it reached a maximum value. The reactors were discarded at $1200 \mathrm{~h}$ after verifying no $\mathrm{CH}_{4}$ increment in overall production. Methane production rate for this set of experiments was in the range of $0.01-0.05 \mathrm{Nmmol} \mathrm{g}^{-1} \mathrm{TVS} / \mathrm{h}$. Lowest $\mathrm{CH}_{4}$ production rate for $\mathrm{L}-\mathrm{HO}$ and $\mathrm{P}-\mathrm{HO}$ further strengthen the assumption that pretreatment conditions for these had barely impacted the sugarcane bagasse structure. 
A comparison of the current study with literature is not possible because of pretreatment conditions and feedstocks differences. Song et al. (Song et al., 2013) reported 88\% (288 mL .g $\mathrm{g}^{-1}$ VS, $12.8 \mathrm{mmol} . \mathrm{g}^{-1} \mathrm{VS}$ ) higher methane production in rice straw, however, the pretreatment conditions are different from the current study. The authors conducted pretreatment at room temperature $25 \pm 2{ }^{\circ} \mathrm{C}$ by impregnating rice straw into $\mathrm{H}_{2} \mathrm{O}_{2}(1-4 \%)$ for $1-7$ days.

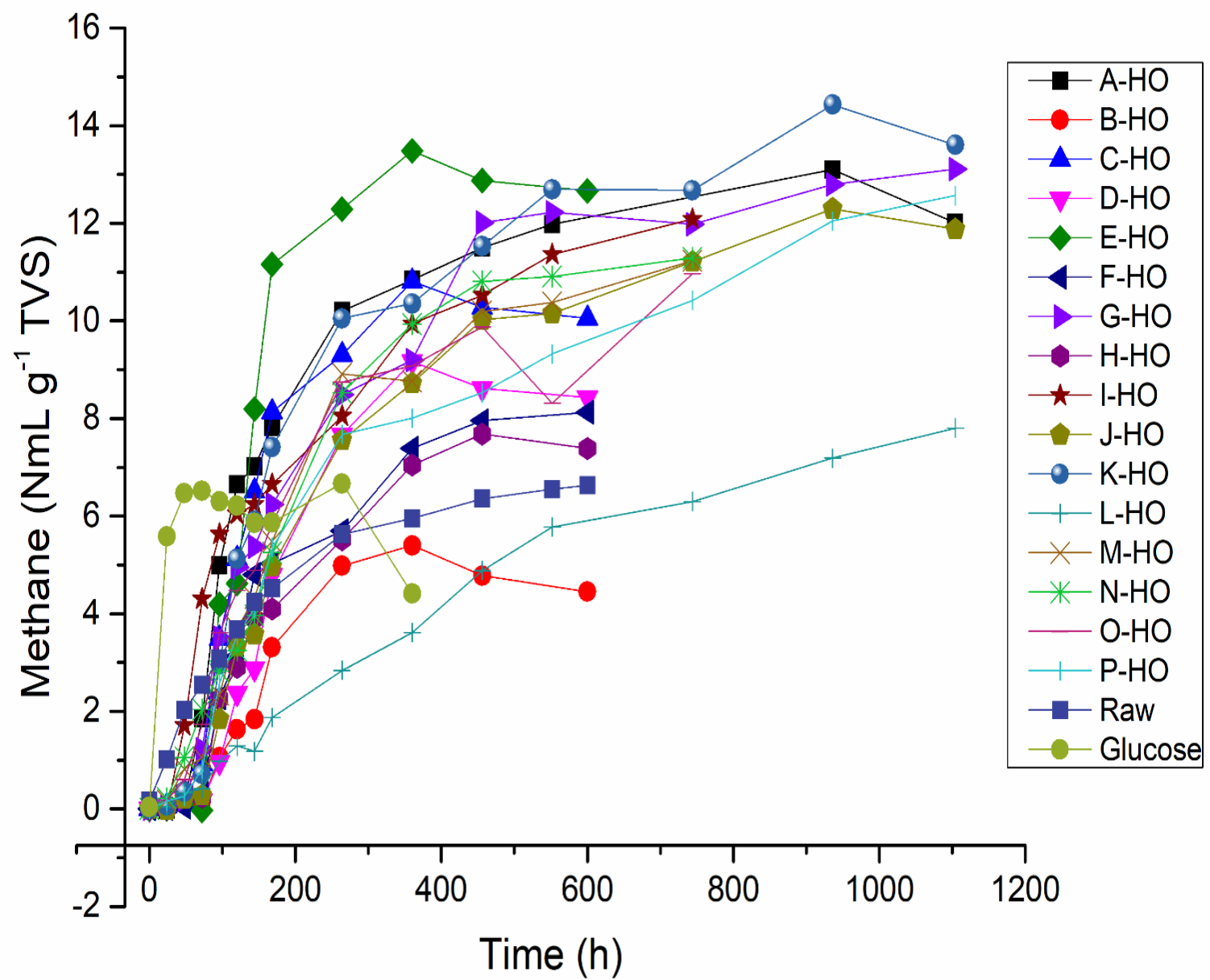

Figure 5.5 - Time-course profile of cumulative methane production for solid fraction of $\mathrm{H}_{2} \mathrm{O}_{2}$ impregnated hydrothermal pretreatment

In another study, Michalsk and Ledakowiz (Michalsk and Ledakowicz, 2014) reported better methane production at $5 \% \mathrm{H}_{2} \mathrm{O}_{2}$ for $24 \mathrm{~h}$ impregnation at $25{ }^{\circ} \mathrm{C}$. Rabelo et al (Rabelo et al., 2011) conducted alkaline hydrogen peroxide pretreatment of sugarcane bagasse at $4-15 \%$ DM with $7.36 \% \mathrm{H}_{2} \mathrm{O}_{2}$ at $25{ }^{\circ} \mathrm{C}$ for $1 \mathrm{~h}$ under $150 \mathrm{rpm}$ and reported a production of $72.1 \mathrm{~L} \mathrm{CH}_{4}$ per kg of bagasse. Song et al (Song et al., 2012) conducted hydrogen peroxide impregnation study on rice straw for 7 days at $4 \%$ and $3 \% \mathrm{H}_{2} \mathrm{O}_{2}$ under room temperature conditions $\left(25^{\circ} \mathrm{C}\right)$ and reported 327.5 and $319.7 \mathrm{~mL}$ biogas per gram of VS. Anna et al (Anna et al., 2010) conducted explosive 
pretreatment on paper tube residuals at $220{ }^{\circ} \mathrm{C}$ for 10 min with the aid of $2 \% \mathrm{NaOH}$ and $2 \% \mathrm{H}_{2} \mathrm{O}_{2}$ and reported $493 \mathrm{Nml} \mathrm{g}^{-1} \mathrm{VS}$ (22.0 Nmmol g${ }^{-1} \mathrm{VS}$ ) methane, which was 107\% higher than untreated residuals. The current study revealed that higher concentration of $\mathrm{H}_{2} \mathrm{O}_{2}$ employed resulted in higher methane production from the pretreated solid fraction owing to the higher amount of contained glucan and lignin removal. Pretreatment $11\left(180{ }^{\circ} \mathrm{C}, 12 \mathrm{~min}, 7.36(\% \mathrm{v} / \mathrm{v})\right.$ $\mathrm{H}_{2} \mathrm{O}_{2}$ ) resulted in maximum methane production of $14.43 \mathrm{Nmmol} \mathrm{g}^{-1}$ TVS.

Microbial acclimatization to the reactor conditions where directed to methane production also caused a simultaneous increase in COD due to the production of organic acids and sugar monomers by the action of fermentative bacteria. As shown in Fig 5.6 COD values for the first set of experiments in the start of digestion process was in the range of $121 \pm 10.61-194.5 \pm 10 \mathrm{mg} . \mathrm{L}^{-}$ ${ }^{1}$ depending upon pretreatment conditions.

Inoculum sludge could also influence initial COD value but since the same volume of inoculum was supplemented on total volatile solids $(2$ g.kg-1) basis, its contribution to COD assumed to be constant in all the pretreatments. A 2-fold increase in COD value was observed in $132 \mathrm{~h}$ ranging from $215.38 \pm 7.06$ to $329.5 \pm 21.92 \mathrm{mg} \mathrm{L}^{-1}$. B-HO presented the lowest increase in $\mathrm{COD}$ in $132 \mathrm{~h}$ from $194.5 \pm 10.61$ to $200.38 \pm 7.06 \mathrm{mg} \mathrm{L}^{-1}$. This low increase justifies the presence of higher lignin that inhibited bacterial cellulase from degrading the polymeric substrate.

COD was in the range of $122 \pm 14.14$ to $248.15 \pm 18.17 \mathrm{mg} \mathrm{L}^{-1}$ at reactor termination. Initial COD for the second set of experiments (Fig 5.6) was in the range of $129.5 \pm 24.75$ to 236.50 $\pm 30.41 \mathrm{mg} \mathrm{L}^{-1}$, which subsequently increased to $302.0 \pm 26.57$ to $344.0 \pm 29.70 \mathrm{mg} . \mathrm{L}^{-1}$ at approx. $\log$ phase in $108 \mathrm{~h}$. High variation in initial COD was due to pretreatment conditions. Highest initial COD was for O-HO, which was conducted at $213.6^{\circ} \mathrm{C}$, while other pretreatments in this set were realized at $180^{\circ} \mathrm{C}$.

Final COD for the second set of experiments was in the range of $238.50 \pm 31.82$ to 273.50 $\pm 23.33 \mathrm{mg} \mathrm{L}^{-1}$. COD values for the third set of experiments (Fig 5.6) increased to $208.50 \pm 10.68$ to $312.60 \pm 18.10 \mathrm{mg} \mathrm{L}^{-1}$ in $108 \mathrm{~h}$ and $228 \mathrm{~h}$ (L-HO and P-HO) from initial COD, which was in the range of $189.86 \pm 6.43$ to $240.48 \pm 21.21 \mathrm{mg} \mathrm{L}^{-1}$.

An increase in COD was noted with an increment in fermentation time due to the production of organic acids. A maximum increase in COD was verified in pretreatment $\mathrm{K}-\mathrm{HO}$ up 
to $396.75 \mathrm{mg} \mathrm{L}^{-1}$, however, subsequently reduced to $186.85 \mathrm{mg} \mathrm{L}^{-1}$ at the end of digestion indicating consumption of organic acids produced during the process. However, minimal increase in COD was observed in pretreatment run 2 indicating minimal activity of fermenting bacteria owing to higher lignin content resulting in lower organic acids production and ultimately lower methane production.

Total carbohydrates (Fig 5.7) at the start of digestion experiments were in the range of $16.83 \pm 4.4$ to $38.55 \pm 3.83 \mathrm{mg} \mathrm{L}^{-1}$ depending upon pretreatment conditions applied and carbohydrates left in solid fraction after separation from the liquid hydrolysate. A subsequent decrease in the total carbohydrate content $\left(8.21 \pm 1.64-30.59 \pm 0.50 \mathrm{mg} \mathrm{L}^{-1}\right)$ was observed during the digestion process that is normal due to the action of acetogenic bacteria utilizing available carbohydrates for the production of organic acids. The minimal decrease was observed in B-HO from 37.25 to $30.59 \mathrm{mg} \mathrm{L}^{-1}$ that justify the higher klason lignin in solid fraction.

On the other hand, an increase in total carbohydrate content was noted for three pretreatments; C-HO (27.63 - $\left.33.55 \mathrm{mg} \mathrm{L}^{-1}\right)$, E-HO (24.7 - $\left.27.69 \mathrm{mg} \mathrm{L}^{-1}\right)$, and K-HO (24.91 $\left.28.39 \mathrm{mg} \mathrm{L}^{-1}\right)$. An increase in total carbohydrate content in these pretreatments could be justified with the argument that since these were pretreated with higher $\mathrm{H}_{2} \mathrm{O}_{2}$ and resulted in efficient lignin removal giving an opportunity for hydrolytic bacteria to act rapidly. The lowest total carbohydrate consumption (45.10\%) was observed in B-HO (37.25 - $\left.20.45 \mathrm{mg} \mathrm{L}^{-1}\right)$. On the other hand, approx. $100 \%$ consumption was seen in G-HO and J-HO where total carbohydrate was below the detection limit. Lowest carbohydrate consumption in B-HO seems obvious due to methanogenic inhibition owing to higher klason lignin content.

$\mathrm{pH}$ decrease is a direct indication of the release of organic acids, it decreased from neutrality to a value in the range of 6.37 to 6.67 for different pretreatment conditions at $108 \mathrm{~h}$, at $132 \mathrm{~h}$, and at $228 \mathrm{~h}$ (Fig 5.8). These points are at around approx. log phase of methane curve for respective pretreatments. $\mathrm{pH}$ remained lower for the entire digestion period. Final $\mathrm{pH}$ for reactors was in the range of 6.15 to 6.61 (Fig 5.8). The optimal range for methanogenesis is reported to be in the range of $6.8-7.5$ (Alrawi et al., 2011). 


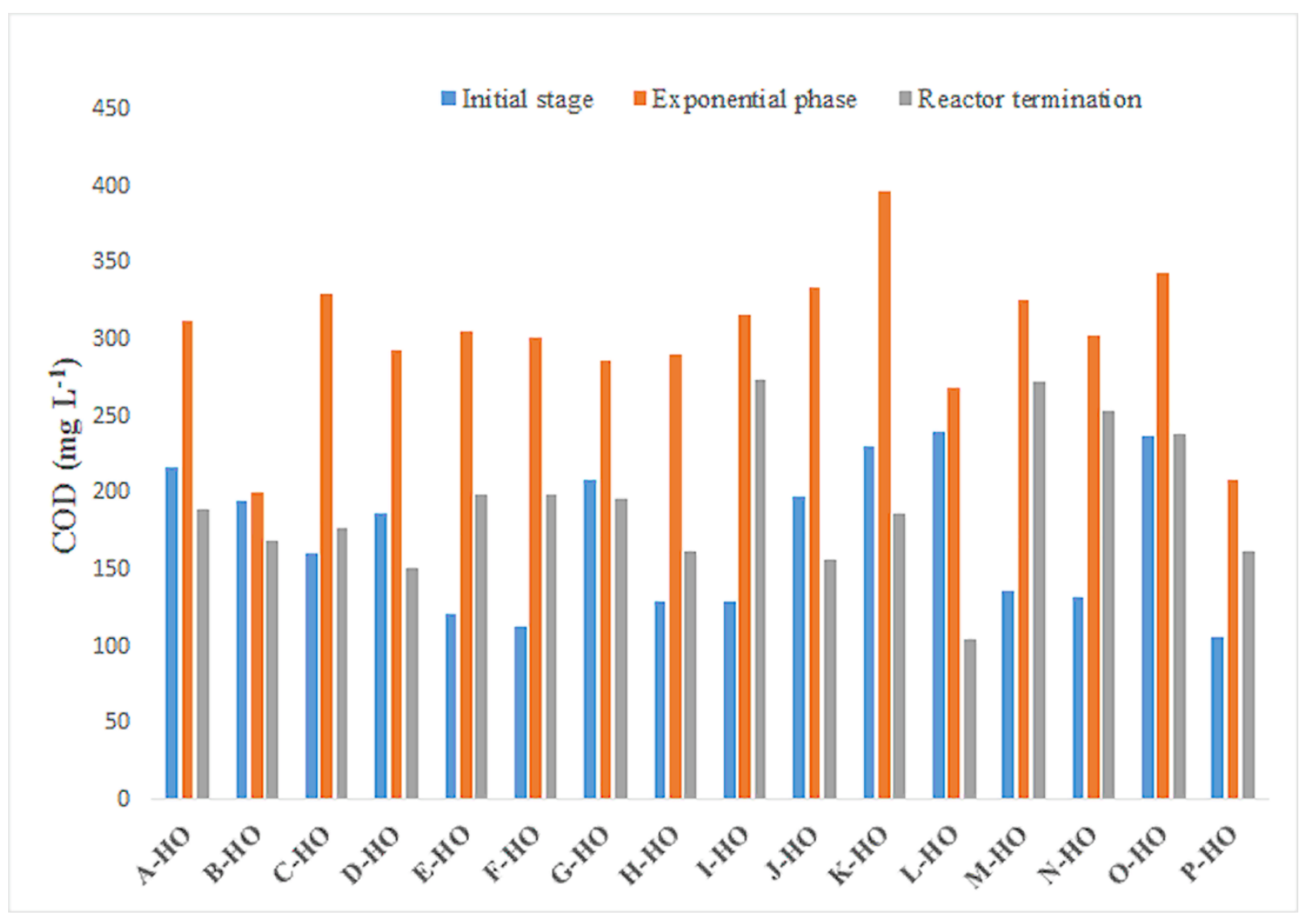

Figure 5.6 - COD variation during digestion experiments

As depicted in Fig 5.9, acetic acid was the most abundant organic acid encountered at the initiation of batch digestion experiments in different pretreatment reactors ranging from 57.2 to $145.6 \mathrm{mg} \mathrm{L}^{-1}$ followed by iso-butyric acid in the range of 8.39 to $105.6 \mathrm{mg} \mathrm{L}^{-1}$. Propionic acid was only observed in pretreatment E-HO $\left(16.27 \mathrm{mg} \mathrm{L}^{-1}\right)$. Butyric, valeric, isovaleric, and formic acid were also found in low quantities ranging from $10.3-51.3,3.0-15.3,4.2-21.8$, and $2.10-10.0$ $\mathrm{mg} \mathrm{L}^{-1}$, respectively. The relatively higher concentration of acetic acid, in addition to other factors, might have helped in improved acclimatization of microbial biomass as indicated by lower lag phase $\left(14.35 \mathrm{~h}\right.$ ) for pretreatment run K-OH containing $145.26 \mathrm{mg} \mathrm{L}^{-1}$ acetic acid. The polymeric carbohydrates contained in lignocellulosic biomass are degraded into glucose then to pyruvate, which further converted to lactic acid or two molecules of acetyl-CoA and either formic acid or $\mathrm{CO}_{2}$. With minor differences, lactate, acetate, ethanol, formate or $\mathrm{CO}_{2}$ production from pyruvate is similar in Gram-positive and Gram-negative bacterial strains (Nielsen et al., 2011)

Cumulative VFAs production at the approx. $\log$ phase $(108,132$ and $228 \mathrm{~h})$ for different pretreatments was in the range of $110.05-228.04 \mathrm{mg} \mathrm{L}^{-1}$. Lower production of organic acids at 
approx. log phase could be due to efficient utilization of organic acids, since bagasse is a heterogeneous material and is not readily available for the microbial enzymatic action of hydrolytic bacteria for the release of sugars to be consumed by fermentative bacteria producing organic acids.

It means methanogenic archaea are scavenging organic acids at a rate much higher than are being produced by the acidogenic bacteria. Zhang et al (Zhang et al., 2011) reported similar situation for total VFAs production at approx. log phase during digestion of cassava residue. O'Sullivan and Burrel (O'Sullivan and Burrell, 2007) reported that lignocellulosics composition and degree of lignification have a direct impact on the release and type of organic acids detected in an acidification system.

Type and concentration of organic acids showed significant change at log phase comparing with initiation phase. The concentration of formic acid reduced substantially at log phase as it is directly taken up by methanogens besides acetic acid, methanol, methylamines, carbon dioxide, methyl-sulfide and $\mathrm{H}_{2}$ (Li et al., 2016). Efficient utilization of acetic acid is reflected by the higher acetotrophic methanogens community in comparison to lower hydrogenotrophic methanogens.

Acids produced in the digestion process are converted to the ultimate substrate for methanogens; acetate, $\mathrm{H}_{2}, \mathrm{CO}_{2}$ and other substrates by various degradation pathways. Isomerization of butyric acid into normal and iso- form of butyric acid is reported into anaerobic digestion where propionic acid is an intermediate product (Lin and Hu, 1993). Since the samples for VFAs were taken within $200 \mathrm{~h}$ of digestion, lower VFAs concentrations (Fig 5.9 )were encountered; $65.72-159.24 \mathrm{mg} \mathrm{L}^{-1}$ acetic acid.

Lower propionic acid concentrations at reactor termination $\left(2.15\right.$ to $\left.15.74 \mathrm{mg} \mathrm{L}^{-1}\right)$ is an indication of stable digestion process as the accumulation of propionic acid is reported to be a sign of process disturbance (Bjornsson et al., 2000; Murto et al., 2004). Propionic acid concentration about 1-2 $\mathrm{g} \mathrm{L}^{-1}$ is considered toxic to digestion process (Wijekoon et al., 2011), while, Wang et al (Wang et al., 2009) reported that $900 \mathrm{mg} \mathrm{L}^{-1}$ propionic acid is enough to inhibit methanogens. The low concentration of propionic acid accumulated during the initial phase of fermentation will benefit subsequent anaerobic digestion because propionate-assimilating microorganisms are among the slowest growing organisms due to low free-energy gain from the conversion of propionate to acetate. Furthermore, their complicated syntrophic relation to hydrogen-utilizing methanogens (Zhang et al., 2011). 
Butyric acid was observed in the range of 2.96 to $\left.34.97 \mathrm{mg} \mathrm{L}^{-1}\right)$. While, ethanol was only observed at the end of digestion experiments in low concentrations $3.02-9.8 \mathrm{mg} \mathrm{L}^{-1}$ ) in some reactors. Relatively higher acetic acid $\left(13.53-103.30 \mathrm{mg} \mathrm{L}^{-1}\right)$ at the end of digestion is an indication that organic acids produced during the digestion process were converted to the principal substrate for methanogenesis. Wang et al (Wang et al., 2009) reported that even higher concentrations of acetic acid $\left(2400 \mathrm{mg} \mathrm{L}^{-1}\right)$ and butyric acid $\left(1800 \mathrm{mg} \mathrm{L}^{-1}\right)$ had not exerted inhibition effect on methanogens.

Relatively higher concentrations of isovaleric acid were found at the end of digestion experiments in the range of 7.5 to $15.4 \mathrm{mg} \mathrm{L}^{-1}$. Hill and Bolte (Hill and Bolte, 1989) reported that isovaleric acid more than $15 \mathrm{mg} \mathrm{L}^{-1}$ is an indication of a problem in the system. However, opinions vary in the literature regarding VFAs concentration for better digestion performance and inhibition indicators. Angelidaki et al (Angelidaki et al., 1993) reported that different systems have their own levels of VFAs being considered 'normal', furthermore, conditions considered abnormal in one system might not be the same for the other system.

A higher production of acetic acid $\left(159.24 \mathrm{mg} \mathrm{L}^{-1}\right)$ at approx. $\log$ phase was recorded in pretreatment run 3. However, it reached to methane value of $10.81 \mathrm{Nmmol} \mathrm{g}^{-1}$ TVS. Methane production rate for this pretreatment was a bit higher $\left(0.08 \mathrm{Nmmol} \mathrm{g}^{-1} \mathrm{TVS} \mathrm{h}^{-1}\right)$ in comparison to pretreatment 11 with a production rate of $0.04 \mathrm{Nmmol} \mathrm{g}^{-1} \mathrm{TVS} \mathrm{h}^{-1}$ even though acetic acid for this pretreatment at $\log$ phase was $110.4 \mathrm{mg} \mathrm{L}^{-1}$. 


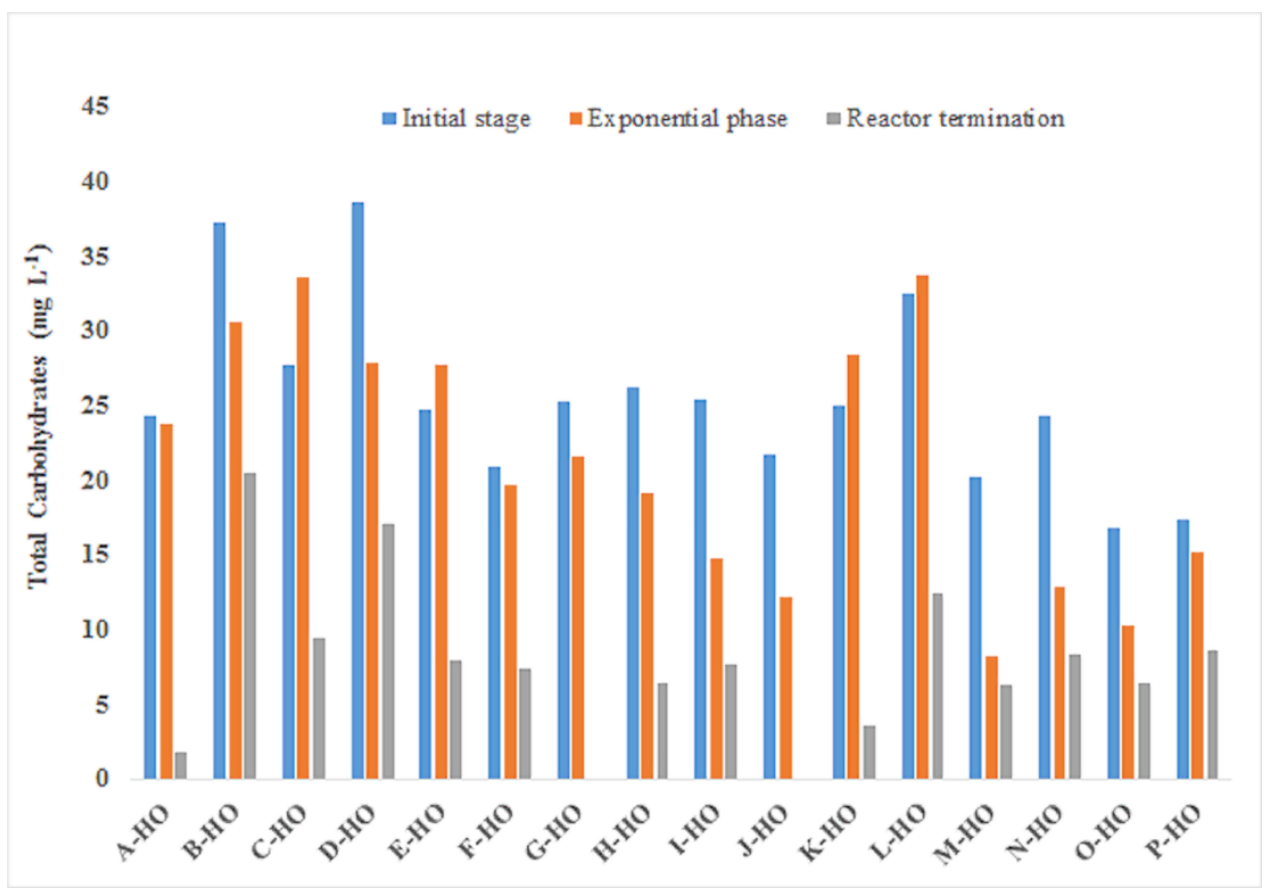

Figure 5.7 - Total carbohydrates consumption during digestion experiments

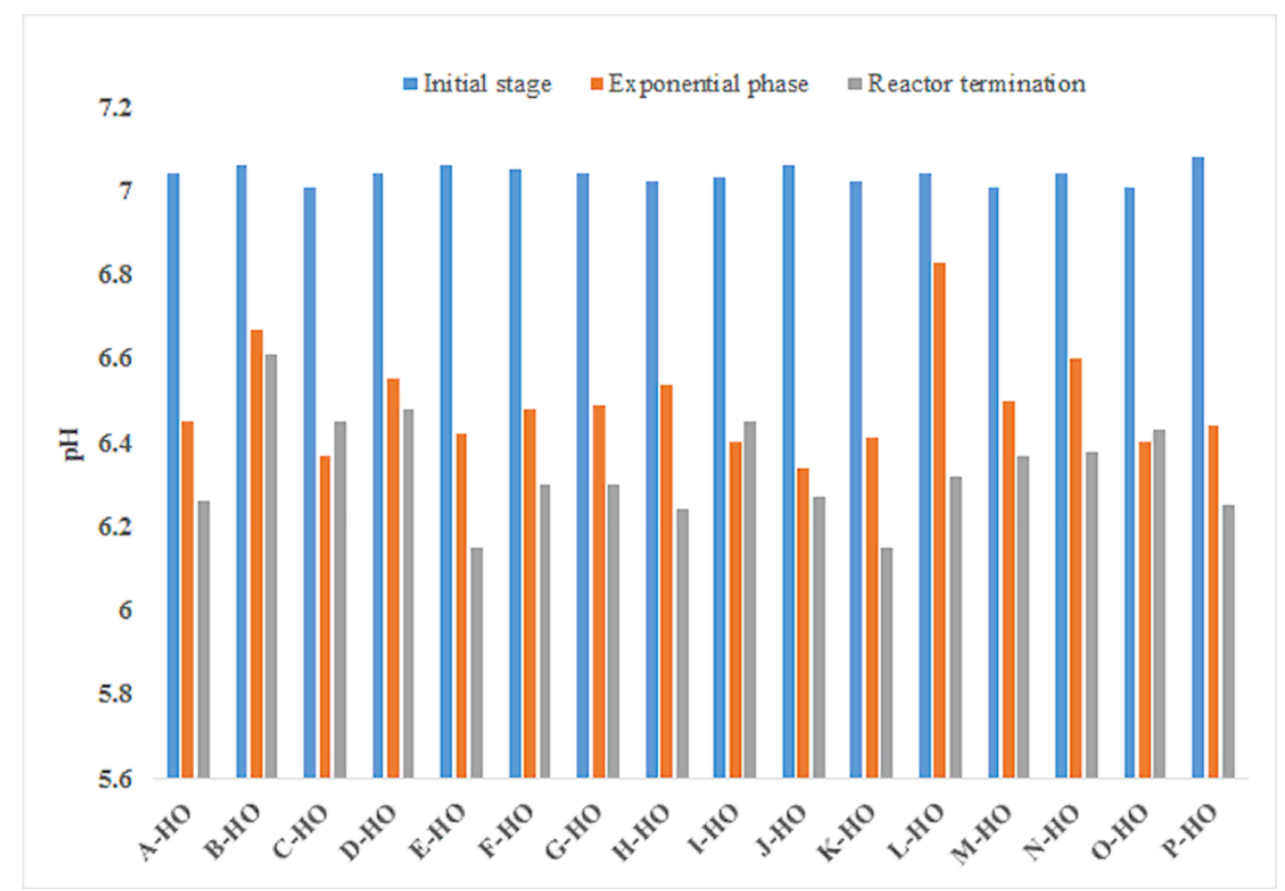

Figure 5.8 - $\mathrm{pH}$ variation in digestion experiments 


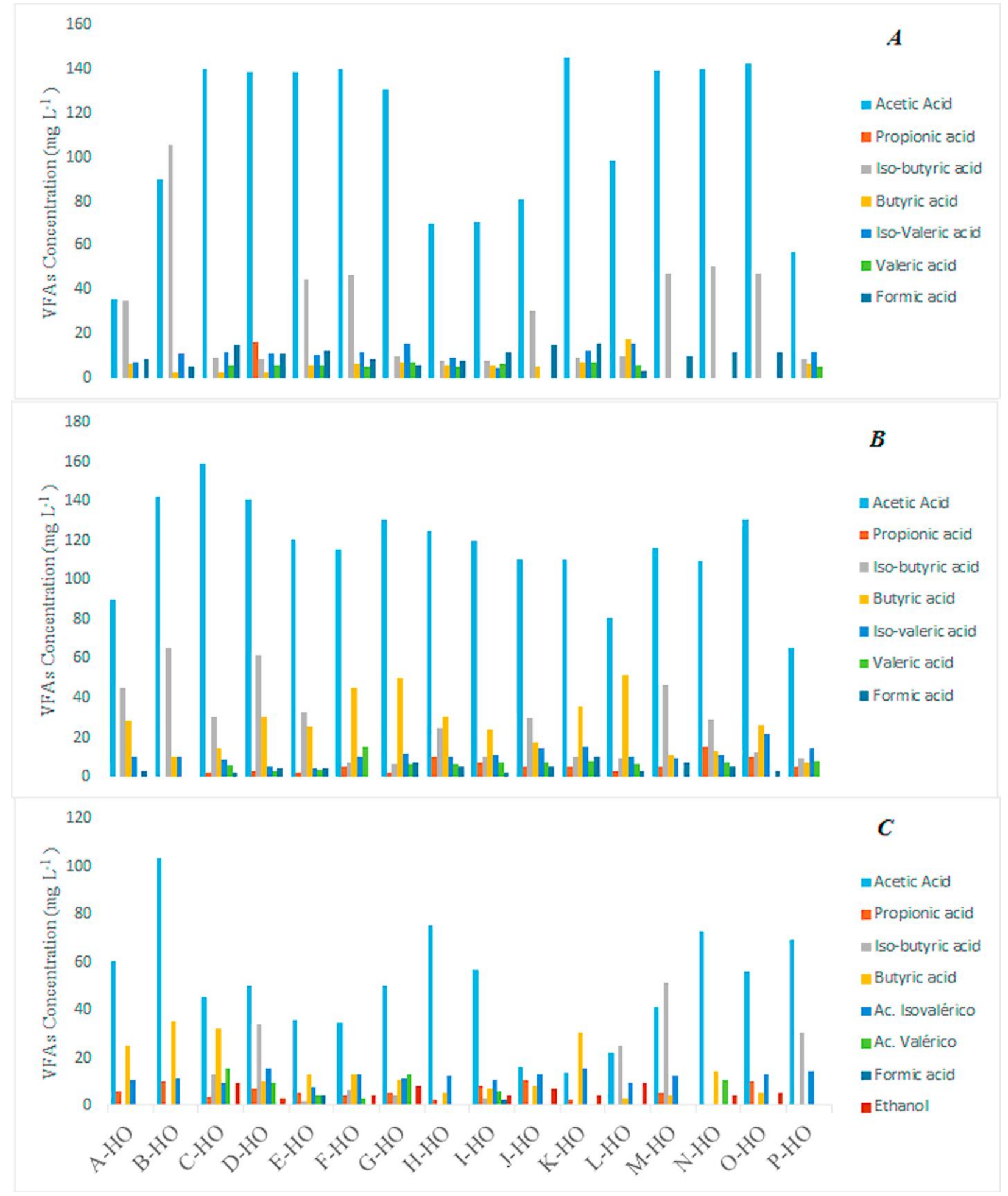

Figure 5.9 - Organic acids at three selected position on methane production curve; A (Initial stage of reactor), B (approx. exponential phase), C (reactor termination) 


\subsection{Statistical methane optimization with $\mathrm{H}_{2} \mathrm{O}_{2}$ assisted HT pretreatment}

The proposed influential parameters; temperature $\left({ }^{\circ} \mathrm{C}\right)$, time $(\mathrm{min})$, and $\mathrm{H}_{2} \mathrm{O}_{2}(\% \mathrm{v} / \mathrm{v})$ were explored with response surface methodology for individual impact and their interaction on $\mathrm{CH}_{4}$ yield (Nmmol g ${ }^{-1}$ TVS) from pretreated sugarcane bagasse in comparison to raw bagasse (Table 5.9). Quadratic regression analysis was conducted on the experimental data to explain $\mathrm{CH}_{4}$ production. Second-order polynomial equation was derived for the parameters is presented in Equation 5.6

$\mathrm{CH}_{4}$ Yield $=12.34-0.48 X_{1}-0.01 X_{2}+2.28 X_{3}-0.46 X_{1}{ }^{2}-0.55 X_{2}{ }^{2}-0.67 X_{3}{ }^{2}-$

$0.26 X_{1} X_{2}-0.21 X_{1} X_{3}+0.73 X_{2} X_{3}$

Where $X_{1}, X_{2}$, and $X_{3}$ are coded values for temperature $\left({ }^{\circ} \mathrm{C}\right)$, time (min), and $\mathrm{H}_{2} \mathrm{O}_{2}(\% \mathrm{v} / \mathrm{v})$, respectively.

The statistical significance of the model was found by F-test (ANOVA) (Table 5.8). Correlation coefficient $\left(\mathrm{R}^{2}\right)$ value was found to be 0.8903 . The $\mathrm{R}$-square value indicated a measure of variability in the observed response values. It implied that the model could explain $89.03 \%$ of the sample variation and the model cannot explain only $10.97 \%$. For a good statistical model $\mathrm{R}^{2}$ value should be in the range of $0.75-1.0$ (Niladevi et al., 2009).

The magnitude and sign are important in the polynomial equation to explain the importance of variables and their interaction. The model Equation indicated that linear model term of time $\left(X_{2}\right)$ besides quadratic model term of temperature $\left(X_{1}^{2}\right)$ were insignificant $(\mathrm{p}>0.05)$ along with the interaction of $\left(X_{1} X_{2}\right)$ and $\left(X_{1} X_{3}\right)$. While linear model terms of temperature $(X 1), \mathrm{H}_{2} \mathrm{O}_{2}$ concentration $\left(X_{3}\right)$ and quadratic model terms of time $\left(X_{2}^{2}\right)$ and $\mathrm{H}_{2} \mathrm{O}_{2}$ concentration $\left(X_{3}^{2}\right)$ and interaction of $X_{2} X_{3}$ showed significant impact $(\mathrm{P}<0.05)$ on $\mathrm{CH}_{4}$ yield. The model coefficient of linear model term $X_{3}$ (2.28) and interaction of $X_{2} X_{3}(0.73)$ exerted positive effect while model coefficients of quadratic model terms $X_{2}^{2}$ and $X_{3}^{2}$ exerted a negative impact on the model. The model coefficients explained that $\mathrm{H}_{2} \mathrm{O}_{2}$ concentration has higher magnitude impact (2.28) in comparison to the interaction of $\mathrm{H}_{2} \mathrm{O}_{2}$ concentration $\left(X_{3}\right)$ and time of pretreatment $\left(X_{2}\right)(0.76)$. 
Table 5.8 - Regression analysis for the experimental methane production for quadratic response surface model fitting (ANOVA)

\begin{tabular}{|c|c|c|c|c|c|}
\hline Source & Sum of square & Degree of freedom & Mean Square & $F$ value & P-value (prob. $>F)$ \\
\hline$X_{1}(T)^{\alpha}$ & 3.15 & 1.00 & 3.15 & 194.62 & $0.0456^{*}$ \\
\hline$X_{1}^{2}$ & 1.95 & 1.00 & 1.95 & 120.48 & 0.0578 \\
\hline$X_{2}(t)^{\beta}$ & 0.00 & 1.00 & 0.00 & 0.13 & 0.7775 \\
\hline$X_{2}^{2}$ & 2.84 & 1.00 & 2.84 & 175.44 & $0.0480 *$ \\
\hline $\begin{array}{c}X_{3} \\
\left(\mathrm{H}_{2} \mathrm{O}_{2} \text { conc. }\right)^{¥}\end{array}$ & 70.91 & 1.00 & 70.91 & 4376.88 & $0.0096^{*}$ \\
\hline$X_{3}^{2}$ & 4.21 & 1.00 & 4.21 & 259.84 & $0.0394 *$ \\
\hline$X_{1} X_{2}$ & 0.54 & 1.00 & 0.54 & 33.42 & 0.1090 \\
\hline$X_{1} X_{3}$ & 0.34 & 1.00 & 0.34 & 20.83 & 0.1373 \\
\hline$X_{2} X_{3}$ & 4.22 & 1.00 & 4.22 & 260.35 & $0.0394 *$ \\
\hline Lack of Fit & 10.37 & 5.00 & 2.07 & 127.97 & 0.0670 \\
\hline Pure Error & 0.02 & 1.00 & 0.02 & & \\
\hline Total SS & 94.68 & 15 & & & \\
\hline
\end{tabular}

R-square $=0.8903$, Adjusted R-square $=0.7258$, MS pure error $=0.0162, *$ represents significant factors, ${ }^{\alpha}(\mathrm{T})$ represents Temperature, ${ }^{\beta}(\mathrm{t})$ represents time, and ${ }^{¥}$ (Conc.) represents $\mathrm{H}_{2} \mathrm{O}_{2}$ concentration

The interaction between temperature $\left({ }^{\circ} \mathrm{C}\right)$ and time $(\mathrm{min})$ on the methane yield $(\mathrm{Nmmol} \mathrm{g}-$ ${ }^{1}$ TVS) is presented in Fig 5.10. It can be seen from the curvature of the surface, an increase in time and temperature up to $180{ }^{\circ} \mathrm{C}$ resulted in a maximum response. It might be due to the fact that higher pretreatment temperature for longer exposure time results in more dissolution of lignin into liquid hydrolysate resulting from the higher availability of carbohydrates in the solid biomass. Higher temperature beyond $180{ }^{\circ} \mathrm{C}$ results into degradation products of sugars; furfural, 5-HMF that have inhibitory effects on methanogenesis

The interaction between hydrogen peroxide and temperature showed that concentration of $\mathrm{H}_{2} \mathrm{O}_{2}$ had a higher impact on the methane yield (Fig 5.11). Methane yield increased with increasing the $\mathrm{H}_{2} \mathrm{O}_{2}$ concentration in the studied range. It seems obvious as being an oxidizing agent $\mathrm{H}_{2} \mathrm{O}_{2}$ has a large influence on lignin dissolution. Lignin content has a negative correlation with the 
methane yield (Kobayashi et al., 2004; Ahring et al., 2015). Fig 5.11 demonstrated that maximum response could be obtained with higher $\mathrm{H}_{2} \mathrm{O}_{2}$ applied even at a lower temperature.

The interaction between time (min) and hydrogen peroxide ( $\% \mathrm{v} / \mathrm{v})$ on the methane yield is shown in Fig 5.12. The curvature of the surface depicted that an increase in pretreatment time coupled with an increase in $\mathrm{H}_{2} \mathrm{O}_{2}$ concentration resulted in a maximum response. Longer the contact time of lignocellulosic biomass with $\mathrm{H}_{2} \mathrm{O}_{2}$ helped in an increase in delignification and consequently higher methane yield.

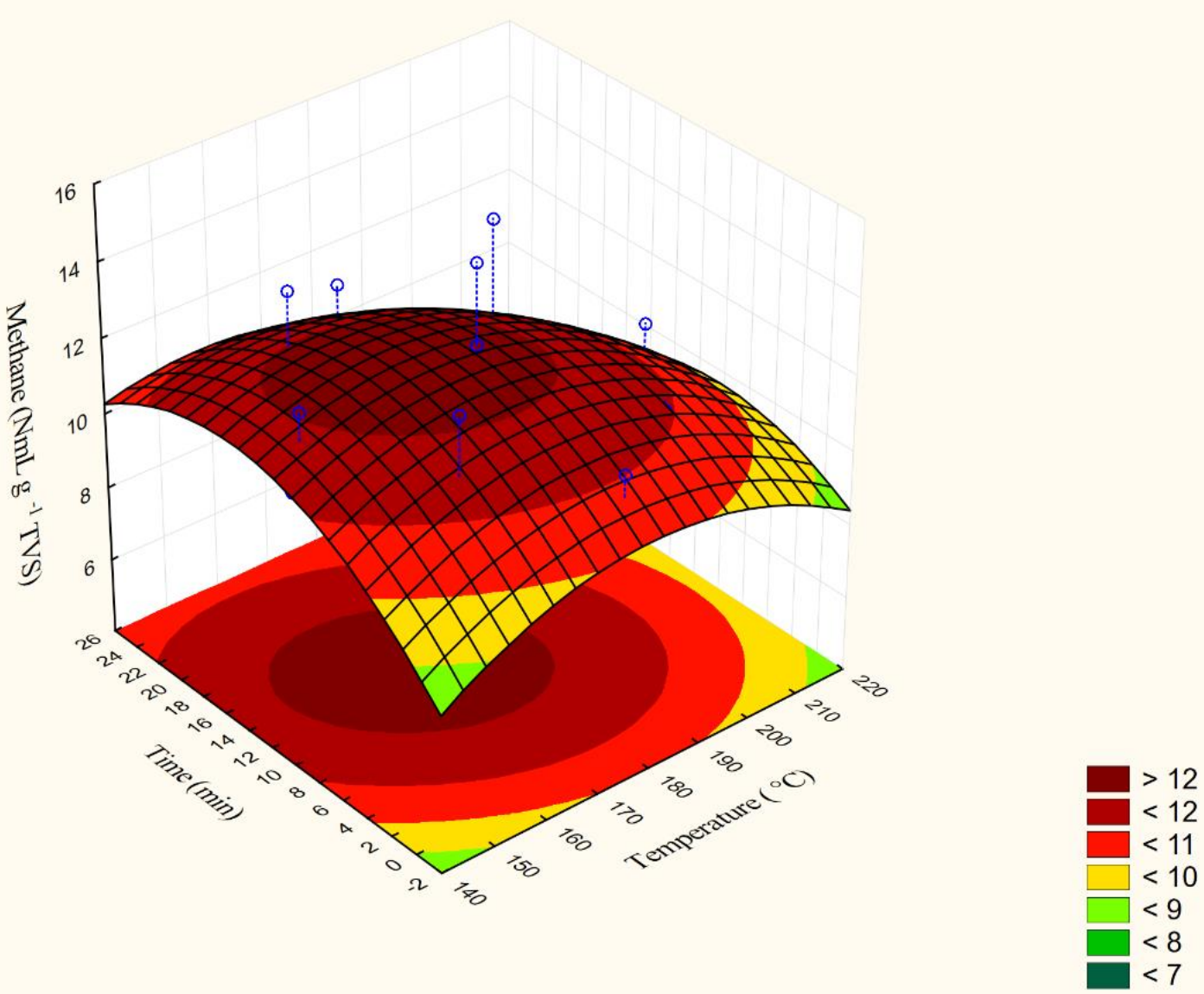

Figure 5.10 - Interaction between temperature $\left({ }^{\circ} \mathrm{C}\right)$ and time $(\mathrm{min})$ on the methane concentration 


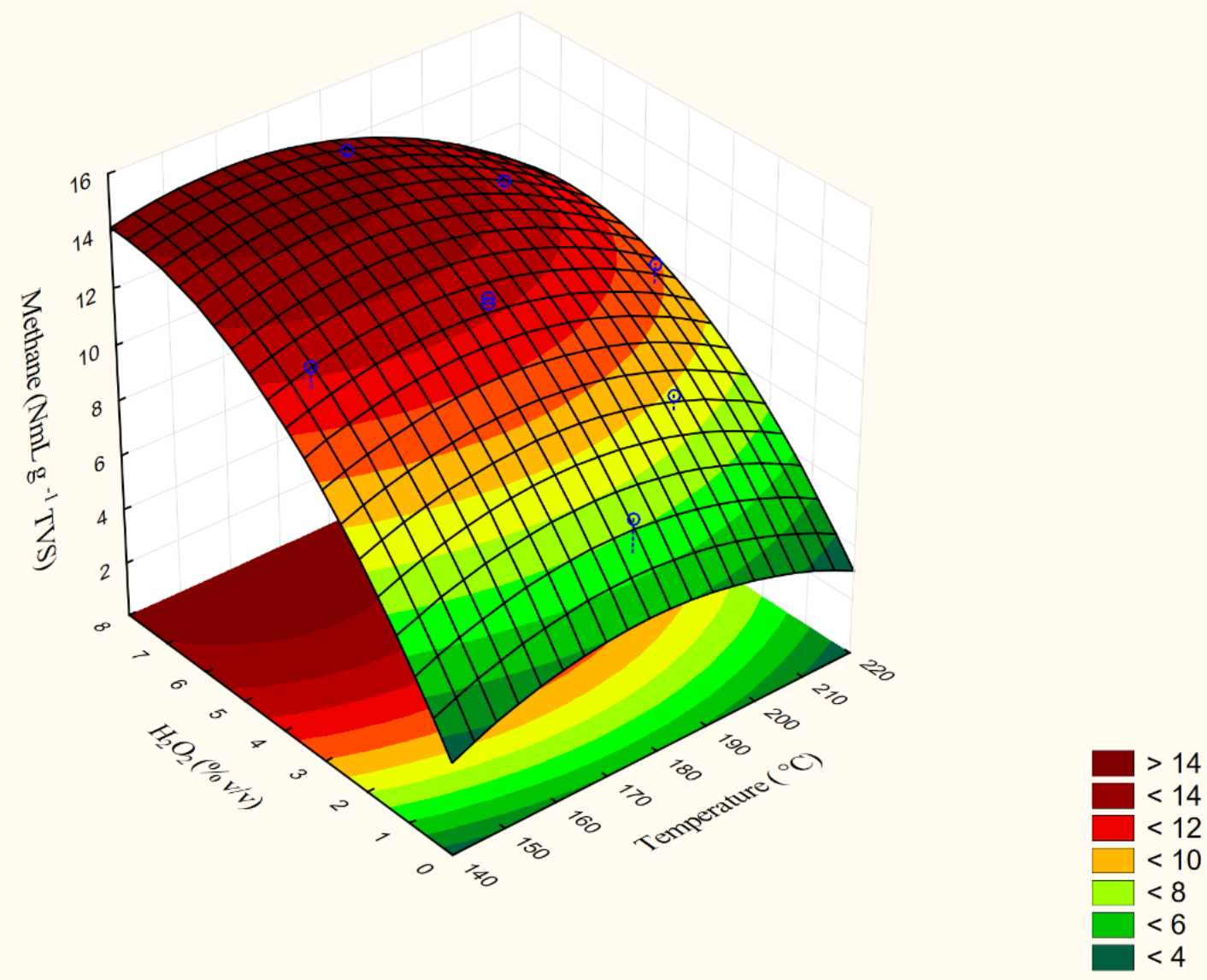

Figure 5.11 - Interaction between temperature $\left({ }^{\circ} \mathrm{C}\right)$ and hydrogen peroxide $(\% \mathrm{v} / \mathrm{v})$ on methane concentration

\subsection{Kinetics analysis of methane production}

Table 5.9 shows the experimental methane (Nmmol g ${ }^{-1}$ TVS), percent variation in methane over raw bagasse, and kinetics data (predicted methane volume, $\mathrm{CH}_{4}$ production rate, lag phase and the goodness of fit; $\mathrm{R}^{2}$ ) obtained from experimental methane data of modified Gompertz equation for $\mathrm{H}_{2} \mathrm{O}_{2}$ impregnated and hydrothermally pretreated sugarcane bagasse. The lowest value obtained for percent variation was observed for pretreatment B-HO (-15.26\%) while the highest was observed for pretreatment K-HO (118.16\%). 


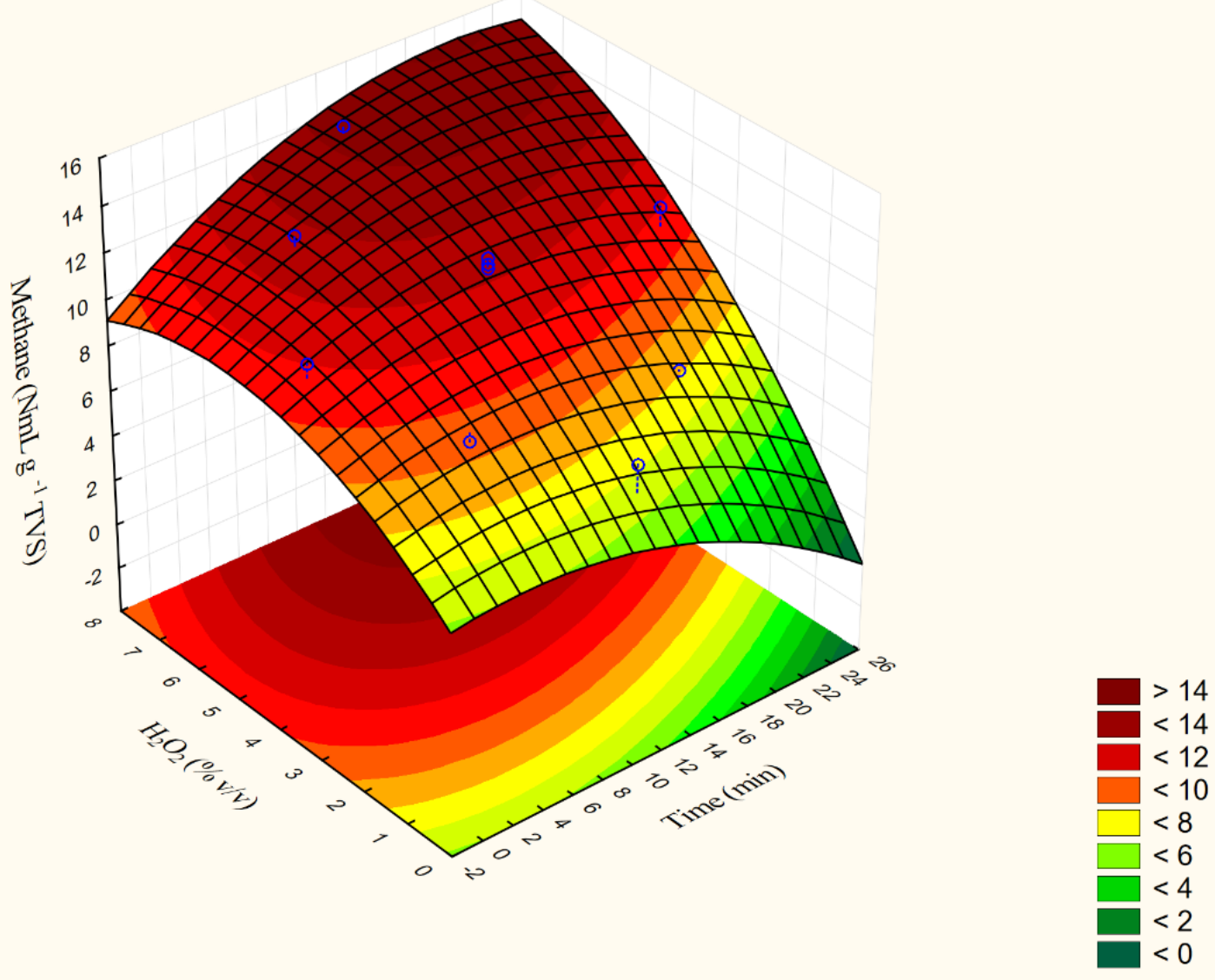

Figure 5.12 - Interaction between hydrogen peroxide (\% v/v) and time (min) on the methane yield

The rate of methane production was not much affected by the pretreatment parameters. $X c$ was limited in the range of 0.02 to $0.12 \mathrm{Nmmol} \mathrm{g}^{-1} \mathrm{TVS} \mathrm{h}^{-1}$. The highest lag phase of $82 \mathrm{~h}$ was observed for pretreatment D-HO $\left(200{ }^{\circ} \mathrm{C}, 5 \mathrm{~min}, 2 \% \mathrm{H}_{2} \mathrm{O}_{2}\right)$, while abrupt methane production was observed for pretreatment I-HO $\left(180{ }^{\circ} \mathrm{C}, 12 \mathrm{~min}, 4 \% \mathrm{H}_{2} \mathrm{O}_{2}\right)$ as evident from the lowest lag phase of $0 \mathrm{~h}$. It indicated that methane production started at once. Similar was noted $(X c 0 h)$ for pretreatment P-HO $\left(146.4{ }^{\circ} \mathrm{C}, 12 \mathrm{~min}, 4 \% \mathrm{H}_{2} \mathrm{O}_{2}\right)$. The goodness of fit $\left(\mathrm{R}^{2}\right)$ values was observed in the range of $0.94-1.00$ for the 16 pretreatments. Graphs with fitted curves are presented in Appendix. 
Table 5.9 - Kinetic parameters of methane production from $\mathrm{H}_{2} \mathrm{O}_{2}$ pretreated sugarcane bagasse

\begin{tabular}{|c|c|c|c|c|c|c|}
\hline \multirow[t]{2}{*}{ Designation } & \multirow{2}{*}{$\begin{array}{c}\text { Experimental } \\
\text { Methane } \\
\text { (Nmmol g-1 } \\
\text { TVS) }\end{array}$} & \multirow{2}{*}{$\begin{array}{c}\% \\
\text { variation } \\
\text { over } \\
\text { SCB } \\
\end{array}$} & \multicolumn{4}{|c|}{ Modified Gompertz Kinetic Data } \\
\hline & & & $\begin{array}{c}A^{¥} \\
\left(\mathrm{Nmmol} \mathrm{g}{ }^{-1}\right. \\
\text { TVS) }\end{array}$ & $\begin{array}{c}X c^{A} \\
\text { Nmmol g-1 }^{-1} \\
\text { TVS h }^{-1}\end{array}$ & $\begin{array}{c}K^{B} \\
\mathrm{~h}\end{array}$ & $\mathrm{R}^{2}$ \\
\hline Raw & 6.59 & - & 6.63 & 0.02 & 0.00 & 0.988 \\
\hline A-HO & 13.11 & 98.14 & 12.22 & 0.05 & 24.44 & 0.971 \\
\hline B-HO & 5.59 & -15.26 & 4.94 & 0.05 & 88.45 & 0.945 \\
\hline C-HO & 10.81 & 63.51 & 10.25 & 0.08 & 57.22 & 0.992 \\
\hline D-HO & 9.17 & 38.75 & 8.76 & 0.06 & 86.80 & 0.993 \\
\hline E-HO & 13.49 & 103.85 & 12.94 & 0.12 & 73.24 & 0.989 \\
\hline F-HO & 8.12 & 7.87 & 7.89 & 0.03 & 34.97 & 0.965 \\
\hline G-HO & 13.12 & 98.36 & 12.69 & 0.03 & 0.50 & 0.972 \\
\hline H-HO & 7.69 & 5.32 & 7.55 & 0.03 & 37.32 & 0.971 \\
\hline I-HO & 12.11 & 83.10 & 12.01 & 0.03 & 0.00 & 0.959 \\
\hline J-HO & 12.29 & 85.82 & 11.67 & 0.03 & 19.21 & 0.968 \\
\hline K-HO & 14.43 & 118.16 & 13.36 & 0.04 & 14.35 & 0.959 \\
\hline L-HO & 7.80 & 18.14 & 7.84 & 0.01 & 21.09 & 0.989 \\
\hline M-HO & 11.55 & 74.70 & 10.89 & 0.04 & 33.30 & 0.981 \\
\hline N-HO & 11.36 & 71.85 & 11.19 & 0.04 & 35.56 & 0.997 \\
\hline O-HO & 10.89 & 64.66 & 9.89 & 0.04 & 28.77 & 0.954 \\
\hline P-HO & 12.57 & 89.99 & 11.47 & 0.02 & 0.00 & 0.936 \\
\hline
\end{tabular}

${ }^{¥}$ Predicted value obtained from Gompertz equation, ${ }^{\mathrm{A}}$ Rate of methane production $\left(\mathrm{Nmmol} \mathrm{g}^{-1} \mathrm{TVS} \mathrm{h}^{-1}\right),{ }^{\text {В }}$ time elapsed before $\mathrm{CH}_{4}$ production started (lag phase),

\subsection{Microbial community analysis}

Microbial community structure was determined with fingerprinting technique DGGE for bacterial and archaeal domains. Selected pretreatment runs were also analyzed with next generation high throughput Illumina MiSeq sequencing. 


\subsubsection{Denaturing Gradient Gel Electrophoresis}

Microbial community structure for bacterial and archaeal domains in response to pretreatment parameters i.e., temperature $\left({ }^{\circ} \mathrm{C}\right)$, time (min) and $\mathrm{H}_{2} \mathrm{O}_{2}$ concentration $(\% \mathrm{v} / \mathrm{v})$ was determined by DGGE at the end of batch reactors. Pretreatment runs $15(\mathrm{O}-\mathrm{HO})$ and $16(\mathrm{P}-\mathrm{HO})$ were excluded from the microbial community analysis based on extreme limits of temperature applied during pretreatment.

Similarity coefficient $\left(\mathrm{S}_{\mathrm{c}}\right)$ between pretreatment runs was calculated by Pearson correlation. PCR-DGGE band profiles for bacterial and archaeal communities are presented as a dendrogram in Fig 5.13 and 5.14, respectively. For bacterial community, $S_{c}$ decreased with a decrease in pretreatment time $(19-5 \mathrm{~min})$ at temperature of $200{ }^{\circ} \mathrm{C}$ from $83 \%(\mathrm{~A}-\mathrm{HO}$ and $\mathrm{B}-\mathrm{HO})$ to $44 \%$ (C-HO and D-HO), while under same conditions, but at lower pretreatment temperature $\left(160{ }^{\circ} \mathrm{C}\right) S_{c}$ increased from $68 \%(\mathrm{E}-\mathrm{HO}$ and F-HO) to $83 \%(\mathrm{G}-\mathrm{HO}$ and $\mathrm{H}-\mathrm{HO})$.

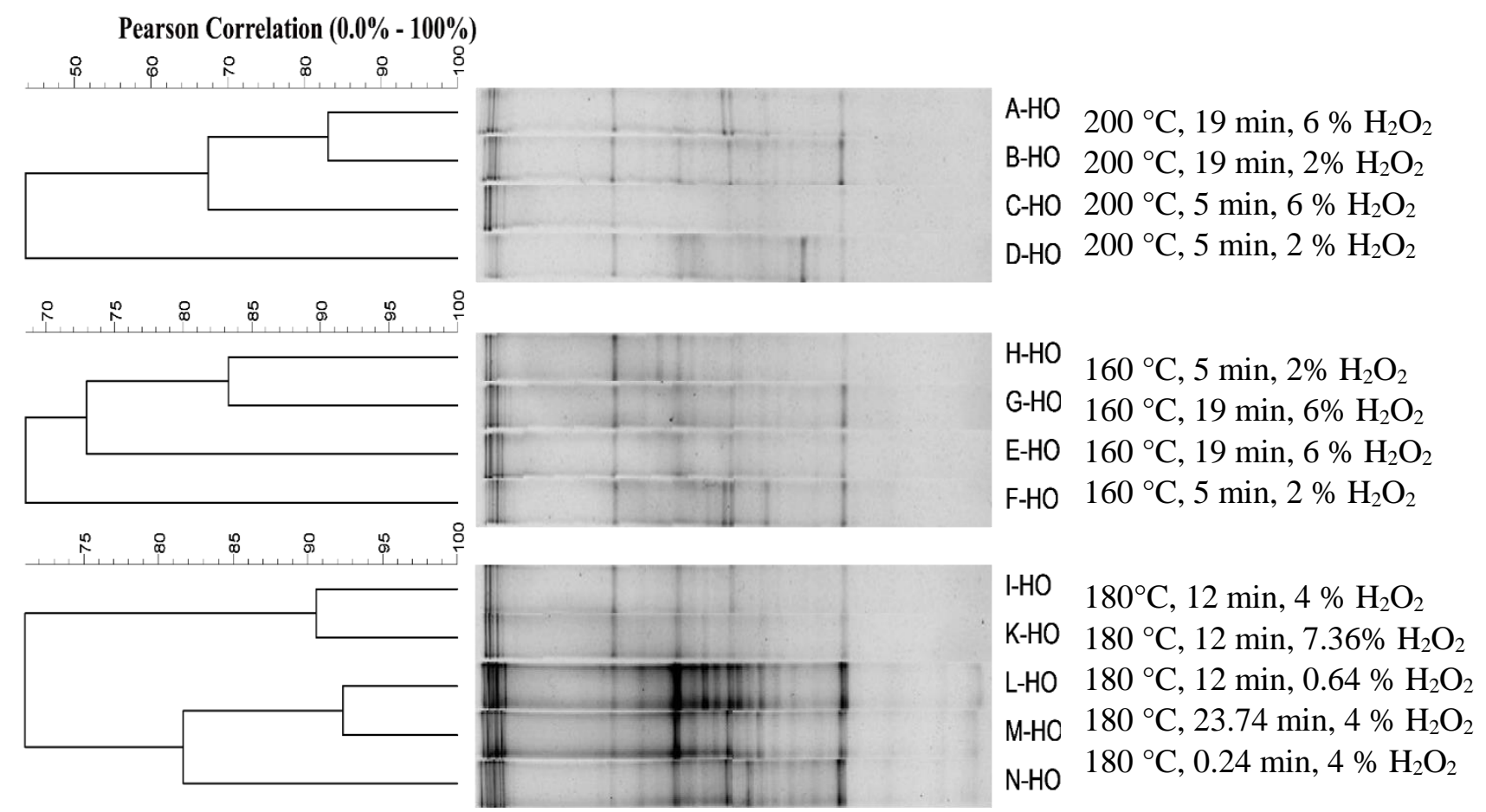

Figure 5.13 - Pearson Similarity Coefficient $\left(\mathrm{S}_{\mathrm{c}}\right)$ of DGGE band patterns for bacterial communities

A decrease in $\mathrm{H}_{2} \mathrm{O}_{2}$ concentration from $6 \%$ to $2 \%$ resulted in a decrease in $S c$ from $67 \%$ (A-HO and C-HO) to $44 \%(\mathrm{~B}-\mathrm{HO}$ and $\mathrm{D}-\mathrm{HO})$ at pretreatment temperature of $200{ }^{\circ} \mathrm{C}$. Similar 
trend was observed at $160{ }^{\circ} \mathrm{C}$ where only $7.3 \%$ decrease in $S c$ was recorded with a decrease in $\mathrm{H}_{2} \mathrm{O}_{2}$ concentration.

Fig 5.13 depicted that the highest $S c$ of $92 \%$ was noted surprisingly between L-HO and MHO though both were pretreated at significantly different conditions; L-HO was pretreated for 12 min with $0.64 \%(\mathrm{v} / \mathrm{v}) \mathrm{H}_{2} \mathrm{O}_{2}$ and $\mathrm{M}-\mathrm{HO}$ was pretreated with $4 \%(\mathrm{v} / \mathrm{v}) \mathrm{H}_{2} \mathrm{O}_{2}$ at 23.7 min, though both conditions met a similarity of temperature, $180{ }^{\circ} \mathrm{C}$. Methane yield of both samples is also quite different; 174.78 and $258.79 \mathrm{NmL} \mathrm{g}^{-1}$ TVS for L-HO and M-HO, respectively. It could possibly mention that only the pretreatment temperature influenced such a high $S c$ between the two samples.

Second highest similarity $91 \%$ was observed between $\mathrm{I}-\mathrm{OH}$ and $\mathrm{K}-\mathrm{OH}$ both pretreated at $180{ }^{\circ} \mathrm{C}$ and $12 \mathrm{~min}$. it showed that change in concentration did not influence the bacterial populations. Furthermore, it can also be seen bacterial populations thrive best when sugarcane bagasse was pretreated at a temperature of $180{ }^{\circ} \mathrm{C}$ and 12 min irrespective of change in $\mathrm{H}_{2} \mathrm{O}_{2}$ concentration employed as indicated by the highest $S c$.

Archaeal community bands on the PCR-DGGE gel as indicated in Fig 5.14 showed not much variation across all the pretreatment runs. Sc varied from $67 \%$ to $98 \%$ from A-OH to N-OH. The lowest Sc 67\% was noted at between two pretreatment sets A-HO and B-HO, and A-HO and $\mathrm{C}-\mathrm{HO}$ at pretreatment temperature $200{ }^{\circ} \mathrm{C}$, while the highest $98 \% S c$ was observed between $\mathrm{K}-\mathrm{HO}$ and L-HO at pretreatment temperature of $180{ }^{\circ} \mathrm{C}$. A comparison of archaeal community with the volume of $\mathrm{CH}_{4}$ produced showed that the volume of $\mathrm{CH}_{4}$ produced was lowest $\left(5.59 \mathrm{Nmmol} \mathrm{g}^{-1}\right.$ TVS) for B-HO whereas 13.11 and $10.81 \mathrm{Nmmol} \mathrm{g}^{-1}$ TVS was recorded for A-HO and C-HO, respectively. Even though the highest similarity was recorded between K-HO and L-HO, however, the $\mathrm{CH}_{4}$ value was approx. 2-fold in K-HO (14.43 $\left.\mathrm{Nmmol} \mathrm{g}^{-1} \mathrm{TVS}\right)$ in comparison to L-HO (7.80 Nmmol g ${ }^{-1}$ TVS). 
Table 5.10 - Microbial diversity (Shannon-Wiener and Dominance) for Bacteria and Archaea of $\mathrm{H}_{2} \mathrm{O}_{2}$ assisted anaerobic digesters

\begin{tabular}{|c|c|c|c|c|c|c|c|}
\hline \multirow[t]{2}{*}{ Designation } & \multirow{2}{*}{$\begin{array}{c}\text { Temperature } \\
\left({ }^{\circ} \mathrm{C}\right)\end{array}$} & \multirow{2}{*}{$\begin{array}{l}\text { Time } \\
\text { (min) }\end{array}$} & \multirow{2}{*}{$\begin{array}{c}\mathrm{H}_{2} \mathbf{O}_{2} \\
\\
(\% \\
\mathrm{v} / \mathrm{v})\end{array}$} & \multicolumn{2}{|c|}{ Bacteria } & \multicolumn{2}{|c|}{ Archaea } \\
\hline & & & & Dominance & $\begin{array}{c}\text { Shannon- } \\
\text { Wiener }\end{array}$ & Dominance & $\begin{array}{c}\text { Shannon- } \\
\text { Wiener }\end{array}$ \\
\hline A-HO & 200 & 19 & 6 & 0.11 & 2.26 & 0.08 & 2.72 \\
\hline $\mathrm{B}-\mathrm{HO}$ & 200 & 19 & 2 & 0.07 & 2.67 & 0.07 & 2.78 \\
\hline $\mathrm{C}-\mathrm{HO}$ & 200 & 5 & 6 & 0.14 & 2.10 & 0.07 & 2.79 \\
\hline D-HO & 200 & 5 & 2 & 0.06 & 2.91 & 0.07 & 2.79 \\
\hline E-HO & 160 & 19 & 6 & 0.08 & 2.57 & 0.07 & 2.78 \\
\hline F-HO & 160 & 19 & 2 & 0.05 & 3.11 & 0.07 & 2.76 \\
\hline G-HO & 160 & 5 & 6 & 0.07 & 2.70 & 0.07 & 2.78 \\
\hline $\mathrm{H}-\mathrm{HO}$ & 160 & 5 & 2 & 0.07 & 2.72 & 0.08 & 2.75 \\
\hline $\mathrm{I}-\mathrm{HO}$ & 180 & 12 & 4 & 0.08 & 2.72 & 0.07 & 2.83 \\
\hline $\mathrm{K}-\mathrm{HO}$ & 180 & 12 & 7.36 & 0.08 & 2.64 & 0.07 & 2.77 \\
\hline $\mathrm{L}-\mathrm{HO}$ & 180 & 12 & 0.64 & 0.04 & 3.18 & 0.06 & 2.86 \\
\hline M-HO & 180 & 23.76 & 4 & 0.04 & 3.22 & 0.07 & 2.78 \\
\hline N-HO & 180 & 0.24 & 4 & 0.04 & 3.18 & 0.07 & 2.76 \\
\hline
\end{tabular}

Shannon-Wiener index $\left(\mathrm{H}^{\prime}\right)$ and Dominance (D) for bacterial communities computed from the DGGE profile patterns is presented in Table 5.10. It indicates a decrease $(6-2)$ in $\mathrm{H}_{2} \mathrm{O}_{2}$ concentration at $200{ }^{\circ} \mathrm{C}$ tends to increase the bacterial diversity and consequently lowers the dominance. Dominance is approximately similar to $200{ }^{\circ} \mathrm{C}$ for same $\mathrm{H}_{2} \mathrm{O}_{2}$ concentrations employed but a noticeable increase in the diversity was seen from 2.26 (A-HO) to 2.91 (D-HO) with a decrease in $\mathrm{H}_{2} \mathrm{O}_{2}(\% \mathrm{v} / \mathrm{v})$ from 6 to 2 and pretreatment time (19-5 min).

Similar conditions of $\mathrm{H}_{2} \mathrm{O}_{2}$ and pretreatment time but a decrease in temperature to $160{ }^{\circ} \mathrm{C}$ resulted in an increase in bacterial diversity. The decrease in $\mathrm{H}_{2} \mathrm{O}_{2}$ at pretreatment time of 5 min did not affect the bacterial diversity indicated by approximate $\mathrm{H}^{\prime}$ values of 2.70 and 2.72 for G$\mathrm{HO}$ and $\mathrm{H}-\mathrm{HO}$, respectively. Interestingly, pretreatment time of 19 min induced a reasonable increase in bacterial diversity as evident from $\mathrm{H}^{\prime}$ values of $2.57(\mathrm{E}-\mathrm{HO})$ and $3.11(\mathrm{~F}-\mathrm{HO})$. The 
highest $\mathrm{H}^{\prime}$ value of 3.22 was noted for $\mathrm{M}-\mathrm{HO}$ at pretreatment conditions of $180{ }^{\circ} \mathrm{C}, 23.76$ min and $4 \%(\mathrm{v} / \mathrm{v}) \mathrm{H}_{2} \mathrm{O}_{2}$.

Surprising results were observed at $180{ }^{\circ} \mathrm{C}$, an increase in $\mathrm{H}_{2} \mathrm{O}_{2}$ from 0.64 to $4 \%$ (v/v) and decrease in pretreatment time from 12 to 0.24 min did not impact bacterial diversity $\left(\mathrm{H}^{\prime}-3.18\right)$, while an increase in $\mathrm{H}_{2} \mathrm{O}_{2}\left(\%\right.$ v/v) from 4 to 7.36 resulted in negligible decrease in $\mathrm{H}^{\prime}$ value (2.72 -2.64) at pretreatment time of $12 \mathrm{~min}$. It could say that pretreatment temperature of $180{ }^{\circ} \mathrm{C}$ solely impacts the bacterial diversity of batch reactors. Higher Shannon diversity implicates lower dominance of community. $\mathrm{H}^{\prime}$ values are generally found between $1.5-3.5$, while $\mathrm{D}$ value mostly occurs between $0-1$ in most ecological studies (Magurran, 2004).

Archaeal Shannon diversity $\left(\mathrm{H}^{\prime}\right)$ was approximately similar across all the pretreatment runs in the range of 2.72 to 2.86 . Table 5.10 indicates a change in temperature, pretreatment time, and change in $\mathrm{H}_{2} \mathrm{O}_{2}$ did not much affect the archaeal community diversity. Even the $\mathrm{H}^{\prime}$ value of pretreatment B-HO (2.78) didn't differ much from the K-HO (2.77) where the former produced the lowest methane (125.17 $\mathrm{NmL} \mathrm{g}^{-1}$ TVS) and the later exhibited maximum methane $323.33 \mathrm{NmL}$ $\mathrm{g}^{-1}$ TVS.

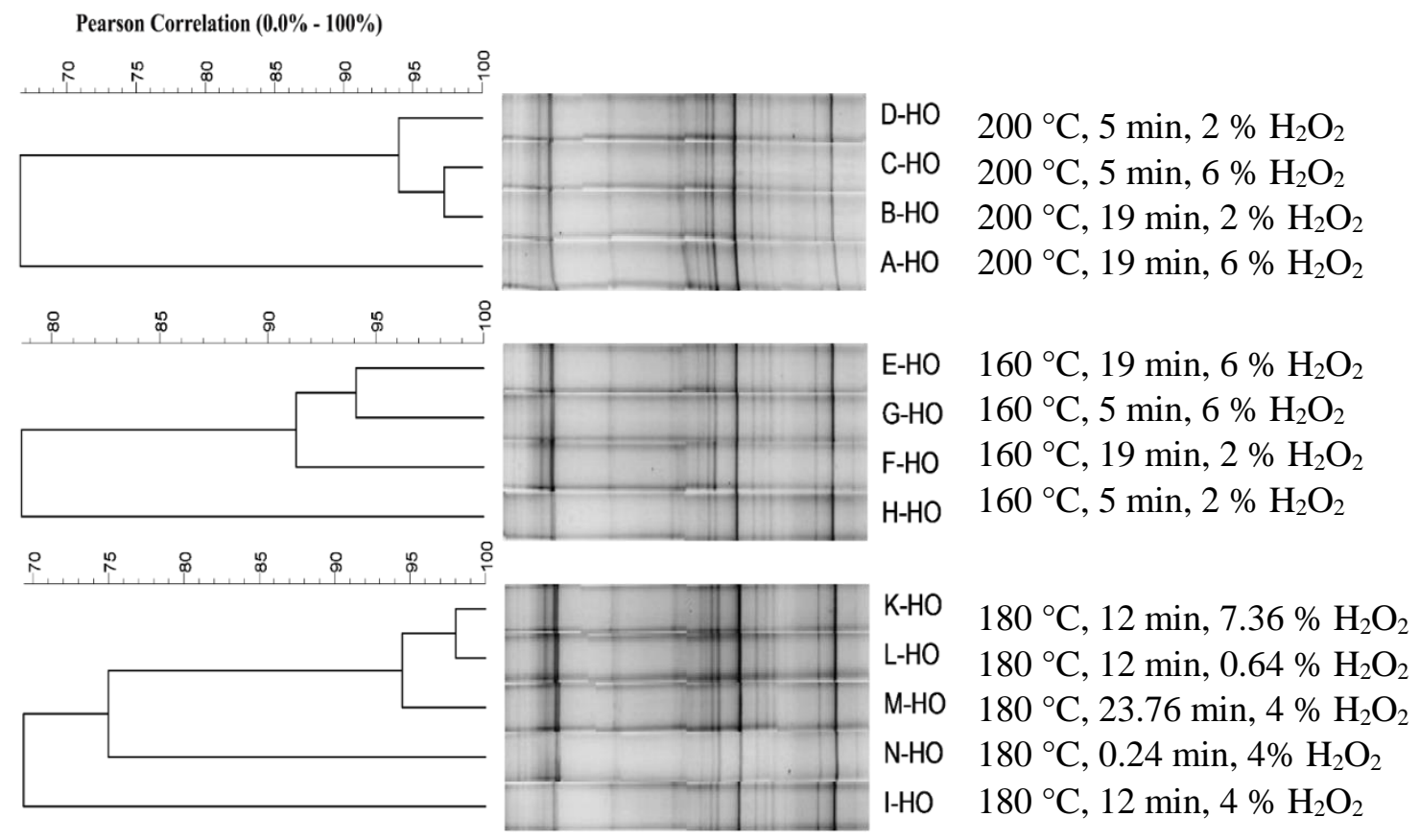

Figure 5.14 - Pearson Similarity Coefficient $\left(\mathrm{S}_{\mathrm{c}}\right)$ of DGGE band patterns for archaeal communities 


\subsubsection{Illumina MiSeq Sequencing}

Pretreatments B-HO, K-HO, and P-HO were selected for Illumina MiSeq sequencing to determine the microbial community structure. The community structure was explored for bacteria and archaea domains. In total, 35,128 sequences were retrieved after RDP classifier. Reads were classified into operational taxonomic units (OTUs) based on 3\% distance level for phylogenetic estimation. Bacterial and archaeal OTUs obtained were 1,025 and 176, respectively. A total of 31, 32, and 33 phyla were noted for bacterial composition for pretreatment B-HO, K-HO, and P-HO, respectively, where only Euryarchaeota was predominant phylum for the archaeal community. Bacterial community in the selected samples was similar but abundance was quite different. Pretreatment P-HO presented a higher Shannon (6.24) and Chao-1 (1314.1) than pretreatment B$\mathrm{HO}$ and $\mathrm{K}-\mathrm{HO}$.

\subsubsection{Bacterial Diversity in $\mathrm{H}_{2} \mathrm{O}_{2}$ pretreated samples}

A heterogeneous bacterial community was observed between pretreated samples. The selected pretreated samples after phylogenetic analysis revealed relatively similar bacterial diversity but quite different abundance at phylum level possibly because of the impact of pretreatment conditions applied (Fig 5.15). Main phyla observed were Bacteroidetes, Thermotogae, Firmicutes, Proteobacteria, Spirochaetes, and Chloroflexi. While Synergistetes, Hyd24-12 lineage, and WWE1 lineage were in lower abundance.

Bacteroidetes was the dominant phylum with the relative abundance of 27.32, 48.66, and $28.96 \%$ for B-HO, K-HO and P-HO, respectively (Fig 5.15) The phylum Bacteroidetes consists of four recognized classes Bacteroidia, Flavobacteria, Sphingobacteria and Cytophagia (Krieg et al., 2010). However, only one class Bacteroidia was found in the current study with the relative abundance of $27.05,31.23$, and $28.52 \%$ for pretreatment B-HO, K-HO, and P-HO, respectively. Members of Bacteroidia are Gram-stain negative, non-motile, anaerobic, saccharolytic, chemoorganotrophic and weakly proteolytic with acetate and succinate as major fermentation products (Song et al., 2015).

Members of BLVii28 belonging to family Rikenellaceae root to phylum Bacteroidetes are a rod or coccus-shaped bacteria producing extracellular hydrolase, supposed to contribute to anaerobic degradation (Hirakata et al., 2016). BLVii28-related bacteria are previously reported in 
granular sludge in UASB reactor and anaerobic wastewater treatment facilities (Kaksonen et al., 2004; Narihiro et al., 2009). Relatively higher BLVii28 abundance was recorded in pretreatment K-HO (3.50 \%) followed by pretreatment run B-HO (2.74 \%) and pretreatment run P-HO (1.72 $\%)$. Relatively higher abundance of BLVIii28 in pretreatment K-HO might be due to higher removal of lignin leaving behind easily accessible degraded cellulose

Thermotoage was the most abundant phylum in pretreatment B-HO (26.58\%) followed by pretreatment K-HO (13.06\%) and P-HO (9.05\%) (Fig 5.15). Thermotogae members are anaerobic thermophilic gram-negative bacteria surrounded by sheath-like envelope called "toga". Thermotogae contains 10 genera with 41 validated species belonging to order Thermotogales that roots to single class Thermotogae (Bhandari and Gupta, 2014). Thermotogales members are anaerobic heterotrophs able to ferment a range of substrates including glucose and xylose. $\mathrm{H}_{2}$ severely inhibits the Thermotogales growth (Reysenbach, 2015).

Huber et al (Huber et al., 1986) reported that acetic acid, $\mathrm{CO}_{2}$ and $\mathrm{H}_{2}$ are the fermentation products of Thermotogales. Phylogenetic analysis indicated two genera of Thermotogaceae for this study; uncultured AUTHM297 and Kosmotoga, where former was abundant with the relative abundance of 8-26\% (Fig 5.17) and later was less than $1 \%$.

Lower hydrogenotrophic activity in pretreatment run B-HO could be a reason for higher AUTHM297 lineage abundance (26.58\%) in comparison to pretreatment K-HO (13.06\%) and PHO $(9.05 \%)$ as indicated by the lower abundance of Methanobacterium (18.22\%) for pretreatment run 2. Briones et al (Briones et al., 2007) reported that AUTHM297 is capable of utilizing elemental sulfur and/or thiosulfate as an electron acceptor to form $\mathrm{H}_{2} \mathrm{~S}$. Since, an $\mathrm{H}_{2} \mathrm{~S}$ determination is beyond the scope of the current study so the author unable to comment due to unavailability of data for $\mathrm{H}_{2} \mathrm{~S}$ and sulfates. Syntrophic activity of Thermotogales with Methanobacteriaceae is reported by Balk et al (Balk et al., 2002) that only one member can serve as a syntrophic member with Thermotogales.

Since, the current study was conducted under mesophilic conditions $\left(37^{\circ} \mathrm{C}\right)$ the presence of Thermotogae was surprising. However, recently other studies (Nesbo et al., 2006; Briones et $a l ., 2007)$ have also been reported the presence of Thermotogae related members in mesophilic conditions in anaerobic reactors treating sulfate-rich waste streams. Though digestion experiments were conducted under mesophilic conditions $\left(37^{\circ} \mathrm{C}\right)$, interestingly AUTHM297 dominance 
followed the order of pretreatment temperature; $26.13 \%$ (pretreatment $\mathrm{B}-\mathrm{HO}-200{ }^{\circ} \mathrm{C}$ ), $12.63 \%$ (pretreatment $\mathrm{K}-\mathrm{HO}-180{ }^{\circ} \mathrm{C}$ ), and $8.55 \%$ (pretreatment $\mathrm{P}-\mathrm{HO}-146.4{ }^{\circ} \mathrm{C}$ ).

Firmicutes was abundant in pretreatment P-HO (19.47\%) followed by pretreatment B-HO $(15.59 \%)$ and K-HO (7.89\%). It is a renowned group for hydrolytic activity, most members stain Gram-positive. Firmicutes contain three classes Bacilli, Clostridia, and Erysipelotrichia.

The current study revealed the presence of one major Class Clostridia with the relative abundance of 15.31, 7.84, and 19.37\%, respectively, for pretreatment B-HO, K-HO and P-HO. Clostridia members perform hydrolysis and acidogenesis, in addition to acetogenesiss and syntrophic acetate oxidation (Wirth et al., 2012; Ziganshin et al., 2013).

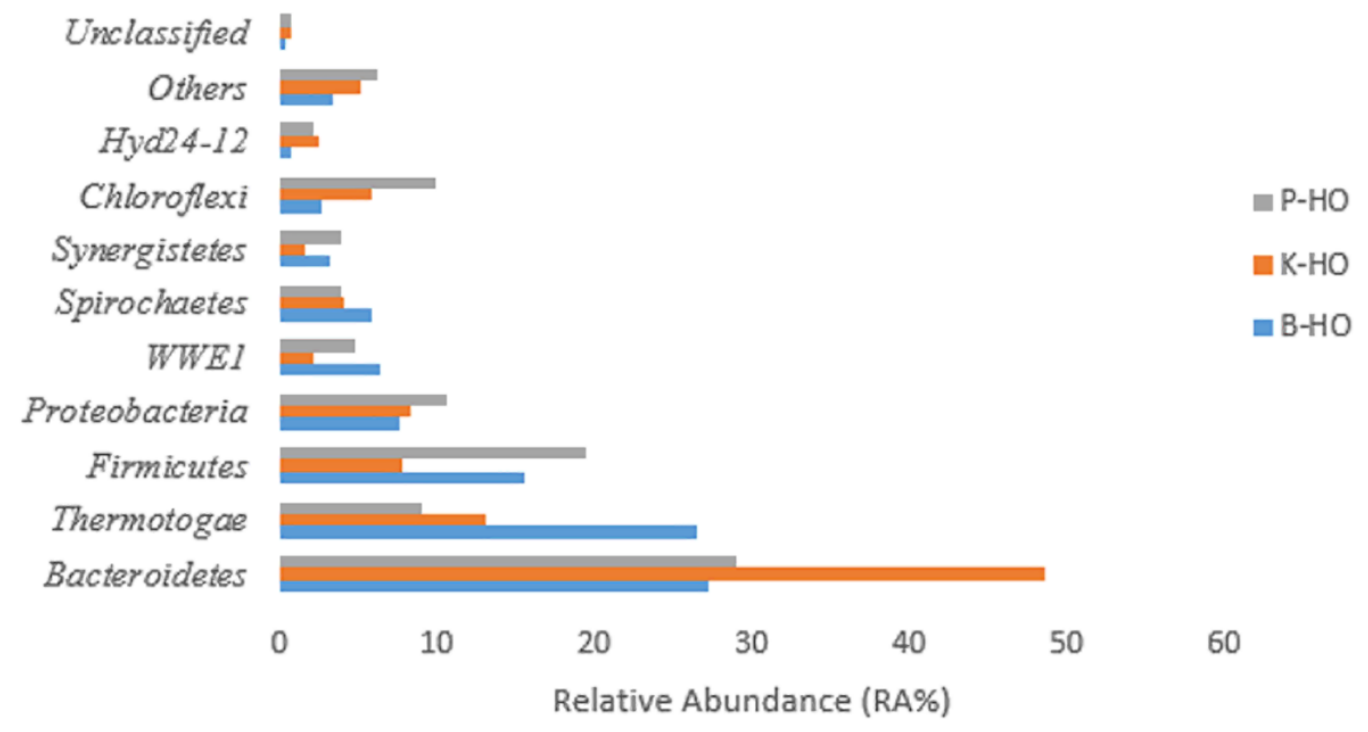

Figure 5.15 - Bacterial community classification at Phylum level. Relative abundance (RA\%) less than 1 in the samples was accumulated and presented as Others.

Clostridia are also efficient hydrogen producers. Clostridia may be saccharolytic, proteolytic or bearing both metabolic pathways. Clostridium may metabolize carbohydrates, amino acids, purines, steroids or other organic compounds (Rainey et al., 2015). Clostridia represent the most prevalent bacterial class in full-scale mesophilic biogas plants fed with plant biomass (Krause et al., 2008). Some species of the order Clostridiales are known to create cellulosomes, which are intensively involved in the anaerobic digestion of recalcitrant cellulose, supporting acetogens and methanogens with compounds necessary for their growth (Ziganshin et al., 2013). 
Members of the clostridial family Ruminococcaceae are known to hydrolyze a variety of polysaccharides by different mechanisms, e.g., the production of a cellulosome enzyme complex and cellulose adhesion proteins (Morrison and Miron, 2000). They are able to ferment hexoses as well as pentoses, which are the hydrolysis products from cellulose and hemicelluloses.

Clostridium genus was negligibly found in the pretreatment B-HO (0.63\%) and K-HO $(0.28 \%)$. However, relatively higher abundance was recorded in pretreatment P-HO (5.23\%). Clostridium are rod-shaped Gram-stain-positive, endospore forming obligate anaerobes. Clostridium spp. are extensively reported in biogas plants treating cellulosic biomass (Herbel et al., 2010; Hanreich et al., 2013; Sun et al., 2015). The relatively higher abundance of Clostridium in the pretreatment 16 could be justified by the lower pretreatment temperature $\left(146.4{ }^{\circ} \mathrm{C}\right)$ applied

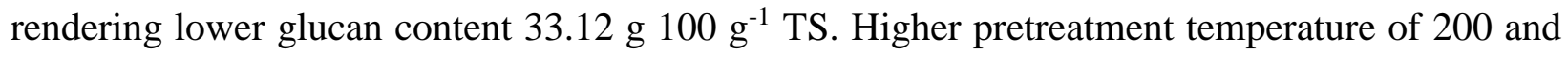
$180^{\circ} \mathrm{C}$, respectively, for pretreatment $\mathrm{B}-\mathrm{HO}$ and $\mathrm{K}-\mathrm{HO}$ might have altered significantly the lignocellulosic structure breaking lignin-carbohydrate matrix though leaving behind higher glucan

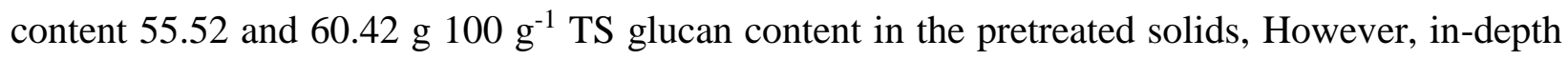
study is required to determine the behavior of clostridia under anaerobic conditions in response to $\mathrm{H}_{2} \mathrm{O}_{2}$ impregnated substrates, as the glucan content was reasonably higher for $\mathrm{K}-\mathrm{HO}(60.42 \%)$ in comparison to $\mathrm{P}-\mathrm{HO}(33.12 \%)$.

Proteobacteria is considered to play an important role in methane production in syntrophic relation with archaea. Bacterial community of the tested samples at phyla rank showed higher abundance for pretreatment $\mathrm{P}-\mathrm{HO}(10.58 \%)$ followed by pretreatment $\mathrm{K}-\mathrm{HO}(8.27 \%)$ and $\mathrm{B}-\mathrm{HO}$ $(7.64 \%)$.

Class Deltaproteobacteria was dominant with the relative abundance of $6.55 \%$ in $\mathrm{P}-\mathrm{HO}$ followed by $4.98 \%(\mathrm{~K}-\mathrm{HO})$, and $3.61 \%$ (B-HO). Other classes alpha, beta, epsilon, and Gammaproteobacteria were also found but in lower abundance. Syntrophus (Deltaproteobacteria) was the only proteobacteria phylotype was above than $1 \%$ in relative abundance. Syntrophus are Gram-negative, strictly anaerobic, chemoorganotrophic rod-shaped bacteria. Kuever and Schink (Kuever and Schink, 2015) reported that Syntrophus could oxidize fatty acids only in the presence of $\mathrm{H}_{2}$ /formate-utilizing methanogenic archaea or sulfate-reducing bacteria. Furthermore, incomplete oxidation could lead to acetate formation. Syntrophomonas-related bacteria are fattyacid-oxidizing bacteria, able to convert various organic acids to $\mathrm{H}_{2}$ and acetate for subsequent 
hydrogenotrophic methanogenesis (Baserba et al., 2012; Li et al., 2013). The lower but approx. similar relative abundance of Syntrophus in the tested samples $(1.08-1.88 \%)$ reflected the occurrence of the syntrophic relationship during methanogenesis.

Comparatively similar Synergistetes abundance was observed for B-HO and P-HO 3.29 and $3.92 \%$, respectively. Members of Synergistetes phylum are gram-negative with various morphologies and metabolism. It was recently characterized into phylum (Jumas-Bilak et al., 2009). Synergistia was the only class encountered in the current study with relative abundance between 1.6-3.92\%. Aminiphilus (family Aminiphilaceae) was the only genus in the phylum Synergistetes above than $1 \%$ relative abundance in pretreatment B-HO and $\mathrm{P}-\mathrm{HO}$

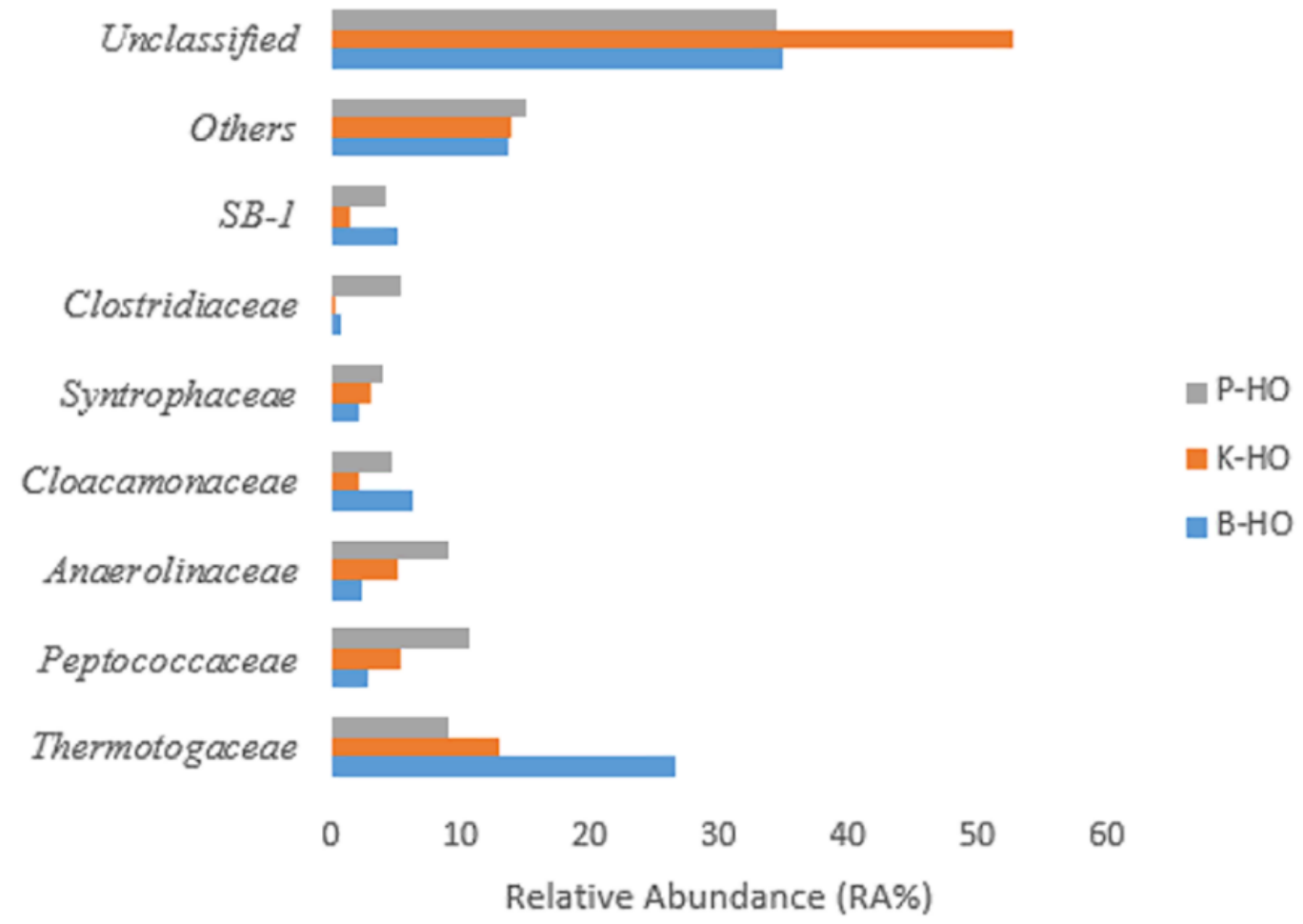

Figure 5.16 - Bacterial community classification at Family-level. Relative abundance (RA\%) less than 1 in the samples was accumulated and presented as Others

The candidate division WWE1 (Waste Water of Evry 1), an uncultured bacterium, was also found in relatively higher proportion (6.38 - 4.77\%) in pretreatments B-HO and P-HO, respectively. WWE1 members are reported to act as amino acid degraders and capable of propionate and butyrate oxidation as well as cellulose degradation (Sieber et al., 2012; Limam et al., 2014). Cloacamonae was the only class with relative abundance between 2.1-6.4\% was 
observed with two distinct phylotypes; uncultured W22 and Candidatus cloacamonas. W22 was observed in relatively higher abundance in pretreatment B-HO $(5.33 \%)$ than pretreatment P-HO $(2.17 \%)$ while negligibly found in pretreatment $\mathrm{K}-\mathrm{HO}(0.48 \%)$.

W22 related species are reported to degrade phenolic compounds under methanogenic conditions (Ju and Zhang, 2014). Pretreatment B-HO had a higher lignin content. Lignin is a highly complex phenolic polymer (Lange et al., 2013). Higher abundance (5.53\%) of W22 in pretreatment B-HO could be attributed to degradation of lignin. W22 related species metabolize amino acids and butyrate during phenol metabolism (Ju and Zhang, 2014). Esquivel-Elizondo et al. (EsquivelElizondo et al., 2016) reported that W22 might responsible for propionate and butyrate fermentation to $\mathrm{H}_{2}, \mathrm{CO}_{2}$, and acetate in the presence of hydrogenotrophic and acetoclastic methanogens. Wong et al. (Wong et al., 2016) reported that W22 might contain unique enzyme system and biochemical pathway relevant to lignocellulose conversion.

Candidatus cloacamonas was found in negligible abundance in pretreatment B-HO $(0.67$ RA\%), K-HO (1.45 RA\%) and P-HO (2.16 RA\%). In silico Proteome analysis indicated that C.clocomonas might attain energy from sugars in the Embden-Meyerhof pathway and from the fermentation of amino acids, thereby, produces hydrogen and carbon dioxide. The occurrence of the oxidative propionate degradation pathway in C. cloacamonas as well as the capability to produce hydrogen via fermentation and its Fe-only hydrogenases are the reasons; the bacterium is assigned as a syntrophic bacterium (Pelletier et al., 2008).

Phylum Spirochaetes found in less abundance with $R A \%$ of $5.79,4.03$, and 3.91, respectively for pretreatment B-HO, K-HO, and P-HO. Spirochaetes generally unable to degrade cellulose but are abundantly reported in anaerobic digesters (Liu et al., 2009; Lee et al., 2012). Rainey et al. (Rainey et al., 1991 1490) isolated only one known cellulose degrading Spirochaetes species. Though members of Spirochaetes unable to degrade cellulose they can ferment carbohydrates and amino acids with major fermentation products; ethanol, acetate, $\mathrm{CO}_{2}$, and $\mathrm{H}_{2}$. Spirochaetes interaction with cellulose degraders might be the reason of their abundance in the anaerobic reactors (Azman et al., 2015). Only one notable class observed in the current study was Spirochaetes. Spirochaetes class was higher for pretreatment B-HO with the relative abundance of $5.27 \%$ in comparison to pretreatment $\mathrm{K}-\mathrm{HO}(2.8 \%)$ and $\mathrm{P}-\mathrm{HO}(3.11 \%)$. 


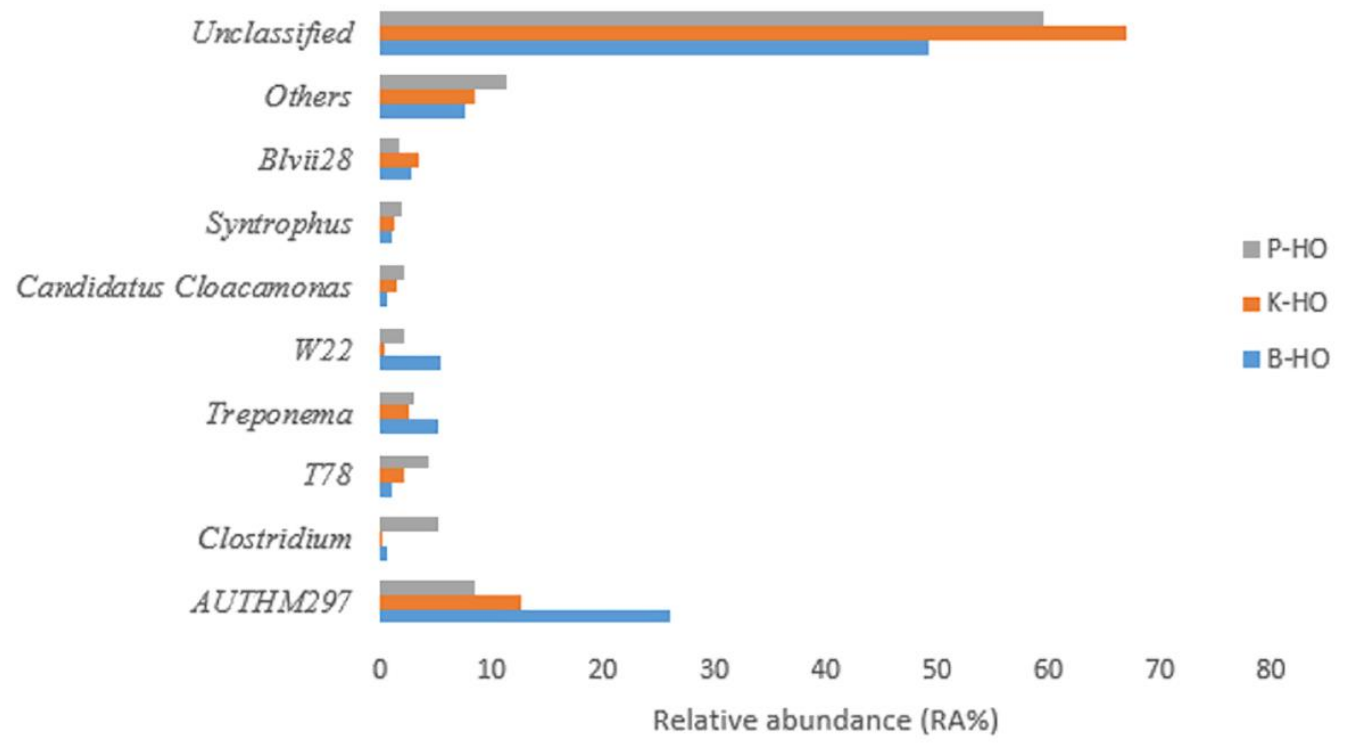

Figure 5.17 - Bacterial community classification at Genus-level. Relative abundance less than 1 in the samples was accumulated and presented as 'Others'

Treponema was the only phylotype significant in the current study with the relative abundance of $5.23 \%$ while approx. similar abundance was noted for pretreatment K-HO (2.69\%) and $\mathrm{P}-\mathrm{HO}(3.03 \%)$. Treponema members being homoacetogens produce acetate by consuming $\mathrm{H}_{2}$ and $\mathrm{CO}_{2}$ (Wang et al., 2013). Homoacetogenesis is typically observed under psychrophilic conditions, as homoacetogens have a better ability to adapt to low temperatures compared with hydrogenotrophic methanogens (Siriwongrungson et al., 2007).

It has been reported that homoacetogenesis cannot compete with hydrogenotrophic methanogenesis under mesophilic or thermophilic conditions because of its lower energy yield. The lower abundance of Treponema in this study might be a reason for the higher competing interest of Treponema with hydrogenotrophic methanogenesis. Li et al. (Li et al., 2016) reported that Treponema proliferation in anaerobic reactors could be used as a potential indicator of process instability. Reactor failure for pretreatment B-HO can be justified with higher Treponema abundance in comparison to pretreatment $\mathrm{K}-\mathrm{HO}$ and $\mathrm{P}-\mathrm{HO}$ with the argument reported by $\mathrm{Li}$ et al. (Li et al., 2016). The genus Treponema consists of various species typically found in animal and human gastrointestinal flora (Nordhoff and Wieler, 2005).

Chloroflexi (green non-sulfur bacteria) is one of the largest phyla with members having various metabolic features. Filamentous morphology is the characteristic feature of its class. 
Members of Chloroflexi are Gram-negative, exhibiting gliding motility and do not contain lipopolysaccharide containing outer membrane (Garrity and Holt, 2015). Class Anaerolineae lineage in Chloroflexi has been reported in anaerobic digesters (Riviere et al., 2009; Narihiro et al., 2012). Some researcher speculated Anaerolineae as semi-syntrophic having the capability of reverse electron transfer via coupled mutualistic interaction with methanogens (Narihiro et al., 2012). However, such interaction is not yet validated (Xia et al., 2016).

A significant difference was observed for Chloroflexi diversity at phylum level in the current study. Maximum abundance was noted for pretreatment P-HO (10.02\%) followed by K$\mathrm{HO}(5.87 \%)$ and B-HO (2.77\%). Higher abundance of Chloroflexi in the pretreatment P-HO could possibly support the argument that cellulose structure might not severely disturb owing to lowest temperature $146.4^{\circ} \mathrm{C}$ that might have helped to develop a higher population of Chloroflexi. This argument could be strengthened by a recent study where Podosokorskaya et al. (Podosokorskaya et al., 2013) reported a discovery of cellulolytic strain Ornatilinea apprima of class Anaerolineae.

Uncultured genus $T 78$ of family Anaerolinaceae was noted in relatively higher abundance in pretreatment P-HO (4.45 \%) than pretreatment B-HO (1.09 \%) and pretreatment K-HO (2.10 $\%) . T 78$ is previously reported in co-digestion of whey permeate and cow manure. It is suggested as carbohydrate utilizer (Miura and Okabe, 2008; Yamada and Sekiguchi, 2009). It also acts as anaerobic degradation of oil hydrocarbons (Parnadi et al., 2007). The lowest abundance of the T78 population in pretreatment $\mathrm{B}-\mathrm{HO}$ further strengthen the fact that higher lignin content resulted into lesser development of carbohydrate degrader bacterial populations.

Uncultured Hyd24-12 members are globally distributed but morphological, ecological, and physiological information about this phylum is not available in the literature. This phylum harbors under mesophilic conditions. Genomic annotation and metabolic reconstruction implicate that members of this phylum are Gram-negative. The Hyd24-12 lineage is delineated into four clades, designated B-1AC, zEL51, Hyd-32 and B9.18 (Kirkegaard et al., 2016). The current study revealed a lower abundance of $H y d 24-12$ lineage with RA\% of $0.73,2.48$, and 2.22 for pretreatment B-HO, K-HO, and P-HO, respectively.

As depicted in Fig 5.17, 49-67\% reads at genus-level were not belong to any known phylum indicating the potential for the new discovery of bacterial taxonomic groups for the samples treated with $\mathrm{H}_{2} \mathrm{O}_{2}$. Such a higher proportion of unclassified reads could be justified by the reason that a 
huge number of bacteria are uncultured and are not classified into taxonomic groups. Furthermore, it also indicated the potential for novel bacterial taxonomic groups that have not yet been discovered.

\subsubsection{Archaeal Diversity in $\mathrm{H}_{2} \mathrm{O}_{2}$ pretreated samples}

Archaeal diversity in $\mathrm{H}_{2} \mathrm{O}_{2}$ pretreated samples at phylum-level indicated the prevalence (99\%) of phylum Euryarchaeota, while Crenarchaeota was found in less than 1\%. Euryarchaeota are rods, cocci, spiral-shaped, triangular, or squares shaped methanogens exhibiting Gram-positive or Gram-negative characteristics (Garrity and Holt, 2015).

As depicted in Fig 5.18 at Class-level, that archaeal community was not as diverse as it appeared for the bacterial population. Phylum Euryarchaeota contains eight classes (Gargaud and Irvine, 2015). However, classes Methanomicrobia and Methanobacteria were predominant in the current. Class Thermoplasmata was also observed in less than $1 \%$ in pretreatment $11(0.77 \%)$ and pretreatment $16(0.69 \%)$. Its abundance was slightly higher in pretreatment $2(1.19 \%)$. However, Class Thermoplasmata is of no interest for methane production because it is a non-methanogenic archaeal class (Bapteste et al., 2005). Uncultivated class MCG (Miscellaneous Crenarchaeota Group) was observed in less than $1 \%$. This taxon is a prominent archaeal group for dehalogenation of aromatic compounds (Meng et al., 2014). The role of $M C G$ in anaerobic digestion is largely unknown; however, Collins et al (Collins et al., 2005) reported that MCG collocate with Methanosaeta cells in granular digester biofilm suggesting a syntrophy interaction with methanogens.

Class Methanomicrobia was predominant (76.26-79.52\%) in the tested samples with the prevalence of two families Methanoregulaceae (44.73-62.33\%) and Methanosaetaceae (15.94$30.42 \%$ ). Members of Methanoregulaceae are hydrogenotrophic, however, each specie exhibits different physiological features (Imachi and Sakai, 2015). Methanoregulaceae members are rod and coccoid-shaped, Gram-negative strict anaerobes that require energy by $\mathrm{CO}_{2}$ reduction to form methane utilizing $\mathrm{H}_{2}$ or formate as electron donors. Two phylotypes within family Methenoregulaceae were observed in the current study (Fig 5.19); Methanolinea (24.52-34.86\%) and Candidatus methanoregula (4.43-4.77\%). 
Higher abundance (34.86\%) of Methanolinea in pretreatment B-HO (Fig 5.20) in comparison to approx. similar abundance in pretreatment run $\mathrm{K}-\mathrm{HO}$ and $\mathrm{P}-\mathrm{HO}(24.52-24.75 \%)$ implicates higher hydrogenotrophic activity in pretreatment B-HO that is supported with lower Methanosaeta (15.94\%) where Methanosatea abundance was two-fold in pretreatment K-HO and P-HO (26.7-30.4\%). Methanosaeta are rod-shaped obligate anaerobes utilizing the only acetate as an energy source while $\mathrm{CO}_{2}$ and acetate serve as a carbon source. Methanosaeta are unable to utilize $\mathrm{H}_{2} / \mathrm{CO}_{2}$, formate, methanol, and methylamine for growth or methane production (Zinder et al., 1987; KAMAGATA and MIKAMI, 1991). Methanolinea are reported previously in digestion of grass Pennisetum (Pengyu et al., 2017) and food waste (Wilkins et al., 2015)

Class Methanobacteria was lower with the relative abundance of (18.56-22.14\%). Methanobacterium was the dominant (18.21-21.95\%) genus while Methanobrevibacter was encountered in less than 1\%. Methanobacterium are Gram-positive strict anaerobes with optimum growth temperature $37-45^{\circ} \mathrm{C}$. Although, some strains use formate, secondary alcohols, and CO, $\mathrm{CO}_{2}$ reduction coupled to $\mathrm{H}_{2}$ oxidation is the major growth mechanism (Boone, 2015). Methanospirillum, Methanomethylovorans, Methanomassiliicoccus, Methanocella were found in less than $1 \%$. 18.25-25.42\% read could not be categorized into archaeal taxonomic groups at the genus level (Fig 5.20).

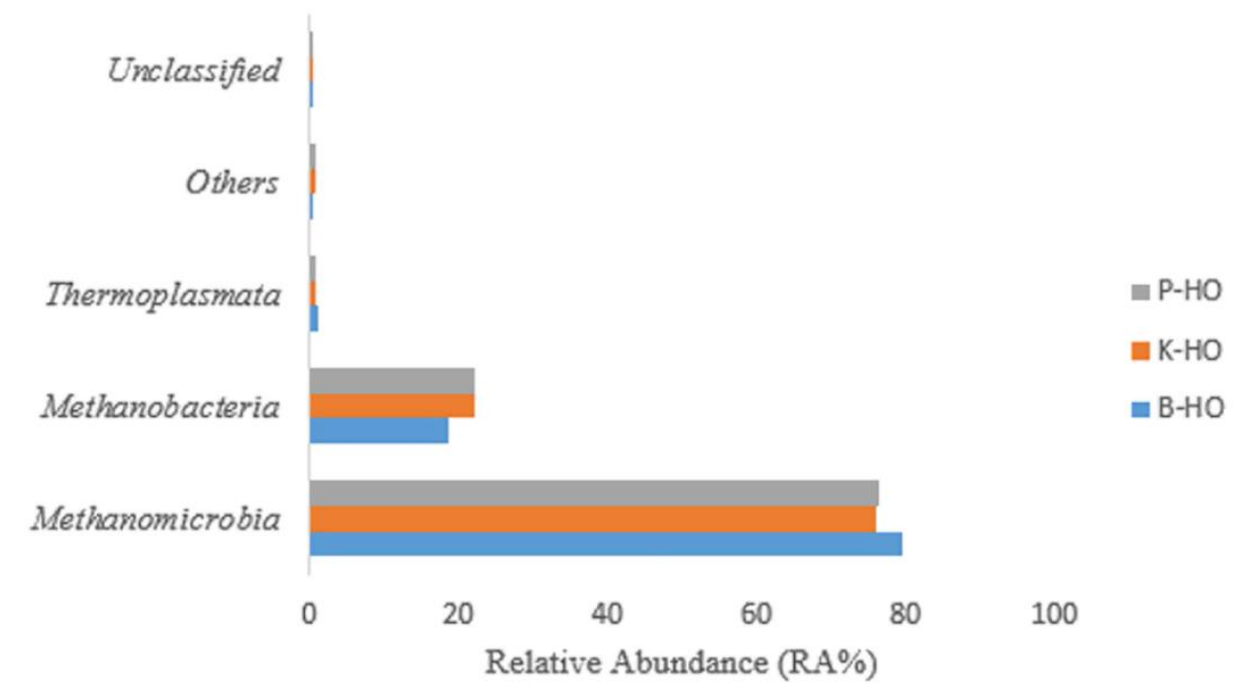

Figure 5.18 - Archaeal community classification for selected $\mathrm{H}_{2} \mathrm{O}_{2}$ pretreated samples at Classlevel. All taxonomic groups with relative abundance less than $1 \%$ are accumulated and presented as others 


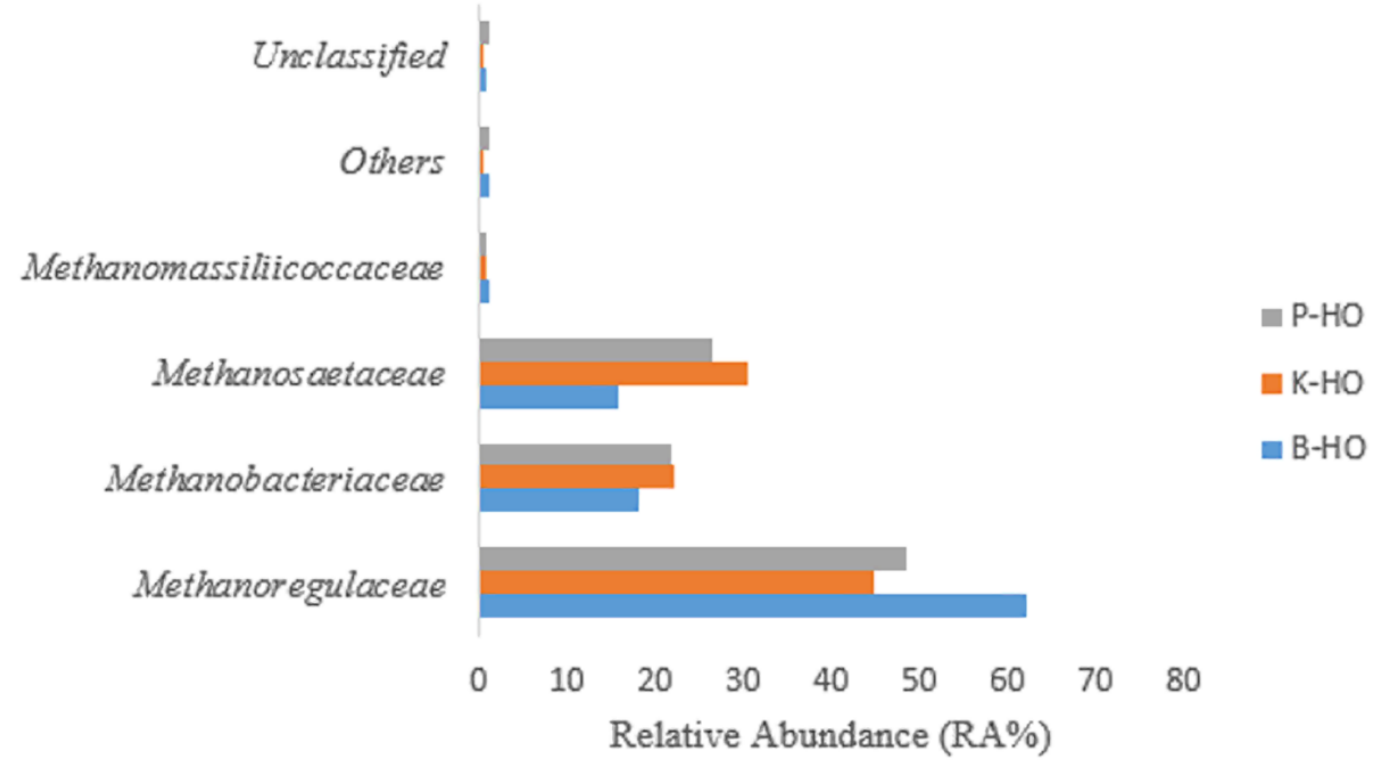

Figure 5.19 - Archaeal community classification for selected $\mathrm{H}_{2} \mathrm{O}_{2}$ samples at Family-level. All taxonomic groups with relative abundance less than $1 \%$ are accumulated and presented as others

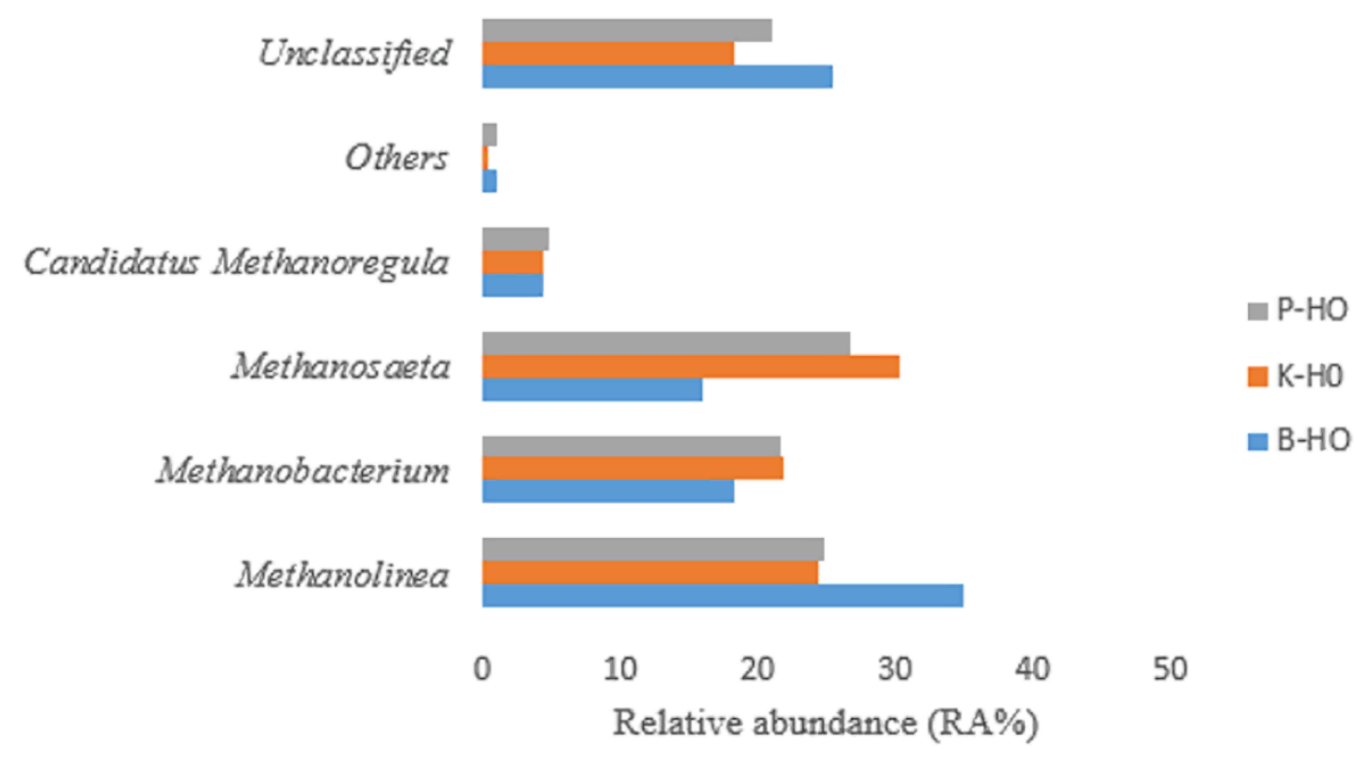

Figure 5.20 - Archaeal community classification for selected $\mathrm{H}_{2} \mathrm{O}_{2}$ samples at Genus-level. All taxonomic groups with relative abundance less than $1 \%$ are accumulated and presented as others. 
5.8 Impact of sugarcane bagasse impregnation in $\mathrm{H}_{2} \mathrm{SO}_{4}$ before hydrothermal pretreatment on pretreated solid characteristics

In the second phase of the study, sugarcane bagasse was impregnated with $\mathrm{H}_{2} \mathrm{SO}_{4}$ for $24 \mathrm{~h}$ before hydrothermal pretreatment according to CCD (Table 4.5). The recovered solid after the pretreatment was characterized for carbohydrate polymers (glucan, xylan), Klason lignin and lignin recovery (Table 5.11).

Table 5.11 - Impact of $\mathrm{H}_{2} \mathrm{SO}_{4}$ impregnation of sugarcane bagasse before hydrothermal pretreatment on Solid yield (\%), Glucan (g $100 \mathrm{~g}^{-1}$ TVS), Xylan (g $100 \mathrm{~g} \mathrm{~g}^{-1}$ TVS), Klason Lignin $(\%)$, Glucan increase (\%), xylan removal (\%), and Lignin Recovery (\%)

\begin{tabular}{|c|c|c|c|c|c|c|c|c|}
\hline Run & Designation & $\begin{array}{l}\text { Solid } \\
\text { yield } \\
(\%)\end{array}$ & $\begin{array}{c}\text { Glucan } \\
\text { (g 100 } \\
\mathrm{g}^{-1} \text { TS) }\end{array}$ & $\begin{array}{l}\text { Xylan } \\
\text { (g 100 } \\
\text { g }^{-1} \text { TS) }\end{array}$ & $\begin{array}{c}\text { Klason } \\
\text { lignin } \\
(\%)\end{array}$ & $\begin{array}{c}\text { Glucan } \\
\text { increase } \\
(\%)\end{array}$ & $\begin{array}{c}\text { Xylan } \\
\text { removal } \\
(\%)\end{array}$ & $\begin{array}{l}\text { Lignin } \\
\text { recovery } \\
(\%)\end{array}$ \\
\hline 1 & A-HSO & 12.27 & 14.34 & 0.00 & 84.61 & $-54.33^{*}$ & 100.00 & 340.08 \\
\hline 2 & B-HSO & 17.83 & 44.15 & 0.00 & 53.20 & 40.60 & 100.00 & 213.84 \\
\hline 3 & C-HSO & 22.04 & 20.98 & 0.00 & 76.74 & -33.18 & 100.00 & 308.47 \\
\hline 4 & D-HSO & 34.95 & 57.09 & 5.40 & 33.96 & 81.81 & 85.25 & 136.49 \\
\hline 5 & E-HSO & 32.83 & 40.29 & 6.80 & 51.11 & 28.31 & 81.43 & 205.43 \\
\hline 6 & F-HSO & 63.00 & 53.60 & 10.50 & 33.05 & 70.70 & 71.32 & 132.83 \\
\hline 7 & G-HSO & 40.69 & 39.28 & 14.15 & 44.65 & 25.09 & 61.35 & 179.49 \\
\hline 8 & H-HSO & 75.28 & 46.81 & 20.80 & 30.87 & 49.07 & 43.19 & 124.08 \\
\hline 9 & I-HSO & 46.48 & 49.48 & 10.60 & 37.69 & 57.58 & 71.05 & 151.50 \\
\hline 10 & $\mathrm{~J}-\mathrm{HSO}$ & 49.04 & 51.10 & 8.10 & 37.33 & 62.74 & 77.88 & 150.04 \\
\hline 11 & K-HSO & 34.03 & 42.54 & 4.30 & 52.12 & 35.47 & 88.26 & 209.51 \\
\hline 12 & L-HSO & 41.28 & 51.00 & 8.80 & 37.30 & 62.42 & 75.97 & 149.91 \\
\hline 13 & M-HSO & 51.44 & 58.80 & 4.80 & 35.72 & 87.26 & 86.89 & 143.59 \\
\hline 14 & N-HSO & 57.10 & 51.14 & 12.40 & 34.11 & 62.86 & 66.13 & 137.10 \\
\hline 15 & O-HSO & 20.02 & 8.12 & 0.00 & 89.28 & -74.14 & 100.00 & 358.85 \\
\hline 16 & P-HSO & 64.52 & 41.80 & 16.90 & 39.80 & 33.12 & 53.84 & 159.99 \\
\hline
\end{tabular}

Where * -ve sign indicates decrease in glucan content 
As indicated in Table 5.11, solid recovery increased with a decrease in reaction temperature and $\mathrm{H}_{2} \mathrm{SO}_{4}$ concentration employed for impregnation of sugarcane bagasse. Solid recovery increased from 12.27 to $17.83(45.31 \%)$ when pretreatment temperature $\left(200{ }^{\circ} \mathrm{C}\right)$ and reaction time (19 min) held constant, and $\mathrm{H}_{2} \mathrm{SO}_{4}$ concentration decreased from 3 to $1 \%(\mathrm{w} / \mathrm{v})$. While, when the reaction time was decreased to 5 min for pretreatment C-HSO and D-HSO at the same reaction temperature of $200{ }^{\circ} \mathrm{C}$, a decrease in $\mathrm{H}_{2} \mathrm{SO}_{4}$ concentration resulted in $58.57 \%$ (22.04 to $34.95 \%$ ) increase in solid recovery.

It showed that a decrease in reaction time increased the solid recovery when reaction temperature and $\mathrm{H}_{2} \mathrm{SO}_{4}$ concentrations were held constant. On the other hand, at a reaction temperature of $160{ }^{\circ} \mathrm{C}$, a decrease in $\mathrm{H}_{2} \mathrm{SO}_{4}$ from 3 to $1 \%$ (w/v) resulted into approx 2-fold increase in solid recovery (32.83 to $63.00 \%$ ) While, $85 \%$ increase (40.69 to $75.28 \%$ ) was observed between pretreatment $\mathrm{G}-\mathrm{HSO}\left(160^{\circ} \mathrm{C}, 5 \mathrm{~min}, 3 \% \mathrm{H}_{2} \mathrm{SO}_{4}\right)$ and pretreatment $\mathrm{H}-\mathrm{HSO}\left(160^{\circ} \mathrm{C}, 5 \mathrm{~min}, 1 \% \mathrm{w} / \mathrm{v}\right.$ $\left.\mathrm{H}_{2} \mathrm{SO}_{4}\right)$

A comparison indicated that when reaction temperature was decreased from $200^{\circ} \mathrm{C}$ (pretreatment A-HSO) to $160^{\circ} \mathrm{C}$ (pretreatment E-HSO) keeping reaction time (19 min) and $\mathrm{H}_{2} \mathrm{SO}_{4}$ concentration (3\%) held constant, solid recovery improved $167.56 \%$ (12.27 to $32.83 \%$ ). Similarly, a decrease in temperature to $160^{\circ} \mathrm{C}$ resulted in $253.3 \%$ (17.83 to $63.00 \%$ ), $84.61 \%$ (22.04 to 40.69 ), and $115.39 \%$ (34.95 to $75.28 \%$ ) increase for pretreatment runs F-HSO, G-HSO, and H-HSO, respectively in comparison to pretreatment runs B-HSO, C-HSO, and D-HSO.

Solid recovery comparison for pretreatment runs K-HSO $\left(3.68 \% \mathrm{w} / \mathrm{v} \mathrm{H}_{2} \mathrm{SO}_{4}\right)$ and $\mathrm{L}-\mathrm{HSO}$ $\left(0.32 \% \mathrm{w} / \mathrm{v} \mathrm{H}_{2} \mathrm{SO}_{4}\right)$ indicated $116.69 \%$ (19.05 to $\left.41.28 \%\right)$ increase where reaction temperature $\left(180{ }^{\circ} \mathrm{C}\right)$ and reaction time $(12 \mathrm{~min})$ held constant. Lesser increase $(11 \%)$ was observed for maximum (23.76 $\mathrm{min})$ and minimum $(0.24 \mathrm{~min})$ reaction time studied at conditions; reaction temperature of $180{ }^{\circ} \mathrm{C}$ and $\mathrm{H}_{2} \mathrm{SO}_{4}$ concentration (2\%). Furthermore, a decrease in reaction temperature from 213.6 to $146.4{ }^{\circ} \mathrm{C}$ resulted into $222.27 \%$ (20.02 to $64.52 \%$ ) increase in solid yield.

Lu et al ( $\mathrm{Lu}$ et al., 2009) conducted $\mathrm{H}_{2} \mathrm{SO}_{4}$-catalyzed hydrothermal pretreatment of rapeseed straw for ethanol conversion and reported maximum solid yield of $88.7 \%$ at $\mathrm{H}_{2} \mathrm{SO}_{4}$ loading of $0.5(\% \mathrm{w} / \mathrm{w}), 5 \mathrm{~min}$ reaction time, $20 \%(\mathrm{w} / \mathrm{w})$ solid loading and reaction temperature of 180 C. In another study, Yang et al. (Yang et al., 2012) reported 92.4\% solid yield for triploid 
poplar chips at reaction temperature of $100^{\circ} \mathrm{C}$ for $2 \mathrm{hrs}$ reaction time and $\mathrm{H}_{2} \mathrm{SO}_{4}$ loading of $0.5(\%$ $\mathrm{v} / \mathrm{v})$. In the current study, maximum solid yield (64.52\%) was achieved at the lowest pretreatment temperature $\left(146.4{ }^{\circ} \mathrm{C}, 12 \mathrm{~min}, 2 \% \mathrm{v} / \mathrm{v} \mathrm{H}_{2} \mathrm{SO}_{4}\right)$. Low solid yield in comparison to referenced studies was due to higher $\mathrm{H}_{2} \mathrm{SO}_{4}$ concentration employed.

Glucan content was affected notably due to pretreatment parameters as represented in Table 5.11. Glucan content in pretreatment run A-HSO and C-HSO were 14.34 and $44.15 \mathrm{~g} 100$ $\mathrm{g}^{-1}$ TS indicating cellulose solubilization owing to lower than raw sugarcane bagasse $31.4{\mathrm{~g} 100 \mathrm{~g}^{-}}^{-}$ ${ }^{1}$ TS for pretreatment A-HSO. However, pretreatment run B-HSO resulted in an increase in glucan content showing lower $\mathrm{H}_{2} \mathrm{SO}_{4}$ concentration was unable to affect the cellulose crystallinity even at $200{ }^{\circ} \mathrm{C}$.

Cellulose is a very coherent and stabilized structure that reported to start to solubilize above $230{ }^{\circ} \mathrm{C}$ and completely decompose at $295{ }^{\circ} \mathrm{C}$ (Sakaki et al., 2002). However, the current study revealed that cellulose degradation could be initiated at a lower temperature $\left(200{ }^{\circ} \mathrm{C}\right)$ if substrate solubilized with $3 \% \mathrm{H}_{2} \mathrm{SO}_{4}$ before hydrothermal pretreatment. Pretreatments conducted at $200{ }^{\circ} \mathrm{C}$ indicated that utilization of $3 \% \mathrm{H}_{2} \mathrm{SO}_{4}$ resulted into cellulose solubilization.

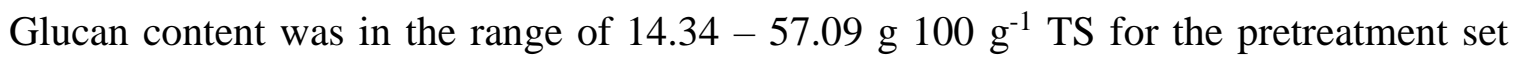
conducted at $200{ }^{\circ} \mathrm{C}$, lower $\mathrm{H}_{2} \mathrm{SO}_{4}$ concentration resulted in percent increase in glucan complemented with xylan and lignin solubilization. While, glucan content was in the range of

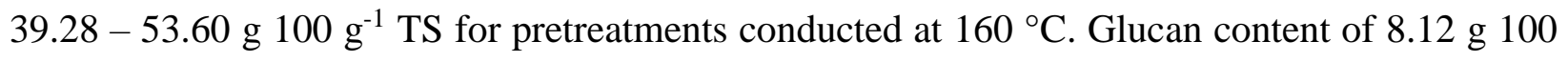
$\mathrm{g}^{-1}$ TS for pretreatment run O-HSO $\left(213.6{ }^{\circ} \mathrm{C}, 12 \mathrm{~min} 2 \% \mathrm{H}_{2} \mathrm{SO}_{4}\right)$ indicated that even $2 \% \mathrm{H}_{2} \mathrm{SO}_{4}$ could result into cellulose solubilization at temperature $213{ }^{\circ} \mathrm{C}$ complemented with $100 \%$ xylan removal and $358.85 \%$ klason lignin recovery in pretreated solid. However, $146.4{ }^{\circ} \mathrm{C}$ (pretreatment run $\mathrm{P}-\mathrm{HSO}$ ) could not dissociate cellulose structure with $2 \% \mathrm{H}_{2} \mathrm{SO}_{4}$ as indicated by higher glucan

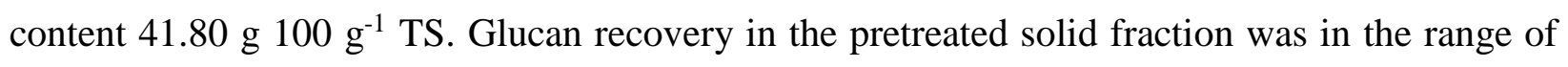
$25.83-187.01 \%$.

Lu et al. (Lu et al., 2009) reported maximum of $105.1 \%$ glucan recovery in the waterinsoluble solid fraction of $\mathrm{H}_{2} \mathrm{SO}_{4}$-catalyzed rapeseed straw at $1 \% \mathrm{H}_{2} \mathrm{SO}_{4}, 10$ min reaction time with solid content of $15 \%$ at $180^{\circ} \mathrm{C}$. However, current study could not be compared on the grounds of different pretreatment conditions, $\mathrm{H}_{2} \mathrm{SO}_{4}$ employed and variation in feedstock composition. 
Xylan content indicated that most of the xylose was solubilized during the pretreatment as it was not observed at higher severity $\left(200{ }^{\circ} \mathrm{C}, 19 \min 3 \% \mathrm{H}_{2} \mathrm{SO}_{4}\right)$. Hydrothermal pretreatment is aimed at the removal of hemicellulose (xylan and arabinan) by xylan depolymerization and cleavage of acetyl groups from hemicellulose as reported by (Xiao et al., 2011; Rocha et al., 2013; Senila et al., 2014). $\mathrm{H}_{2} \mathrm{SO}_{4}$ further catalyze the process by lowering the $\mathrm{pH}$. Xylan content was in

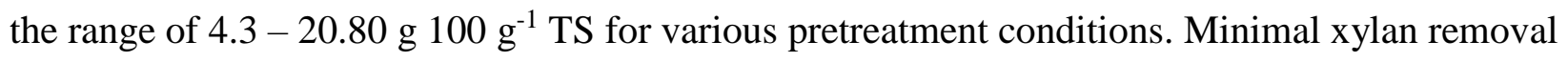
was noted for pretreatment run $\mathrm{H}-\mathrm{HSO}$ conducted at $160{ }^{\circ} \mathrm{C}, 5 \mathrm{~min}$ and $1 \% \mathrm{H}_{2} \mathrm{SO}_{4}(\% \mathrm{w} / \mathrm{v})$. Xylan removal was recorded in the range of 43.19 to $100 \%$. Even though minimal temperature (146.4 ${ }^{\circ} \mathrm{C}$ ) was studied for pretreatment P-HSO, xylan solubilization was lower on account of higher $\mathrm{H}_{2} \mathrm{SO}_{4}$ concentration employed.

Yang et al. (Yang et al., 2012) reported 100\% xylan removal for hydrothermal pretreatment of triploid poplar at $200{ }^{\circ} \mathrm{C}$ catalyzed with $0.5 \mathrm{H}_{2} \mathrm{SO}_{4}$. In another study, $\mathrm{Lu}$ and colleagues (Lu et $a l ., 2009$ ) observed a decrease in xylan content from $19.6 \%$ to $1.4 \%$ for hydrothermal pretreatment of rapeseed straw at $180{ }^{\circ} \mathrm{C}, 2 \% \mathrm{w} / \mathrm{w} \mathrm{H}_{2} \mathrm{SO}_{4}, 20 \mathrm{~min}$ reaction time and with a solid content ratio of $5 \%(\mathrm{w} / \mathrm{w})$.

Second-order polynomial equation was derived from the experimental data of glucan content (g $100 \mathrm{~g}^{-1} \mathrm{TS}$ ) to determine the impact of pretreatment parameters; reaction temperature, reaction time, and $\mathrm{H}_{2} \mathrm{SO}_{4}$ concentration on their availability in the solid fraction in response to $\mathrm{H}_{2} \mathrm{SO}_{4}$ assisted hydrothermal pretreatment. Equation 5.7 represents the second order polynomial equations for glucan (g $100 \mathrm{~g}^{-1} \mathrm{TS}$ ). The model equation presented that linear terms of temperature $\left(X_{1}\right), \mathrm{H}_{2} \mathrm{SO}_{4}$ concentration $\left(X_{3}\right)$, quadratic term of temperature $X_{1}^{2}$, and interaction between temperature and concentration $X_{1} X_{3}$ were negatively significant with magnitude values of 7.32 , $7.39,9.46$, and 5.63, respectively. While, linear term of reaction time $\left(X_{2}\right)$, quadratic terms of reaction time $\left(X_{2}^{2}\right)$ and $\mathrm{H}_{2} \mathrm{SO}_{4}$ concentration $\left(X_{3}^{2}\right)$, and interaction terms of $X_{1} X_{2}$ and $X_{2} X_{3}$ were insignificant as indicated in ANOVA (Table 5.12).

$$
\begin{array}{rr}
\text { Glucan }\left(\mathrm{g} 100 \mathrm{~g}^{-1} \mathrm{TS}\right)=50.49-7.32 X_{1}+0.08 X_{2}-7.39 X_{3}-9.46 X_{1}{ }^{2}+1.15 X_{2}{ }^{2}- \\
1.75 X_{3}{ }^{2}-3.42 X_{1} X_{2}-5.63 X_{1} X_{3}+0.06 X_{2} X_{3} & \text { Equation } 5.7
\end{array}
$$


Table 5.12 - Analysis of variance (ANOVA) for glucan content (g $\left.100 \mathrm{~g}^{-1} \mathrm{TS}\right)$ in pretreated solids impregnated in $\mathrm{H}_{2} \mathrm{SO}_{4}$

\begin{tabular}{|c|c|c|c|c|c|}
\hline Source & Sum of square & Degree of freedom & Mean Square & $F$ value & P-value (prob. $>F$ ) \\
\hline$X_{1}(T)^{\alpha}$ & 733.206 & 1 & 733.2064 & 558.8102 & $0.026915 *$ \\
\hline$X_{1}^{2}$ & 829.291 & 1 & 829.2913 & 632.0410 & $0.025309^{*}$ \\
\hline$X_{2}(t)^{\beta}$ & 0.091 & 1 & 0.0913 & 0.0696 & 0.835781 \\
\hline$X_{2}^{2}$ & 12.208 & 1 & 12.2079 & 9.3042 & 0.201680 \\
\hline $\begin{array}{c}X_{3} \\
\left(\mathrm{H}_{2} \mathrm{SO}_{4} \text { Conc. }\right)^{¥}\end{array}$ & 746.821 & 1 & 746.8206 & 569.1862 & $0.026669 *$ \\
\hline $\mathrm{X}_{3}^{2}$ & 28.354 & 1 & 28.3536 & 21.6096 & 0.134893 \\
\hline$X_{1} X_{2}$ & 93.717 & 1 & 93.7170 & 71.4260 & 0.074979 \\
\hline$X_{1} X_{3}$ & 254.002 & 1 & 254.0018 & 193.5865 & $0.045677^{*}$ \\
\hline$X_{2} X_{3}$ & 0.033 & 1 & 0.0332 & 0.0253 & 0.899570 \\
\hline Lack of Fit & 379.358 & 5 & 75.8717 & 57.8253 & 0.099496 \\
\hline Pure Error & 1.312 & 1 & 1.3121 & & \\
\hline Total SS & 3340.561 & 15 & & & \\
\hline
\end{tabular}

Klason lignin increased with a successive increase in pretreatment temperature and $\mathrm{H}_{2} \mathrm{SO}_{4}$ concentration (Table 5.11). Klason lignin was in the range of 33.96 to $84.61 \%$ for pretreatment set A-HSO - D-HSO conducted at $200{ }^{\circ} \mathrm{C}$ with varying retention time and $\mathrm{H}_{2} \mathrm{SO}_{4}$. A decrease in $\mathrm{H}_{2} \mathrm{SO}_{4}$ (3 to $1 \%$ ) resulted in $37.12 \%$ decrease in klason lignin keeping reaction time (19 min) and reaction temperature $200{ }^{\circ} \mathrm{C}$ held constant. A predominant influence of decreasing reaction temperature was observed on klason lignin where it was in the range of 30.57 to $51.11 \%$ for pretreatments E-HSO - H-HSO.

Reaction temperature directly influence on the release of hemicellulosic sugar thereby have a direct impact on klason lignin. Hydrothermal pretreatment not only increases the lignin content but it also effectively modify the structure of lignin due to simultaneous de- and re-polymerization reactions of lignin (Chang and Holtzapple, 2000; Li et al., 2007). Yang et al (Yang et al., 2012) reported lignin redeposition on the polymeric structure during dilute acid pretreatment under severe condition resulting into a physical barrier to enzymatic action. 
It was observed in the current study that a decrease in reaction temperature $\left(200\right.$ to $\left.160{ }^{\circ} \mathrm{C}\right)$ resulted in $40 \%$ (84.61 to $51.11 \%$ ) decrease in klason lignin for pretreatment run E-HSO in comparison to pretreatment run A-HSO, where reaction time and $\mathrm{H}_{2} \mathrm{SO}_{4}$ conc held constant. It was observed that decrease in reaction time from 23.76 to 0.24 min had virtually no impact on klason lignin where pretreatment temperature $\left(180^{\circ} \mathrm{C}\right)$ and $\mathrm{H}_{2} \mathrm{SO}_{4}(2 \% \mathrm{w} / \mathrm{v})$ held constant. It indicated that reaction temperature was a more important factor in comparison to reaction time for the release of sugars and subsequently for klason lignin content.

In comparison, when reaction temperature was decreased from 213.6 to $146.6{ }^{\circ} \mathrm{C}, 55.42 \%$ decrease in klason lignin was observed between pretreatment runs O-HSO and P-HSO. Yang et al (Yang et al., 2012) reported an increase in klason lignin from 20.78 to $50.35 \%$ with increasing severity for triploid poplar wood chips. A possible reason for an increase in klason lignin is explained by (Hu and Ragauskas, 2012), that xylose depolymerized into furfural during hydrothermal pretreatment. Repolymerization of furfural and other aromatic compounds produced during pretreatment may turn into pseudo-lignin, which results in an increase in klason lignin. Ramos et al (Ramos, 2003) reported that $\mathrm{C}_{5}$ sugars are the principal source of pseudo-lignin formation.

Second-order polynomial equation (Equation 5.8) was derived from the lignin recovery experimental data to determine the impact of studied parameters. Maximum lignin recovery $(358.85 \%)$ was observed for the maximum temperature employed $\left(213.6{ }^{\circ} \mathrm{C}\right)$ for pretreatment run O-HSO. The model explained that studied parameters; temperature $X_{1}$, time $X_{2}$, and $\mathrm{H}_{2} \mathrm{SO}_{4}$ concentration $X_{3}$ showed significant impact as presented in ANOVA (Table 5.13).

The model presented that linear model terms $X_{1}, X_{2}, X_{3}$ and quadratic model terms $X_{1}^{2}$ and $X_{3}{ }^{2}$ showed positive significant effect with magnitude values of 50.63, 11.32, 38.55, 40.59 and 12.41 , respectively while quadratic model term $X_{2}^{2}$ showed negative non-significant impact with magnitude value of 1.51. The interaction of studied parameters indicated that $X_{1} X_{2}$ and $X_{1} X_{3}$ showed positive significant impact whilst $X_{2} X_{3}$ showed the negative non-significant effect on lignin recovery in pretreated solids.

\% lignin Recovery $=149.87+50.63 X_{1}+11.32 X_{2}+38.55 X_{3}+40.59 X_{1}{ }^{2}-1.51 X_{2}{ }^{2}+$ $12.41 X_{3}^{2}+9.28 X_{1} X_{2}+21.28 X_{1} X_{3}-3.57 X_{2} X_{3}$ 
Table 5.13 - Analysis of variance for percent lignin recovery in pretreated solids impregnated in $\mathrm{H}_{2} \mathrm{SO}_{4}$

\begin{tabular}{|c|c|c|c|c|c|}
\hline Source & Sum of square & Degree of freedom & Mean Square & $F$ value & P-value (prob. $>F)$ \\
\hline$X_{1}(T)^{\alpha}$ & 35012.71 & 1 & 35012.71 & 33048.67 & $0.003502 *$ \\
\hline$X_{1}^{2}$ & 15264.82 & 1 & 15264.82 & 14408.54 & $0.005303^{*}$ \\
\hline$X_{2}(t)^{\beta}$ & 1749.63 & 1 & 1749.63 & 1651.49 & $0.015662^{*}$ \\
\hline$X_{2}^{2}$ & 21.02 & 1 & 21.02 & 19.84 & 0.140605 \\
\hline $\begin{array}{c}X_{3} \\
\left(\mathrm{H}_{2} \mathrm{SO}_{4} \text { Conc. }\right)^{¥}\end{array}$ & 20295.47 & 1 & 20295.47 & 19157.00 & $0.004599 *$ \\
\hline $\mathrm{X}_{3}^{2}$ & 1427.36 & 1 & 1427.36 & 1347.30 & $0.017340^{*}$ \\
\hline$X_{1} X_{2}$ & 689.28 & 1 & 689.28 & 650.61 & $0.024946^{*}$ \\
\hline$X_{1} X_{3}$ & 3621.49 & 1 & 3621.49 & 3418.35 & $0.010888 *$ \\
\hline$X_{2} X_{3}$ & 101.92 & 1 & 101.92 & 96.20 & 0.064683 \\
\hline Lack of Fit & 6511.21 & 5 & 1302.24 & 1229.19 & $0.021651^{*}$ \\
\hline Pure Error & 1.06 & 1 & 1.06 & & \\
\hline Total SS & 87149.55 & 15 & & & \\
\hline
\end{tabular}

$\mathrm{R}$-square $=0.925$, Adj. R-square $=0.813 .726, \mathrm{MS}$ pure error $=1.06,{ }^{\alpha}(\mathrm{T})$ represents Temperature, ${ }^{\beta}(\mathrm{t})$ represents time, and ${ }^{¥}$ (Conc.) represents $\mathrm{H}_{2} \mathrm{O}_{2}$ concentration

5.8.1 Morphological characteristics of $\mathrm{H}_{2} \mathrm{SO}_{4}$ assisted hydrothermally pretreated solid fraction

Only one pretreatment O-HSO was selected to determine the morphological characteristics in response to $\mathrm{H}_{2} \mathrm{SO}_{4}$ impregnation before hydrothermal pretreatment because this pretreatment resulted in the lowest methane $0.58 \mathrm{Nmmol} \mathrm{g}^{-1}$ TVS in this phase of the study. The surface of untreated sugarcane bagasse showed smooth intact fibril symmetry rather compact structure (Fig $5.21 \mathrm{~A}$ ) in comparison to an extremely shattered structure for O-HSO (Fig 5.21 B) that could be attributed to cellulose disintegration and disturbance of lignin-carbohydrate meshwork. It further describes a decrease in particle size that could play a significant role in the availability of larger surface area for microbial action, but lignin deposition could severely affect enzymatic action.

Fig 5.21 B further indicated that hydrothermal pretreatment at higher severity $\left(213.6{ }^{\circ} \mathrm{C}\right.$, $12 \mathrm{~min}, 2 \% \mathrm{H}_{2} \mathrm{SO}_{4}$ ) significantly altered the structure at ultra-molecular level. A huge number of drop-like structures are quite visible on the surface of pretreated residue (Fig 5.21 C). These structures are reported as lignin droplets in literature. Several researchers reported about the 
presence of lignin droplets on the surface of pretreated residues, which have a negative impact on cellulose hydrolysis in downstream processing (Donohoe et al., 2008; Li et al., 2014).

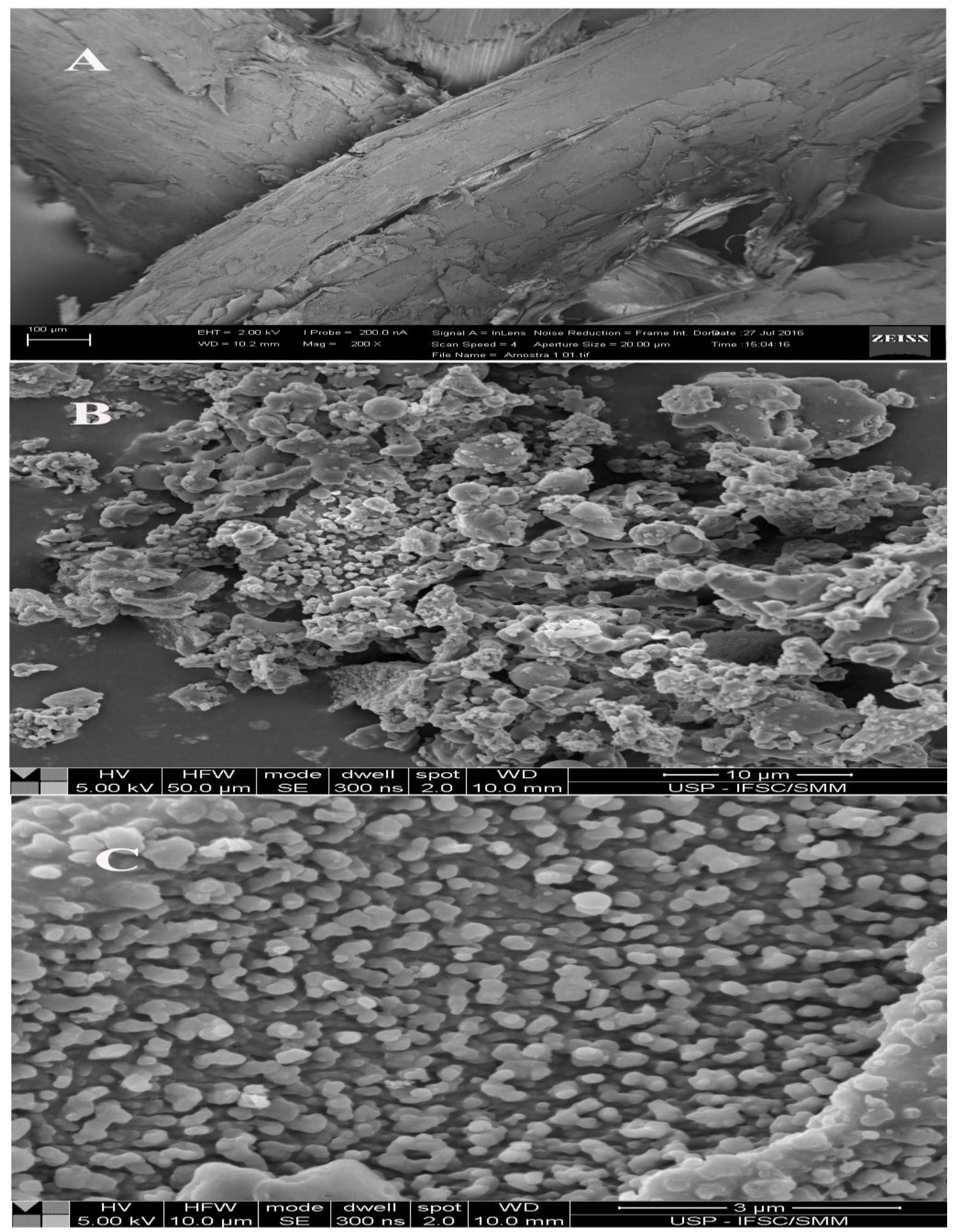

Figure 5.21 - Comparison between SEM images of untreated sugarcane bagasse (A) and O-HSO $(\mathrm{B}, \mathrm{C})$ 
Selig et al (Selig et al., 2007) speculated that at higher temperature lignin mass turns to fluid (phase change) that could transfuse through cell wall matrix into the liquid stream and redeposit on the surface, as spherical droplets (Fig 5.21 C). Commercial cellulase preparations are reported to bind to lignin unproductively (Berlin et al., 2006; Yang and Wyman, 2006), thereby impeding cellulose hydrolysis. This could be the reason that digestion experiments of O-HSO resulted in methanogenic inhibition on the basis of unavailability of cellulosic material for hydrolytic bacteria to initiate the chain process. The impact of $\mathrm{H}_{2} \mathrm{SO}_{4}$ assisted pretreatment on visual appearance of sugarcane bagasse is depicted in Fig 5.22.
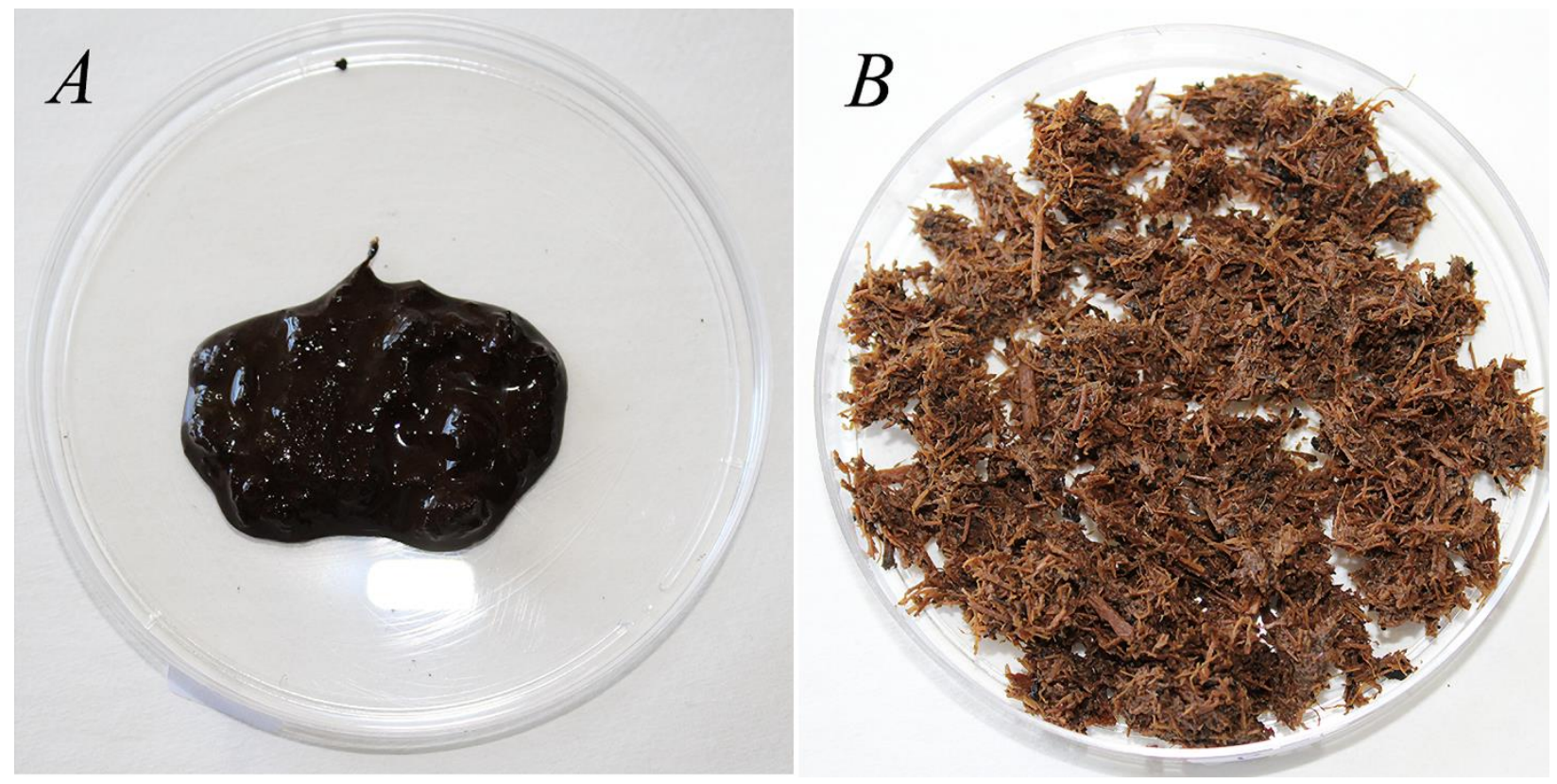

Figure 5.22 - Impact of $\mathrm{H}_{2} \mathrm{SO}_{4}$ assisted hydrothermal pretreatment on visual appearance of sugarcane bagasse; (A) Highest studied temperature (pretreatment run O-HSO $-213.6{ }^{\circ} \mathrm{C}$ ), (B) Lowest studied temperature (pretreatment run $\mathrm{P}-\mathrm{HSO}-146.4^{\circ} \mathrm{C}$ )

\subsection{Chemical composition of liquid hydrolysate obtained from $\mathrm{H}_{2} \mathrm{SO}_{4}$ assisted Hydrothermal pretreatment}

Liquid hydrolysate fraction separated from pretreated slurry was characterized for following parameters; chemical oxygen demand, total carbohydrate content, total phenolic content (TPC), organic acids, sulfate $\left(\mathrm{SO}_{4}{ }^{-2}\right)$ content, and monomeric sugars; glucose, xylose and arabinose and furanic compounds; furfural and 5-hydroxymethylfurfural (Table 5.14 and 5.15).

$\mathrm{H}_{2} \mathrm{SO}_{4}$ impregnation of sugarcane bagasse facilitated the removal of hemicellulose partially removing lignin and hydrating cellulose, therefore, resulting in the release of monomeric 
sugars, oligomers, and organic acids from cell wall matrix into hydrolysate. This resulted in an overall increase in COD of resulting hydrolysate stream. In the current study, COD value of hydrolysate affected by the joint impact of pretreatment parameters, $\mathrm{H}_{2} \mathrm{SO}_{4}$ concentration, reaction time, and reaction temperature.

Table 5.14 - Characterization of liquid hydrolysate obtained from $\mathrm{H}_{2} \mathrm{SO}_{4}$ aided hydrothermal pretreatment

\begin{tabular}{|c|c|c|c|c|c|c|c|}
\hline $\begin{array}{l}\text { Pretreatment } \\
\text { run }\end{array}$ & $\begin{array}{l}\text { Temperature } \\
\left({ }^{\circ} \mathbf{C}\right)\end{array}$ & $\begin{array}{l}\text { Time } \\
\text { (min) }\end{array}$ & $\begin{array}{c}\mathrm{H}_{2} \mathrm{SO}_{4} \\
(\mathrm{w} / \mathrm{v} \\
\%)\end{array}$ & $\begin{array}{l}\mathrm{COD}_{s} \\
\left(\mathrm{~g} \mathrm{~L}^{-1}\right)\end{array}$ & $\begin{array}{c}\text { Total } \\
\text { Carbohydrate } \\
\left(\mathrm{g} \mathrm{L}^{-1}\right)\end{array}$ & $\begin{array}{c}\text { Phenolic } \\
\text { content } \\
\text { (ppm) }\end{array}$ & $\begin{array}{l}\mathrm{SO}^{-2} \\
\mathrm{mg} \mathrm{L}^{-}\end{array}$ \\
\hline A-HSO & 200 & 19 & 3 & 16.81 & 2.96 & 1014.38 & 4702.5 \\
\hline B-HSO & 200 & 19 & 1 & 14.97 & 6.25 & 1101.88 & 1250 \\
\hline C-HSO & 200 & 5 & 3 & 25.20 & 13.26 & 1399.69 & 5655 \\
\hline D-HSO & 200 & 5 & 1 & 18.61 & 6.05 & 683.13 & 1445 \\
\hline E-HSO & 160 & 19 & 3 & 21.79 & 11.19 & 1674.22 & 5245 \\
\hline F-HSO & 160 & 19 & 1 & 15.02 & 12.98 & 708.13 & 1765 \\
\hline G-HSO & 160 & 5 & 3 & 19.64 & 20.90 & 1008.13 & 5210 \\
\hline H-HSO & 160 & 5 & 1 & 16.58 & 17.06 & 689.38 & 1520 \\
\hline I-HSO & 180 & 12 & 2 & 8.91 & 5.74 & 808.13 & 4328.5 \\
\hline J-HSO & 180 & 12 & 2 & 8.33 & 4.96 & 826.88 & 3657.5 \\
\hline K-HSO & 180 & 12 & 3.68 & 20.09 & 12.56 & 1369.53 & 7240 \\
\hline L-HSO & 180 & 12 & 0.32 & 11.77 & 8.20 & 596.72 & 360 \\
\hline M-HSO & 180 & 23.76 & 2 & 9.24 & 7.26 & 901.88 & 3569.5 \\
\hline N-HSO & 180 & 0.24 & 2 & 18.83 & 16.31 & 801.88 & 3811.5 \\
\hline O-HSO & 213.6 & 12 & 2 & 24.07 & 8.55 & 1615.31 & 3338.5 \\
\hline P-HSO & 146.4 & 12 & 2 & 17.01 & 13.06 & 658.13 & 3954.5 \\
\hline
\end{tabular}

For a reaction temperature of $200{ }^{\circ} \mathrm{C}$, COD value varied from 14.97 to $25.20 \mathrm{~g} \mathrm{~L}^{-1}$. Higher reaction time (19 min) resulted in lower COD value (14.97-16.87 $\mathrm{g} \mathrm{L}^{-1}$ ) for pretreatment runs AHSO and B-HSO in comparison to lower reaction time of $5 \mathrm{~min}$., where it was in the range of 18.61-25.20 $\mathrm{g} \mathrm{L}^{-1}$ for pretreatment runs C-HSO and D-HSO. Lower COD value at higher retention time could be justified by the argument some organics converted into volatiles and water. Quitain 
et al (Quitain et al., 2002) reported that formic and acetic acids transformed to water and volatiles thereby decreasing COD value.

For a reaction temperature of $160{ }^{\circ} \mathrm{C}$, COD varied from 15.02 to $21.79 \mathrm{~g} \mathrm{~L}^{-1}$. Higher reaction time (19 $\mathrm{min}$ ) resulted in $31.06 \%$ (21.79 to $\left.15.02 \mathrm{~g} \mathrm{~L}^{-1}\right)$, while lower reaction time (5 min) resulted in $15.58 \%$ (19.64 to $16.58 \mathrm{~g} \mathrm{~L}^{-1}$ ) decrease in $\mathrm{COD}$ value when $\mathrm{H}_{2} \mathrm{SO}_{4}$ concentration decreased from 3 to $1 \%$ at a reaction temperature of $160{ }^{\circ} \mathrm{C}$.

COD values at central points (pretreatment runs I-HSO and J-HSO) were not much differed from each other as expected. A decrease in $\mathrm{H}_{2} \mathrm{SO}_{4}$ concentration from 3.68 to $0.32 \%$ (w/v) resulted into $41.41 \%$ (20.09 to $11.77 \mathrm{~g} \mathrm{~L}^{-1}$ ) decrease in COD, while a decrease in reaction time from 23.76 to 0.24 min resulted in $103.78 \%$ (9.24 to $18.83 \mathrm{~g} \mathrm{~L}^{-1}$ ) increase in COD. It implicated that $\mathrm{H}_{2} \mathrm{SO}_{4}$ and reaction time notably contributed to the release of organics into the liquid stream to aid in COD value. The decrease in reaction temperature from 213.6 to $146.4{ }^{\circ} \mathrm{C}$ indicated $29.33 \%$ decrease in COD value of hydrolysate.

Total carbohydrates are the amount of sugar monomers and oligomers released in response to pretreatment. Table 5.14 indicated that pretreatment parameters collectively affected the total carbohydrate content in the hydrolysate. Total carbohydrates varied between 2.96 and $13.26 \mathrm{~g} \mathrm{~L}^{-1}$ for pretreatments conducted at $200{ }^{\circ} \mathrm{C}$ implicating that reaction time and $\mathrm{H}_{2} \mathrm{SO}_{4}$ concentration had an effect on the release of sugars.

Higher reaction time (19 min) resulted in lower total carbohydrates $\left(2.96\right.$ to $\left.6.25 \mathrm{~g} \mathrm{~L}^{-1}\right)$ in comparison to $5 \mathrm{~min}$ reaction time where it was higher 6.05 (pretreatment run D-HSO) and 13.26 $\mathrm{g} \mathrm{L}^{-1}$ (pretreatment run C-HSO). It was seen that higher reaction time coupled with higher $\mathrm{H}_{2} \mathrm{SO}_{4}$ concentration resulted into lower carbohydrates released possibly due to degradation to organic acids.

Pretreatments conducted at a reaction temperature of $160{ }^{\circ} \mathrm{C}$ and 5 min reaction time presented higher carbohydrate content than at 19 min reaction time. Furthermore, pretreatment GHSO (3\% w/v H2 $\mathrm{SO}_{4}$ ) showed highest (20.90 $\left.\mathrm{g} \mathrm{L}^{-1}\right)$ carbohydrate content in the tested conditions. A comparison between pretreatment conducted at 200 and $160{ }^{\circ} \mathrm{C}$, while keeping reaction time and $\mathrm{H}_{2} \mathrm{SO}_{4}$ concentration constant, 278.04, 107.68, 57.62 and $181.98 \%$ increase was observed for pretreatment runs E-HSO, F-HSO, G-HSO, and I-HSO, respectively, in comparison to 
pretreatment runs A-HSO, B-HSO, C-HSO, and D-HSO. Central points differed only $13.58 \%$ from each other.

Total carbohydrate content in comparison to decrease in $\mathrm{H}_{2} \mathrm{SO}_{4}$ concentration from 3.68 to $0.32(\% \mathrm{w} / \mathrm{v})$ indicated $34.71 \%$ (12.56 to $\left.8.20 \mathrm{~g} \mathrm{~L}^{-1}\right)$ decrease with other parameters held constant at $180{ }^{\circ} \mathrm{C}$ and $12 \mathrm{~min}$. On the other hand, a decrease in reaction time from 23.76 to $0.24 \mathrm{~min}$ indicated $124.66 \%$ (7.26 to $16.31 \mathrm{~g} \mathrm{~L}^{-1}$ ) increase in carbohydrate content. Similarly, reduction in reaction temperature showed $52.75 \%$ ( 8.55 to $\left.13.06 \mathrm{~g} \mathrm{~L}^{-1}\right)$ increase in total carbohydrate content for pretreatment run P-HSO. Higher carbohydrate content at lower reaction time $(0.24 \mathrm{~min})$ in comparison to pretreatment run M-HSO demonstrated a higher sugar degradation that longer the sugarcane bagasse remain in contact with reaction medium higher degradation of sugars will result and vice versa.

Total phenolic content varied from 683.13 to $1101.88 \mathrm{ppm}$ for pretreatments conducted at $200{ }^{\circ} \mathrm{C}$. Much lower phenolics were observed in hydrolysate of $\mathrm{H}_{2} \mathrm{SO}_{4}$ pretreatment in comparison to $\mathrm{H}_{2} \mathrm{O}_{2}$ pretreatment where it was in the range of 1316.25 to $3005.63 \mathrm{ppm}$ at $200{ }^{\circ} \mathrm{C}$. This much difference can be justified that $\mathrm{H}_{2} \mathrm{SO}_{4}$ primarily aimed to remove hemicellulose and partially degrade lignin (Kim et al., 2005), while $\mathrm{H}_{2} \mathrm{O}_{2}$ principally act to delignify lignocellulosic biomass (Chaturvedi and Verma, 2013).

Phenolic contents for pretreatments conducted at $160{ }^{\circ} \mathrm{C}$ varied between 689.38 to 1674.22 ppm. It was observed that decrease in $\mathrm{H}_{2} \mathrm{SO}_{4}$ from 3 to $1 \%$ resulted in $57.70 \%$ (1674.22 to 708.14 $\mathrm{ppm}$ ) and $31.62 \%$ (1008.13 to $689.38 \mathrm{ppm}$ ) decrease in phenolic content for a reaction temperature of $160{ }^{\circ} \mathrm{C}, 19 \mathrm{~min}$ and $5 \mathrm{~min}$, respectively. A comparison between pretreatment conducted at 200 and $160{ }^{\circ} \mathrm{C}$ showed $65.05 \%$ (1014.38 to $1674.22 \mathrm{ppm}$ ) increase for pretreatment run E-HSO in comparison to pretreatment run A-HSO. However, $35.73 \%$ and $27.96 \%$ decrease was noted in phenolic contents for pretreatment runs F-HSO and G-HSO in comparison to pretreatment runs B$\mathrm{HSO}$ and $\mathrm{C}-\mathrm{HSO}$, respectively. Central points presented $2.32 \%$ difference in at reaction temperature $180{ }^{\circ} \mathrm{C}$, for $12 \mathrm{~min}$ and $2 \%(\mathrm{w} / \mathrm{v}) \mathrm{H}_{2} \mathrm{SO}_{4}$. A decrease in $\mathrm{H}_{2} \mathrm{SO}_{4}$ from 3.68 to $0.32 \%$ resulted in $56.43 \%$ (1369.53 to $596.72 \mathrm{ppm}$ ) decrease in phenolic content. On the other hand, a decrease in reaction time from 23.76 to $0.24 \mathrm{~min}$ and decrease in reaction temperature (213.6 to $146.4{ }^{\circ} \mathrm{C}$ ) resulted in $11.09 \%(901.88$ to $801.88 \mathrm{ppm})$ and $59.26 \%$ (1615.31 to $\left.658.13 \mathrm{ppm}\right)$ decrease in phenolic contents of liquid hydrolysate, respectively. 
Since sugarcane bagasse was impregnated in $\mathrm{H}_{2} \mathrm{SO}_{4}$ prior to hydrothermal pretreatment, the appearance of sulfate in the liquid filtrate was inevitable; sulfate concentration in the liquid was proportional to $\mathrm{H}_{2} \mathrm{SO}_{4}$ concentration employed for the impregnation. However, reaction temperature and reaction time of hydrothermal pretreatment had an effect on sulfate concentration in the liquid hydrolysate. Minimal concentration $\left(360 \mathrm{mg} \mathrm{L}^{-1}\right)$ was seen in pretreatment run LHSO, where 0.32 (\% w/v) $\mathrm{H}_{2} \mathrm{SO}_{4}$ was used for impregnation, similarly impregnation in higher concentration ( $3.68 \%$ w/v) of $\mathrm{H}_{2} \mathrm{SO}_{4}$ resulted in maximum $\left(7240 \mathrm{mg} \mathrm{L}^{-1}\right)$ sulfate concentration for pretreatment 11.

Sulfate concentration was in the range of $1250-5655 \mathrm{mg} \mathrm{L}^{-1}$ ) for pretreatment set A-HSO - D-HSO following a similar pattern as described above. Higher reaction temperature (pretreatment run $\mathrm{O}-\mathrm{HSO}-213.6^{\circ} \mathrm{C}$ ) and longer reaction time (pretreatment $\mathrm{M}-\mathrm{HSO}-23.76 \mathrm{~min}$ ) resulted into dissociation of sulfate thereby leading to lower concentration in the liquid filtrate.

Monomeric sugars concentration in the liquid filtrate of $\mathrm{H}_{2} \mathrm{SO}_{4}$ assisted hydrothermal pretreatment are presented in Table 5.15. Relatively higher glucose concentration was seen in comparison to xylose concentration. It demonstrated that xylose was much solubilized and further degraded into organic acids and furanic compounds under higher severity conditions as evidenced from higher furfural concentration (Table 5.15).

Highest glucose $\left(13.53 \mathrm{mg} \mathrm{mL}^{-1}\right)$ was noted at pretreatment run G-HSO $\left(160{ }^{\circ} \mathrm{C}, 5 \mathrm{~min}\right.$, $3 \% \mathrm{H}_{2} \mathrm{SO}_{4}$ ). It indicated that higher pretreatment temperature combined with higher $\mathrm{H}_{2} \mathrm{SO}_{4}$ concentration though resulted into more solubilization of hemicellulose and solubilization of cellulose. However, monomeric sugars further degraded into organic acids and furanic compounds. Higher contact time also resulted into lower glucose $1.93 \mathrm{mg} \mathrm{mL}^{-1}$ (pretreatment run M-HSO $-180{ }^{\circ} \mathrm{C}, 23.76 \mathrm{~min}, 2 \% \mathrm{H}_{2} \mathrm{SO}_{4}$ ) in comparison to higher glucose $6.65 \mathrm{mg} \mathrm{mL}^{-1}$ for less reaction time (pretreatment run $\mathrm{N}-\mathrm{HSO}-180{ }^{\circ} \mathrm{C}, 0.24 \min 2 \% \mathrm{H}_{2} \mathrm{SO}_{4}$ ). Longer the contact time, higher will be the degradation of monomeric sugar to organic acids and furanic compounds. Similar is true for highest reaction temperature studied $\left(213.6{ }^{\circ} \mathrm{C}\right)$. Pretreatment run O-HSO resulted into lower glucose $\left(2.51 \mathrm{mg} \mathrm{mL}^{-1}\right)$ in comparison to pretreatment run P-HSO $\left(146.4{ }^{\circ} \mathrm{C}\right)$ it is strengthened by the almost 2-fold production of formic acid (3611.28 $\left.\mathrm{mg} \mathrm{L}^{-1}\right)$ in pretreatment 15 comparing to $1405.49 \mathrm{mg} \mathrm{L}^{-1}$ ) for pretreatment 16 . 
Though most of the xylose was solubilized at $200{ }^{\circ} \mathrm{C}$ (pretreatment set A-HSO - D-HSO), lesser recovery in liquid filtrate indicated that it was further degraded into organic acids. Higher recovery of xylose was recorded at $160{ }^{\circ} \mathrm{C}$ irrespective of $\mathrm{H}_{2} \mathrm{SO}_{4}$ concentration employed (pretreatment set E-HSO - H-HSO). Higher xylose $\left(13.87 \mathrm{mg} \mathrm{mL}^{-1}\right)$ in liquid filtrate was noted at pretreatment run $\mathrm{H}-\mathrm{HSO}\left(160{ }^{\circ} \mathrm{C}, 5 \mathrm{~min}, 1 \% \mathrm{H}_{2} \mathrm{SO}_{4}\right)$, followed by pretreatment run $\mathrm{N}-\mathrm{HSO}(180$ $\left.{ }^{\circ} \mathrm{C}, 0.24 \mathrm{~min}, 2 \% \mathrm{H}_{2} \mathrm{SO}_{4}\right)$ and pretreatment run P-HSO $\left(146.4{ }^{\circ} \mathrm{C}, 12 \mathrm{~min}, 2 \% \mathrm{H}_{2} \mathrm{SO}_{4}\right)$.

Table 5.15 - Selected organic acid and furanic compounds in liquid hydrolysate obtained from $\mathrm{H}_{2} \mathrm{SO}_{4}$ assisted hydrothermal pretreatment of sugarcane bagasse

\begin{tabular}{cccccccc}
\hline $\begin{array}{c}\text { Pretreatment } \\
\text { run }\end{array}$ & pH & $\begin{array}{c}\text { Glucose } \\
\left(\mathbf{m g ~ m L ^ { - }}\right.\end{array}$ & $\begin{array}{c}\text { Xylose } \\
(\mathbf{m g ~ m L} \\
\mathbf{1})\end{array}$ & $\begin{array}{c}\text { Acetic } \\
\text { acid } \\
\left(\mathbf{m g ~ L}^{-1}\right)\end{array}$ & $\begin{array}{c}\text { Formic } \\
\text { acid } \\
\left(\mathbf{m g ~ L}^{-1}\right)\end{array}$ & $\begin{array}{c}\text { Furfural } \\
\left(\mathbf{m g ~ L}^{-1}\right)\end{array}$ & $\begin{array}{c}\text { 5-HMF } \\
\left(\mathbf{m g ~ L}^{-}\right.\end{array}$ \\
\hline A-HSO & 1.12 & 2.34 & 1.03 & $1,892.73$ & $1,093.66$ & $1,402.19$ & 147.36 \\
\hline B-HSO & 1.48 & 4.86 & 1.44 & $1,114.61$ & 834.35 & $1,080.94$ & 471.52 \\
\hline C-HSO & 1.22 & 4.40 & 0.43 & $2,205.76$ & $2,425.46$ & $1,321.73$ & 493.70 \\
\hline D-HSO & 1.76 & 2.54 & 2.06 & $1,435.21$ & 688.31 & $3,013.14$ & 342.74 \\
\hline E-HSO & 1.19 & 4.00 & 4.92 & $2,080.82$ & $2,668.62$ & $2,216.47$ & 970.08 \\
\hline F-HSO & 1.65 & 5.23 & 9.30 & $2,031.71$ & $1,463.78$ & $1,839.84$ & 174.94 \\
\hline G-HSO & 1.20 & 13.53 & 8.09 & $1,927.23$ & $1,977.09$ & $2,181.24$ & 713.26 \\
\hline H-HSO & 1.60 & 3.02 & 13.87 & $1,408.34$ & $1,003.07$ & 925.77 & 70.95 \\
\hline I-HSO & 1.50 & 2.77 & 2.56 & $1,608.05$ & 799.22 & $1,239.33$ & 178.80 \\
\hline J-HSO & 1.49 & 2.36 & 2.03 & $1,435.73$ & 729.84 & $1,122.86$ & 168.93 \\
\hline K-HSO & 1.38 & 7.81 & 1.97 & $2,198.89$ & $2,384.15$ & $1,774.14$ & 788.62 \\
\hline L-HSO & 2.86 & 2.83 & 2.66 & $1,888.45$ & 788.04 & $1,674.15$ & 285.99 \\
\hline M-HSO & 1.42 & 1.93 & 1.49 & $1,445.42$ & 796.93 & 939.89 & 245.89 \\
\hline N-HSO & 1.36 & 6.65 & 12.69 & $1,685.85$ & $1,763.46$ & $1,283.79$ & 130.57 \\
\hline O-HSO & 1.65 & 2.51 & 0.73 & $2,191.82$ & $3,611.28$ & $1,135.85$ & 296.11 \\
\hline P-HSO & 1.81 & 3.26 & 10.29 & $1,750.05$ & $1,405.49$ & $1,178.81$ & 106.38 \\
\hline
\end{tabular}

A higher concentration of organic acids (acetic and formic) and sugar degradation products (furfural and 5-HMF) were noted in hydrolysate fraction of $\mathrm{H}_{2} \mathrm{SO}_{4}$ impregnated hydrothermal pretreatment. Acetic acid was in the range of 1,114.61 - 2,198.89 $\mathrm{mg} \mathrm{L}^{-1}$. Furthermore, it was observed that higher $\mathrm{H}_{2} \mathrm{SO}_{4}$ conc. resulted in the higher acetic acid release into hydrolysate 
implicating higher removal of the hemicellulosic fraction. Formic acid was in the range of 729.84 $-3,611.28 \mathrm{mg} \mathrm{L}^{-1}$, it also demonstrated a similar trend to acetic acid release. However, highest formic acid release $\left(3,611.28 \mathrm{mg} \mathrm{L}^{-1}\right)$ was noted for O-HSO $\left(213.6{ }^{\circ} \mathrm{C}, 12 \mathrm{~min}, 2 \% \mathrm{H}_{2} \mathrm{SO}_{4}\right)$. Yang et al (Yang et al., 2012) reported highest acetic acid and formic acid release of 109.96 and 130.15 $\mathrm{mg} \mathrm{L}{ }^{-1}$, respectively, at 200 and $130{ }^{\circ} \mathrm{C}$ for triploid poplar wood chips.

The relatively higher concentration of furfural $\left(925.77-3,013.14 \mathrm{mg} \mathrm{L}^{-1}\right)$ was observed comparing to 5-HMF (70.95 - $970.08 \mathrm{mg} \mathrm{L}^{-1}$ ). A lower concentration of 5-HMF was expected based on lower hexose content in hemicellulose, higher hexose resistance and higher 5-HMF reactivity as reported by Mussatto et al. (Mussatto and Roberto, 2004). Another reason of lower 5-HMF concentration is its conversion into levulinic acid and formic acid under acidic hydrothermal conditions (Nitsos et al., 2013). Yang et al (Yang et al., 2012) reported that furfural and 5-HMF appeared in hydrolysate when pretreatment temperature was increased above $140{ }^{\circ} \mathrm{C}$. Similarly, Marasabessy et al (Marasabessy et al., 2012) reported that pretreatment temperature above $160{ }^{\circ} \mathrm{C}$ did not result in an increase in pentose release due to degradation into furfural. A lower concentration of pentose sugar in the hydrolysate of current study verify the above said findings of Marasabessy and colleagues (Marasabessy et al., 2012) since reaction temperature employed was much higher $180^{\circ} \mathrm{C}$ up to $213.6^{\circ} \mathrm{C}$.

\subsection{Impact of $\mathrm{H}_{2} \mathrm{SO}_{4}$ impregnation before hydrothermal pretreatment on methane production}

$\mathrm{H}_{2} \mathrm{SO}_{4}$ impregnation of sugarcane bagasse for $24 \mathrm{~h}$ before hydrothermal pretreatment according to CCD matrix (Table 4.5) was studied on the methane production (Nmmol g-1 TVS) for obtained water-insoluble solid fractions. Reactor composition for each tested pretreatment is presented in Table 9.2 (Appendix). Digestion experiments were realized at neutral $\mathrm{pH}$ supplemented with $1 \mathrm{~g}$ TVS substrate with $2 \mathrm{~g}$ TVS inoculum under mesophilic conditions $\left(37^{\circ} \mathrm{C}\right)$. Total digestion time was $800 \mathrm{~h}$. Experimental data of methane production was processed with modified Gompertz model (Zwietering et al., 1990).

Table 5.16 presents the methane values obtained after incubation and percent increase or decrease in comparison to methane (Nmmol g ${ }^{-1}$ TVS) obtained from raw sugarcane bagasse (6.60 Nmmol g ${ }^{-1}$ TVS). In the first set of experiments, eight pretreatments namely A-HSO, and B-HSO were realized for biomethane potential. Cumulative methane production was 1.22 and $3.97 \mathrm{Nmmol}$ 
$\mathrm{g}^{-1}$ TVS which was less than untreated sample (5.59 Nmmol g $\mathrm{g}^{-1}$ TVS). In the second set, D-HSO, F-HSO, H-HSO, I-HSO, J-HSO, M-HSO, and N-HSO were realized for biomethane potential. Cumulative methane production for this set of experiments was in the range of $1.73-7.14 \mathrm{Nmmol}$ $\mathrm{g}^{-1}$ TVS. Cumulative methane value of the pretreated samples was less than untreated sugarcane bagasse except for H-HSO, I-HSO, and N-HSO.

Fig 5.23 indicated that $\mathrm{CH}_{4}$ appeared after a lag phase of $150.75 \mathrm{~h}$ (Table 5.16) for A-HSO but only reached to a maximum of $1.22 \mathrm{Nmmol} \mathrm{g}^{-1}$ TVS in $306 \mathrm{~h}$ thereafter the production was ceased. An abrupt increase in methane was noted for pretreatment I-HSO, it reached to $4.2 \mathrm{Nmmol}$ $\mathrm{g}^{-1}$ TVS in $168 \mathrm{~h}$ afterward a slower increase was observed until it reached a maximum value of 7.14 Nmmol g-1 TVS. A similar trend was noted in rest of the pretreatments in this set of experiments.

In the third set of experiments, C-HSO, E-HSO, G-HSO, K-HSO, L-HSO, O-HSO, and PHSO were realized for biomethane potential. Cumulative methane production was in the range of $0.55-5.77 \mathrm{Nmmol} \mathrm{g}^{-1}$ TVS. All the pretreatments in this set exhibited lower methane than untreated sugarcane bagasse $\left(6.60 \mathrm{Nmmol} \mathrm{g}^{-1} \mathrm{TVS}\right)$. The lowest methane value $0.55 \mathrm{Nmmol} \mathrm{g}^{-1}$ TVS for pretreatment O-HSO $\left(213.6^{\circ} \mathrm{C}, 12 \mathrm{~min}, 2 \% \mathrm{H}_{2} \mathrm{SO}_{4}(\% \mathrm{w} / \mathrm{v})\right)$ could be justified with the highest klason lignin recovery $(358.85 \%)$ in solid fraction of this pretreatment.

Since sugarcane bagasse was $\mathrm{H}_{2} \mathrm{SO}_{4}$ impregnated, the presence of $\mathrm{SO}_{4}{ }^{-2}$ is inevitable. Lowest methane production might be a result of competition between methanogens and sulfate reducers. Sulfate reducers could outcompete methanogens under higher $\mathrm{SO}_{4}{ }^{-2}$ concentrations. Sulfate reducers compete with methanogens for acetate and $\mathrm{H} 2 / \mathrm{CO}_{2}$ (MIZUNO et al., 1998). Sulfate reducers outcompete methanogens and homoacetogens when $\mathrm{H}_{2}$ is deficient in the system with higher $\mathrm{SO}_{4}{ }^{-2}$ availability (Muyzer and Stams, 2008). 


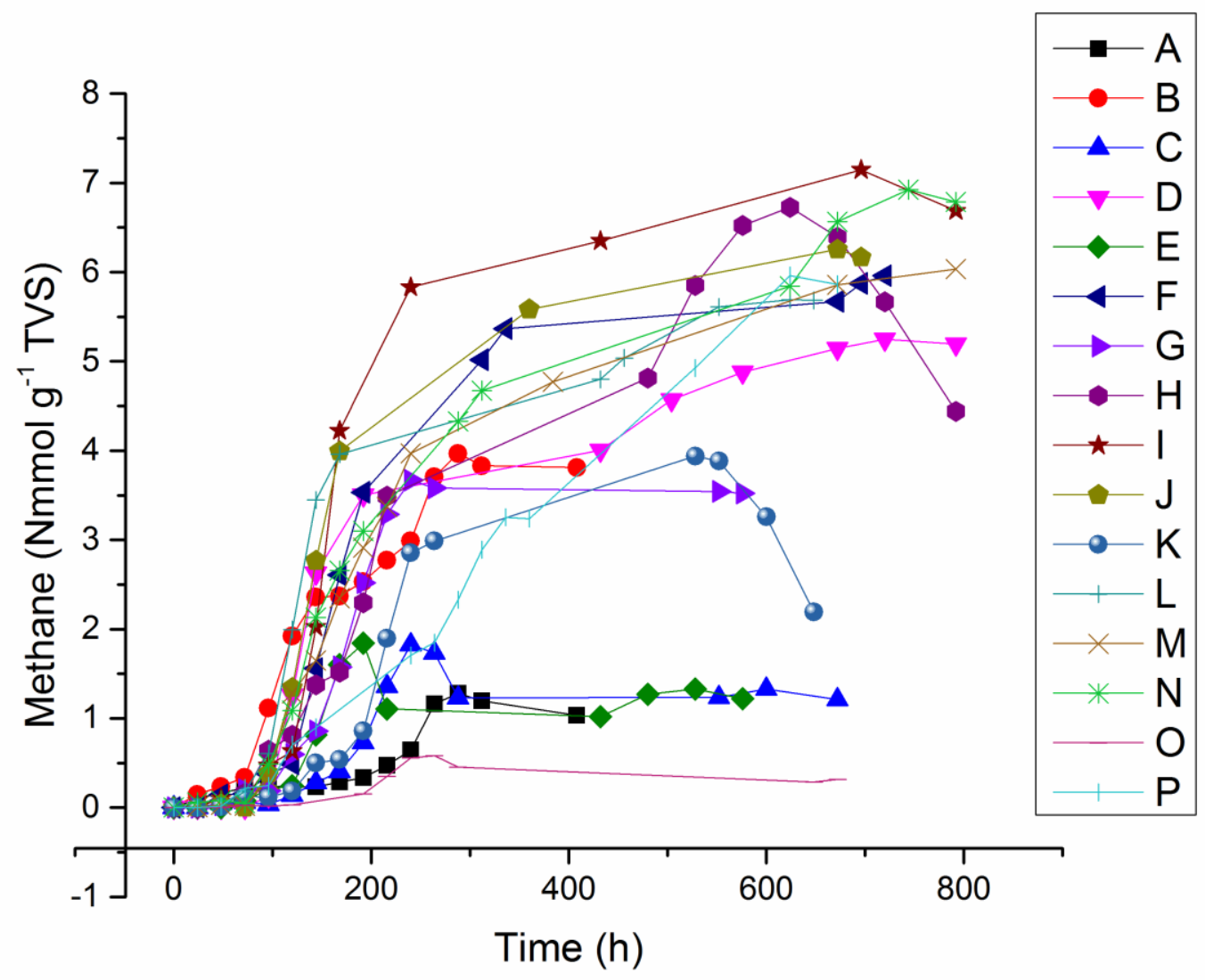

Figure 5.23 - Time-course profile of Methane production for solid fraction of $\mathrm{H}_{2} \mathrm{SO}_{4}$-catalyzed hydrothermal pretreatment

Table 5.16 demonstrated that fermentation of solid fraction obtained from $\mathrm{H}_{2} \mathrm{SO}_{4}$ impregnated hydrothermal pretreatment resulted in methanogenic inhibition when compared with the raw bagasse. Maximum production $\left(7.15 \mathrm{Nmmol} \mathrm{g}^{-1} \mathrm{TVS}\right)$ was observed at pretreatment IHSO corresponds to $8.18 \%$ increase over raw bagasse (6.59 $\left.\mathrm{Nmmol} \mathrm{g}^{-1} \mathrm{TVS}\right)$. Maximum percent decrease of $91.67 \%$ was noted at pretreatment O-HSO followed by $81.52 \%$ for pretreatment AHSO. It was observed that higher temperatures were chosen during HT pretreatment with higher $\mathrm{H}_{2} \mathrm{SO}_{4}$ conc. resulted in methanogenic inhibition from solid fraction as evident from O-HSO $\left(213.6{ }^{\circ} \mathrm{C}, 2 \% \mathrm{H}_{2} \mathrm{SO}_{4}\right)$ and A-HSO $\left(200{ }^{\circ} \mathrm{C}, 3 \% \mathrm{H}_{2} \mathrm{SO}_{4}\right)$.

The possible reason for the lower methane production is the transfer of fermentable sugar into liquid hydrolysate as indicated by higher glucose and xylose contents obtained in the liquid 
hydrolysate fraction (Table 5.15) resulting in a higher fraction of klason lignin content. Pretreatment O-HSO exhibited the highest klason lignin value $89.28 \%$ followed by A-HSO 84.61\%. Methane yield and lignin content are reported to have an inverse linear relationship i.e., higher the lignin content lower will be the methane and vice versa (Kobayashi et al., 2004; Liew et al., 2012; Ahring et al., 2015). Current study reported the similar trend (Fig 5.24).

In contrast, a number of studies have been reported that lignin can be degraded anaerobically (Yue et al., 2008; Ko et al., 2009) even into methane (Healy and Young, 1979; Barakat et al., 2012). However, P-coumaric acid, a lignin monomer reported to severely inhibit methane production. Den Camp et al (den Camp et al., 1988) reported that higher concentrations $(30 \mathrm{mM})$ of $p$-coumaric acid completely inhibit cellulose degradation and in turn methane production. In another study, Schroyen et al (Schroyena et al., 2016) reported that $2000 \mathrm{mg} \mathrm{L}^{-1} p$ coumaric acid resulted in $33 \%$ methanogenic inhibition.

Since, the impact of pretreatment on the release of lignin monomers was beyond the scope of current study; therefore, further study is required to determine the impact of $\mathrm{H}_{2} \mathrm{SO}_{4}$ impregnated hydrothermal pretreatment on sugarcane bagasse for the availability of $p$-coumaric acid in solid fraction regarding its effect on the digestion process. The results of the current study could be strengthened by the Giuseppe et al (Giuseppe et al., 2013). The authors observed methanogenic inhibition for $24 \mathrm{~h}$ impregnated $\mathrm{H}_{2} \mathrm{SO}_{4}(2 \% \mathrm{w} / \mathrm{w})$ pretreated Arundo donax (giant cane). In another study, Jorn et al (Jörn et al., 2014) observed that a temperature of $220^{\circ} \mathrm{C}$ led to lower degradability and lower methane output for dairy cattle waste. 


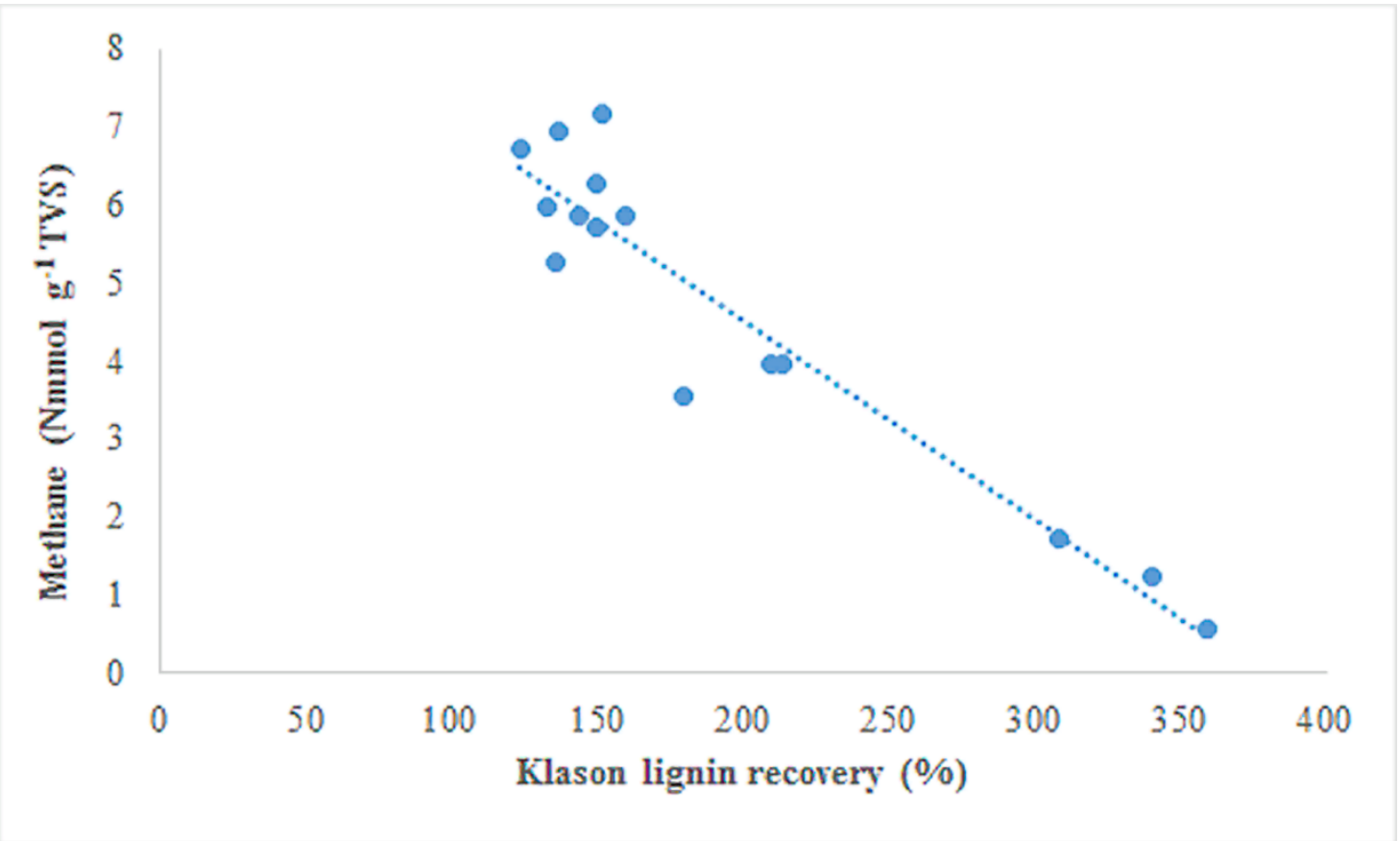

Figure 5.24 - Relationship between klason lignin (\%) and methane production

Fig 5.25 depicts the change in COD in time-course fashion. COD was in the range of 97.45 $\pm 1.77-183.45 \pm 12.52 \mathrm{mg} \mathrm{L}^{-1}$ for all the pretreatments at the start of digestion depending upon pretreatment conditions applied. Minimal COD was observed for pretreatment L-HSO $\left(180^{\circ} \mathrm{C}\right.$, $12 \mathrm{~min}, 0.32 \% \mathrm{H}_{2} \mathrm{SO}_{4}$ ). An increase in COD values was observed as the digestion proceeds. At approx. $\log$ phase, COD values increased to $194 \pm 7.95-316.5 \pm 10.61 \mathrm{mg} \mathrm{L}^{-1}$ with a simultaneous decrease in $\mathrm{pH}$ (Fig 5.27) implicating an increase in VFAs production. Final COD values at the end of digestion process were in a range of $175.9 \pm 16.12$ to $440.30 \pm 14.28 \mathrm{mg} \mathrm{L}^{-1}$. An increase in COD was recorded at the end of digestion process in all the pretreatments comparing to initial COD that might be justified by the fact that methane production was inhibited.

Total carbohydrates content were not notably reduced (Fig 5.26) during second-phase of study i.e., digestion of $\mathrm{H}_{2} \mathrm{SO}_{4}$ pretreated solid fraction. Total carbohydrates were in the range of $39.65 \pm 1.48-106.1 \pm 10.04 \mathrm{mg} \mathrm{L}^{-1}$ depending upon pretreatment conditions at the initial stage of digestion. Total carbohydrate contents decreased to $28.15 \pm 1.34-90.6 \pm 3.39 \mathrm{mg} \mathrm{L}^{-1}$ on approx. $\log$ phase at respective pretreatments. Since hemicellulosic and cellulosic fractions are enclosed within lignin cover as indicated in (Fig $5.21 \mathrm{C}$ ). It is difficult for the microbial enzymes of hydrolytic bacteria to degrade cellulosic fractions. Acetogenic bacteria might have degraded the freely available sugars present in the solid fraction after separation from liquid hydrolysate to 
VFAs. Since SRB (sulfate reducing bacteria) do not metabolize natural biopolymers; starch, protein and lipid. Therefore, they have to depend upon the action of hydrolytic bacteria for their degradation products. The SRB do not compete with fast-growing fermentative bacteria (Muyzer and Stams, 2008)

Igarashi and fellows (Igarashi et al., 2011) reported that cellulase started cellulose hydrolysis layer by layer from the surface by sliding in unidirectional form, therefore, when cellulose surface is blocked by lignin droplet (Fig 5.21 C) it stopped cellulase access to inner layers of cellulose. Two approaches are reported in the literature to address this situation to start cellulose hydrolysis "traffic jam" approach and "enzymatic deinking". In the former approach, accumulation of enzyme molecules exerts a push to eliminate the lignin droplets to start cellulose hydrolysis (Igarashi et al., 2011). In Enzymatic deinking approach, lignin droplets believed to be 'peeled off' from the cellulose surface due to loosening by enzymatic action. In the current study, it seemed to be true as total carbohydrate content started to increase in P-HSO and L-HSO. It could also be a reason of lower consumption of total carbohydrates that cellulose hydrolysis stopped and started due to traffic jam approach resulting in production and consumption of fermentable sugars. However, due to only one point selection during the digestion process this hypothesis could not be verified.

A significant decrease in $\mathrm{pH}$ was seen as depicted in Fig 5.27 at approx. log phase except for O-HSO, where it was interestingly increased to 7.1, but afterward decreased to 6.98 suggesting the lowest production of organic acids supported with a lower decrease in total carbohydrate content. After an initial decrease, $\mathrm{pH}$ appears to increase due to the buffering capacity of the system. 


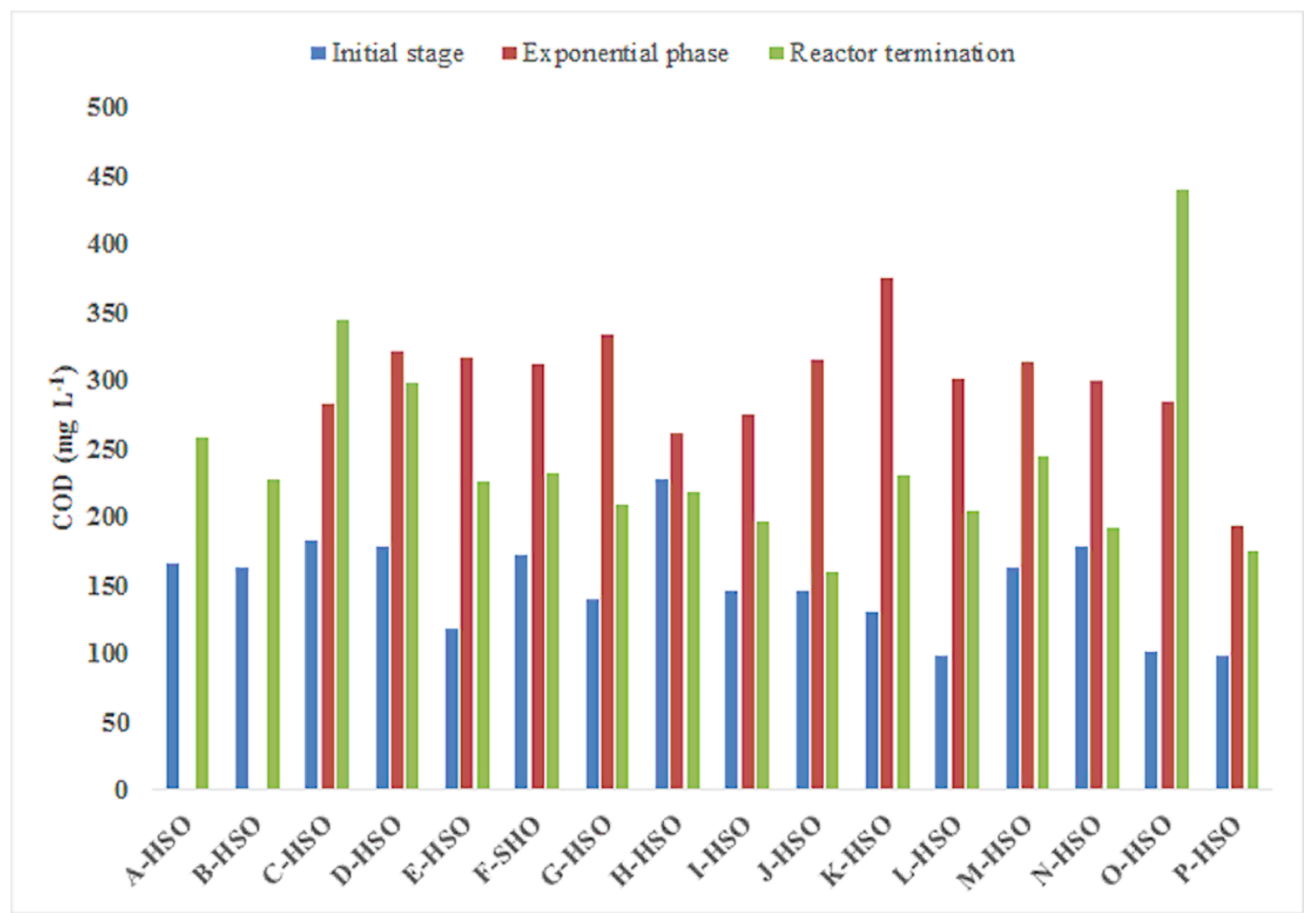

Figure 5.25 - $\mathrm{COD}\left(\mathrm{mg} \mathrm{L}^{-1}\right)$ variation during digestion process of $\mathrm{H}_{2} \mathrm{SO}_{4}$ pretreated samples

Acetic acid was the predominant volatile fatty acid encountered at reactor initiation in the range of 71.42 to $153.35 \mathrm{mg} \mathrm{L}^{-1}$. The formic acid, butyric acid, propionic acid, ethanol and furanic compounds were observed in lower concentration. Only $4 \mathrm{mg} \mathrm{L}^{-1}$. 5-HMF was encountered at initial digestion in pretreatment run H-HSO, while for other reactors its concentration was below detection limit. Furfural concentration was also below the detection limit. Therefore, it could be stated that methanogenic inhibition was solely the result of higher Klason lignin in solid fraction and competition between SRB and methanogens. Even though a significant decrease in $\mathrm{pH}$ was noted, VFAs appeared to below detection limit at the end of digestion period. 


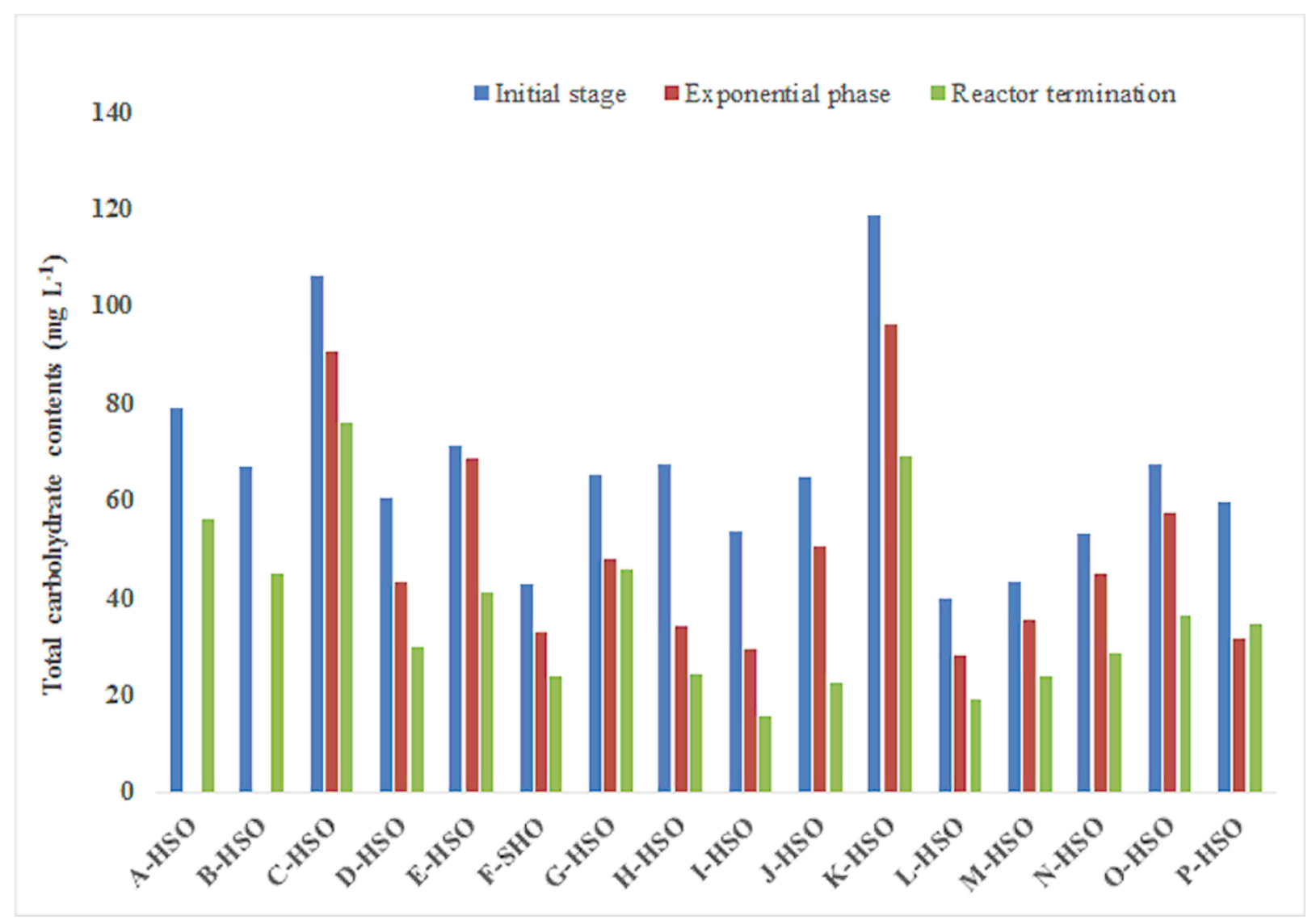

Figure 5.26 - Total carbohydrate content $\left(\mathrm{mg} \mathrm{L}^{-1}\right)$ during digestion process of $\mathrm{H}_{2} \mathrm{SO}_{4}$ pretreated samples

It could be speculated that VFAs produced are taken up by sulfate-reducing bacteria as indicated by their higher microbial flora at the end of digestion process (Fig 5.34). Therefore, VFAs concentration at the approx. $\log$ phase was below detection limit. Since only one point was selected during the digestion process. It is difficult to report VFAs production and consumption along the digestion process. SRB show higher affinity for $\mathrm{H}_{2}$ than methanogens, which gives them an additional competitive advantage (Colleran et al., 1995). 


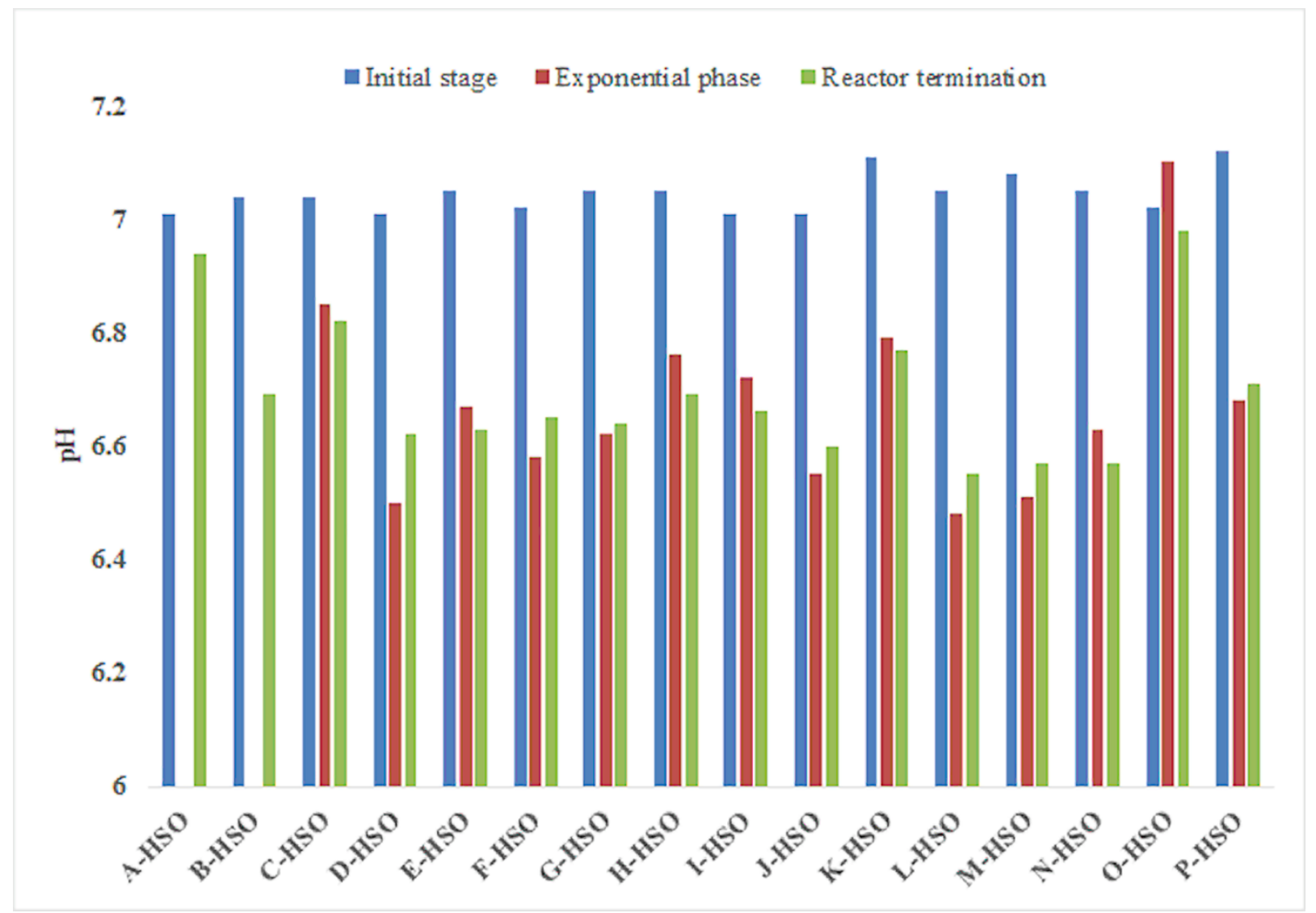

Figure 5.27 - pH variation during digestion process

Kinetic data for digestion obtained from anaerobic reactors supplemented with $\mathrm{H}_{2} \mathrm{SO}_{4}$ pretreated sugarcane bagasse is presented in Table 5.16. Maximum predicted the value of methane (Nmmol g- ${ }^{-1}$ TVS) 6.87 was observed for I-HSO while the lowest was for O-HSO 0.54 ( $\mathrm{Nmmol} \mathrm{g}^{-}$ ${ }^{1}$ TVS). Methanogens are slow-growing microorganisms. Van Haandel and Lettinga (van Haandel and Lettinga, 1994) reported a low specific growth rate of $0.0167 \mathrm{~h}^{-1}$ for methanogens though it increased with temperature. A general rule for microbial growth is explained by Arrhenius equation i.e., growth rate doubles with every $10^{\circ} \mathrm{C}$ increase (Connors, 1990). For the current study, the rate of methane production $(X c)$ ranges from 0.01 to $0.066 \mathrm{Nmmol} \mathrm{g}^{-1} \mathrm{TVS}_{\text {. }}$ 
Table 5.16 - Experimental value of methane (Nmmol g-1 TVS) and kinetic analysis data obtained from Gompertz equation

\begin{tabular}{|c|c|c|c|c|c|c|}
\hline \multirow[t]{2}{*}{ Designation } & \multirow{2}{*}{$\begin{array}{c}\text { Experimental } \\
\text { Methane } \\
\text { (Nmmol g-1 } \\
\text { TVS) }\end{array}$} & \multirow{2}{*}{$\begin{array}{c}\text { Percent } \\
\text { variation } \\
\text { over } \\
\text { SCB }\end{array}$} & \multicolumn{4}{|c|}{ Kinetics analysis data } \\
\hline & & & $\begin{array}{c}\mathrm{A}^{¥} \\
(\mathrm{Nmmol} \mathrm{g}- \\
\left.{ }^{1} \mathrm{TVS}\right)\end{array}$ & $\begin{array}{c}\mathrm{Xc}^{A} \\
\mathrm{Nmmol} \mathrm{g}^{-1} \\
\mathrm{TVS} \mathrm{h}^{-1}\end{array}$ & $\begin{array}{c}\mathrm{K}^{B} \\
\mathrm{~h}\end{array}$ & $\mathrm{R}^{2}$ \\
\hline Raw & 6.60 & - & 6.63 & 0.027 & 0 & 0.988 \\
\hline A-HSO & 1.22 & -81.52 & 1.15 & 0.010 & 150.75 & 0.86 \\
\hline B-HSO & 3.97 & -41.06 & 3.99 & 0.020 & 41.42 & 0.97 \\
\hline C-HSO & 1.73 & -72.58 & 1.63 & 0.024 & 153.45 & 0.92 \\
\hline D-HSO & 5.26 & -22.12 & 4.83 & 0.044 & 91.58 & 0.97 \\
\hline E-HSO & 1.33 & -71.82 & 1.54 & 0.039 & 118.40 & 0.88 \\
\hline F-HSO & 5.96 & -14.24 & 5.71 & 0.039 & 102.98 & 0.99 \\
\hline G-HSO & 3.54 & -44.70 & 3.69 & 0.039 & 120.84 & 0.98 \\
\hline H-HSO & 6.73 & 1.36 & 6.03 & 0.025 & 94.22 & 0.96 \\
\hline I-HSO & 7.15 & 8.18 & 6.87 & 0.066 & 110.03 & 0.99 \\
\hline J-HSO & 6.25 & -12.27 & 6.01 & 0.059 & 97.08 & 1.00 \\
\hline K-HSO & 3.94 & -43.18 & 3.88 & 0.032 & 156.17 & 0.99 \\
\hline L-HSO & 5.69 & -14.09 & 5.36 & 0.057 & 85.15 & 0.99 \\
\hline M-HSO & 5.86 & -17.73 & 5.74 & 0.026 & 80.45 & 0.99 \\
\hline N-HSO & 6.93 & 1.67 & 6.54 & 0.022 & 66.96 & 0.98 \\
\hline O-HSO & 0.58 & -91.67 & 0.54 & 0.012 & 180.13 & 0.96 \\
\hline P-HSO & 5.86 & -12.58 & 6.82 & 0.013 & 109.39 & 0.99 \\
\hline
\end{tabular}

${ }^{¥}$ Predicted value obtained from Gompertz equation, ${ }^{\mathrm{A}}$ Rate of methane production $\left(\mathrm{Nmmol} \mathrm{g}{ }^{-1} \mathrm{TVS} \mathrm{h}^{-1}\right),{ }^{\text {В }}$ time elapsed before $\mathrm{CH}_{4}$ production started (lag phase),

Similar $X c$ values of 0.012 and $0.013 \mathrm{Nmmol} \mathrm{g}^{-1} \mathrm{TVS} \mathrm{h}^{-1}$ were observed for the lowest methane value (pretreatment run O-HSO, $0.54 \mathrm{Nmmol} \mathrm{g}^{-1} \mathrm{TVS}$ ) and second highest methane production (pretreatment run P-HSO, $6.82 \mathrm{Nmmol} \mathrm{g}^{-1} \mathrm{TVS}$ ), respectively. It suggests that rate of production does not depend upon the maximum methane harvest during the study. However, maximum production rate $\left(0.066 \mathrm{Nmmol} \mathrm{g}^{-1} \mathrm{TVS} \mathrm{h}^{-1}\right)$ was noted for the highest methane produced (6.87 Nmmol g $\left.\mathrm{N}^{-1} \mathrm{TVS}\right)$.

Lag phase observed was too high ranging from $41.42 \mathrm{~h}$ (pretreatment run B-HSO - 200 ${ }^{\circ} \mathrm{C}, 1 \% \mathrm{H}_{2} \mathrm{SO}_{4}, 5 \mathrm{~min}$ ) to $180.13 \mathrm{~h}$ (pretreatment run $\mathrm{O}-\mathrm{HSO}-213.6{ }^{\circ} \mathrm{C}, 2 \% \mathrm{H}_{2} \mathrm{SO}_{4}, 12 \mathrm{~min}$ ). Table 5.16 indicates that at $200{ }^{\circ} \mathrm{C}, 3 \% \mathrm{H}_{2} \mathrm{SO}_{4}$ (pretreatment A-HSO and C-HSO) resulted in higher lag phase compared to $1 \% \mathrm{H}_{2} \mathrm{SO}_{4}$ (pretreatment B-HSO and D-HSO). While, change in 
pretreatment time from 19 to 5 min showed no impact on lag phase when compared with $\mathrm{H}_{2} \mathrm{SO}_{4}$ concentration at $200{ }^{\circ} \mathrm{C}$. A decrease in pretreatment temperature to $160^{\circ} \mathrm{C}$ (pretreatment run E$\mathrm{HSO}-\mathrm{H}-\mathrm{HSO}$ ) resulted in a corresponding decrease in lag phase as compared to $200{ }^{\circ} \mathrm{C}$, but with similar trend i.e., $3 \% \mathrm{H}_{2} \mathrm{SO}_{4}$ showed higher lag phase of 118.40 and $120.84 \mathrm{~h}$ for pretreatment $\mathrm{E}-$ HSO and G-HSO, respectively.

Pretreatment temperature of $180{ }^{\circ} \mathrm{C}$ (pretreatment run I-HSO-N-HSO) showed lower lag phase compared to $200{ }^{\circ} \mathrm{C}$ it could be explained with lower $\mathrm{H}_{2} \mathrm{SO}_{4}$ employed except pretreatment K-HSO where highest $3.68 \% \mathrm{H}_{2} \mathrm{SO}_{4}$ was utilized resulting into a lag phase of $156.17 \mathrm{~h}$. It is also worth noting that pretreatment time of $23.76 \mathrm{~h}$ (pretreatment M-HSO) showed lower lag phase $80.45 \mathrm{~h}$ indicating that it is the pretreatment temperature that affects the lag phase as indicated by $180.13 \mathrm{~h}$ of lag phase exhibited by pretreatment run O-HSO $\left(213.6^{\circ} \mathrm{C}\right)$.

\subsubsection{Response surface methodology}

The second-order polynomial equation was derived from the experimental methane data (Nmmol $\mathrm{g}^{-1}$ TVS) to interpret the effects of pretreatment parameters and their interaction on the methane production. The equation is presented in Equation 5.9.

$$
\begin{aligned}
& \text { Methane production }\left(\mathrm{Nmmol} \mathrm{g}^{-1} \mathrm{TVS}\right)=6.54-1.068 X_{1}-0.499 X_{2}-1.177 X_{3}- \\
& 1.354{X_{1}}^{2}-0.325{X_{2}}^{2}-0.806 X_{3}^{2}+0.123 X_{1} X_{2}+0.105 X_{1} X_{3}-0.013 X_{2} X_{3}
\end{aligned}
$$

The model Equation indicated that linear term of temperature $\left(X_{1}\right)$ and $\mathrm{H}_{2} \mathrm{SO}_{4}$ concentration $\left(X_{3}\right)$ while the quadratic term of temperature $X_{1}^{2}$ showed the significant negative impact on the methane production. Linear term of time $X_{2}$, quadratic terms of time $X_{2}^{2}$, and concentration $X_{3}^{2}$, and interaction between temperature and time $\left(X_{1} X_{2}\right)$, temperature and $\mathrm{H}_{2} \mathrm{SO}_{4}$ concentration $\left(X_{1} X_{3}\right)$, and time and concentration $\left(X_{2} X_{3}\right)$ did not show significant impact on the methane yield. Magnitude values 1.068 and 1.177 of linear terms of temperature $\left(X_{1}\right)$ and $\mathrm{H}_{2} \mathrm{SO}_{4}$ concentration $\left(X_{3}\right)$, respectively as presented in equation 5.6 implied that pretreatment temperature and $\mathrm{H}_{2} \mathrm{SO}_{4}$ concentration must be decreased to get a higher methane. 
Table 5.17 - Multiple-regression analysis for experimental methane production for quadratic response methodology

\begin{tabular}{|c|c|c|c|c|c|}
\hline & Sum of square & $\begin{array}{l}\text { Degree of } \\
\text { freedom }\end{array}$ & $\begin{array}{l}\text { Mean } \\
\text { square }\end{array}$ & F Value & $\begin{array}{l}p \text {-value } \\
\text { Prob }>\text { F }\end{array}$ \\
\hline $\begin{array}{l}X_{1} \\
(T)^{\alpha}\end{array}$ & 15.56 & 1.00 & 15.56 & 10.23 & $0.02 *$ \\
\hline$X_{1}^{2}$ & 16.98 & 1.00 & 16.98 & 11.17 & $0.02 *$ \\
\hline $\begin{array}{l}X_{2} \\
(t)^{\beta}\end{array}$ & 3.40 & 1.00 & 3.40 & 2.23 & 0.19 \\
\hline$X_{2}^{2}$ & 0.98 & 1.00 & 0.98 & 0.64 & 0.45 \\
\hline $\begin{array}{l}X_{3} \\
\left(\mathrm{H}_{2} \mathrm{SO}_{4} \text { Conc. }\right)^{\ddagger}\end{array}$ & 18.91 & 1.00 & 18.91 & 12.43 & $0.01 *$ \\
\hline$X_{3}^{2}$ & 6.02 & 1.00 & 6.02 & 3.96 & 0.09 \\
\hline$X_{1} X_{2}$ & 0.12 & 1.00 & 0.12 & 0.08 & 0.79 \\
\hline$X_{1} X_{3}$ & 0.09 & 1.00 & 0.09 & 0.06 & 0.82 \\
\hline$X_{2} X_{3}$ & 0.00 & 1.00 & 0.00 & 0.00 & 0.98 \\
\hline Error & 9.13 & 6.00 & 1.52 & & \\
\hline Total SS & 66.04 & 15.00 & & & \\
\hline
\end{tabular}

$\mathrm{R}$-square $=0.862$, Adj. R-square $=0.654, \mathrm{MS}$ residual $=1.521,{ }^{*}$ represents significant factors, ${ }^{\alpha}(\mathrm{T})$ represents Temperature, ${ }^{\beta}(\mathrm{t})$ represents time, and ${ }^{\ddagger}$ (Conc.) represents $\mathrm{H}_{2} \mathrm{O}_{2}$ concentration

Table 5.17 presents the one-way analysis of variance (ANOVA) for the quadratic response model presented in the equation in 5.6. Significant model parameters were determined at 5\% confidence interval. ANOVA described that linear terms of temperature $\left(X_{1}\right), \mathrm{H}_{2} \mathrm{SO}_{4}$ concentration $\left(X_{3}\right)$ and quadratic term of temperature $\left(X_{l}^{2}\right)$ were significant with a $p$-value less than 0.05 . The goodness of model fit was determined with $\mathrm{F}$-value. $\mathrm{R}^{2}$ value of 0.862 indicated that model was significantly supported with lower $\mathrm{F}$ tabulated value of 4.76 compared to the higher F-calculated value of $11.27 . \mathrm{R}^{2}$ indicated that there is $86.2 \%$ variation in the response data could be explained by the model and only $13.8 \%$ could not be explained with proposed model.

The interaction between temperature $X_{1}$ and time $X_{2}$ on methane production in a response surface curve (Fig 5.28) depicted a plateau for methane production for variable time $X_{2}$ implicating that changing the time variable had no impact on methane production after a specified temperature limit. Maximum response was seen for $X_{1}$ at around $180{ }^{\circ} \mathrm{C}$, while changing the $X_{2}$ value from 0 
to 16 min showed no increase in the in the response value. It could be explained by the fact that at $180^{\circ} \mathrm{C}$ maximum sugars might have been released into liquid hydrolysate making solid fraction sugar deficient with higher klason lignin.

The interaction between temperature $\left(X_{1}\right)$ and $\mathrm{H}_{2} \mathrm{SO}_{4}$ concentration $\left(X_{3}\right)$ is depicted in Fig 5.29. A critical analysis of the Fig 5.29 demonstrated that there is a significant effect on methane production when $\mathrm{H}_{2} \mathrm{SO}_{4}$ conc. and pretreatment time is compared. A concurrent increase in the response value (methane production) was observed with an increase in pretreatment temperature and $\mathrm{H}_{2} \mathrm{SO}_{4}$ concentration up to a certain limit.

Maximum response value was observed at $180{ }^{\circ} \mathrm{C}$ for $1 \%(\mathrm{w} / \mathrm{v}) \mathrm{H}_{2} \mathrm{SO}_{4}$ utilized for bagasse impregnation. A further increase in in pretreatment temperature above $180{ }^{\circ} \mathrm{C}$ and higher $\mathrm{H}_{2} \mathrm{SO}_{4}$ concentration resulted in lower methane production as depicted in the response curve. Furthermore, response surface revealed that maximum response point was located within the experimental region.

Effect on methane production in relation to the interaction between pretreatment time and $\mathrm{H}_{2} \mathrm{SO}_{4}$ conc. is presented in Fig 5.30. The interaction of both parameters depicted that response value had a plateau for reaction time; increase in pretreatment time above $12 \mathrm{~min}$ had a similar impact on response value at $1 \% \mathrm{H}_{2} \mathrm{SO}_{4}$ concentration. Furthermore, the visual inspection of the graph depicted that maximum point was located within the experimental region. 


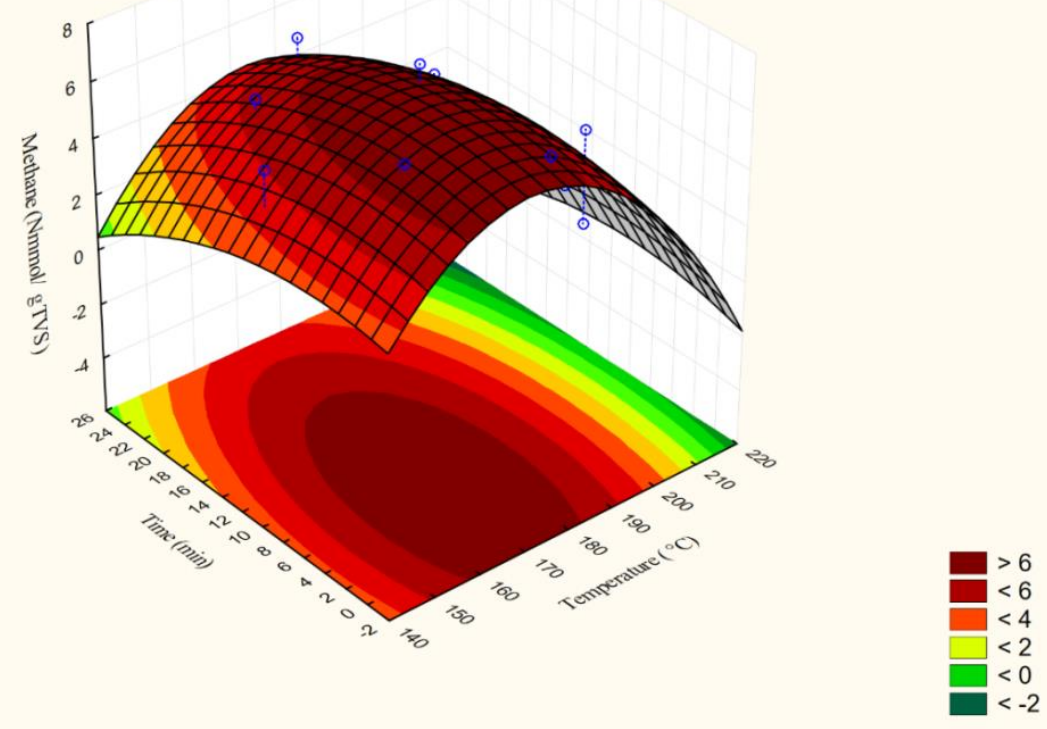

Figure 5.28 - Interaction between temperature $\left({ }^{\circ} \mathrm{C}\right)$ and time $(\mathrm{min})$ variable on Methane (Nmmol $\mathrm{g}^{-1}$ TVS) production
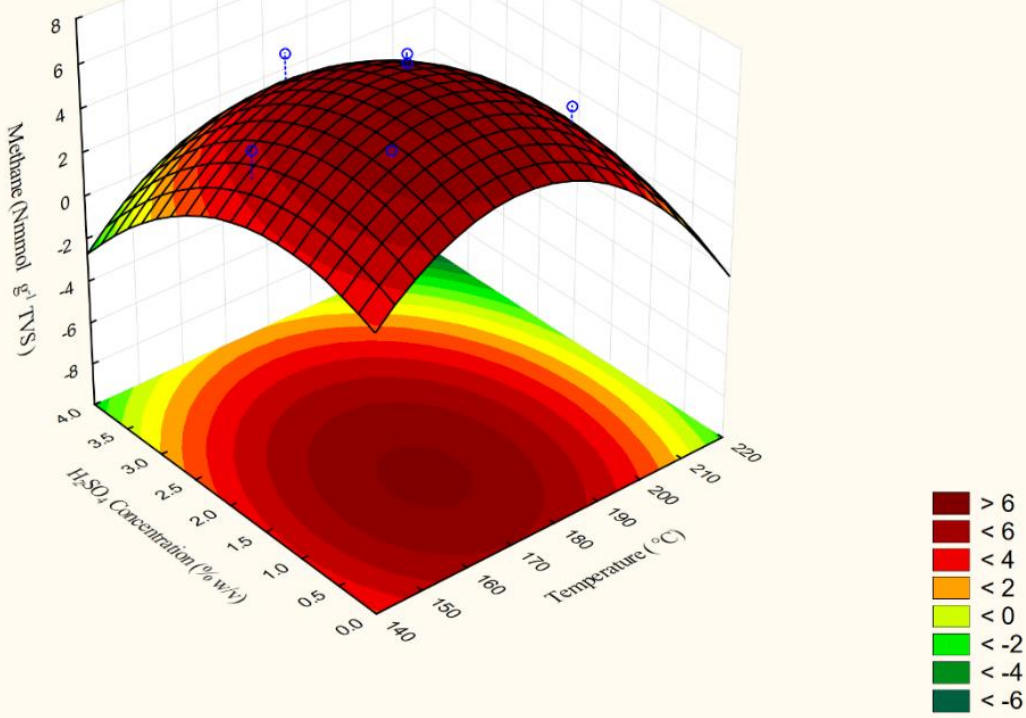

Figure 5.29 - Interaction between temperature $\left({ }^{\circ} \mathrm{C}\right)$ and $\mathrm{H}_{2} \mathrm{SO}_{4}(\% \mathrm{w} / \mathrm{v})$ variable on Methane (Nmmol g ${ }^{-1}$ TVS) production 

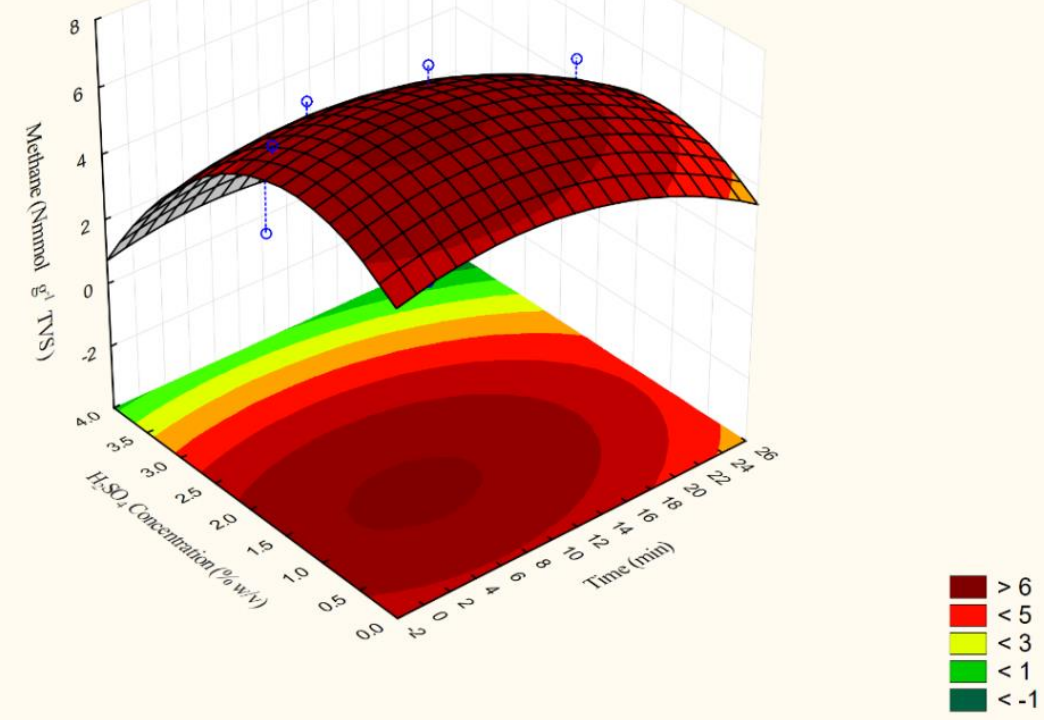

Figure 5.30 - Interaction between Time ( $\mathrm{min})$ and $\mathrm{H}_{2} \mathrm{SO}_{4}(\% \mathrm{w} / \mathrm{v})$ variable on Methane $\left(\mathrm{Nmmol} \mathrm{g}^{-}\right.$ 1 TVS) production

\subsection{Microbial community Structure of $\mathrm{H}_{2} \mathrm{SO}_{4}$ impregnated sugarcane bagasse}

5.11.1 Denaturing gradient gel electrophoresis for $\mathrm{H}_{2} \mathrm{SO}_{4}$ impregnated anaerobic reactors

Dendrogram for the bacterial community of anaerobic reactors supplemented with $\mathrm{H}_{2} \mathrm{SO}_{4}$ assisted hydrothermally pretreated sugarcane bagasse is depicted in Fig 5.31. The band pattern showed notable variability in bacterial community structure among anaerobic reactors. Similarity coefficient varied from $16 \%$ (K-HSO - L-HSO) to $88 \%$ between M-HSO and N-HSO. A decrease in pretreatment time (19-5 min) with similar $\mathrm{H}_{2} \mathrm{SO}_{4}$ conditions resulted in a decrease in $\mathrm{Sc}$ from $69 \%$ (A-HSO - B-HSO) to $38 \%$ (C-HSO - D-HSO) at $200{ }^{\circ} \mathrm{C}$. Similar trend was observed for 160 ${ }^{\circ} \mathrm{C}$ under similar condition where Sc decreased from $79 \%$ (E-HSO - F-HSO) to $61 \%$ (G-HSO H-HSO). It also indicated that a decrease in temperature from $200{ }^{\circ} \mathrm{C}$ to $160{ }^{\circ} \mathrm{C}$ resulted in increase in bacterial similarity i.e., from 69\% (A-HSO - B-HSO) to 79\% (E-HSO -F-HSO)

An increase in similarity coefficient from $38 \%$ (A-HSO - C-HSO) to $77 \%$ (B-HSO - DHSO) was noted with a decrease in $\mathrm{H}_{2} \mathrm{SO}_{4}$ concentration $(3-1 \% \mathrm{w} / \mathrm{v})$ with constant pretreatment time at pretreatment temperature of $200{ }^{\circ} \mathrm{C}$. While a decrease in pretreatment temperature to 160 ${ }^{\circ} \mathrm{C}$ resulted in a decrease in $\mathrm{Sc}$ value from $79 \%$ (E-HSO - G-HSO) to $61 \%$ (F-HSO - H-HSO) at similar pretreatment time conditions. It can be seen when comparing $\mathrm{H}_{2} \mathrm{SO}_{4}$ concentrations a 
decrease in temperature $\left(200-160{ }^{\circ} \mathrm{C}\right)$ resulted in an increase in bacterial similarity $(38 \%-79 \%)$ at $3 \% \mathrm{H}_{2} \mathrm{SO}_{4}$, while a decrease in $\mathrm{Sc}$ value $(77-61 \%)$ was observed for $1 \% \mathrm{H}_{2} \mathrm{SO}_{4}$.

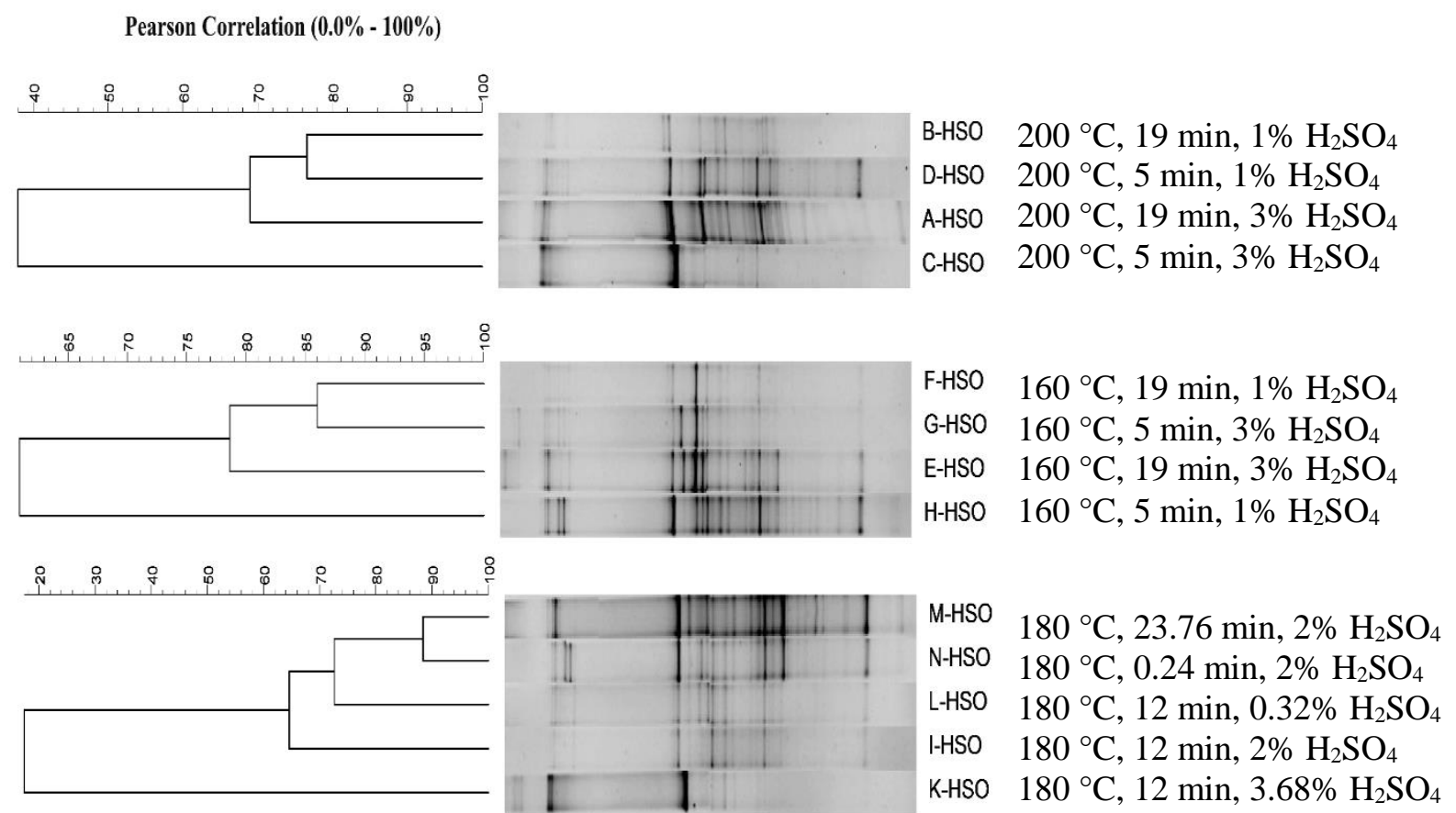

Figure 5.31 - PCR-DGGE band profile for bacterial community structure for $\mathrm{H}_{2} \mathrm{SO}_{4}$ impregnated anaerobic reactors

It is interesting to note that lowest and maximum similarity between reactors was observed at $180{ }^{\circ} \mathrm{C}$. It was noted at similar pretreatment time of 12 min a decrease in $\mathrm{H}_{2} \mathrm{SO}_{4}$ conc. from $2 \%$ to $0.32 \%$ and an increase in $\mathrm{H}_{2} \mathrm{SO}_{4}$ conc. from $2 \%$ to $3.68 \%$ had no impact on bacterial composition as evident from 16\% Sc value between I-HSO - L-HSO and I-HSO - K-HSO, respectively. Similarly, at similar $\mathrm{H}_{2} \mathrm{SO}_{4}$ conc. increase or decrease in pretreatment time did not affect the bacterial community as represented by $S c$ value of $65 \%$ for I-HSO - M-HSO and I-HSO - N-HSO. However, it was noted that change in pretreatment time resulted in higher bacterial similarity value (65\%) than a change in $\mathrm{H}_{2} \mathrm{SO}_{4}$ conc. (16\%).

Archaeal PCR-DGGE profile for anaerobic reactors supplemented with $\mathrm{H}_{2} \mathrm{SO}_{4}$ impregnated sugarcane bagasse is shown in Fig 5.32. A critical look of DGGE gel indicated that archaeal community is not much affected by the pretreatment parameters. $S c$ value for archaeal community varied from $35 \%$ to $93 \%$ as indicated in Fig 5.32. It is indicated that a decrease in 
pretreatment temperature (19 -5 min) resulted in a decrease in $S c$ value from 93\% (A-HSO - B$\mathrm{HSO}$ ) to $83 \%$ (C-HSO - D-HSO) at similar $\mathrm{H}_{2} \mathrm{SO}_{4}$ conc. values under pretreatment temperature of $200{ }^{\circ} \mathrm{C}$. Keeping $\mathrm{H}_{2} \mathrm{SO}_{4}$ and pretreatment time values constant, a decrease in pretreatment temperature resulted in a slight decrease in $S c$ value to $90 \%$ for E-HSO - F-HSO at 19 min while a slight increase (92\% Sc value) was observed for G-HSO - H-HSO at pretreatment time of 5 min. It is shown that a decrease of $40{ }^{\circ} \mathrm{C}$ from $200{ }^{\circ} \mathrm{C}$ to $160{ }^{\circ} \mathrm{C}$ resulted in a minimal decrease in archaeal similarity value at $19 \mathrm{~min}$ while the minimal increase was observed at 5 min pretreatment time.

A notable increase in the archaeal $S c$ value was observed from $56 \%$ to $83 \%$ when $\mathrm{H}_{2} \mathrm{SO}_{4}$ conc. value decreased $(3-1 \%)$ at pretreatment temperature of $200{ }^{\circ} \mathrm{C}$. Conversely, at $160{ }^{\circ} \mathrm{C}$ keeping pretreatment time and $\mathrm{H}_{2} \mathrm{SO}_{4}$ values same as at $200{ }^{\circ} \mathrm{C}$, the archaeal similarity between reactors was unaffected being $72 \%$ for E-HSO - G-HSO and F-HSO - H-HSO. A comparison of $S c$ value at $200{ }^{\circ} \mathrm{C}$ and $160{ }^{\circ} \mathrm{C}$ for similar pretreatment times indicated approx. negligible decrease in $S c$ values at $19 \mathrm{~min}(93 \%-90 \%)$ and increase in $S c$ value from 83 to $92 \%$ at $5 \mathrm{~min}$. A similar comparison for $\mathrm{H}_{2} \mathrm{SO}_{4}$ conc. values indicated a decrease in temperature resulted in an increase in archaeal similarity from 56 to $72 \%$ for $3 \% \mathrm{H}_{2} \mathrm{SO}_{4}$ while a decrease in archaeal $\mathrm{Sc}$ value from 83 to $72 \%$ for $1 \% \mathrm{H}_{2} \mathrm{SO}_{4}$ conc.

The lowest $S c$ values were noted between three pretreatment sets I-HSO - K-HSO, I-HSO - M-HSO, and I-HSO - N-HSO where I-HSO, M-HSO, N-HSO were pretreated at $2 \% \mathrm{H}_{2} \mathrm{SO}_{4}$ and pretreatment time of 12, 23.7, and 0.24 min, respectively. While, K-HSO was pretreated for 12 min with $3.68(\% \mathrm{w} / \mathrm{v}) \mathrm{H}_{2} \mathrm{SO}_{4}$. The lowest $S c$ value was satisfied owing to significant different pretreatment conditions. The high $S c$ value of $88 \%$ between $\mathrm{K}-\mathrm{HSO}$ and $\mathrm{L}-\mathrm{HSO}$ at $180{ }^{\circ} \mathrm{C}$ indicated that pretreatment time could be a possible reason for such a high archaeal similarity between two pretreatments as both were pretreated at significant different $\mathrm{H}_{2} \mathrm{SO}_{4}$ conc. but at similar pretreatment time of $12 \mathrm{~min}$. 


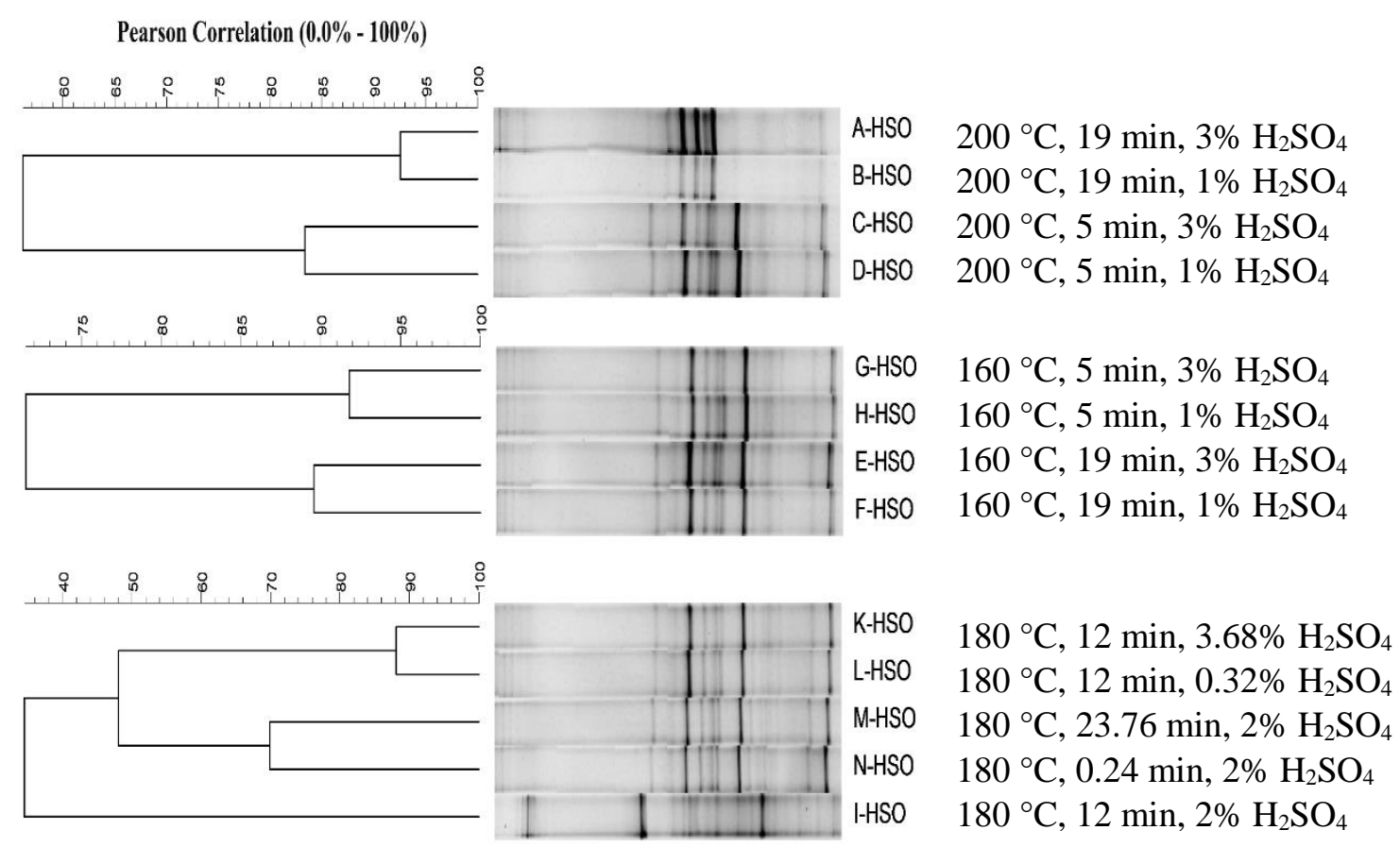

Figure 5.32 - PCR-DGGE band profile for archaeal community of $\mathrm{H}_{2} \mathrm{SO}_{4}$ impregnated anaerobic reactors

Shannon diversity $\left(\mathrm{H}^{\prime}\right)$ and dominance (D) for bacterial and archaea communities are presented in Table 5.18. Approximately negligible effect of pretreatment parameters was observed on Shannon diversity $\left(\mathrm{H}^{\prime}\right)$ and dominance (D). $\mathrm{H}^{\prime}$ value ranged from 2.59 to 3.25 for pretreatment temperature of $200{ }^{\circ} \mathrm{C}$ for Bacteria. Approx. similar values 3.12 and 3.25 were noted for A-HSO and D-HSO, respectively though both were pretreated at distinctly different pretreatment conditions. It indicated that change in pretreatment conditions did not have a significant effect on bacterial diversity. A similar trend was observed for bacterial Shannon diversity at $160^{\circ} \mathrm{C}$. Approx. values of 3.17 and 3.23 were recorded for E-HSO (19 min, $3 \% \mathrm{H}_{2} \mathrm{SO}_{4}$ ) and $\mathrm{H}-\mathrm{HSO}(5 \mathrm{~min}, 1 \%$ $\mathrm{H}_{2} \mathrm{SO}_{4}$ ), respectively.

On the other hand, a distinct pattern was observed for archaeal diversity for pretreatment time; decrease in pretreatment time resulted into increase in Shannon diversity. In other words, at similar pretreatment time, change in $\mathrm{H}_{2} \mathrm{SO}_{4}$ conc. showed no impact on archaeal diversity at 200 ${ }^{\circ} \mathrm{C}$. 
Table 5.18 - Microbial diversity (Shannon-Wiener and Dominance) for Bacteria and Archaea of $\mathrm{H}_{2} \mathrm{SO}_{4}$ assisted anaerobic reactors

\begin{tabular}{|c|c|c|c|c|c|c|c|}
\hline \multirow[t]{2}{*}{ Designation } & \multirow{2}{*}{$\begin{array}{c}\text { Temperature } \\
\left({ }^{\circ} \mathrm{C}\right)\end{array}$} & \multirow{2}{*}{$\begin{array}{l}\text { Time } \\
\text { (min) }\end{array}$} & \multirow{2}{*}{$\begin{array}{c}\mathrm{H}_{2} \mathrm{SO}_{4} \\
(\% \\
\mathrm{w} / \mathrm{v})\end{array}$} & \multicolumn{2}{|c|}{ Bacteria } & \multicolumn{2}{|c|}{ Archaea } \\
\hline & & & & Dominance & $\begin{array}{l}\text { Shannon- } \\
\text { Wiener }\end{array}$ & Dominance & $\begin{array}{l}\text { Shannon- } \\
\text { Wiener }\end{array}$ \\
\hline A-HSO & 200 & 19 & 3 & 0.05 & 3.12 & 0.13 & 2.14 \\
\hline B-HSO & 200 & 19 & 1 & 0.07 & 2.66 & 0.14 & 2.09 \\
\hline C-HSO & 200 & 5 & 3 & 0.08 & 2.59 & 0.09 & 2.51 \\
\hline D-HSO & 200 & 5 & 1 & 0.04 & 3.25 & 0.10 & 2.43 \\
\hline E-HSO & 160 & 19 & 3 & 0.05 & 3.17 & 0.09 & 2.50 \\
\hline F-HSO & 160 & 19 & 1 & 0.07 & 2.80 & 0.10 & 2.49 \\
\hline G-HSO & 160 & 5 & 3 & 0.07 & 2.80 & 0.10 & 2.49 \\
\hline H-HSO & 160 & 5 & 1 & 0.04 & 3.23 & 0.09 & 2.58 \\
\hline I-HSO & 180 & 12 & 2 & 0.05 & 2.92 & 0.06 & 2.87 \\
\hline K-HSO & 180 & 12 & 3,68 & 0.08 & 2.58 & 0.10 & 2.48 \\
\hline L-HSO & 180 & 12 & 0.24 & 0.06 & 2.87 & 0.10 & 2.49 \\
\hline M-HSO & 180 & 23.76 & 2 & 0.04 & 3.23 & 0.09 & 2.51 \\
\hline N-HSO & 180 & 0.24 & 2 & 0.05 & 3.03 & 0.11 & 2.39 \\
\hline
\end{tabular}

\subsection{Illumina MiSeq Sequencing of selected $\mathrm{H}_{2} \mathrm{SO}_{4}$ pretreatments}

5.12.1 Bacterial diversity for $\mathrm{H}_{2} \mathrm{SO}_{4}$ pretreated samples

Microbial community structure for $\mathrm{H}_{2} \mathrm{SO}_{4}$ pretreated samples was conducted for 3 selected pretreatments D-HSO, I-HSO, and N-HSO to have an idea how pretreatment parameters impacted the microbial diversity. RDP-classifier after Illumina MiSeq sequencing resulted into 220569, 189756, 206848, reads for D-HSO, I-HSO, and N-HSO, respectively. Phylogenetic estimation at 3\% distance level resulted into 2700 and 2667 OTUs for Bacteria and Archaea domains, respectively. Bacterial diversity was characterized into 23 phyla; however, only Bacteroidetes, (16.82-34.16\%), Firmicutes (18.40-19.83\%), Chloroflexi (13.68-19.71\%), Proteobacteria (11.9219.31\%), Cloacimonates (5.25-6.52\%), Thermotogae (6.24-9.17\%), and Spirochaete (2.80$5.53 \%$ ) were abundant. Furthermore, phyla with relative abundance less than $1 \%$ were Actinobacteria, Planctomycetes, Caldiserica, Chlamydiae, Fusobacteria, Cyanobacteria, Nitrospinae, Chlorbi, and Nitrospirae. Euryarchaeota (98.05-99.13\%) was the only predominant archaeal phylum. 
As depicted in Fig 5.33 bacterial community was not as diverse as the relative abundance that might be due to pretreatment conditions. Bacterial diversity at genus-level indicated that it was rich in lignin degrading (aromatic compound degraders) and sulfate-reducing phylotypes with lower abundance of polysaccharide degrading microbial communities. Bacteroidetes was the dominant phylum with $34.16 \%$ in pretreatment N-HSO where its abundance was almost half in DHSO (16.82\%) and I-HSO (18.20\%). Three of the four recognized classes in the tested sample were Bacteroidia (9.04-14.80\%), Flavobacteria (0.31-22.83\%), and Cytophagia (1.54-2.22\%). Bacteroides and Anaerophaga were the predominant genera in class Bacteroidia while Cytophaga and Flavobacterium were dominant of class Cytophagia and Flavobacteria, respectively. Bacteroides abundance was approx. similar in D-HSO (10.64\%) and I-HSO (11.54\%), while it was lower in N-HSO (7.14\%). Bacteroides are known to metabolize cellobiose and xylose (Pobeheim et al., 2010). Bacteroides is one of the bacterial populations involved in hydrolysis step of digestion process (Anderson et al., 2003).

Anaerophaga was in lower abundance in D-HSO and I-HSO (2.56-2.83\%) while was not identified in N-HSO $(0.85 \%)$. Anaerophaga are chemoorganotrophic, nonphotosynthetic strict rod-shaped Gram-negative anaerobes bearing a fermentative type of metabolism, using organic compounds as substrates. Anaerophaga members are unable to utilize inorganic electron acceptors (Schink, 2015). Denger et al (Denger et al., 2002) reported that some strains of Anaerophaga ferment hexoses and pentoses to equal molar amounts of acetate, propionate, and succinate. Lower abundance of Anaerophaga in current study indicated lower fermentative activity. Furthermore, complete removal of Anaerophaga in N-HSO might be justified by the competition among bacterial strains for metabolites.

Members of Cytophagia are Gram-negative, microaerobic to strict anaerobic, chemoorganotrophs with the capability to metabolize proteins, lipids, starch, and cellulose (Nakagawa, 2015). Lower abundance (1.53-2.12\%) of Cytophaga members indicated inaccessibility of cellulose due to higher lignin sheath that has resulted owing to pretreatment. Pandit et al (Pandit et al., 2016) reported Cytophaga as cellulose and hemicellulose degraders.

Flavobacterium (Family Flavobacteriaceae) astonishingly identified with maximum abundance $(22.82 \%)$ in N-HSO, while in other studied pretreatments it was $(0.29-0.44 \%)$. Koga et al. (Koga et al., 1999) reported Flavobacterium meningosepticum to grow on phenolic 
compounds. Some Flavobacterium spp. can degrade carboxymethylcellulose (Bernardet and Bowman, 2015).

Desulfosporosinus (8.85-11.20\%) and Clostridum (2.32-7.28\%) belonging to Class Clostridia of Firmcutes were abundant in the current study. Desulfosporosinus is a member of sulfate-reducing bacteria; the majority of them belong to $\delta$-proteobacteria (Moestedt, 2015). Desulfosporosinus members are Gram-positive strict anaerobes with three documented species (Hippe and Stackebrandt, 2015). Syntrophic relation of Desulfosporosinus with methanogens has not been validated (Kato et al., 2015). Higher abundance of Desulfosporosinus could be justified with the presence of higher lignin content (aromatic compounds) in the pretreated solids. Desulfosporosinus members are frequently recovered in microbial consortia aimed to degrade aromatic compounds (Fowler et al., 2014; Kuppardt et al., 2014). Clostridium population was in the range of 2.32 to $7.23 \%$, the lower population could be related to lower hydrolytic activity.

Geotoga (Family Thermotogaceae), a newly defined genus, was the only genus encountered in the current study with relative abundance in the range of $6.13-9.09 \%$. Geotoga are Gram-negative, fermentative, strict anaerobes. They are moderate thermophilic i.e., grow in a range of 30 to $60{ }^{\circ} \mathrm{C}$ (Davey et al., 2015). Geotoga could metabolize mannose, glucose, galactose, maltose, sucrose as carbon and energy source, but could not grow on xylose. Furthermore, Geotoga members are unable to utilize ethanol, lactate, acetate, and formate (Davey et al., 2015).

Chloroflexi categorized into two classes Anaerolinea and Dehalococcoidia were observed in $\mathrm{H}_{2} \mathrm{SO}_{4}$ pretreated samples. Genera reported in this study under Anaerolinea were Bellilinea (5.10-7.73\%), Levilinea (1.60-4.03\%), and Longilinea (1.75-2.02\%) while Dehalococcoides (3.35-4.89\%) was an only abundant genus in class Dehalococcoidia. Bellilinea, Levilinea, and Longinilea members are Gram-negative, nonsporulating, strict anaerobes. Bellilinea is newly classified genus that is reported to grow under thermophilic conditions. The type strain Bellilinea caldifistuale sp. nov. is reported to grow optimally at $55^{\circ} \mathrm{C}$ (Yamada et al., 2007). In contrast, relatively higher abundance was observed under mesophilic condition $\left(37^{\circ} \mathrm{C}\right)$. Furthermore, its growth is supported with hydrogenotrophic methanogens. Levilinea spp. was identified in this study even without supplementation of yeast extract. Yeast extract is reported to be a primary growth factor for Levilinea spp. (Yamada, 2006). It exhibits optimum growth at $37{ }^{\circ} \mathrm{C}$ at $\mathrm{pH} 7$. Yamada et al (Yamada et al., 2007) reported that Levilinea members could not utilize sulfate, 
sulfite, thiosulfate and elemental sulfur as electron acceptors. Since these are the newly classified genera literature is unable to furnish much information for discussion and comparison with other studies.

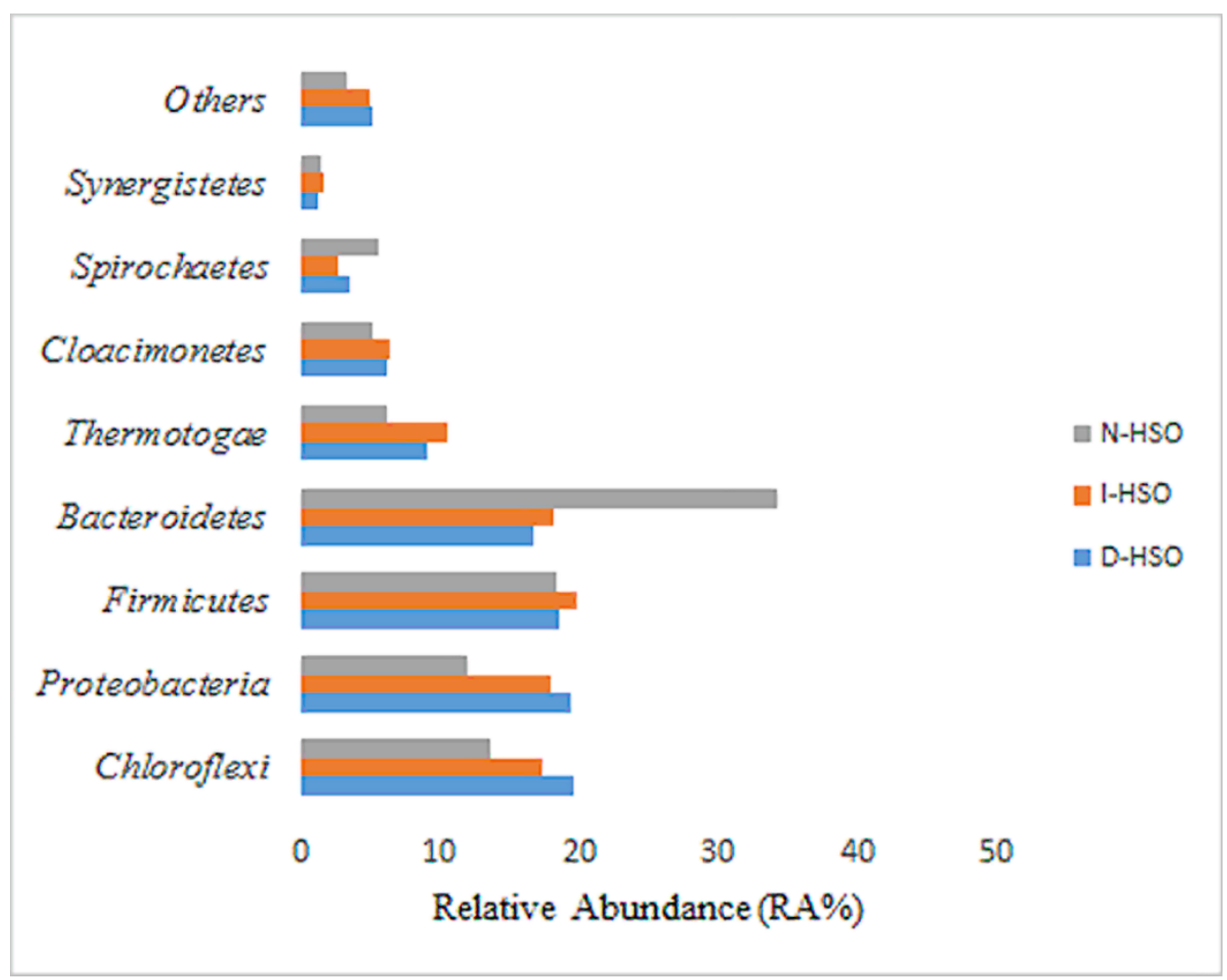

Figure 5.33 - Bacterial community classification at Phylum-level. Relative abundance less than $1 \%$ of the samples was accumulated and presented as 'Others'

Dehalococcoides were found in relatively lower abundance $(3.35-4.88 \%)$ might be due to the presence of higher lignin. Dehalococcoides are slow-growing, strictly anaerobic, diskshaped bacteria. 16S rRNA phylogeny revealed their cell-wall resemblance to archaea than to Gram-positive or Gram-negative (Koukkou, 2011). Hydrothermal pretreatment resulted in phase transition of lignin; solid to liquid to glass transition phase. It could happen over a range of temperature $80-193{ }^{\circ} \mathrm{C}$ (Irvine, 1985; Trajano et al., 2013). Lignin is composed of methoxylated derivatives of benzene called monolignols (coniferyl, sinapyl, and coumaryl alcohols) (Moore et al., 2011). Lignin depolymerization and recondensation during hydrothermal pretreatment are reported by Trajano et al (Trajano et al., 2013). Dehalococcoides identified in the three selected samples could be attributed to degrade benzene monomers (Kublik et al., 2016). 
Proteobacteria is a diverse phylum harboring bacteria of varied physiological functions and metabolic pathways. The genera identified in this study belonging to Proteobacteria were sulfate-reducers and aromatic compound degraders. Bugg et al (Bugg et al., 2011) reported that potential lignin-degrading bacteria are mostly derived from guts of wood-eating insects and include Alphaproteobacteria, Gammaproteobacteria and Actinomycetes. Syntrophus (2.52$3.78 \%)$, Syntrophorhabdus (0.97-1.30\%) and Geobacter (1.06-1.85\%) root to class Deltaproteobacteria while Pseudomonas (0.49-2.83\%) and Sulfurovum (0.96-1.53\%) belong to class Gammaproteobacteria and Epsilonproteobacteria. Despite belonging to the same class, each genus root to a different family.

Syntrophus (Family Syntrophaceae) were identified in lower abundance with approx. similar abundance $(2.52-3.78 \%)$ in tested samples. Members are strictly anaerobic, having the fermentative type of metabolism and grow only in the presence of $\mathrm{H}_{2} /$ formate-utilizing partners in syntrophic associations. Substrates are oxidized either incompletely to acetate or completely to carbon dioxide. Syntrophorhabdus are Gram-negative, nonsporulating, nonmotile strict anaerobe having an obligate syntrophic metabolism. It is an aromatic compound degrader that exhibits obligate syntrophic relation with $\mathrm{H}_{2}$ scavenging methanogen (Qiu et al., 2008). Lower abundance (0.97-1.30\%) of Syntrophorhabdus in the tested samples indicated unavailability of $\mathrm{H}_{2}$ for their growth. Syntrophorhabdus members are previously reported in sulfate-reducing co-cultures from sewage sludge treatment plants (Qiu et al., 2004).

Pseudomonas spp. recently reported to produce novel cellulolytic enzymes consisting of an endoglucanase, exoglucanase, $\beta$-glucosidase and xylanase that could effectively hydrolyze alkaline-pretreated bagasse, achieving over 95\% monosaccharide yield (Cheng and Chang, 2011), Pseudomonas identified in the current study for $\mathrm{H}_{2} \mathrm{SO}_{4}$ pretreated samples are in the range of 0.852.83\%. Pseudomonas spp. reported to degrade cellulose and hemicellulose (Zhong et al., 2011). Tian et al (Tian et al., 2014) reported that Pseudomonas could utilize biphenyl components of lignin, which are nearly $10 \%$ constituents of total lignin depending upon the source of lignin. Some strains of Pseudomonas reported exhibiting Beta-ketoadepate pathway, which is significant for lignin degradation (Bugg et al., 2011). P. fluorescenswas reported producing extracellular lignin peroxidase for lignin degradation (Kong et al., 2010). The difference in Pseudomonas abundance 
$(0.49-2.83 \%)$ in the tested samples could be related to lignin degradation and release of phenolic monomers depending upon pretreatment temperature employed.

Geobacter another Deltaproteobacteria member with similar abundance (1.06-1.85\%) was identified in tested samples. Members are non-fermenting, chemoorganotrophic mesophilic anaerobes with the capability to oxidize acetate, $\mathrm{C}_{1}-\mathrm{C}_{5}$ organic acids and $\mathrm{C}_{2}-\mathrm{C}_{4}$ alcohols. Species of this genus are reported to perform versatile physiological functions. Rotaru et al (Rotaru et al., 2014) reported that Methanosaeta spp. directly accepts an electron from Geobacter spp. to reduce $\mathrm{CO}_{2}$ into methane via direct electron transfer process instead of $\mathrm{H}_{2}$ inter-specie transfer. In another study Childers et al (Childers et al., 2002) reported aromatic compounds degradation in Geobacter metallireducens with $\mathrm{Fe}^{3+}$ as electron acceptor under anaerobic conditions suggesting the existence of specific enzymes. Some species are also reported to oxidize monoaromatic hydrocarbons like benzene and phenol (Roling, 2014).

Sulfurovum (Class Epsilonproteobacteria) were identified in lower abundance (0.951.53\%). This genus was first described in 2004 after its discovery from hydrothermal vents. Sulfurovum members are Gram-negative, non-motile, coccoid-shaped, mesophilic, chemolithoautotrophic facultative anaerobes utilizing elemental sulfur or thiosulfate as an electron donor (Inagaki et al., 2004). Organic acids, alcohols, sugars and hydrogen do not support the growth of Sulfurovum lithotrophicum.

Treponema (Class Spirochaetia) abundance was in the range of 1.06 to $3.92 \%$ in tested samples. Treponema species have been shown to interact with cellulolytic bacteria and increase the degradation rate of cellulose. Bacteria from this genus likely are able to metabolize exopolysaccharides produced by the primary cellulolytic bacteria, functioning as fermenters (Warnecke et al., 2007). 


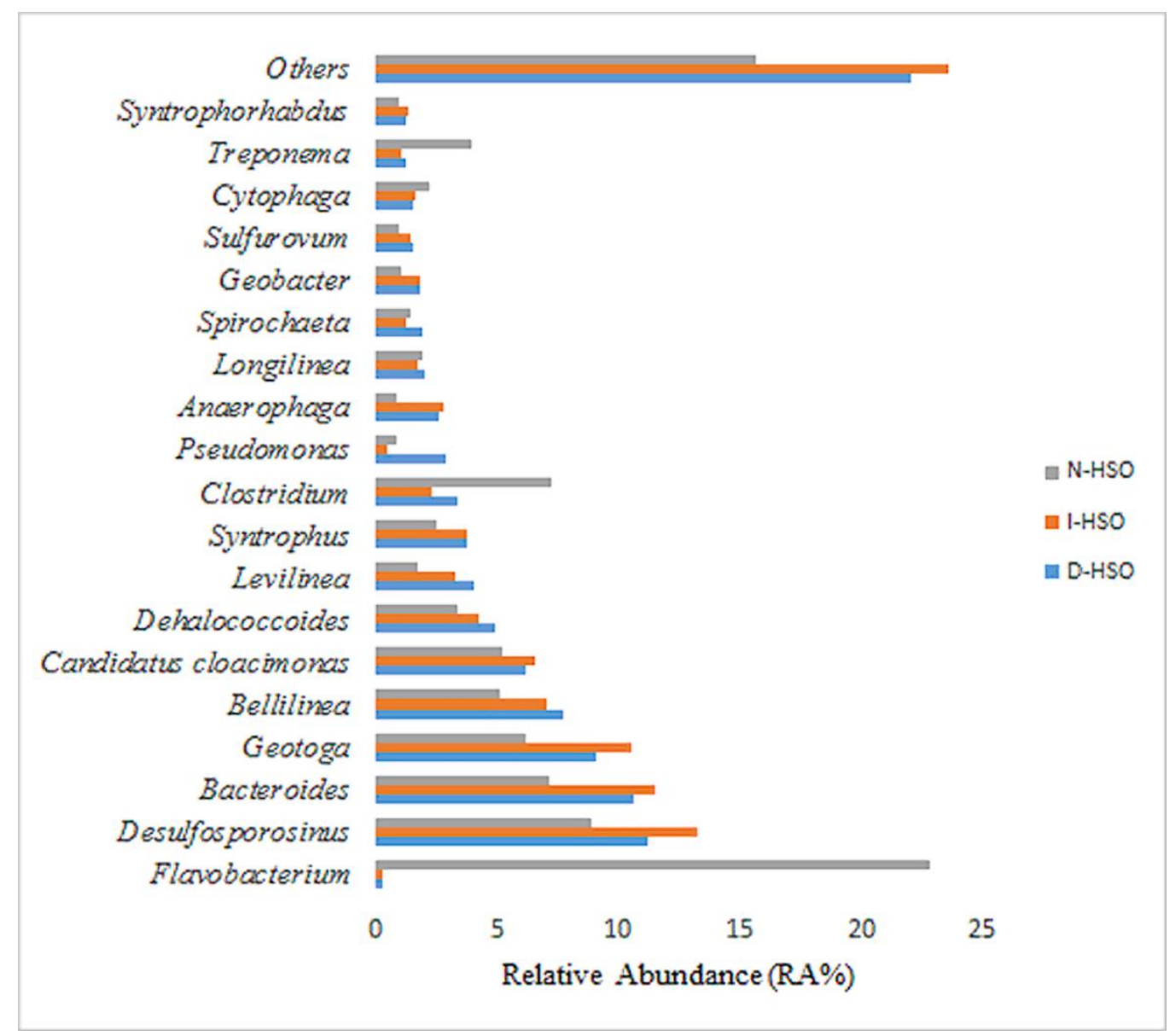

Figure 5.34 Bacterial community classification for $\mathrm{H}_{2} \mathrm{SO}_{4}$ pretreated samples at Genus-level. Relative abundance less than $1 \%$ of the samples was accumulated and presented as 'Others'

5.12.2 Archaeal diversity in selected $\mathrm{H}_{2} \mathrm{SO}_{4}$ pretreated samples

Archaea belonging to Phylum Eurarychaeota were predominant in sequences with relative abundance in the range of 98.05 to $99.22 \%$ of the tested samples. While, Crenarchaeota abundance was between 0.86 to $1.94 \%$. Class Methanomicrobia was the most dominant $(71.43-83.22 \%)$ followed by Methanobacteria (13.40 - 25.28\%) and Thermoplasmata (1.29-2.43\%) (Fig. 5.35). 


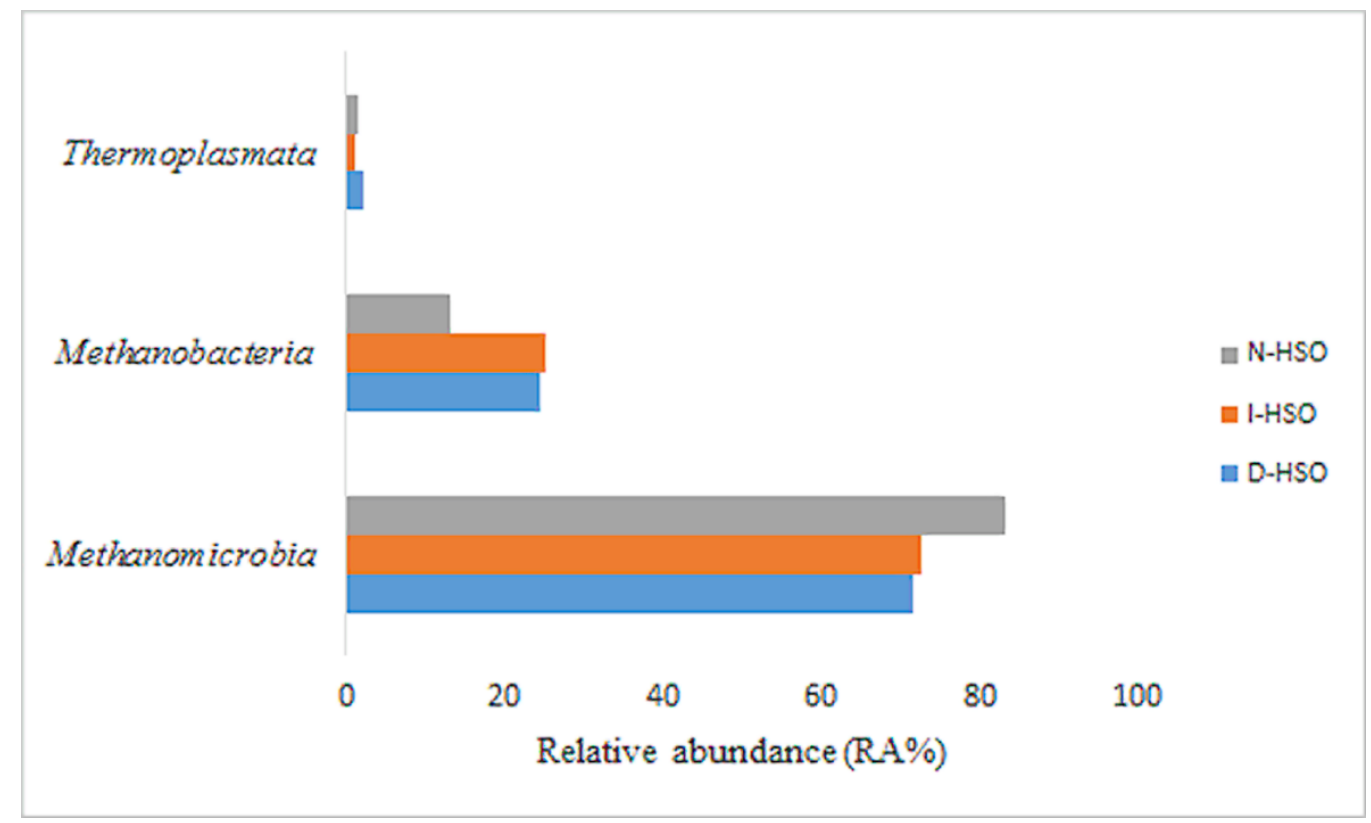

Figure 5.35 - Archaeal community classification for selected $\mathrm{H}_{2} \mathrm{SO}_{4}$ pretreated samples at Classlevel.

Representatives belonging to Family Methanoregulaceae (57.3 - 68.3\%), Methanobacteriaceae $(13.4$ - 25.3\%) and Methanosaetaceae (11.7 - 14.4\%) were the most prevalent in pretreatments D-HSO, I-HSO, and N-HSO (Fig 5.36). The family Methanoregulaceae currently consists of three genera: Methanoregula, Methanolinea, and Methanosphaerula. The family is affiliated with the order Methanomicrobiales, which were identified in D-HSO, I-HSO, and N-HSO reactors at 59.4\%, 58\% and $68.9 \%$, respectively. The members are slow-growing, rodshaped or coccoid, nonmotile methanogens that can use $\mathrm{H}_{2} / \mathrm{CO}_{2}$ and sometimes formate as substrates for methanogenesis. The members are neutrophilic or slightly acidophilic mesophiles. Some species of Methanoregulaceae were isolated in diverse habitats including reactors for the anaerobic treatment of organic waste, and oil fields (Garcia et al., 2006) The most abundant genus of Methanoregulaceae family, in current study using sulfuric acid, was Methanolineae that grouped 51,9\%, 51,2\% and 63,1\% in reactors D-HSO, I-HSO, and N-HSO, respectively. Methanolineae is a methanogen that uses $\mathrm{H}_{2} / \mathrm{CO}_{2}$ and requires acetate for growth (Imachi et al., 2008; Sakai et al., 2012)

Representatives belonging to Family Methanobacteriaceae comprehend morphologically diverse microorganism with cell shape varying from cocci or short rods to long filamentous rods. All species are strict anaerobes, and most members of the family obtain energy for growth from 
the reduction of $\mathrm{CO}_{2}$ with $\mathrm{H}_{2}$. Members of the family are widely distributed in anaerobic environments including aquatic sediments, sewage treatment systems, gastrointestinal tracts of animals, and in geothermal areas (Bonnin and Boone, 2006; Tabatabaei et al., 2010). In acid pretreatment, the representative genus of Methanobacteriaceae was Methanobacterium (13.8 24.7\%). Some species of Methanobacterium use formate, secondary alcohols, and $\mathrm{CO}, \mathrm{CO}_{2}$ reduction coupled to $\mathrm{H}_{2}$ oxidation is the major growth mechanism (Boone, 2015).

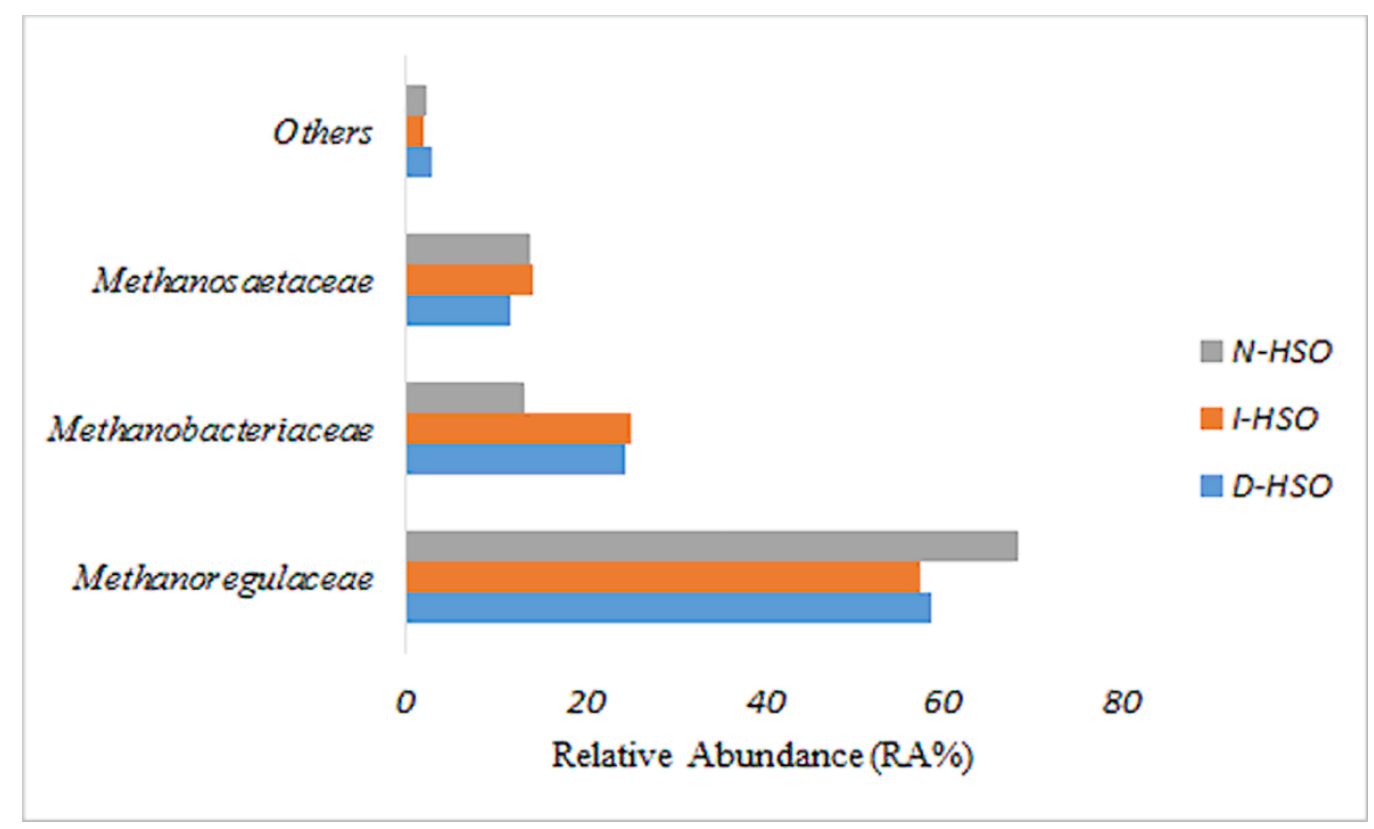

Figure 5.36 - Archaeal community classification for $\mathrm{H}_{2} \mathrm{SO}_{4}$ pretreated samples at Family-level. Relative abundance less than $1 \%$ of the samples was accumulated and presented as 'Others'

The most abundant genera identified, in reactors under acid pretreatment, were Methanolinea (51.15 - 63.06\%), Methanobacterium (13.08 - 24.67\%), Methanosaeta (11.77 13.99\%), and Methanoregula (5.22 - 6.79\%), while, Thermogymnomonas, Candidatus nitrosocaldus and Methanomassiliicoccus grouped less than 3\% (Fig 5.37)

Methanoregula represented $6.79 \%$ (D-HSO), 6.11\% (I-HSO) and 5.22\% (N-HSO), respectively, of total sequences. Some species of this genus have been isolated from anaerobic reactors (Brauer et al., 2011; Yashiro et al., 2011). The microorganism can use $\mathrm{H}_{2} / \mathrm{CO}_{2}$ and formate in methane production, growth occurs at $\mathrm{pH} 7.0-7.6$ and temperature range between $10-40{ }^{\circ} \mathrm{C}$.

Methanomassiliicoccus members are regular or coccoid shaped Gram-stain positive obligate mesophilic anaerobes and slightly alkaliphilic. Methanomassiliicoccus luminyensis 
produces methane by methanol reduction with $\mathrm{H}_{2}$ as an electron donor. It is unable to produce methane with methanol when $\mathrm{H}_{2}$ or methanol is the only energy source. Specie cannot produce methane from a formate, acetate, trimethylamine, 2-butanol, 2-propanol, cyclopentanol, 2pentanol, and ethanol (Dridi et al., 2012). Candidatus nitrosocaldus is an autotrophic crenarchaeota and not relevant to methane production; the major metabolism of this genus is ammonia oxidation (De La Torre et al., 2008).

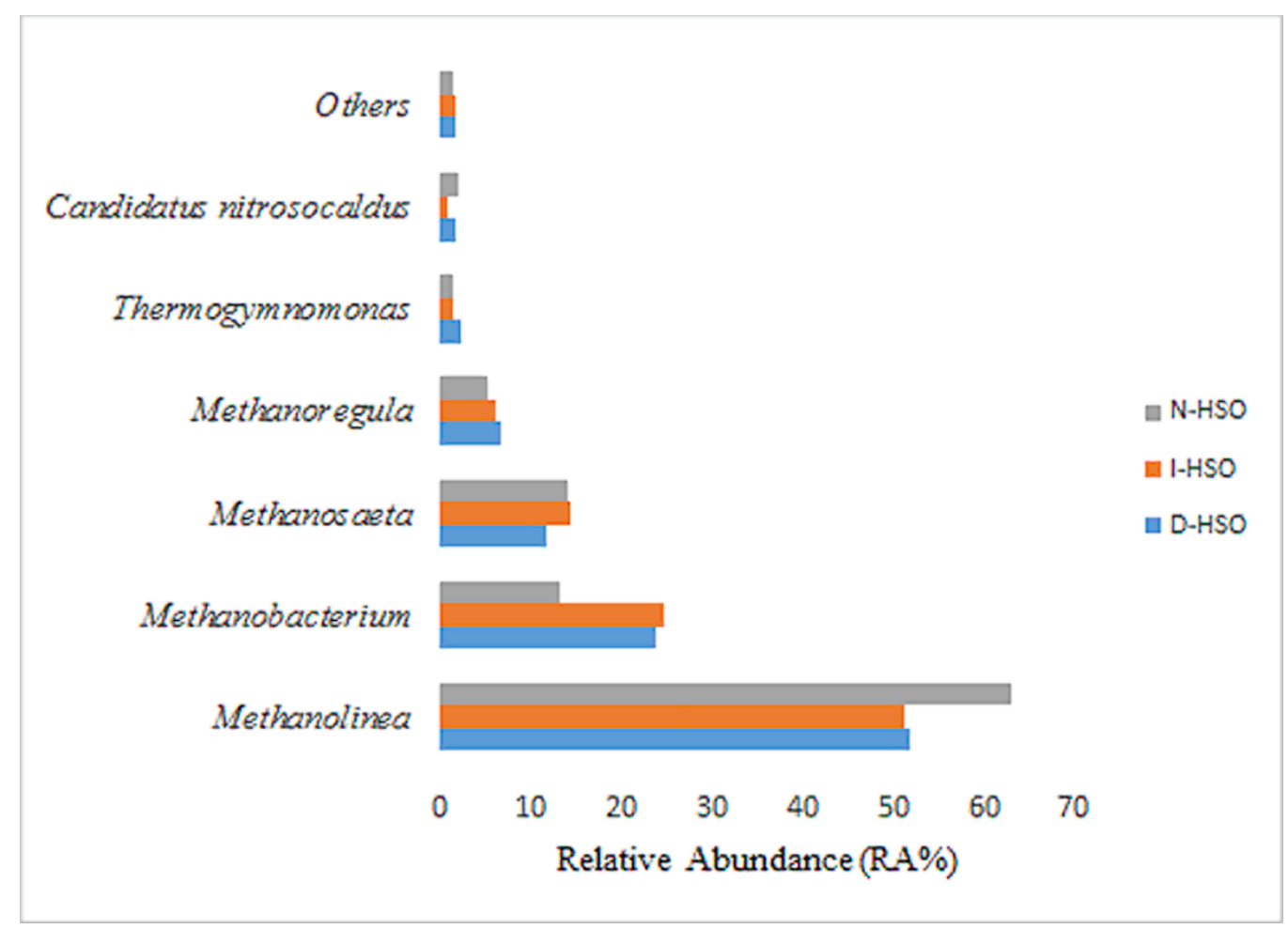

Figure 5.37 - Archaeal community classification for $\mathrm{H}_{2} \mathrm{SO}_{4}$ pretreated samples at Genus-level. Relative abundance less than $1 \%$ of the samples was accumulated and presented as 'Others'

5.13 Microbial community structure difference between positive control and pretreated samples

The microbial community of positive control (glucose) was also determined at the end of the digestion by Illumina MiSeq sequencing. RDP-classifier resulted into 165901 reads that were characterized into 2700 OTUs. Bacterial and archaeal diversity for the positive control (glucose) indicated a distinct difference in comparison to the microbial community of $\mathrm{H}_{2} \mathrm{O}_{2}$ and $\mathrm{H}_{2} \mathrm{SO}_{4}$ pretreated samples.

Firmicutes (66.0\%) and Proteobacteria (23.29\%) were the dominant bacterial phyla along with a lower abundance of Bacteroidetes (3.34\%) and Chloroflexi (2.04\%) in the positive control. 
Clostridia (63.12\%) and Gammaproteobacteria (19.15\%) were identified as the dominant classes in the positive control whereas Chloroflexi, Firmicutes, Bacteroiedetes, Thermotogae, Cloacimonetes, Spirochaetes were the dominant classes in $\mathrm{H}_{2} \mathrm{O}_{2}$ and $\mathrm{H}_{2} \mathrm{SO}_{4}$ samples. The Most abundant bacterial genera (Fig 5.38 A) identified in the positive control were Clostridium (55.68\%), Aeromonas (13.37\%), Tolumonas (5.48\%), and Bacteroides (2.60\%), whereas Methanobacteirum $(95.90 \%)$ was the sole abundant archaeal genus (Fig 5.38 B).

Since Clostridia bears saccharolytic, proteolytic or both metabolic pathways. Clostridium encountered in the positive control could be of saccharolytic nature because glucose was the only substrate provided. Clostridia are also efficient hydrogen producers. Kim et al. (Kim et al., 2014) reported Clostridial proliferation in their study suggesting excessive $\mathrm{H}_{2}$ production. Clostridial community (55.68\%) in positive control supports higher Methanobacterium abundance (95.90\%), a hydrogenotrophic bacterium, suggesting that hydrogenotrophic methanogenesis might be the sole mechanism for methane production in the positive control.

Aeromonas and Tolumonas of family Aeromonadaceae were abundant genera in the positive control next to Clostridium. However, these genera were not identified in $\mathrm{H}_{2} \mathrm{O}_{2}$ pretreated (B-HO, K-HO, and P-HO) and $\mathrm{H}_{2} \mathrm{SO}_{4}$ pretreated (D-HSO, I-HSO, and N-HSO) samples. Aeromonas are Gram-negative, chemoorganotrophic, facultative anaerobes exhibiting fermentative metabolism of $D$-glucose with optimum growth temperature in the range of $22-37$ ${ }^{\circ} \mathrm{C}$. Aeromonas exhibits versatile metabolic growth to utilize amino acids, carboxylic acids, and carbohydrates for organic acid production (Brenner et al., 2004) that results in its rapid growth and absolute abundance during reactor startup (Kim, 2007). Easy availability of substrate (glucose) might be the reason of Aeromonas abundance in positive control as reported by (Kim, 2007) for its rapid growth during the digestion process.

Tolumonas is facultative anaerobic, Gram-negative Gammaproteobacteria only identified in the positive control (5.48\%). It is reported to be isolated from wastewater and anoxic sediments of freshwater (Fischer-Romero et al., 1996; Caldwell et al., 2011). Ethanol, acetate, formate, and short chain organic acids are metabolic products when grown on glucose (Caldwell et al., 2011). Lactobacillus, Ethanoligenens, and Bacteroides were also found in similar abundance in the positive control with the relative abundance of $2.53 \%, 2.46 \%$, and $2.31 \%$, respectively. 
Lactobacillus and Ethanoligenens were not identified in pretreated samples, whereas Bacteroides was observed in less than $1 \%$ abundance in $\mathrm{H}_{2} \mathrm{O}_{2}$ and $7.14-10.64 \%$ in $\mathrm{H}_{2} \mathrm{SO}_{4}$ pretreated samples. Lactobacillus (Family Lactobacillaceae) is Gram-positive, non-spore-forming bacteria with an optimum growth temperature of $30-40{ }^{\circ} \mathrm{C}$. Lactobacillus generally possess complex nutritional requirement; vitamins, salts, fatty acid esters, and fermentable carbohydrates. Lactic acid is considered the sole product of carbohydrate metabolism by Lactobacillus (Walter, 2008).Oude et al. (Oude Elferink et al., 2001) reported that Lactobacillus buchneri could convert lactic acid to acetic acid; a principal substrate for acetoclastic methanogenesis. The lower abundance of Lactobacillus further confirmed that hydrogenotrophic methanogenesis was favored in positive control.

Ethanoligenens (Family Ruminococcaceae) are Gram-positive, non-spore-forming, chemo-organotrophic, obligate anaerobes with optimum temperature and $\mathrm{pH}$ range, respectively, $20-44{ }^{\circ} \mathrm{C}$, and 3.5 - 9.0. Ethanoligenens can ferment several mono-, di-, and oligosaccharides. Major fermentation products of glucose metabolism include ethanol, $\mathrm{H}_{2}, \mathrm{CO}_{2}$ and acetate (Xing et al., 2006).

Methanobacterium was the only abundant genus in archaeal diversity (95.89\%) where Methanomassiliicoccus and Methanosaeta were present in lower abundance 1.57\% and 1.3\%, respectively. It suggested that hydrogenotrophic methanogenesis was the only mechanism for methane production in positive control.

To sum up, a distinct difference in the microbial community structure was observed between positive control (Fig 5.38) and both pretreated samples; $\mathrm{H}_{2} \mathrm{O}_{2}$ (Fig 5.39) and $\mathrm{H}_{2} \mathrm{SO}_{4}$ (Fig 5.40) primarily because of difference in the substrate provided. Sugarcane bagasse is a heterogeneous feedstock so a number of bacterial strains belonging to different taxonomic groups needed to work together for the release of fermentable sugars to initiate the digestion process chain whereas it was not the case for pure glucose; readily available for the microbial 


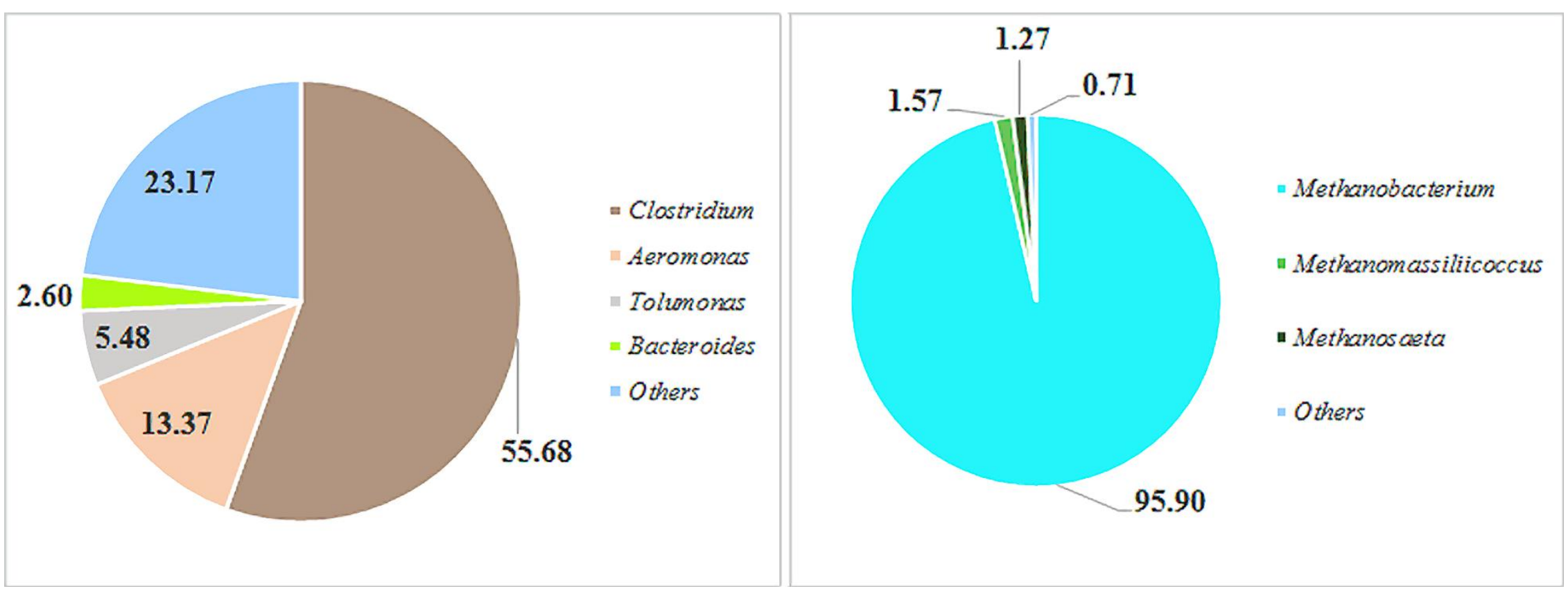

Figure 5.38 - Microbial community structure of positive control at Genus-level for bacteria (A) and archaea (B). All the taxonomic groups less than $1 \%$ are accumulated and represented as 'Others' 


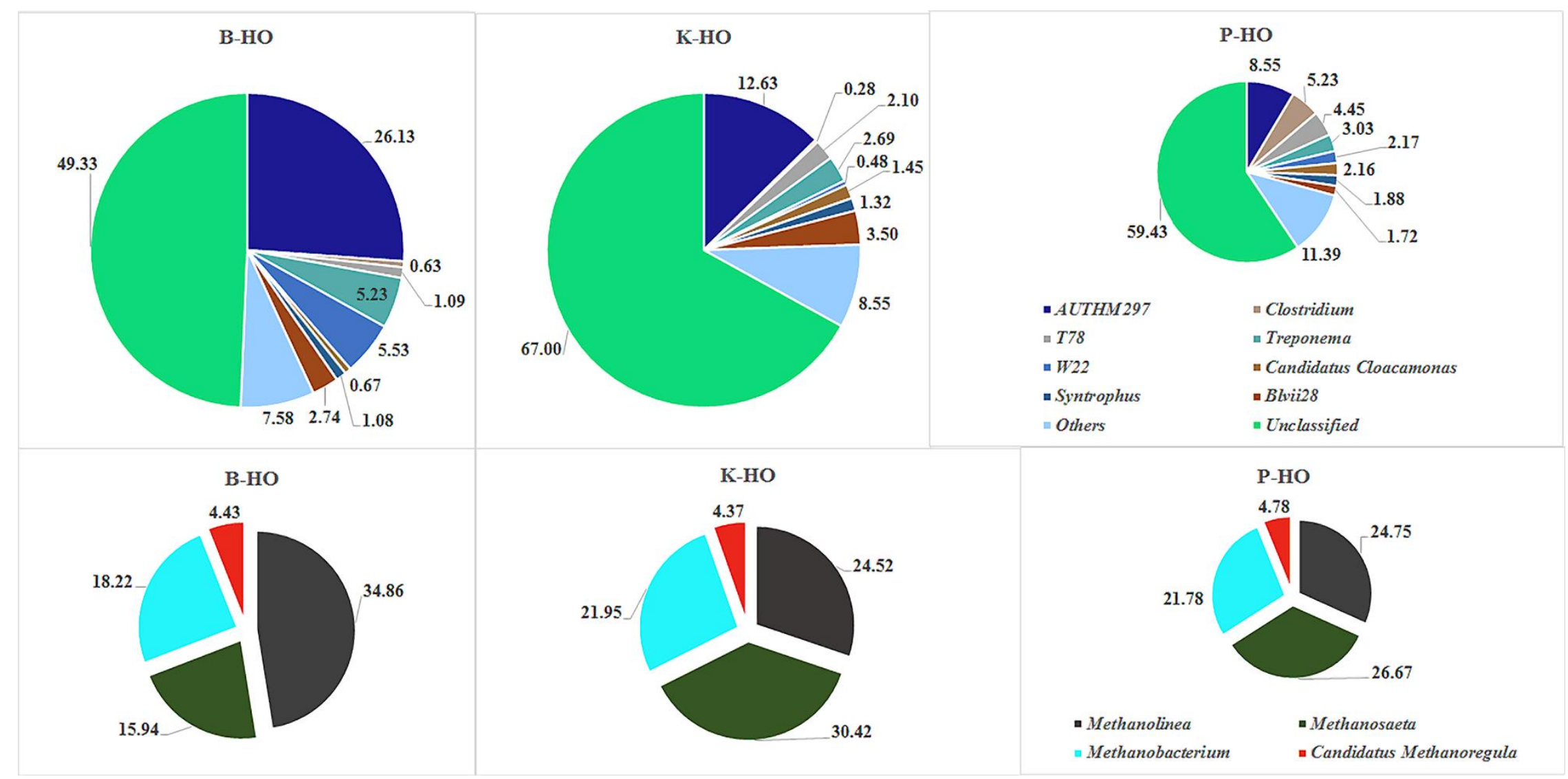

Figure 5.39 - Microbial community structure of bacteria (upper row) and archaea (lower row) at Genus-level for selected $\mathrm{H}_{2} \mathrm{O}_{2}$ treated batch digestion reactors. All the taxonomic groups less than $1 \%$ are accumulated and represented as 'Others' 

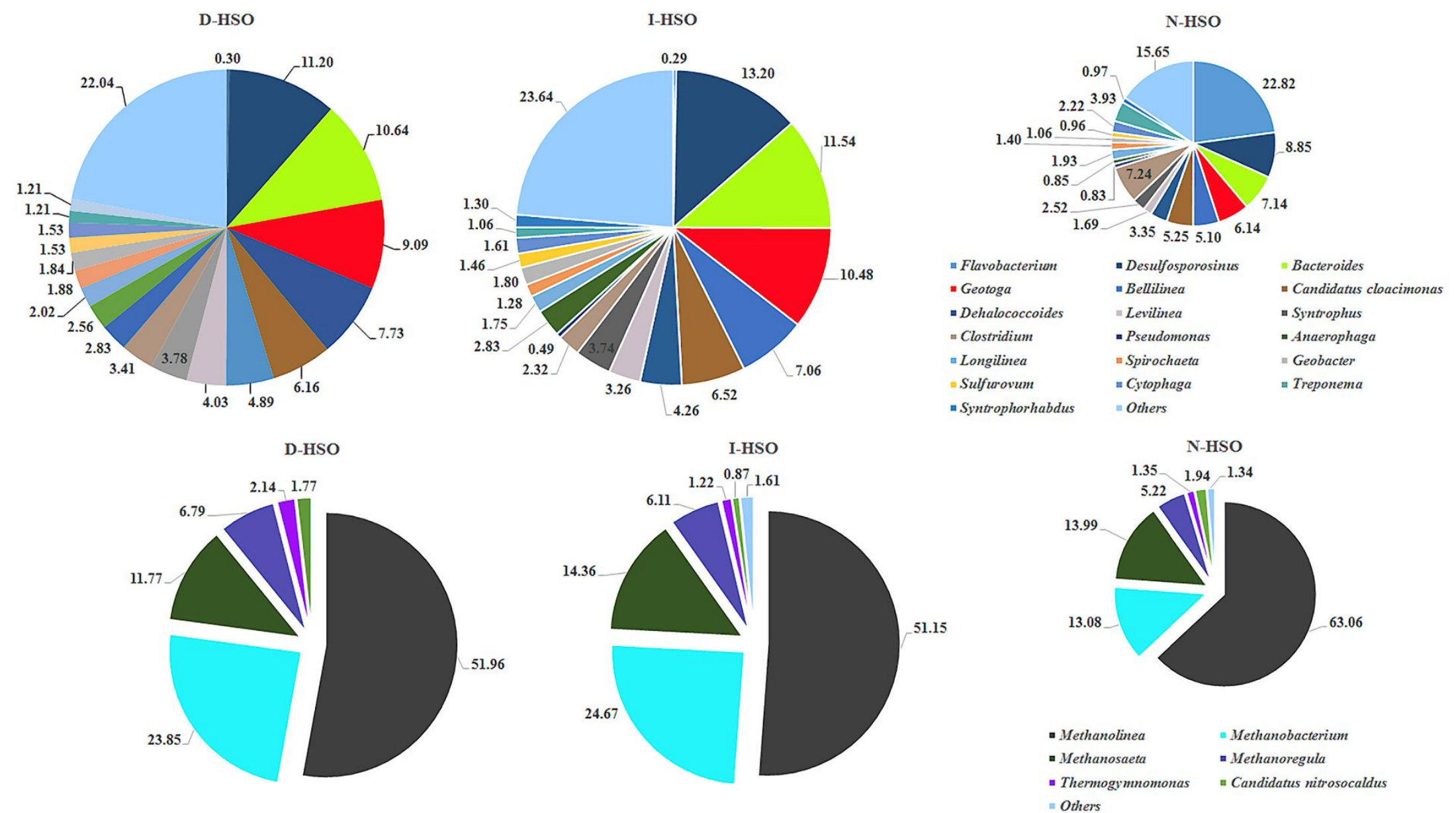

Figure 5.40 - Microbial community structure of bacteria (upper row) and archaea (lower row) at Genus-level for selected $\mathrm{H}_{2} \mathrm{SO}_{4}$ treated batch digestion reactors. All the taxonomic groups less than $1 \%$ are accumulated and represented as 'Others' 

ASSISTED HYDROTHERMAL PRETREATMENT

Methane production from lignocellulosic feedstocks appears a favorable renewable energy option to lower the world's dependence on fossil fuels while at the same time mitigating Food vs. Fuel dilemma. However, the recalcitrance of lignocellulosic material needs to be reduced to utilize this valuable resource at its optimum potential. Pretreatment step is a mandatory requirement to fractionate lignocellulosic material for downstream processing. The thesis focused on a novel pretreatment strategy applied to the sugarcane bagasse; sugarcane bagasse was impregnated with $\mathrm{H}_{2} \mathrm{O}_{2}$ and $\mathrm{H}_{2} \mathrm{SO}_{4}$ separately before hydrothermal pretreatment employing a central composite design of three factors; temperature $\left({ }^{\circ} \mathrm{C}\right)$, time (min), and chemical compounds concentration. The notable results were obtained from the both pretreatments, which are contrasting to each other primarily due to the difference in chemical compound utilized for the impregnation of sugarcane bagasse. Chemical composition of solid and liquid fraction, morphological characteristics of solid fraction, impact on subsequent digestion experiments, and impact on microbial community structure will be briefly compared for the both pretreatments in this subsection.

A notable impact on the solid recovery after hydrothermal pretreatment was verified for both pretreatments. Solid yield tends to decrease with an increase in temperature and chemical compound $\left(\mathrm{H}_{2} \mathrm{O}_{2}, \mathrm{H}_{2} \mathrm{SO}_{4}\right)$ utilized for sugarcane bagasse impregnation. $\mathrm{H}_{2} \mathrm{O}_{2}$ resulted in significant lignin solubilization while $\mathrm{H}_{2} \mathrm{SO}_{4}$ effected hemicellulose thereby leading to breakdown of inter-molecular bonding between polymeric sugars and lignin meshwork resulting in lower solid recovery. The lowest solid yield $\left(12.27 \%\right.$ ) was observed for $\mathrm{H}_{2} \mathrm{SO}_{4}$ assisted hydrothermal pretreatment (pretreatment run $\mathrm{A}-\mathrm{HSO}-200{ }^{\circ} \mathrm{C}, 19 \mathrm{~min}, 3 \% \mathrm{w} / \mathrm{v} \mathrm{H}_{2} \mathrm{SO}_{4}$ ) in comparison to $\mathrm{H}_{2} \mathrm{O}_{2}$ assisted pretreatment where maximum solid yield $\left(93.13 \%\right.$ ) was noted for the lowest $\mathrm{H}_{2} \mathrm{O}_{2}$ employed (pretreatment run $\mathrm{L}-\mathrm{HO}-180{ }^{\circ} \mathrm{C}, 12 \mathrm{~min}, 0.64 \% \mathrm{v} / \mathrm{v}_{2} \mathrm{O}_{2}$ ). Compositional analysis of solid fraction revealed significant lignin solubilization $(73.09 \%)$ for $\mathrm{H}_{2} \mathrm{O}_{2}$. On the other hand, maximal lignin recovery $\left(358.85 \%\right.$ ) was recorded for $\mathrm{H}_{2} \mathrm{SO}_{4}$ assisted hydrothermal pretreatment.

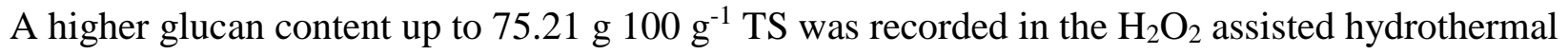
pretreatment (pretreatment run $\mathrm{O}-\mathrm{HO}-213.6{ }^{\circ} \mathrm{C}, 12 \mathrm{~min}, 4 \% \mathrm{v} / \mathrm{v} \mathrm{H}_{2} \mathrm{O}_{2}$ ) primarily due to lignin solubilization and xylan removal to the liquid stream. Whilst, glucan degradation was observed in the $\mathrm{H}_{2} \mathrm{SO}_{4}$ assisted hydrothermal pretreatment at higher reaction temperature $\left(200{ }^{\circ} \mathrm{C}\right)$, reaction time (19 $\mathrm{min})$, and $3 \% \mathrm{w} / \mathrm{v} \mathrm{H}_{2} \mathrm{SO}_{4}$. 
Xylan content was also decreased in $\mathrm{H}_{2} \mathrm{O}_{2}$ assisted pretreatment. The lowest xylan removal (12.11\%) was noted in pretreatment run $\mathrm{H}-\mathrm{HO}\left(160{ }^{\circ} \mathrm{C}, 5 \mathrm{~min}, 2 \% \mathrm{v} / \mathrm{v} \mathrm{H}_{2} \mathrm{O}_{2}\right)$. In contrast, $\mathrm{H}_{2} \mathrm{SO}_{4}$ assisted pretreatment indicated significant impact on xylan removal up to $100 \%$ removal in a number of pretreatments (A-HSO, B-HSO, C-HSO and O-HSO) depending upon the joint impact of reaction temperature, reaction time and $\mathrm{H}_{2} \mathrm{SO}_{4}$ concentration.

Morphological characterization by scanning electron microscopy verified significant differences in structural characterization of sugarcane bagasse in response to both studied pretreatments besides raw sugarcane bagasse. Micrographs depicted compact and smooth surface for raw sugarcane bagasse. However, selected $\mathrm{H}_{2} \mathrm{O}_{2}$ assisted pretreatment (pretreatment run K-HO $-180{ }^{\circ} \mathrm{C}, 12 \min 7.36 \% \mathrm{v} / \mathrm{v} \mathrm{H}_{2} \mathrm{O}_{2}$ ) displayed porous surface indicating lignin removal whereas pretreatment run O-HSO $\left(213.6{ }^{\circ} \mathrm{C}, 12 \mathrm{~min}, 2 \% \mathrm{w} / \mathrm{v} \mathrm{H}_{2} \mathrm{SO}_{4}\right)$ resulted in repolymerization of klason lignin (pseudo lignin) in droplets form on the cell wall surface.

Liquid hydrolysate characterization of both pretreatments resulted significant differences in their chemical composition. Lower concentration of furfural and 5-HMF in the range of 0 $56.91 \mathrm{mg} \mathrm{L}^{-1}$ and $2.56-56.60 \mathrm{mg} \mathrm{L}^{-1}$, respectively, were verified in liquid hydrolysate of $\mathrm{H}_{2} \mathrm{O}_{2}$ assisted hydrothermal pretreatment besides lower concentrations of glucose $\left(0.50-1.29 \mathrm{mg} \mathrm{L}^{-1}\right)$ and xylose $\left(1.27-9.60 \mathrm{mg} \mathrm{L}^{-1}\right)$ and higher concentrations of acetic acid $\left(107.42-581.02 \mathrm{mg} \mathrm{L}^{-1}\right)$ and formic acid $\left(54.95-1108.02 \mathrm{mg} \mathrm{L}^{-1}\right)$, COD $\left(8.07-17.75 \mathrm{~g} \mathrm{~L}^{-1}\right)$, total carbohydrate $(1.96$ $4.14 \mathrm{~g} \mathrm{~L}^{-1}$ ), and phenolic content (741.25-3,005.63 ppm). In contrast, liquid hydrolysate of $\mathrm{H}_{2} \mathrm{SO}_{4}$ assisted hydrothermal pretreatment presented higher furanic compounds concentration; furfural and 5-HMF in the range of $939.89-2,181.24 \mathrm{mg} \mathrm{L}^{-1}$ and $70.95-970.08 \mathrm{mg} \mathrm{L}^{-1}$, respectively. Higher concentration of organic acids was also verified; acetic acid (1,114.61 -2,198.89 $\left.\mathrm{mg} \mathrm{L}^{-1}\right)$, formic acid $\left(688.31-3,611.28 \mathrm{mg} \mathrm{L}^{-1}\right)$. Chemical oxygen demand was in the range of $8.33-25.20$ $\mathrm{g} \mathrm{L}^{-1}$, total carbohydrate content $\left(2.96-20.90 \mathrm{~g} \mathrm{~L}^{-1}\right)$. However, lower phenolic content 596.72 $1674.22 \mathrm{ppm}$ ) was noted in comparison to $\mathrm{H}_{2} \mathrm{O}_{2}$ assisted pretreatment. Sulfate (360.0 - 7,240.0 mg L ${ }^{-1}$ ) was only determined for $\mathrm{H}_{2} \mathrm{SO}_{4}$ pretreatment. Furthermore, relatively higher concentrations of glucose $\left(1.93-13.53 \mathrm{mg} \mathrm{L}^{-1}\right)$ and xylose $\left(0.43-13.87 \mathrm{mg} \mathrm{L}^{-1}\right)$ was verified when compared to $\mathrm{H}_{2} \mathrm{O}_{2}$ assisted hydrothermal pretreatment for glucose $\left(0.19-1.29 \mathrm{mg} \mathrm{L}^{-1}\right)$ and xylose $\left(1.27-9.60 \mathrm{mg} \mathrm{L}^{-1}\right)$, respectively. 
Biomethane potential assays for the solid fraction of both pretreatments indicated significant differences in the methane yield. $\mathrm{H}_{2} \mathrm{O}_{2}$ assisted hydrothermal pretreatment resulted into notably higher methane production primarily due to lignin solubilization and higher glucan content in the solid fraction. Maximum methane production (14.43 $\mathrm{Nmmol} \mathrm{g}^{-1} \mathrm{TVS}$ ) was recorded in the pretreatment run $\mathrm{K}-\mathrm{HO}\left(180{ }^{\circ} \mathrm{C}, 12 \mathrm{~min}, 7.36 \% \mathrm{v} / \mathrm{v} \mathrm{H}_{2} \mathrm{O}_{2}\right)$, which was $118.16 \%$ higher than the methane production of raw sugarcane bagasse $6.59 \mathrm{Nmmol} \mathrm{g}^{-1} \mathrm{TVS}$. However, $\mathrm{H}_{2} \mathrm{SO}_{4}$ assisted hydrothermal pretreatment resulted in significant methanogenic inhibition in most of the studied pretreatments. It could be explained with the logic that most of the fermentable sugars were released into liquid fraction coupled with high klason lignin content in the solid fraction.

Microbial community structure determined with DGGE revealed that reaction temperature, reaction time, and $\mathrm{H}_{2} \mathrm{O}_{2}$ concentration had a notable impact on Pearson similarity coefficient for the bacterial community; similarity coefficient decreased with a decrease in reaction time and $\mathrm{H}_{2} \mathrm{O}_{2}$ concentration. However, increased with a decrease in reaction temperature. On the other hand, for an archaeal community much difference in the Pearson similarity coefficient was not observed. Shannon-Wiener $\left(\mathrm{H}^{\prime}\right)$ values were in the range of $2.10-3.18$ and $2.72-2.86$, respectively for Bacteria and Archaea while Dominance values were in the range of 0.04-0.14 and 0.06-0.08, respectively for Bacteria and Archaea.

DGGE band profile of $\mathrm{H}_{2} \mathrm{SO}_{4}$ assisted batch digestion reactors depicted notable variability in Pearson similarity coefficient for bacteria; decrease in reaction time resulted in a decrease in similarity coefficient value while a decrease in reaction temperature resulted in an increase in similarity coefficient value. On the other hand, an increase in similarity coefficient value was observed with a decrease in $\mathrm{H}_{2} \mathrm{SO}_{4}$ concentration. The archaeal population was not much affected by pretreatment parameters. Shannon-Wiener $\left(\mathrm{H}^{\prime}\right)$ values were in the range of $2.59-3.23$ and 2.09 - 2.51, respectively for Bacteria and Archaea. While Dominance values were in the range of 0.04 -0.08 and $0.06-0.14$, respectively for Bacteria and Archaea.

Illumina MiSeq sequencing of selected pretreatments identified the predominance of uncultured AUTHM297 genera belonging to phylum Thermotogae in $\mathrm{H}_{2} \mathrm{O}_{2}$ assisted samples whereas Flavobacterium, Desulfosporosinus, Bacteroides and Geotoga were abundant in $\mathrm{H}_{2} \mathrm{SO}_{4}$ 
treated samples. However, Methanolinea was the abundant archaeal genus in $\mathrm{H}_{2} \mathrm{O}_{2}$ and $\mathrm{H}_{2} \mathrm{SO}_{4}$ treated samples.

\section{CONCLUSIONS}

The experimental studies are concluded with the following observations according to specified objectives:

a) Compositional analysis of sugarcane bagasse verified that it is a suitable lignocellulosic material for methane production owing to its higher polymeric sugar content (73\%) and lower ash content (1.2\%). Morphological characterization depicted that its structure was compact and smooth that necessitate a pretreatment step for further down processing.

b) Pretreatment severity of $\mathrm{H}_{2} \mathrm{O}_{2}$ assisted hydrothermal pretreatment did not influence the formation of furfural and 5-hydroxymethylfurfural formation because of high $\mathrm{pH}$ value. Furthermore, it indicated that $\mathrm{pH}$ value of resulting hydrolysate dictate the formation of furanic compounds. On the other hand, $\mathrm{H}_{2} \mathrm{SO}_{4}$ assisted hydrothermal pretreatment indicated that pretreatment severity resulted in high production of furfural and 5hydroxymethylfurfural formation. Increase in severity resulted in increased furanic compounds concentration and vice versa.

c) Highest methane production $14.43 \mathrm{Nmmol} \mathrm{g}{ }^{-1}$ TVS was obtained in $\mathrm{H}_{2} \mathrm{O}_{2}$ assisted hydrothermal pretreatment for pretreatment run $\mathrm{K}-\mathrm{HO}\left(180^{\circ} \mathrm{C}, 12 \mathrm{~min}, 7.36 \% \mathrm{v} / \mathrm{v} \mathrm{H}_{2} \mathrm{O}_{2}\right)$. Whereas, methanogenic inhibition was encountered in most of $\mathrm{H}_{2} \mathrm{SO}_{4}$ assisted hydrothermal pretreatment. Cumulative organic acids at approx. log phase was in the range of $110.05-228.04 \mathrm{mg} \mathrm{L}^{-1}$ for batch anaerobic reactors treated with $\mathrm{H}_{2} \mathrm{O}_{2}$ assisted hydrothermal reactors where acetic acid was the major organic acid observed. However, in batch anaerobic reactors of $\mathrm{H}_{2} \mathrm{SO}_{4}$ assisted reactors organic acids were below the detection limit.

d) Microbial community structure of selected pretreatments in both pretreatment conditions indicated difference verified by Illumina MiSeq sequencing. Uncultured AUTHM297 was predominant in batch reactors of $\mathrm{H}_{2} \mathrm{O}_{2}$ assisted pretreatments while Flavobacterium, Desulfosporosinus, Bacteroides and Geotoga were abundant in batch reactors of $\mathrm{H}_{2} \mathrm{SO}_{4}$ assisted pretreatment. However, Methanolinea was abundant in both $\mathrm{H}_{2} \mathrm{O}_{2}$ and $\mathrm{H}_{2} \mathrm{SO}_{4}$ assisted hydrothermal pretreatments. 


\section{FUTURE RECOMMENDATIONS}

a) There is a need for improved understanding of the complex chemical reactions taking place in the lignin and polysaccharide phases, which lead to the formation of acidic, furanic and phenolic compounds

b) Enzymatic hydrolysis of pretreated solid fraction of $\mathrm{H}_{2} \mathrm{O}_{2}$ assisted HT pretreatment is needed to be explored in future for enhanced glucose yield for further downstream processing

c) $\mathrm{H}_{2} \mathrm{O}_{2}$ assisted HT pretreatment resulted into maximal lignin solubilization $(73.09 \%)$ into the liquid stream. Lignin is a valuable compound for various products including activated carbon, binders, carbon fibers, and sorbents. Further research is needed to develop methods to extract and purify lignin from solubilized liquid fraction for its potential application. Therefore, $\mathrm{H}_{2} \mathrm{O}_{2}$ assisted HT could be used for the production of an array of products in a biorefinery perspective

d) Author recommend a lower concentration of $\mathrm{H}_{2} \mathrm{SO}_{4}(\% \mathrm{w} / \mathrm{v})$ as an impregnation agent before HT with minimal impregnation period. Hydrolysate of $\mathrm{H}_{2} \mathrm{SO}_{4}-\mathrm{HT}$ could further study for digestion owing to higher COD and lower total phenolic contents with possible longer lag phase due to appreciable furanic compounds.

e) A dedicated study is required with lower $\mathrm{H}_{2} \mathrm{SO}_{4}$ concentration to optimize HT pretreatment for minimal monomeric sugar dehydration into furanic compounds.

f) $\mathrm{H}_{2} \mathrm{O}_{2}$ assisted $\mathrm{HT}$ would be a good option to scale-up for continuous methane production but further study is required to minimize impregnation time to determine optimum lignin solubilization 
ABATZOGLOU, N. et al. Phenomenological kinetics of complex systems: the development of a generalized severity parameter and its application to lignocellulosics fractionation. Chemical Engineering Science, v. 47, n. 5, p. 1109-1122, 1992/04/01 1992. ISSN 0009-2509. Available at: < http://www.sciencedirect.com/science/article/pii/0009250992802355 >.

ADEKUNLE, K. F.; OKOLIE, J. A. A review of biochemical process of anaerobic digestion. Advances in Bioscience and Biotechnology, v. 6, p. 205-212, 2015.

ADLER, E. Lignin chemistry-past, present and future. Wood Science and Technology, v. 11, n. 3, p. 169218, 1977. ISSN 0043-7719. Available at: 〈 http://dx.doi.org/10.1007/BF00365615 >.

AGBOR, V. B. et al. Biomass pretreatment: Fundamentals toward application. Biotechnology Advances, v. 29, n. 6, p. 675-685, 11// 2011. ISSN 0734-9750. Available at: < http://www.sciencedirect.com/science/article/pii/S0734975011000607 >. Accessed on: 2011/12//.

AHMAD, F. "Plant cell wall structure-pretreatment" the critical relationship in biomass conversion to fermentable sugars. In: SHARMA, S. K. (Ed.). Green biomass pretreatment for biofuels production: Springer, 2013. p.1 - 30.

AHRING, B. K. et al. Making lignin accessible for anaerobic digestion by wet-explosion pretreatment. Bioresource Technology, v. 175, p. 182188, 2015. ISSN 0960-8524. Available at: < http://dx.doi.org/10.1016/j.biortech.2014.10.082 >.

AHUJA, N. Impact of Operating Conditions on Thermal Hydrolysis Pre-Treated Digestion Return Liquor. 2015. 132 (Master of Science). Civil and Environmental Engineering, Virginia Polytechnic Institute and State University, Blacksburg, VA.

AITA, G. M.; KIM, M. Pretreatment technologies for the conversionof lignocellulosic materials to bioethanol. In: EGGLESTON, G. (Ed.). Sustainability of the Sugar and Sugar-Ethanol Industries: American Chemical Society, 2010. p.117-145.

ALMEIDA, J. R. M. et al. Metabolic effects of furaldehydes and impacts on biotechnological processes. Applied Microbiology and Biotechnology, v. 82, n. 4, p. 625-638, 2009. ISSN 1432-0614. Available at: < http://dx.doi.org/10.1007/s00253-009-1875-1 >.

ALRAWI, R. A. et al. Anaerobic co-digestion of palm oil mill effluent with rumen fluid as a co-substrate. Desalination, v. 269, n. 1-3, p. 50-57, 3/15/ 2011. ISSN 0011-9164. Available at: < http://www.sciencedirect.com/science/article/pii/S0011916410007563 >.

ALVAREZ, R.; LIDÉN, G. Semi-continuous co-digestion of solid slaughterhouse waste, manure, and fruit and vegetable waste. Renewable Energy, v. 33, n. 4, p. 726-734, 4// 2008. ISSN 0960-1481. Available at: < http://www.sciencedirect.com/science/article/pii/S0960148107001309 >. 
ALVIRA, P. et al. Pretreatment technologies for an efficient bioethanol production process based on enzymatic hydrolysis: A review. Bioresource Technology, v. 101, n. 13, p. 4851-4861, 7// 2010. ISSN 0960-8524. Available at: < http://www.sciencedirect.com/science/article/pii/S0960852409015983 >.

ANDERSON, K.; SALLIS, P.; UYANIK, S. 24 - Anaerobic treatment processes. In: (Ed.). Handbook of Water and Wastewater Microbiology. London: Academic Press, 2003. p.391-426. ISBN 978-0-12470100-7.

ANGELIDAKI, I.; ELLEGAARD, L.; AHRING, B. K. A mathematical model for dynamic simulation of anaerobic digestion of complex substrates: focusing on ammonia inhibition. Biotechnol Bioeng, v. 42, $\mathrm{n}$. 2, p. 159-66, Jun 20 1993. ISSN 0006-3592 (Print)

0006-3592.

ANNA, T. et al. Pretreatment of paper tube residuals for improved biogas production. Bioresource Technology, v. 101, n. 4, p. 12061212, 2010. ISSN 0960-8524. Available at: < http://dx.doi.org/10.1016/j.biortech.2009.09.029 >.

ANUJ, K. C. et al. Sugarcane bagasse and leaves: foreseeable biomass of biofuel and bio-products. Journal of Chemical Technology and Biotechnology, v. 87, n. 1, p. 11-20, 2012. ISSN 1097-4660. Available at: < http://dx.doi.org/10.1002/jctb.2742 >.

APHA; AWWA; WEF. Standard methods for the examination of water and wastewater. Washington DC: American Public Health Assocition, 2005.

AZMAN, S. et al. Presence and Role of Anaerobic Hydrolytic Microbes in Conversion of Lignocellulosic Biomass for Biogas Production. Critical Reviews in Environmental Science and Technology, v. 45, n. 23 , p. 2523-2564, 2015/12/02 2015. ISSN 1064-3389. Available at: < http://dx.doi.org/10.1080/10643389.2015.1053727 >.

BADSHAH, M. et al. Use of an Automatic Methane Potential Test System for evaluating the biomethane potential of sugarcane bagasse after different treatments. Bioresource technology, v. 114, p. 262-269, 2012. ISSN 0960-8524. Available at: < http://dx.doi.org/10.1016/j.biortech.2012.02.022 >.

BALK, M.; WEIJMA, J.; STAMS, A. J. Thermotoga lettingae sp. nov., a novel thermophilic, methanoldegrading bacterium isolated from a thermophilic anaerobic reactor. Int J Syst Evol Microbiol, v. 52, n. Pt 4, p. 1361-8, Jul 2002. ISSN 1466-5026 (Print)

1466-5026.

BAPTESTE, E.; BROCHIER, C.; BOUCHER, Y. Higher-level classification of the Archaea: evolution of methanogenesis and methanogens. Archaea, v. 1, n. 5, p. 353-63, May 2005. ISSN 1472-3646 (Print). 
BARAKAT, A. et al. Effect of lignin-derived and furan compounds found in lignocellulosic hydrolysates on biomethane production. Bioresource Technology, v. 104, p. 90-99, 1// 2012. ISSN 0960-8524. Available at: < http://www.sciencedirect.com/science/article/pii/S0960852411015264 >.

BASERBA, M. G.; ANGELIDAKI, I.; KARAKASHEV, D. Effect of continuous oleate addition on microbial communities involved in anaerobic digestion process. Bioresource Technology, v. 106, p. 7481, 2// 2012. ISSN 0960-8524. Available at: < //www.sciencedirect.com/science/article/pii/S0960852411017664 >.

BASSO, T. P. et al. Towards the production of second generation ethanol from sugarcane bagasse in Brazil. In: MATOVIC, M. D. (Ed.). Biomass Now - Cultivation and Utilization: InTech, 2013.

BERLIN, A. et al. Inhibition of cellulase, xylanase and beta-glucosidase activities by softwood lignin preparations. J Biotechnol, v. 125, n. 2, p. 198-209, Sep 1 2006. ISSN 0168-1656 (Print)

0168-1656.

BERLIN, A. et al. Inhibition of cellulase, xylanase and $\beta$-glucosidase activities by softwood lignin preparations. Journal of Biotechnology, v. 125, n. 2, p. 198-209, 9/1/ 2006. ISSN 0168-1656. Available at: < http://www.sciencedirect.com/science/article/pii/S0168165606001714 >.

BERNARDET, J.-F.; BOWMAN, J. P. Flavobacterium. In: (Ed.). Bergey's Manual of Systematics of Archaea and Bacteria: John Wiley \& Sons, Ltd, 2015. ISBN 9781118960608.

BHANDARI, V.; GUPTA, R. S. The Phylum Thermotogae. In: ROSENBERG, E.;DELONG, E. F., et al (Ed.). The Prokaryotes: Other Major Lineages of Bacteria and The Archaea. Berlin, Heidelberg: Springer Berlin Heidelberg, 2014. p.989-1015. ISBN 978-3-642-38954-2.

BHARATHIRAJA, B. et al. Insights on Lignocellulosic Pretreatments for Biofuel Production- SEM and Reduction of Lignin Analysis. International Journal of ChemTech Research, v. 6, n. 9, p. 4334 - 4444 , 2014. ISSN 0974-4290. Available at: < http://sphinxsai.com/2014/RTBCE/6/(4434-4445)\%20014.pdf >.

BJORNSSON, L.; MURTO, M.; MATTIASSON, B. Evaluation of parameters for monitoring an anaerobic co-digestion process. Appl Microbiol Biotechnol, v. 54, n. 6, p. 844-9, Dec 2000. ISSN 0175-7598 (Print) 0175-7598.

BOERJAN, W.; RALPH, J.; BAUCHER, M. LIGNIN BIOSYNTHESIS. Annual Review of Plant Biology, v. 54, n. 1, p. 519-546, $2003 . \quad$ Available at: < http://www.annualreviews.org/doi/abs/10.1146/annurev.arplant.54.031902.134938 >.

BONAWITZ, N. D.; CHAPPLE, C. The Genetics of Lignin Biosynthesis: Connecting Genotype to Phenotype. Annual Review of Genetics, v. 44, n. 1, p. 337-363, 2010. Available at: < http://www.annualreviews.org/doi/abs/10.1146/annurev-genet-102209-163508 >. 
BONNIN, A. S.; BOONE, D. R. The order Methanobacteriales. In: DWORKIN, M.;FALKOW, S., et al (Ed.). The Prokaryotes: Archaea. Bacteria: Firmicutes, Actinomycetes. Singapore: Springer, 2006.

BOONE, D. R. Methanobacterium. In: (Ed.). Bergey's Manual of Systematics of Archaea and Bacteria: John Wiley \& Sons, Ltd, 2015. ISBN 9781118960608.

BOUCHARD, J. et al. Analytical methodology for biomass pretreatment. Part 2: Characterization of the filtrates and cumulative product distribution as a function of treatment severity. Bioresource Technology, v. 36, n. 2, p. 121-131, 1991/01/01 1991. ISSN 0960-8524. Available at: < http://www.sciencedirect.com/science/article/pii/096085249190169K >.

BRAUER, S. L. et al. Methanoregula boonei gen. nov., sp. nov., an acidiphilic methanogen isolated from an acidic peat bog. Int J Syst Evol Microbiol, v. 61, n. Pt 1, p. 45-52, Jan 2011. ISSN 1466-5026.

BRÄUER, S. L. et al. Characterization of acid-tolerant H2/CO2-utilizing methanogenic enrichment cultures from an acidic peat bog in New York State. FEMS Microbiology Ecology, v. 57, n. 2, p. 206-216, 2006. ISSN 1574-6941. Available at: < http://dx.doi.org/10.1111/j.1574-6941.2006.00107.x >.

BRAUN, R.; WEILAND, P.; WELLINGER, A. Biogas from energy crop digestion. IEA Bioenergy Task 37, <www.IEA-Biogas.net/>, 2010.

BRENNER, D.; KRIEG, N.; STALEY, J. Bergey's Manual of Systematic Bacteriology: Proteobacteria. 2nd. New York: Springer, 2004.

BRIENZO, M.; SIQUEIRA, A. F.; MILAGRES, A. M. F. Search for optimum conditions of sugarcane bagasse hemicellulose extraction. Biochemical Engineering Journal, v. 46, n. 2, p. 199-204, 10/1/ 2009. ISSN 1369-703X. Available at: < http://www.sciencedirect.com/science/article/pii/S1369703X09001569 $>$.

BRIONES, A. M. et al. Microbial diversity and dynamics in multi- and single-compartment anaerobic bioreactors processing sulfate-rich waste streams. Environ Microbiol, v. 9, n. 1, p. 93-106, Jan 2007. ISSN 1462-2912 (Print)

$1462-2912$.

BROWN, T. M.; DUAN, P.; SAVAGE, P. E. Hydrothermal Liquefaction and Gasification of Nannochloropsis sp. Energy \& Fuels, v. 24, n. 6, p. 3639-3646, 2010/06/17 2010. ISSN 0887-0624. Available at: $\langle$ http://dx.doi.org/10.1021/ef100203u $\rangle$.

BUGG, T. D. et al. The emerging role for bacteria in lignin degradation and bio-product formation. Curr Opin Biotechnol, v. 22, n. 3, p. 394-400, Jun 2011. ISSN 0958-1669.

CALDWELL, M. E. et al. Tolumonas osonensis sp. nov., isolated from anoxic freshwater sediment, and emended description of the genus Tolumonas. International Journal of Systematic and Evolutionary 
Microbiology, v. 61, n. 11, p. 2659-2663, 2011. Available at: < http://ijs.microbiologyresearch.org/content/journal/ijsem/10.1099/ijs.0.023853-0 >.

CANILHA, L. et al. A study on the pretreatment of a sugarcane bagasse sample with dilute sulfuric acid. Journal of Industrial Microbiology \& Biotechnology, v. 38, n. 9, p. 1467-1475, 2011/09/01 2011. ISSN 1367-5435. Available at: < http://dx.doi.org/10.1007/s10295-010-0931-2 >.

CAO, S.; AITA, G. M. Enzymatic hydrolysis and ethanol yields of combined surfactant and dilute ammonia treated sugarcane bagasse. Bioresource Technology, v. 131, n. 0, p. 357-364, 3// 2013. ISSN 0960-8524. Available at: < http://www.sciencedirect.com/science/article/pii/S0960852412020287 >.

CARBALLA, M.; REGUEIRO, L.; LEMA, J. M. Microbial management of anaerobic digestion: exploiting the microbiome-functionality nexus. Current Opinion in Biotechnology, v. 33, p. 103-111, 6// 2015. ISSN 0958-1669. Available at: < http://www.sciencedirect.com/science/article/pii/S0958166915000178 >.

CARVALHEIRO, F. et al. Wheat straw autohydrolysis: process optimization and products characterization. Applied biochemistry and biotechnology, v. 153, n. 1-3, p. 84-93, 2009. Available at: < http://dx.doi.org/10.1007/s12010-008-8448-0 $>$.

CASU, R. E. et al. Identification of transcripts associated with cell wall metabolism and development in the stem of sugarcane by Affymetrix GeneChip Sugarcane Genome Array expression profiling. Funct Integr Genomics, v. 7, n. 2, p. 153-67, Apr 2007. ISSN 1438-793X (Print)

1438-793x.

CAZA, N. et al. Removal of phenolic compounds from synthetic wastewater using soybean peroxidase. Water Research, v. 33, n. 13, p. 3012-3018, 9// 1999. ISSN 0043-1354. Available at: < http://www.sciencedirect.com/science/article/pii/S0043135498005259 >.

CHABAN, B.; HILL, J. E. A 'universal' type II chaperonin PCR detection system for the investigation of Archaea in complex microbial communities. Isme j, v. 6, n. 2, p. 430-9, Feb 2012. ISSN 1751-7362.

CHANDEL, A. K. et al. Multi-scale structural and chemical analysis of sugarcane bagasse in the process of sequential acid-base pretreatment and ethanol production by Scheffersomyces shehatae and Saccharomyces cerevisiae. Biotechnology for Biofuels, v. 7, n. 1, p. 1-17, 2014. ISSN 1754-6834. Available at: < http://dx.doi.org/10.1186/1754-6834-7-63 >.

CHANDEL, A. K.; SILVA, S. S. R. D.; SINGH, O. V. Detoxification of Lignocellulosic Hydrolysates for Improved Bioethanol Production. In: BERNARDES, M. A. D. S. (Ed.). Biofuel Production-Recent Developments and Prospects: In Tech, 2011. ISBN 10.5772/16454.

CHANDRA, R.; TAKEUCHI, H.; HASEGAWA, T. Hydrothermal pretreatment of rice straw biomass: A potential and promising method for enhanced methane production. Applied Energy, 2012. ISSN 03062619. Available at: < http://dx.doi.org/10.1016/j.apenergy.2012.01.027 >. 
CHANG, V. S.; HOLTZAPPLE, M. T. Fundamental factors affecting biomass enzymatic reactivity. Appl Biochem Biotechnol, v. 84-86, p. 5-37, Spring 2000. ISSN 0273-2289 (Print)

0273-2289.

CHATURVEDI, V.; VERMA, P. An overview of key pretreatment processes employed for bioconversion of lignocellulosic biomass into biofuels and value added products. 3 Biotech, v. 3, n. 5, p. 415-431, 09/05

05/27/received

$08 / 13 /$ accepted

http://www.ncbi.nlm.nih.gov/pmc/articles/PMC3781263/ >.

CHEN, F.; DIXON, R. A. Lignin modification improves fermentable sugar yields for biofuel production. Nature Biotechnology, v. 25, n. 7, p. 759-761, 2007. ISSN 1087-0156. Available at: < http://dx.doi.org/10.1038/nbt1316 >.

CHEN, H. Biotechnology of lignocellulose: Theory and practice. Chemical Industry Press, Springer, 2014.

CHEN, X.; LAWOKO, M.; HEININGEN, A. V. Kinetics and mechanism of autohydrolysis of hardwoods. Bioresource Technology, v. 101, n. 20, p. 7812-7819, 10// 2010. ISSN 0960-8524. Available at: < http://www.sciencedirect.com/science/article/pii/S0960852410008175 >.

CHENG, C.-L.; CHANG, J.-S. Hydrolysis of lignocellulosic feedstock by novel cellulases originating from Pseudomonas sp. CL3 for fermentative hydrogen production. Bioresource Technology, v. 102, n. 18, p. 8628-8634, 9// 2011. ISSN 0960-8524. Available at: < http://www.sciencedirect.com/science/article/pii/S096085241100410X >.

CHILDERS, S. E.; CIUFO, S.; LOVLEY, D. R. Geobacter metallireducens accesses insoluble Fe(III) oxide by chemotaxis. Nature, v. 416, n. 6882, p. 767-9, Apr 18 2002. ISSN 0028-0836 (Print)

0028-0836.

CHUM, H. L. et al. Pretreatment-Catalyst effects and the combined severity parameter. Applied Biochemistry and Biotechnology, v. 24, n. 1, p. 1-14, 1990. ISSN 1559-0291. Available at: < http://dx.doi.org/10.1007/BF02920229 >.

CHUNDAWAT, S. P. S. et al. Multi-scale visualization and characterization of lignocellulosic plant cell wall deconstruction during thermochemical pretreatment. Energy \& Environmental Science, v. 4, n. 3, p. 973-984, 2011. ISSN 1754-5692. Available at: < http://dx.doi.org/10.1039/C0EE00574F >.

CLARK, T. A.; MACKIE, K. L. Fermentation inhibitors in wood hydrolysates derived from the softwood Pinus radiata. Journal of Chemical Technology and Biotechnology. Biotechnology, v. 34, n. 2, p. 101110, 1984. ISSN 1935-1828. Available at: < http://dx.doi.org/10.1002/jctb.280340206 >. 
COLLERAN, E.; FINNEGAN, S.; LENS, P. Anaerobic treatment of sulphate-containing waste streams. Antonie van Leeuwenhoek, v. 67, n. 1, p. 29-46, 1995. ISSN 1572-9699. Available at: < http://dx.doi.org/10.1007/BF00872194 >.

COLLINS, G. et al. Distribution, Localization, and Phylogeny of Abundant Populations of Crenarchaeota in Anaerobic Granular Sludge. Applied and Environmental Microbiology, v. 71, n. 11, p. 7523-7527, November 1, 2005 2005. Available at: 〈 http://aem.asm.org/content/71/11/7523.abstract $>$.

CONNORS, K. A. Chemical Kinetics: The Study of Reaction Rates in Solutions. New York: VCH Publishers, 1990.

CORRALES, R. C. N. R. et al. Structural evaluation of sugar cane bagasse steam pretreated in the presence of CO2 and SO2. Biotechnology for Biofuels, v. 5, 2012.

DA SILVA, A. et al. Milling pretreatment of sugarcane bagasse and straw for enzymatic hydrolysis and ethanol fermentation. Bioresource technology, v. 101, n. 19, p. 7402-7409, 2010. ISSN 0960-8524. Available at: < http://dx.doi.org/10.1016/j.biortech.2010.05.008 >.

DAMAURAI, J.; CHAMPREDA, V.; LAOSIRIPOJANA, N. Optimization of alkaline peroxide pretreatment of rice straw. Journal of Natural Sciences Research, v. 4, n. 13, p. 29-33, 2014.

DAVEY, M. E.; MACGREGOR, B. J.; STAHL, D. A. Geotoga. In: (Ed.). Bergey's Manual of Systematics of Archaea and Bacteria: John Wiley \& Sons, Ltd, 2015. ISBN 9781118960608.

DE LA TORRE, J. R. et al. Cultivation of a thermophilic ammonia oxidizing archaeon synthesizing crenarchaeol. Environmental Microbiology, v. 10, n. 3, p. 810-818, 2008. ISSN 1462-2920. Available at: 〈 http://dx.doi.org/10.1111/j.1462-2920.2007.01506.x >.

DE MORAES, R. G. J. et al. Dilute mixed-acid pretreatment of sugarcane bagasse for ethanol production. Biomass and Bioenergy, v. 35, 2011. ISSN 0961-9534. Available at: < http://dx.doi.org/10.1016/j.biombioe.2010.10.018 >.

DE MOUTTA, R. et al. Comparative Response and Structural Characterization of Sugarcane Bagasse, Straw and Bagasse-Straw 1:1 Mixtures Subjected to Hydrothermal Pretreatment and Enzymatic Conversion. Journal of Microbial \& Biochemical Technology, v. 01, n. S12, 2013. Available at: < http://dx.doi.org/10.4172/1948-5948.S12-005 >.

DE VASCONCELOS, S. M. et al. Diluted phosphoric acid pretreatment for production of fermentable sugars in a sugarcane-based biorefinery. Bioresource Technology, v. 135, p. 46-52, 5// 2013. ISSN 09608524. Available at: < http://www.sciencedirect.com/science/article/pii/S0960852412015854 >. 
DE VRIEZE, J.; VERSTRAETE, W. Perspectives for microbial community composition in anaerobic digestion: from abundance and activity to connectivity. Environmental Microbiology, v. 18, n. 9, p. 2797 2809, 2016. ISSN 1462-2920. Available at: < http://dx.doi.org/10.1111/1462-2920.13437 >.

DEGUCHI, S.; TSUJII, K.; HORIKOSHI, K. Cooking cellulose in hot and compressed water. Chemical Communications, n. 31, p. 3293-3295, 2006. ISSN 1359-7345. Available at: < http://dx.doi.org/10.1039/B605812D >.

DEMIRBAS, A. Biorefineries: for biomass upgrading facilities. New York: Springer, 2009.

DEN CAMP, H. J. M. O. et al. Effects of lignin on the anaerobic degradation of (ligno) cellulosic wastes by rumen microorganisms. Applied Microbiology and Biotechnology, v. 29, n. 4, p. 408-412, 1988. ISSN 1432-0614. Available at: 〈 http://dx.doi.org/10.1007/BF00265827 >.

DENG, A. J. et al. Corncob lignocellulose for the production of furfural by hydrothermal pretreatment and heterogeneous catalytic process. Rsc Advances, v. 5, n. 74, p. 60264-60272, 2015. ISSN 2046-2069. Available at: < <Go to ISI $>$ :/WOS:000358230400056 >.

DENGER, K. et al. Anaerophaga thermohalophila gen. nov., sp. nov., a moderately thermohalophilic, strictly anaerobic fermentative bacterium. Int J Syst Evol Microbiol, v. 52, n. Pt 1, p. 173-8, Jan 2002. ISSN 1466-5026 (Print)

1466-5026.

DING, S.-Y. et al. How Does Plant Cell Wall Nanoscale Architecture Correlate with Enzymatic Digestibility? Science, v. 338, n. 6110, p. 1055-1060, 2012-11-23 00:00:00 2012. Available at: < http://science.sciencemag.org/sci/338/6110/1055.full.pdf $>$.

DOE, U. Breaking the Biological Barriers to Cellulosic Ethanol: A Joint Research Agenda. Report from the December 2005 Workshop. U.S. Department of Energy Office of Science 2006

DONALDSON, L. A.; WONG, K. K. Y.; MACKIE, K. L. Ultrastructure of steam-exploded wood. Wood Science and Technology, v. 22, n. 2, p. 103-114, 1988. ISSN 1432-5225. Available at: < http://dx.doi.org/10.1007/BF00355846 >.

DONOHOE, B. S. et al. Visualizing lignin coalescence and migration through maize cell walls following thermochemical pretreatment. Biotechnology and Bioengineering, v. 101, n. 5, p. 913-925, 2008. ISSN 1097-0290. Available at: 〈http://dx.doi.org/10.1002/bit.21959 >.

DRIDI, B. et al. Methanomassiliicoccus luminyensis gen. nov., sp. nov., a methanogenic archaeon isolated from human faeces. Int J Syst Evol Microbiol, v. 62, n. Pt 8, p. 1902-7, Aug 2012. ISSN 1466-5026.

DU, B. et al. Effect of varying feedstock-pretreatment chemistry combinations on the formation and accumulation of potentially inhibitory degradation products in biomass hydrolysates. Biotechnology and 
Bioengineering, v. 107, n. 3, p. 430-440, 2010. ISSN 1097-0290. Available at: < http://dx.doi.org/10.1002/bit.22829 >.

DUBOIS, M. et al. Colorimetric Method for Determination of Sugars and Related Substances. Analytical Chemistry, v. 28, n. 3, p. 350-356, 1956/03/01 1956. ISSN 0003-2700. Available at: < http://dx.doi.org/10.1021/ac60111a017 >.

EBRINGEROVÁ, A.; HEINZE, T. Xylan and xylan derivatives - biopolymers with valuable properties, 1. Naturally occurring xylans structures, isolation procedures and properties. Macromolecular Rapid Communications, v. 21, n. 9, p. 542-556, 2000. ISSN 1521-3927. Available at: < http://dx.doi.org/10.1002/1521-3927(20000601)21:9<542::AID-MARC542>3.0.CO;2-7 >.

EDWARD, M. R. Genomics of cellulosic biofuels. Nature, v. 454, n. 7206, p. 841-845, 2008. ISSN 00280836. Available at: < http://dx.doi.org/10.1038/nature07190 >.

EFFENDI, A.; GERHAUSER, H.; BRIDGWATER, A. V. Production of renewable phenolic resins by thermochemical conversion of biomass: A review. Renewable and Sustainable Energy Reviews, v. 12, n. 8 , p. 2092-2116, 10// 2008. ISSN 1364-0321. Available at: < http://www.sciencedirect.com/science/article/pii/S1364032107000652 >.

EGGEMAN, T.; ELANDER, R. T. Process and economic analysis of pretreatment technologies. Bioresource Technology, v. 96, n. 18, p. 2019-2025, 12// 2005. ISSN 0960-8524. Available at: < http://www.sciencedirect.com/science/article/pii/S0960852405000702 >.

EL HAGE, R. et al. Effect of autohydrolysis of Miscanthus x giganteus on lignin structure and organosolv delignification. Bioresource Technology, v. 101, n. 23, p. 9321-9329, 12// 2010. ISSN 0960-8524. Available at: < http://www.sciencedirect.com/science/article/pii/S096085241001148X >.

ERCOLINI, D. PCR-DGGE fingerprinting: novel strategies for detection of microbes in food. J Microbiol Methods, v. 56, n. 3, p. 297-314, Mar 2004. ISSN 0167-7012 (Print)

0167-7012.

ESQUIVEL-ELIZONDO, S. et al. Archaea and Bacteria Acclimate to High Total Ammonia in a Methanogenic Reactor Treating Swine Waste. Archaea, v. 2016, p. 10, 2016. Available at: < http://dx.doi.org/10.1155/2016/4089684 >.

FAN, L. T.; GHARPURAY, M. M.; LEE, Y. H. Cellulose hydrolysis. Berlin: Springer, 1987. 57.

FANG, C. et al. Hydrothermal Pretreatment of Date Palm (Phoenix dactylifera L.) Leaflets and Rachis to Enhance Enzymatic Digestibility and Bioethanol Potential. BioMed Research International, v. 2015, p. $216454,08 / 12$

02/03/received

$03 / 18 /$ revised 
03/28/accepted 2015. ISSN 2314-6133

2314-6141. Available at: < http://www.ncbi.nlm.nih.gov/pmc/articles/PMC4549489/ >.

FANG, C. J. et al. Hydrothermal Pretreatment of Date Palm (Phoenix dactylifera L.) Leaflets and Rachis to Enhance Enzymatic Digestibility and Bioethanol Potential. Biomed Research International, 2015. ISSN 2314-6133. Available at: <<Go to ISI>://WOS:000360209500001 >.

FANG, Y. et al. An Acidic Two-Step Hydrothermal Process To Enhance Acetic Acid Production from Carbohydrate Biomass. Industrial \& Engineering Chemistry Research, v. 51, n. 12, p. 4759-4763, 2012/03/28 2012. ISSN 0888-5885. Available at: 〈 http://dx.doi.org/10.1021/ie202506c >.

FERNANDES, T. V. et al. Effects of thermo-chemical pre-treatment on anaerobic biodegradability and hydrolysis of lignocellulosic biomass. Bioresource Technology, v. 100, n. 9, p. 2575-2579, 5// 2009. ISSN 0960-8524. Available at: < http://www.sciencedirect.com/science/article/pii/S0960852408010705 >.

FERNANDEZ-CEGRI, V. et al. Effect of hydrothermal pretreatment of sunflower oil cake on biomethane potential focusing on fibre composition. Bioresource Technology, v. 123, p. 424-429, Nov 2012. ISSN 0960-8524. Available at: <<Go to ISI>://WOS:000310401100063 >.

FISCHER-ROMERO, C.; TINDALL, B. J.; JUTTNER, F. Tolumonas auensis gen. nov., sp. nov., a toluene-producing bacterium from anoxic sediments of a freshwater lake. Int J Syst Bacteriol, v. 46, n. 1, p. 183-8, Jan 1996. ISSN 0020-7713 (Print)

0020-7713.

FORSTER-CARNEIRO, T. et al. Anaerobic Digestion: Pretreatments of Substrates. In: (Ed.). Biogas Production: John Wiley \& Sons, Inc., 2012. p.1-25. ISBN 9781118404089.

FOWLER, S. J. et al. Identification of toluene degraders in a methanogenic enrichment culture. FEMS microbiology ecology, v. 89, n. 3, p. 625-636, 2014. ISSN 0168-6496. Available at: < http://dx.doi.org/10.1111/1574-6941.12364 >.

FRANKE-WHITTLE, I. H. et al. Investigation into the effect of high concentrations of volatile fatty acids in anaerobic digestion on methanogenic communities. Waste Management, v. 34, n. 11, p. 2080-2089, 11// 2014. ISSN 0956-053X. Available at: http://www.sciencedirect.com/science/article/pii/S0956053X14003250 >.

GARCIA, J.; OLLIVIER, B.; WHITMAN, W. B. The Order Methanomicrobiales. In: DWORKIN, M.;FALKOW, S., et al (Ed.). The Prokaryotes: Archaea. Bacteria: Firmicutes, Actinomycetes. Singapore: Springer, 2006.

GARGAUD, M.; IRVINE, W. M. Encyclopedia of Astrobiology. 2nd. Springer, 2015. 
GARRITY, G. M.; HOLT, J. G. Chloroflexi phy. nov. In: (Ed.). Bergey's Manual of Systematics of Archaea and Bacteria: John Wiley \& Sons, Ltd, 2015. ISBN 9781118960608.

Euryarchaeota phy. nov. In: (Ed.). Bergey's Manual of Systematics of Archaea and Bacteria: John Wiley \& Sons, Ltd, 2015. ISBN 9781118960608.

GARROTE, G.; DOMÍNGUEZ, H.; PARAJÓ, C. J. Hydrothermal processing of lignocellulosic materials. Holz als Roh- und Werkstoff, v. 57, n. 3, p. 191-202, 1999. ISSN 1436-736X. Available at: < http://dx.doi.org/10.1007/s001070050039 >.

GARROTE, G.; DOMÍNGUEZ, H.; PARAJÓ, J. C. Hydrothermal processing of lignocellulosic materials. Holz als Roh- und Werkstoff, 1999. ISSN 0018-3768. Available at: < http://dx.doi.org/10.1007/s001070050039 >.

GARROTE, G. et al. Autohydrolysis of agricultural residues: Study of reaction byproducts. Bioresource Technology, v. 98, n. 10, p. 1951-1957, 7// 2007. ISSN 0960-8524. Available at: < http://www.sciencedirect.com/science/article/pii/S0960852406004019 >.

GAVALA, H. N. et al. Mesophilic and thermophilic anaerobic digestion of primary and secondary sludge. Effect of pre-treatment at elevated temperature. Water Res, v. 37, n. 19, p. 4561-72, Nov 2003. ISSN 00431354 (Print)

0043-1354.

GHASEMIAN, M.; ZILOUEI, H.; ASADINEZHAD, A. Enhanced Biogas and Biohydrogen Production from Cotton Plant Wastes Using Alkaline Pretreatment. Energy \& Fuels, v. 30, n. 12, p. 10484-10493, 2016/12/15 2016. ISSN 0887-0624. Available at: < http://dx.doi.org/10.1021/acs.energyfuels.6b01999 >.

GHASIMI, D. S. M. et al. Impact of lignocellulosic-waste intermediates on hydrolysis and methanogenesis under thermophilic and mesophilic conditions. Chemical Engineering Journal, v. 295, p. 181-191, 7/1/ 2016. ISSN 1385-8947. Available http://www.sciencedirect.com/science/article/pii/S1385894716302753 $>$.

GIUSEPPE, D. G. et al. Effects of hydrothermal pre-treatments on Giant reed (Arundo donax) methane yield. Bioresource Technology, v. 147, p. 152159, 2013. ISSN 0960-8524. Available at: < http://dx.doi.org/10.1016/j.biortech.2013.08.006 >.

GONZÁLEZ-FERNÁNDEZ, C. et al. Thermal pretreatment to improve methane production of Scenedesmus biomass. Biomass and Bioenergy, v. 40, p. 105-111, 5// 2012. ISSN 0961-9534. Available at: 〈 http://www.sciencedirect.com/science/article/pii/S0961953412000803 >.

GONZÁLEZ, L. et al. Effect of liquid hot water pre-treatment on sugarcane press mud methane yield. Bioresource Technology, v. 169, 2014. ISSN 0960-8524. Available at: < http://dx.doi.org/10.1016/j.biortech.2014.06.107 >. 
GOODWIN, J. A. S.; WASE, D. A. J.; FORSTER, C. F. Effects of nutrient limitation on the anaerobic upflow sludge blanket reactor. Enzyme and Microbial Technology, v. 12, n. 11, p. 877-884, 11// 1990. ISSN 0141-0229. Available at: < http://www.sciencedirect.com/science/article/pii/014102299090026M >.

GOULD, M. J. Studies on the mechanism of alkaline peroxide delignification of agricultural residues. Biotechnology and Bioengineering, v. 27, n. 3, p. 225-231, 1985. ISSN 1097-0290. Available at: < http://dx.doi.org/10.1002/bit.260270303 >.

GRIFFITHS, R. I. et al. Rapid Method for Coextraction of DNA and RNA from Natural Environments for Analysis of Ribosomal DNA- and rRNA-Based Microbial Community Composition. Applied and Environmental Microbiology, v. 66, n. 12, p. 5488-5491, December 1, 2000 2000. Available at: < http://aem.asm.org/content/66/12/5488.abstract $>$.

GRIMALDI, M. P. et al. Evaluation of lime and hydrothermal pretreatments for efficient enzymatic hydrolysis of raw sugarcane bagasse. Biotechnology for Biofuels, v. 8, p. 205, 12/02

07/01/received

11/16/accepted 2015. ISSN 1754-6834. Available at: http://www.ncbi.nlm.nih.gov/pmc/articles/PMC4667421/ >.

GUILLIAMS, A. et al. Physical and chemical differences between one-stage and two-stage hydrothermal pretreated hardwood substrates for use in cellulosic ethanol production. Biotechnology for Biofuels, v. 9, n. 1, p. 1-13, 2016. ISSN 1754-6834. Available at: 〈 http://dx.doi.org/10.1186/s13068-016-0446-9 >.

HANREICH, A. et al. Metagenome and metaproteome analyses of microbial communities in mesophilic biogas-producing anaerobic batch fermentations indicate concerted plant carbohydrate degradation. Syst Appl Microbiol, v. 36, n. 5, p. 330-8, Jul 2013. ISSN 0723-2020.

HANSEN, T. L. et al. Method for determination of methane potentials of solid organic waste. Waste Management, v. 24, n. 4, p. 393-400, // 2004. ISSN 0956-053X. Available at: < http://www.sciencedirect.com/science/article/pii/S0956053X0300223X >.

HAO, W. et al. Digestibility Improvement of Sorted Waste with Alkaline Hydrothermal Pretreatment. TSINGHUA SCIENCE AND TECHNOLOGY, v. 14, n. 3, p. 378-382, 2009.

HARMSEN, P. et al. Literature review of physical and chemical pretreatment processes for lignocellulosic biomass: Tech. Rep. 1184, Biosynergy, Wageningen UR Food \& Biobased Research 2010.

HARRIS, P. W.; MCCABE, B. K. Review of pre-treatments used in anaerobic digestion and their potential application in high-fat cattle slaughterhouse wastewater. Applied Energy, v. 155, p. 560-575, 10/1/ 2015. ISSN 0306-2619. Available at: < http://www.sciencedirect.com/science/article/pii/S0306261915007849 >. 
HARTMANN, H.; AHRING, B. K. Strategies for the anaerobic digestion of the organic fraction of municipal solid waste: An overview. Water Science and Technology, v. 53, n. 8, p. 7-22, 2006.

HARTMANN, H.; AHRING, B. K. Strategies for the anaerobic digestion of the organic fraction of municipal solid waste: an overview. Water Sci Technol, v. 53, n. 8, p. 7-22, 2006. ISSN 0273-1223 (Print)

0273-1223.

HATTI-KAUL, R. et al. Industrial biotechnology for the production of bio-based chemicals--a cradle-tograve perspective. Trends in biotechnology, v. 25, n. 3, p. 119-124, 2007. ISSN 0167-7799. Available at: < http://dx.doi.org/10.1016/j.tibtech.2007.01.001 >.

HE, L. L. et al. A Review of Hydrothermal Pretreatment of Lignocellulosic Biomass for Enhanced Biogas Production. Current Organic Chemistry, v. 19, n. 5, p. 437-446, 2015. ISSN 1385-2728. Available at: < $<$ Go to ISI $>$ ://WOS:000352166300006 >.

HEALY, J. B.; YOUNG, L. Y. Anaerobic biodegradation of eleven aromatic compounds to methane. Applied and Environmental Microbiology, 1979. Available at: < http://aem.asm.org/content/38/1/84.short $>$.

HEATHER, L. T.; CHARLES, E. W. Fundamentals of biomass pretreatment at low pH. In: CHARLES, E. W. (Ed.). Aqueous pretreatmet of plant biomass for biological and chemical conversion to fuels and chemicals: John Wiley \& Sons, 2013. ISBN 978-0-470-97202-1.

HEATHER, L. T. et al. The fate of lignin during hydrothermal pretreatment. Biotechnology for Biofuels, 2013. ISSN 1754-6834. Available at: < http://dx.doi.org/10.1186/1754-6834-6-110 >.

HEILMANN, S. M. et al. Hydrothermal carbonization of microalgae II. Fatty acid, char, and algal nutrient products. Applied Energy, v. 88, n. 10, p. 3286-3290, 10// 2011. ISSN 0306-2619. Available at: < http://www.sciencedirect.com/science/article/pii/S0306261910005611 >.

HEITZ, M. et al. Fractionation of Populus tremuloides at the pilot plant scale: Optimization of steam pretreatment conditions using the STAKE II technology. Bioresource Technology, v. 35, n. 1, p. 23-32, 1991/01/01 1991. ISSN 0960-8524. Available at: < http://www.sciencedirect.com/science/article/pii/096085249190078X >.

HEMMINGSEN, S. M. et al. Homologous plant and bacterial proteins chaperone oligomeric protein assembly. Nature, v. 333, n. 6171, p. 330-334, 05/26/print 1988. Available at: < http://dx.doi.org/10.1038/333330a0 >.

HENDRIKS, A. T. W. M.; ZEEMAN, G. Pretreatments to enhance the digestibility of lignocellulosic biomass. Bioresource technology, v. 100, n. 1, p. 10-18, 2009. ISSN 0960-8524. Available at: < http://dx.doi.org/10.1016/j.biortech.2008.05.027 >. 
HENNING, J.; JAN BACH, K.; CLAUS, F. Enzymatic conversion of lignocellulose into fermentable sugars: challenges and opportunities. Biofuels, Bioproducts and Biorefining, v. 1, n. 2, p. 119-134, 2007. ISSN 1932-1031. Available at: < http://dx.doi.org/10.1002/bbb.4 >.

HENZE, M.; HARREMOËS, P. Anaerobic Treatment of Wastewater in Fixed Film Reactors - A Literature Review. Water Science and Technology, v. 15, n. 8-9, p. 1-101, 1983.

HERBEL, Z. et al. Exploitation of the extremely thermophilic Caldicellulosiruptor saccharolyticus in hydrogen and biogas production from biomasses. Environmental Technology, v. 31, n. 8-9, p. 1017-1024, 2010/07/01 2010. ISSN 0959-3330. Available at: 〈 http://dx.doi.org/10.1080/09593330.2010.484075 >.

HILL, D. T.; BOLTE, J. P. Digester stress as related to iso-butyric and iso-valeric acids. Biological Wastes, v. $28, \quad$ n. $1, \quad$ p. 33-37, 1989/01/01 1989. ISSN 0269-7483. Available at: < http://www.sciencedirect.com/science/article/pii/0269748389900475 >.

HILL, J. E. et al. cpnDB: A Chaperonin Sequence Database. Genome Research, v. 14, n. 8, p. 1669-1675, 04/01/received

05/28/accepted 2004. ISSN 1088-9051. Available at: http://www.ncbi.nlm.nih.gov/pmc/articles/PMC509277/ >.

HIMMEL, M. E. et al. Biomass Recalcitrance: Engineering Plants and Enzymes for Biofuels Production. Science, v. 315, n. 5813, p. 804-807, February 9, 2007 2007. Available at: < http://www.sciencemag.org/content/315/5813/804.abstract >.

HIPPE, H.; STACKEBRANDT, E. Desulfosporosinus. In: (Ed.). Bergey's Manual of Systematics of Archaea and Bacteria: John Wiley \& Sons, Ltd, 2015. ISBN 9781118960608.

HIRAKATA, Y. et al. Effects of Predation by Protists on Prokaryotic Community Function, Structure, and Diversity in Anaerobic Granular Sludge. Microbes and Environments, v. 31, n. 3, p. 279-287, 07/12

04/04/received

05/20/accepted 2016. ISSN 1342-6311

1347-4405. Available at: < http://www.ncbi.nlm.nih.gov/pmc/articles/PMC5017804/ > .

HON, D.; SHIRAISHI, N. Wood and cellulosic chemistry: CRC Press 2001.

HU, F.; RAGAUSKAS, A. Pretreatment and Lignocellulosic Chemistry. Bioenergy Research, v. 5, n. 4, p. 1043-1066, Dec 2012. ISSN 1939-1234. Available at: < <Go to ISI>://WOS:000310377600022 >.

HUBER, R. et al. Thermotoga maritima sp. nov. represents a new genus of unique extremely thermophilic eubacteria growing up to 90 oC. Arch. Microbiol., v. 144, p. 324-333, 1986. 
IGARASHI, K. et al. Traffic Jams Reduce Hydrolytic Efficiency of Cellulase on Cellulose Surface. Science, v. 333, n. 6047, p. 1279-1282, 2011. ISSN 0036-8075. Available at: < http://dx.doi.org/10.1126/science.1208386 >.

IMACHI, H.; SAKAI, S. Methanoregulaceae. In: (Ed.). Bergey's Manual of Systematics of Archaea and Bacteria: John Wiley \& Sons, Ltd, 2015. ISBN 9781118960608.

IMACHI, H. et al. Methanolinea tarda gen. nov., sp. nov., a methane-producing archaeon isolated from a methanogenic digester sludge. INTERNATIONAL JOURNAL OF SYSTEMATIC AND EVOLUTIONARY MICROBIOLOGY, v. 58, n. 1, p. 294-301, 2008. ISSN 1466-5026. Available at: < http://dx.doi.org/10.1099/ijs.0.65394-0 >.

INAGAKI, F. et al. Sulfurovum lithotrophicum gen. nov., sp. nov., a novel sulfur-oxidizing chemolithoautotroph within the $\varepsilon$-Proteobacteria isolated from Okinawa Trough hydrothermal sediments. International Journal of Systematic and Evolutionary Microbiology, v. 54, n. 5, p. 1477-1482, 2004. Available at: < http://ijs.microbiologyresearch.org/content/journal/ijsem/10.1099/ijs.0.03042-0 >.

IRVINE, G. M. The significance of the glass transition of lignin in thermomechanical pulping. Wood Science and Technology, v. 19, n. 2, p. 139-149, 1985. ISSN 1432-5225. Available at: < http://dx.doi.org/10.1007/BF00353074 >.

IWONA, C.; GRZEGORZ, B.; HANWU, L. Hydrothermal Pretreatment of Lignocellulosic Biomass. In: GU, T. (Ed.). Green Biomass Pretreatment for Biofuels Production. Dordrecht Heidelberg New York London: Springer 2013. ISBN 978-94-007-6052-3 (ebook).

JIN, F. et al. Hydrothermal conversion of carbohydrate biomass into formic acid at mild temperatures. Green Chemistry, v. 10, n. 6, p. 612-615, 2008. ISSN 1463-9262. Available at: < http://dx.doi.org/10.1039/B802076K >.

JIN, F. et al. Controlling Hydrothermal Reaction Pathways To Improve Acetic Acid Production from Carbohydrate Biomass. Environmental Science \& Technology, v. 39, n. 6, p. 1893-1902, 2005/03/01 2005. ISSN 0013-936X. Available at: < http://dx.doi.org/10.1021/es048867a >.

JOLLEZ, P.; CHORNET, E.; OVEREND, R. Steam-aqueous fractionation of sugar cane bagasse: An optimization study of process conditions at the pilot plant level. In: BRIDGEWATER, A. V. (Ed.). Advances in thermochemical biological conversion, 1994. p.1659-1669.

JÖNSSON, L. J.; MARTÍN, C. Pretreatment of lignocellulose: Formation of inhibitory by-products and strategies for minimizing their effects. Bioresource Technology, v. 199, p. 103-112, 1// 2016. ISSN 09608524. Available at: < http://www.sciencedirect.com/science/article/pii/S0960852415014042 >.

JÖRN, B. et al. Effects of thermobarical pretreatment of cattle waste as feedstock for anaerobic digestion. Waste Management, 2014. ISSN 0956-053X. Available at: < http://dx.doi.org/10.1016/j.wasman.2013.10.023 >. 
JU, F.; ZHANG, T. Novel microbial populations in ambient and mesophilic biogas-producing and phenoldegrading consortia unraveled by high-throughput sequencing. Microb Ecol, v. 68, n. 2, p. 235-46, Aug 2014. ISSN 0095-3628.

JUMAS-BILAK, E.; ROUDIERE, L.; MARCHANDIN, H. Description of 'Synergistetes' phyl. nov. and emended description of the phylum 'Deferribacteres' and of the family Syntrophomonadaceae, phylum 'Firmicutes'. Int J Syst Evol Microbiol, v. 59, n. Pt 5, p. 1028-35, May 2009. ISSN 1466-5026 (Print)

1466-5026.

KABEL, M. A. et al. Effect of pretreatment severity on xylan solubility and enzymatic breakdown of the remaining cellulose from wheat straw. Bioresource Technology, v. 98, n. 10, p. 2034-2042, 7// 2007. ISSN 0960-8524. Available at: < http://www.sciencedirect.com/science/article/pii/S0960852406004032 >.

KADLA, J. F.; CHANG, H. M. The Reactions of Peroxides with Lignin and Lignin Model Compounds. In: (Ed.). Oxidative Delignification Chemistry: American Chemical Society, v.785, 2001. chap. 6, p.108129. (ACS Symposium Series). ISBN 0-8412-3738-7.

KAKSONEN, A. H. et al. Culturable Diversity and Community Fatty Acid Profiling of Sulfate-Reducing Fluidized-Bed Reactors Treating Acidic, Metal-Containing Wastewater. Geomicrobiology Journal, v. 21, n. 7 , p. 469-480, 2004/10/01 2004. ISSN 0149-0451. Available at: < http://dx.doi.org/10.1080/01490450490505455 >.

KAMAGATA, Y.; MIKAMI, E. Isolation and Characterization of a Novel Thermophilic Methanosaeta Strain. International Journal of Systematic and Evolutionary Microbiology, v. 41, n. 2, p. 191-196, 1991. Available at: < http://ijs.microbiologyresearch.org/content/journal/ijsem/10.1099/00207713-41-2$191>$.

KANOKRATANA, P. et al. Phylogenetic analysis and metabolic potential of microbial communities in an industrial bagasse collection site. Microb Ecol, v. 66, n. 2, p. 322-34, Aug 2013. ISSN 0095-3628.

KAPARAJU, P.; FELBY, C. Characterization of lignin during oxidative and hydrothermal pre-treatment processes of wheat straw and corn stover. Bioresource Technology, v. 101, n. 9, p. 3175-3181, 5// 2010. ISSN 0960-8524. Available at: < http://www.sciencedirect.com/science/article/pii/S0960852409016368 >.

KAPARAJU, P.; SERRANO, M.; ANGELIDAKI, I. Effect of reactor configuration on biogas production from wheat straw hydrolysate. Bioresource Technology, v. 100, n. 24, p. 6317-6323, 12// 2009. ISSN 0960-8524. Available at: < http://www.sciencedirect.com/science/article/pii/S0960852409007822 >.

KARIMI, K.; TAHERZADEH, M. J. A critical review of analytical methods in pretreatment of lignocelluloses: Composition, imaging, and crystallinity. Bioresource Technology, v. 200, p. 1008-1018, 1// 2016. ISSN 0960-8524. Available at: http://www.sciencedirect.com/science/article/pii/S0960852415015485 >. 
KARP, S. G. et al. Pretreatment strategies for delignification of sugarcane bagasse: a review. Brazilian Archives of Biology and Technology, v. 56, p. 679-689, 2013. ISSN 1516-8913. Available at: < http://www.scielo.br/scielo.php?script=sci_arttext\&pid=S1516-89132013000400019\&nrm=iso >.

KATO, S. et al. Methanogenic degradation of lignin-derived monoaromatic compounds by microbial enrichments from rice paddy field soil. Scientific Reports, v. 5, p. 14295, 2015. Available at: < http://dx.doi.org/10.1038/srep14295 >.

KATUKURI, N. R. et al. Enhanced methane production of Miscanthus floridulus by hydrogen peroxide pretreatment. Fuel, v. 199, p. 562-566, 7/1/ 2017. ISSN 0016-2361. Available at: < http://www.sciencedirect.com/science/article/pii/S0016236117302879 >.

KAVUMA, C. Variation of Methane and Carbon dioxide Yield in a biogas plant. 2013. 46 (MSc). Department of Energy Technology, Royal Institute of Technology, Stockholm, Sweden.

KAYHANIAN, M.; RICH, D. Pilot-scale high solids thermophilic anaerobic digestion of municipal solid waste with an emphasis on nutrient requirements. Biomass and Bioenergy, v. 8, n. 6, p. 433-444, // 1995. ISSN 0961-9534. Available at: < http://www.sciencedirect.com/science/article/pii/0961953495000437 >.

KHANAL, S. K. Anaerobic Biotechnology for Bioenergy Production: Principles and Applications. KHANL, S. K.: Wiley-Blackwell 2008.

KIM, J. Characterization population dynamics in acidogenesis of various substrates by use of $16 \mathrm{~S}$ rRNA gene quantification: diversity and biokinetics. . 2007. (PhD). POSTECH, Pohang - South Korea.

KIM, K. H.; TUCKER, M.; NGUYEN, Q. Conversion of bark-rich biomass mixture into fermentable sugar by two-stage dilute acid-catalyzed hydrolysis. Bioresour Technol, v. 96, n. 11, p. 1249-55, Jul 2005. ISSN 0960-8524 (Print)

0960-8524.

KIM, S. et al. A pilot scale two-stage anaerobic digester treating food waste leachate (FWL): Performance and microbial structure analysis using pyrosequencing. Process Biochemistry, v. 49, n. 2, p. 301-308, 2// 2014. ISSN 1359-5113. Available at: <//www.sciencedirect.com/science/article/pii/S1359511313006247 $>$.

KIM, S.; LEE, Y. Y. Fractionation of herbaceous biomass by ammonia-hydrogen peroxide percolation treatment. Applied Biochemistry and Biotechnology, v. 57-58, n. 1, p. 147-156, 1996. ISSN 0273-2289. Available at: 〈 http://dx.doi.org/10.1007/BF02941695 >.

KIRKEGAARD, R. H. et al. Genomic insights into members of the candidate phylum Hyd24-12 common in mesophilic anaerobic digesters. ISME J, 04/08/online 2016. ISSN 1751-7370. Available at: < http://dx.doi.org/10.1038/ismej.2016.43 >. 
KO, J. J. et al. Biodegradation of high molecular weight lignin under sulfate reducing conditions: Lignin degradability and degradation by-products. Bioresource ..., 2009. Available at: < http://www.sciencedirect.com/science/article/pii/S0960852408007943 >.

KO, J. K. et al. Effect of liquid hot water pretreatment severity on properties of hardwood lignin and enzymatic hydrolysis of cellulose. Biotechnology and Bioengineering, v. 112, n. 2, p. 252-262, 2015. ISSN 1097-0290. Available at: < http://dx.doi.org/10.1002/bit.25349 >.

KOBAYASHI, F. et al. Methane production from steam-exploded bamboo. Journal of Bioscience and Bioengineering, v. 97, n. 6, p. 426428, 2004. ISSN 1389-1723. Available at: < http://dx.doi.org/10.1016/S1389-1723(04)70231-5 >.

KOGA, S. et al. Novel bacterial peroxidase without catalase activity from Flavobacterium meningosepticum: purification and characterization. Biochim Biophys Acta, v. 1435, n. 1-2, p. 117-26, Nov 16 1999. ISSN 0006-3002 (Print)

0006-3002.

KONG, L. et al. Preliminary purification and characterization of extracellular lignin peroxidase from Pseudomonas fluorescens GcM5-1A. Journal of Beijing Forestry University, v. 32, n. 3, p. 112-116, 2010. ISSN 1000-1522.

KOPONEN, H. Biogas production from ensiled maize with and without hydrothermal pretreatment. 2010. 24 (Masters). Department of Biological and Environmental Science, UNIVERSITY OF JYVÄSKYLÄ

Finland.

KOUKKOU, A.-I. Microbial Bioremediation of Non-metals: Current Research | Book. Greece: Caister Academic Press, 2011. ISBN 978-1-904455-83-7.

KOVÁCS, E. et al. Augmented biogas production from protein-rich substrates and associated metagenomic changes. Bioresource Technology, v. 178, p. 254-261, 2// 2015. ISSN 0960-8524. Available at: < http://www.sciencedirect.com/science/article/pii/S0960852414012279 >.

KRAUSE, L. et al. Taxonomic composition and gene content of a methane-producing microbial community isolated from a biogas reactor. Journal of Biotechnology, v. 136, n. 1-2, p. 91-101, 8/31/ 2008. ISSN 0168-1656. Available at: <//www.sciencedirect.com/science/article/pii/S0168165608002629 >.

KRIEG, N. R. et al. Phylum XIV. Bacteroidetes phyl. nov. In: KRIEG, N. R.;PARTE, A., et al (Ed.). Bergey's Manual of Systematic Bacteriology. 2nd, v.4, 2010. p.25.

KRISTENSEN, J. B. et al. Cell-wall structural changes in wheat straw pretreated for bioethanol production. Biotechnology for Biofuels, v. 1, n. 1, p. 1-9, 2008. ISSN 1754-6834. Available at: < http://dx.doi.org/10.1186/1754-6834-1-5 >. 
KUBLIK, A. et al. Identification of a multi-protein reductive dehalogenase complex in Dehalococcoides mccartyi strain CBDB1 suggests a protein-dependent respiratory electron transport chain obviating quinone involvement. Environmental Microbiology, v. 18, n. 9, p. 3044-3056, 2016. ISSN 1462-2920. Available at: 〈 http://dx.doi.org/10.1111/1462-2920.13200 >.

KUDO, Y. et al. Methanogen flora of paddy soils in Japan. FEMS Microbiology Ecology, v. 22, n. 1, p. 39-48, 1997. ISSN 1574-6941. Available at: 〈 http://dx.doi.org/10.1111/j.1574-6941.1997.tb00354.x 〉.

KUEVER, J.; SCHINK, B. Syntrophus. In: (Ed.). Bergey's Manual of Systematics of Archaea and Bacteria: John Wiley \& Sons, Ltd, 2015. ISBN 9781118960608.

KUMAR, R. et al. Carbohydrate derived-pseudo-lignin can retard cellulose biological conversion. Biotechnol Bioeng, v. 110, n. 3, p. 737-53, Mar 2013. ISSN 0006-3592.

KUPPARDT, A. et al. Phylogenetic and Functional Diversity Within Toluene-Degrading, SulphateReducing Consortia Enriched from a Contaminated Aquifer. Microbial Ecology, v. 68, n. 2, p. 222-234, 2014. ISSN 1432-184X. Available at: < http://dx.doi.org/10.1007/s00248-014-0403-8 > .

LANGE, H.; DECINA, S.; CRESTINI, C. Oxidative upgrade of lignin - Recent routes reviewed. European Polymer Journal, v. 49, n. 6, p. 1151-1173, 6// 2013. ISSN 0014-3057. Available at: < http://www.sciencedirect.com/science/article/pii/S0014305713001183 >.

LEE, J. W.; JEFFRIES, T. W. Efficiencies of acid catalysts in the hydrolysis of lignocellulosic biomass over a range of combined severity factors. Bioresour Technol, v. 102, n. 10, p. 5884-90, May 2011. ISSN 0960-8524.

LEE, S.-H. et al. Monitoring bacterial community structure and variability in time scale in full-scale anaerobic digesters. Journal of Environmental Monitoring, v. 14, n. 7, p. 1893-1905, 2012. ISSN 14640325. Available at: 〈 http://dx.doi.org/10.1039/C2EM10958A $>$.

LEVEN, L.; ERIKSSON, A. R.; SCHNURER, A. Effect of process temperature on bacterial and archaeal communities in two methanogenic bioreactors treating organic household waste. FEMS Microbiol Ecol, v. 59, n. 3, p. 683-93, Mar 2007. ISSN 0168-6496 (Print)

0168-6496.

LI, A. et al. A pyrosequencing-based metagenomic study of methane-producing microbial community in solid-state biogas reactor. Biotechnology for Biofuels, v. 6, n. 1, p. 3, 2013// 2013. ISSN 1754-6834. Available at: 〈 http://dx.doi.org/10.1186/1754-6834-6-3 >.

LI, C. et al. Assessment of regional biomass as co-substrate in the anaerobic digestion of chicken manure: Impact of co-digestion with chicken processing waste, seagrass and Miscanthus. Biochemical Engineering Journal, v. 118, p. 1-10, 2/15/ 2017. ISSN 1369-703X. Available at: < http://www.sciencedirect.com/science/article/pii/S1369703X1630314X >. 
LI, H.-Q. et al. Pretreatment on Miscanthus lutarioriparious by liquid hot water for efficient ethanol production. Biotechnology for Biofuels, v. 6, n. 1, p. 1-10, 2013. ISSN 1754-6834. Available at: < http://dx.doi.org/10.1186/1754-6834-6-76 >.

LI, H. et al. Investigation of lignin deposition on cellulose during hydrothermal pretreatment, its effect on cellulose hydrolysis, and underlying mechanisms. Biotechnology and Bioengineering, v. 111, n. 3, p. 485492, 2014. ISSN 1097-0290. Available at: < http://dx.doi.org/10.1002/bit.25108 >.

LI, J.; HENRIKSSON, G.; GELLERSTEDT, G. Lignin depolymerization/repolymerization and its critical role for delignification of aspen wood by steam explosion. Bioresource Technology, v. 98, n. 16, p. 30613068, 11// 2007. ISSN 0960-8524. Available at: < http://www.sciencedirect.com/science/article/pii/S0960852406005724 >.

LI, L. et al. A mesophilic anaerobic digester for treating food waste: process stability and microbial community analysis using pyrosequencing. Microbial Cell Factories, v. 15, n. 1, p. 65, 2016// 2016. ISSN 1475-2859. Available at: 〈 http://dx.doi.org/10.1186/s12934-016-0466-y 〉.

LI, X. et al. Evaluation biogas production performance and dynamics of the microbial community in different straw. J Microbiol Biotechnol, Nov 04 2016. ISSN 1017-7825.

LIEW, L. N.; SHI, J.; LI, Y. Methane production from solid-state anaerobic digestion of lignocellulosic biomass. Biomass and Bioenergy, v. 46, p. 125-132, 11// 2012. ISSN 0961-9534. Available at: < http://www.sciencedirect.com/science/article/pii/S0961953412003546 >.

LILIS, S. et al. Effect of hydrothermolysis process conditions on pretreated switchgrass composition and ethanol yield by SSF with Kluyveromyces marxianus IMB4. Process Biochemistry, 2009. ISSN 13595113. Available at: < http://dx.doi.org/10.1016/j.procbio.2009.01.011 >.

LIMAM, R. D. et al. Members of the uncultured bacterial candidate division WWE1 are implicated in anaerobic digestion of cellulose. Microbiologyopen, v. 3, n. 2, p. 157-67, Apr 2014. ISSN 2045-8827.

LIN, C.-Y.; HU, Y.-Y. Mesophilic degradation of butyric acid in anaerobic digestion. Journal of Chemical Technology \& Biotechnology, v. 56, n. 2, p. 191-194, 1993. ISSN 1097-4660. Available at: < http://dx.doi.org/10.1002/jctb.280560212 >.

LINKS, M. et al. The Chaperonin-60 Universal Target Is a Barcode for Bacteria That Enables De Novo Assembly of Metagenomic Sequence Data. PLoS One, v. 7, n. 11, p. e49755, 2012.

LISBOA, C. C. et al. Bioethanol production from sugarcane and emissions of greenhouse gases - known and unknowns. GCB Bioenergy, v. 3, n. 4, p. 277-292, 2011. ISSN 1757-1707. Available at: < http://dx.doi.org/10.1111/j.1757-1707.2011.01095.x >. 
LIU, C.; CHARLES, E. W. Partial flow of compressed-hot water through corn stover to enhance hemicellulose sugar recovery and enzymatic digestibility of cellulose. Bioresource Technology, 2005. ISSN 0960-8524. Available at: < http://dx.doi.org/10.1016/j.biortech.2005.01.012 >.

LIU, C.; WYMAN, C. E. Partial flow of compressed-hot water through corn stover to enhance hemicellulose sugar recovery and enzymatic digestibility of cellulose. Bioresour Technol, v. 96, n. 18, p. 1978-85, Dec 2005. ISSN 0960-8524 (Print)

0960-8524.

LIU, F. H. et al. The structure of the bacterial and archaeal community in a biogas digester as revealed by denaturing gradient gel electrophoresis and 16S rDNA sequencing analysis. J Appl Microbiol, v. 106, n. 3, p. 952-66, Mar 2009. ISSN 1364-5072.

LIU, Z. L. et al. Adaptive response of yeasts to furfural and 5-hydroxymethylfurfural and new chemical evidence for HMF conversion to 2,5-bis-hydroxymethylfuran. Journal of Industrial Microbiology and Biotechnology, v. 31, n. 8, p. 345-352, 2004. ISSN 1476-5535. Available at: < http://dx.doi.org/10.1007/s10295-004-0148-3 >.

LLOYD, T. A.; WYMAN, C. E. Predicted Effects of Mineral Neutralization and Bisulfate Formation on Hydrogen Ion Concentration for Dilute Sulfuric Acid Pretreatment. In: FINKELSTEIN, M.;MCMILLAN, J. D., et al (Ed.). Proceedings of the Twenty-Fifth Symposium on Biotechnology for Fuels and Chemicals Held May 4-7, 2003, in Breckenridge, CO. Totowa, NJ: Humana Press, 2004. p.1013-1022. ISBN 978-1-59259-837-3.

LU, X. B.; ZHANG, Y. M.; ANGELIDAKI, I. Optimization of H2SO4-catalyzed hydrothermal pretreatment of rapeseed straw for bioconversion to ethanol: Focusing on pretreatment at high solids content. Bioresource Technology, v. 100, n. 12, p. 3048-3053, Jun 2009. ISSN 0960-8524. Available at: $<<$ Go to ISI $>$ ://WOS:000265335400024 >.

LUCAS, M. et al. Evidence for room temperature delignification of wood using hydrogen peroxide and manganese acetate as a catalyst. Bioresource Technology, v. 119, p. 174-180, 9// 2012. ISSN 0960-8524. Available at: 〈 http://www.sciencedirect.com/science/article/pii/S0960852412008395 >.

LYNAM, J. G. et al. Hydrothermal carbonization of various lignocellulosic biomass. Biomass Conversion and Biorefinery, v. 5, n. 2, p. 173-181, 2014. ISSN 2190-6823. Available at: < http://dx.doi.org/10.1007/s13399-014-0137-3 >.

MA, J. et al. The mechanism of xylans removal during hydrothermal pretreatment of poplar fibers investigated by immunogold labeling. Planta, v. 242, n. 1, p. 327-337, 2015. ISSN 1432-2048. Available at: $\langle$ http://dx.doi.org/10.1007/s00425-015-2313-5 >.

MA, X. J. et al. Hydrothermal pretreatment of bamboo and cellulose degradation. Bioresource technology, v. 148 , p. 408-413, 2013. ISSN 0960-8524. Available at: < http://dx.doi.org/10.1016/j.biortech.2013.09.021 >. 
MAGURRAN, A. E. Measuring Biological Diversity. Blackwell Publishing Company, 2004.

MAPA. Ministério da Agricultura, P. e A. 2016. Avaialble at: < http://www.agricultura.gov.br/vegetal/culturas/cana-de-acucar $>$.

MARASABESSY, A. et al. Dilute H2SO4-catalyzed hydrothermal pretreatment to enhance enzymatic digestibility of Jatropha curcas fruit hull for ethanol fermentation. International Journal of Energy and Environmental Engineering, v. 3, n. 1, p. 15, 2012. ISSN 2251-6832. Available at: < http://dx.doi.org/10.1186/2251-6832-3-15 >.

MARTÍN, C. et al. Enzyme loading dependence of cellulose hydrolysis of sugarcane bagasse. Química Nova, v. 35 , p. 1927-1930, 2012. ISSN 0100-4042. Available at: < http://www.scielo.br/scielo.php?script=sci_arttext\&pid=S0100-40422012001000007\&nrm=iso $>$.

MENDEZ, L. et al. Effect of high pressure thermal pretreatment on Chlorella vulgaris biomass: Organic matter solubilisation and biochemical methane potential. Fuel, v. 117, p. 674-679, 2014. ISSN 0016-2361. Available at: < http://dx.doi.org/10.1016/j.fuel.2013.09.032 >.

MENG, J. et al. Genetic and functional properties of uncultivated MCG archaea assessed by metagenome and gene expression analyses. Isme j, v. 8, n. 3, p. 650-9, Mar 2014. ISSN 1751-7362.

MICHALSK, K.; LEDAKOWICZ, S. Alkaline hydrogen peroxide pretreatment of energy crops for biogas production. Chemical Papers, v. 68, n. 7, p. 913-922, 2014. ISSN 1336-9075. Available at: < http://dx.doi.org/10.2478/s11696-013-0531-5 >.

MITAL, K. M. Biogas Systems: Principles and Applications. New Delhi, India: New Age International (P) Limited Publishers, 1996.

MITTAL, A. et al. Modeling xylan solubilization during autohydrolysis of sugar maple wood meal: Reaction kinetics. Holzforschung, v. 63, p. 307-314, 2009.

MIURA, Y.; OKABE, S. Quantification of Cell Specific Uptake Activity of Microbial Products by Uncultured Chloroflexi by Microautoradiography Combined with Fluorescence In Situ Hybridization. Environmental Science \& Technology, v. 42, n. 19, p. 7380-7386, 2008/10/01 2008. ISSN 0013-936X. Available at: < http://dx.doi.org/10.1021/es800566e $>$.

MIZUNO, O.; LI, M. Y. Y.; NOIKE1, M. T. THE BEHAVIOR OF SULFATE-REDUCING BACTERIA IN ACIDOGENIC PHASE OF ANAEROBIC DIGESTION. Water Res, v. 32, n. 5, p. 1626-1634, 1998.

MOESTEDT, J. Biogas production from thin stillage. 2015. (PhD). Department of Microbiology, University of Uppsala, Uppsala - Sweden. 
MOHANTY, A. K.; MISRA, M.; HINRICHSEN, G. Biofibres, biodegradable polymers and biocomposites: An overview. Macromolecular Materials and Engineering, v. 276-277, n. 1, p. 1-24, 2000. ISSN 1439-2054. Available at: < http://dx.doi.org/10.1002/(SICI)14392054(20000301)276:1<1::AID-MAME1>3.0.CO;2-W >.

MOK, W. S.; ANTAL, M. J.; VARHEGYI, G. Productive and parasitic pathways in dilute acid-catalyzed hydrolysis of cellulose. Industrial \& Engineering Chemistry Research, v. 31, n. 1, p. 94-100, 1992. ISSN 0888-5885. Available at: < http://dx.doi.org/10.1021/ie00001a014 >.

MONLAU, F. et al. Lignocellulosic Materials Into Biohydrogen and Biomethane: Impact of Structural Features and Pretreatment. Critical Reviews in Environmental Science and Technology, v. 43, n. 3, p. 260-322, 2013. ISSN 1064-3389. Available at: < http://dx.doi.org/10.1080/10643389.2011.604258 >.

MONLAU, F. et al. Do furanic and phenolic compounds of lignocellulosic and algae biomass hydrolyzate inhibit anaerobic mixed cultures? A comprehensive review. Biotechnology advances, v. 32, n. 5, p. 934951, 2014. ISSN 0734-9750. Available at: < http://dx.doi.org/10.1016/j.biotechadv.2014.04.007 >.

MONTANÉ, D. et al. Phenomenological kinetics of wood delignification: application of a time-dependent rate constant and a generalized severity parameter to pulping and correlation of pulp properties. Wood Science and Technology, v. 28, n. 6, p. 387-402, 1994. ISSN 1432-5225. Available at: < http://dx.doi.org/10.1007/BF00225458 >.

MOORE, D.; ROBSON, G. D.; TRINCI, A. P. J. 21st century guidebook to fungi. Cambridge, UK: Cambridge University Press, 2011.

MORRISON, M.; MIRON, J. Adhesion to cellulose by Ruminococcus albus: a combination of cellulosomes and Pil-proteins?1. FEMS Microbiology Letters, v. 185, n. 2, p. 109-115, 4/15/ 2000. ISSN 0378-1097. Available at: <//www.sciencedirect.com/science/article/pii/S0378109700000409 > .

MOSELE, J. I.; MACIÀ, A.; MOTILVA, M.-J. Metabolic and microbial modulation of the large intestine ecosystem by non-absorbed diet phenolic compounds: a review. Molecules, v. 20, n. 9, p. 17429-17468, 2015.

MOSIER, N. et al. Features of promising technologies for pretreatment of lignocellulosic biomass. Bioresource Technology, v. 96, n. 6, p. 673-686, 4// 2005. ISSN 0960-8524. Available at: < http://www.sciencedirect.com/science/article/pii/S0960852404002536 >.

MOTTERAN, F. et al. Methanogenic potential of an anaerobic sludge in the presence of anionic and nonionic surfactants. International Biodeterioration \& Biodegradation, v. 96, p. 198-204, 12// 2014. ISSN 0964-8305. Available at: < http://www.sciencedirect.com/science/article/pii/S0964830514002893 >.

MOUTTA, R. et al. Comparative Response and Structural Characterization of Sugarcane Bagasse, Straw and Bagasse-Straw 1:1 Mixtures Subjected to Hydrothermal Pretreatment and Enzymatic Conversion. 
Journal of Microbial \& Biochemical Technology, v. 01, n. S12, 2013. Available at: < http://dx.doi.org/10.4172/1948-5948.S12-005 >.

MUHAMMAD, N. I.; MOHD GHAZI, T. I.; OMAR, R. Production of biogas from solid organic wastes through anaerobic digestion: a review. Appl Microbiol Biotechnol, v. 95, n. 2, p. 321-9, Jul 2012. ISSN 0175-7598.

MURTO, M.; BJÖRNSSON, L.; MATTIASSON, B. Impact of food industrial waste on anaerobic codigestion of sewage sludge and pig manure. Journal of Environmental Management, v. 70, n. 2, p. 101107, 2// 2004. ISSN 0301-4797. Available at: < http://www.sciencedirect.com/science/article/pii/S0301479703001981 >.

MUSSATTO, S. I.; ROBERTO, I. C. Alternatives for detoxification of diluted-acid lignocellulosic hydrolyzates for use in fermentative processes: a review. Bioresource Technology, v. 93, n. 1, p. 1-10, 5// 2004. ISSN 0960-8524. Available http://www.sciencedirect.com/science/article/pii/S0960852403002827 >.

MUYZER, G.; DE WAAL, E. C.; UITTERLINDEN, A. G. Profiling of complex microbial populations by denaturing gradient gel electrophoresis analysis of polymerase chain reaction-amplified genes coding for 16S rRNA. Applied and Environmental Microbiology, v. 59, n. 3, p. 695-700, 1993. ISSN 0099-2240

1098-5336. Available at: < http://www.ncbi.nlm.nih.gov/pmc/articles/PMC202176/ >.

MUYZER, G.; STAMS, A. J. M. The ecology and biotechnology of sulphate-reducing bacteria. Nat Rev Micro, v. 6, n. 6, p. 441-454, 06//print 2008. ISSN 1740-1526. Available at: < http://dx.doi.org/10.1038/nrmicro1892 >.

NAKAGAME, S. et al. Enhancing the enzymatic hydrolysis of lignocellulosic biomass by increasing the carboxylic acid content of the associated lignin. Biotechnology and Bioengineering, v. 108, n. 3, p. 538548, 2011. ISSN 1097-0290. Available at: < http://dx.doi.org/10.1002/bit.22981 >.

NAKAGAWA, Y. Cytophagaceae. In: (Ed.). Bergey's Manual of Systematics of Archaea and Bacteria: John Wiley \& Sons, Ltd, 2015. ISBN 9781118960608.

NARIHIRO, T. et al. Comparative analysis of bacterial and archaeal communities in methanogenic sludge granules from upflow anaerobic sludge blanket reactors treating various food-processing, high-strength organic wastewaters. Microbes Environ, v. 24, n. 2, p. 88-96, 2009. ISSN 1342-6311 (Print)

$1342-6311$.

NARIHIRO, T. et al. Quantitative detection of previously characterized syntrophic bacteria in anaerobic wastewater treatment systems by sequence-specific rRNA cleavage method. Water Research, v. 46, n. 7, p. 2167-2175, 5/1/ 2012. ISSN 0043-1354. Available at: < http://www.sciencedirect.com/science/article/pii/S0043135412000541 >. 
NAYAK, B. S. et al. Microbial population dynamics in laboratory-scale solid waste bioreactors in the presence or absence of biosolids. J Appl Microbiol, v. 107, n. 4, p. 1330-9, Oct 2009. ISSN 1364-5072.

NESBO, C. L. et al. Evidence for existence of "mesotogas," members of the order Thermotogales adapted to low-temperature environments. Appl Environ Microbiol, v. 72, n. 7, p. 5061-8, Jul 2006. ISSN 00992240 (Print)

0099-2240. Available at: < https://www.ncbi.nlm.nih.gov/pmc/articles/PMC1489369/pdf/0342-06.pdf >.

NIELSEN, J.; VILLADSEN, J.; LIDEN, G. Bioreaction Engineering Principles. Springer, 2011. ISBN 978-1-4419-9688-6.

NILADEVI, K. N. et al. Optimization of laccase production from a novel strain-Streptomyces psammoticus using response surface methodology. Microbiological Research, v. 164, n. 1, p. 105-113, 1// 2009. ISSN 0944-5013. Available at: http://www.sciencedirect.com/science/article/pii/S0944501306001303 >.

NITSOS, C. K.; MATIS, K. A.; TRIANTAFYLLIDIS, K. S. Optimization of Hydrothermal Pretreatment of Lignocellulosic Biomass in the Bioethanol Production Process. Chemsuschem, v. 6, n. 1, p. 110-122, Jan 2013. ISSN 1864-5631. Available at: < <Go to ISI>://WOS:000313702200016 >.

NITSOS, C. K. et al. The role of catalytic pretreatment in biomass valorization toward fuels and chemicals. In: TRIANTAFYLLIDIS, K. S.;LAPPAS, A. A., et al (Ed.). The role of catalysis for the sustainable production of biofuels and biochemicals. Great Britain: Elsevier, 2013. ISBN 978-0-444-56330-9.

NORDHOFF, M.; WIELER, L. H. [Incidence and significance of treponemes in animals]. Berl Munch Tierarztl Wochenschr, v. 118, n. 1-2, p. 24-36, Jan-Feb 2005. ISSN 0005-9366 (Print)

0005-9366.

NUBEL, U. et al. Sequence heterogeneities of genes encoding 16S rRNAs in Paenibacillus polymyxa detected by temperature gradient gel electrophoresis. J Bacteriol, v. 178, n. 19, p. 5636-43, Oct 1996. ISSN 0021-9193 (Print)

0021-9193.

O'SULLIVAN, C. A.; BURRELL, P. C. The effect of media changes on the rate of cellulose solubilisation by rumen and digester derived microbial communities. Waste Manag, v. 27, n. 12, p. 1808-14, 2007. ISSN 0956-053X (Print)

0956-053x.

OUDE ELFERINK, S. J. W. H. et al. Anaerobic Conversion of Lactic Acid to Acetic Acid and 1,2Propanediol by Lactobacillus buchneri. Applied and Environmental Microbiology, v. 67, n. 1, p. 125132, 05/15/received

10/11/accepted 2001. ISSN 0099-2240 
1098-5336. Available at: < http://www.ncbi.nlm.nih.gov/pmc/articles/PMC92530/ >.

OVEREND, R. P.; CHORNET, E. Steam and aqueous pretreatments: are they prehydrolyses? In: CHICHESTER, E. H. L. (Ed.). Wood processing and utilization. New York: Elsevier, 1989. p.395-400.

OVEREND, R. P.; CHORNET, E.; GASCOIGNE, J. A. Fractionation of Lignocellulosics by SteamAqueous Pretreatments [and Discussion]. 1987. 523-536 Available at: < http://rsta.royalsocietypublishing.org/roypta/321/1561/523.full.pdf $>$.

PALMQVIST, E.; HAHN-HÄGERDAL, B. Fermentation of lignocellulosic hydrolysates. II: inhibitors and mechanisms of inhibition. Bioresource Technology, v. 74, n. 1, p. 25-33, 8// 2000. ISSN 0960-8524. Available at: < http://www.sciencedirect.com/science/article/pii/S0960852499001613 >.

PANDIT, P. D. et al. Mining of hemicellulose and lignin degrading genes from differentially enriched methane producing microbial community. Bioresource Technology, v. 216, p. 923-930, 9// 2016. ISSN 0960-8524. Available at: < http://www.sciencedirect.com/science/article/pii/S0960852416308380 >.

PARNADI, P. S. et al. Improving the Effectiveness of Crude-Oil Hydrocarbon Biodegradation Employing Azotobacter chroococcum as Co-Inoculant. Microbiol Indones, v. 1, p. 5-10, 2007.

PASSOS, F.; FERRER, I. Influence of hydrothermal pretreatment on microalgal biomass anaerobic digestion and bioenergy production. Water Research, v. 68, p. 364-373, Jan 1 2015. ISSN 0043-1354. Available at: <<Go to ISI>://WOS:000347756900032 >.

PEDERSEN, M.; MEYER, A. S. Lignocellulose pretreatment severity - relating pH to biomatrix opening. New biotechnology, v. 27, n. 6, p. 739-750, 2010. ISSN 1871-6784. Available at: < http://dx.doi.org/10.1016/j.nbt.2010.05.003 >.

PELLETIER, E. et al. "Candidatus Cloacamonas acidaminovorans": genome sequence reconstruction provides a first glimpse of a new bacterial division. J Bacteriol, v. 190, n. 7, p. 2572-9, Apr 2008. ISSN 0021-9193.

PENGYU, D. et al. Comparison of dry and wet milling pre-treatment methods for improving the anaerobic digestion performance of the Pennisetum hybrid. RSC Advances, v. 7, n. 21, p. 12610-12619, 2017. Available at: 〈 http://dx.doi.org/10.1039/C6RA27822A >.

PENTEADO, E. D. et al. Influence of seed sludge and pretreatment method on hydrogen production in packed-bed anaerobic reactors. International Journal of Hydrogen Energy, v. 38, n. 14, p. 6137-6145, 5/10/ 2013. ISSN 0360-3199. Available at: http://www.sciencedirect.com/science/article/pii/S0360319913001535 >.

PÉREZ, J. A. et al. Effect of process variables on liquid hot water pretreatment of wheat straw for bioconversion to fuel-ethanol in a batch reactor. Journal of Chemical Technology \& Biotechnology, v. 82, n. 10, p. 929-938, 2007. ISSN 1097-4660. Available at: < http://dx.doi.org/10.1002/jctb.1765 > 
PITARELO, A. P. Avaliac, ` ao da susceptibilidade do bagac, o e da palha de cana-de-ac,' ucar`a bioconvers ' ao via pr'e-tratamento a vapor e hidr' olise enzim' atica (Evaluation of susceptibility of sugarcane bagasse and straw on the bioconversion by steamexplosion and enzymatic hydrolysis). 2007. (M.Sc.). Federal Univesity of Paran, Paran, Brazil.

POBEHEIM, $\mathrm{H}$. et al. Characterization of an anaerobic population digesting a model substrate for maize in the presence of trace metals. Chemosphere, v. 80, n. 8, p. 829-836, 8// 2010. ISSN 0045-6535. Available at: < http://www.sciencedirect.com/science/article/pii/S0045653510006582 >.

PODOSOKORSKAYA, O. A. et al. Ornatilinea apprima gen. nov., sp. nov., a cellulolytic representative of the class Anaerolineae. International Journal of Systematic and Evolutionary Microbiology, v. 63, n. $1, \quad$ p. $\quad 86-92, \quad 2013 . \quad$ Available at: < http://ijs.microbiologyresearch.org/content/journal/ijsem/10.1099/ijs.0.041012-0 >.

QIAO, W. et al. Evaluation of biogas production from different biomass wastes with/without hydrothermal pretreatment. Renewable Energy, v. 36, n. 12, p. 3313-3318, Dec 2011. ISSN 0960-1481. Available at: < $<$ Go to ISI>://WOS:000293424400011 >.

QIU, Y.-L. et al. Syntrophorhabdus aromaticivorans gen. nov., sp. nov., the First Cultured Anaerobe Capable of Degrading Phenol to Acetate in Obligate Syntrophic Associations with a Hydrogenotrophic Methanogen. Applied and Environmental Microbiology, v. 74, n. 7, p. 2051-2058, April 1, 20082008. Available at: $<$ http://aem.asm.org/content/74/7/2051.abstract $>$.

QIU, Y.-L. et al. Identification and Isolation of Anaerobic, Syntrophic Phthalate Isomer-Degrading Microbes from Methanogenic Sludges Treating Wastewater from Terephthalate Manufacturing. Applied and Environmental Microbiology, v. 70, n. 3, p. 1617-1626, March 1, 2004 2004. Available at: < http://aem.asm.org/content/70/3/1617.abstract $>$.

QUÉMÉNEUR, M. et al. Inhibition of fermentative hydrogen production by lignocellulose-derived compounds in mixed cultures. International Journal of Hydrogen Energy, v. 37, n. 4, p. 3150-3159, 2//

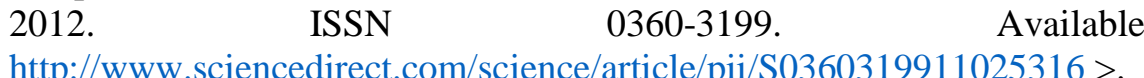

QUITAIN, A. T. et al. Low-molecular-weight carboxylic acids produced from hydrothermal treatment of organic wastes. Journal of Hazardous Materials, v. 93, n. 2, p. 209-220, 7/22/ 2002. ISSN 0304-3894. Available at: < http://www.sciencedirect.com/science/article/pii/S0304389402000249 >.

RABELO, S. et al. Production of bioethanol, methane and heat from sugarcane bagasse in a biorefinery concept. Bioresource technology, v. 102, n. 17, p. 7887-7895, 2011. ISSN 0960-8524. Available at: < http://dx.doi.org/10.1016/j.biortech.2011.05.081 >.

RABELO, S. C. et al. Ethanol production from enzymatic hydrolysis of sugarcane bagasse pretreated with lime and alkaline hydrogen peroxide. Biomass and Bioenergy, v. 35, n. 7, p. 2600-2607, 7// 2011. ISSN 0961-9534. Available at: < http://www.sciencedirect.com/science/article/pii/S0961953411001176 >. 
RAHIKAINEN, J. et al. Inhibition of enzymatic hydrolysis by residual lignins from softwood — study of enzyme binding and inactivation on lignin-rich surface. Biotechnology and Bioengineering, v. 108, n. 12, p. 2823-2834, 2011. ISSN 1097-0290. Available at: < http://dx.doi.org/10.1002/bit.23242 >.

RAINEY, F. A.; HOLLEN, B. J.; SMALL, A. M. Clostridium. In: (Ed.). Bergey's Manual of Systematics of Archaea and Bacteria: John Wiley \& Sons, Ltd, 2015. ISBN 9781118960608.

RAINEY, F. A. et al. Isolation and characterization of an obligately anaerobic, polysaccharolytic, extremely thermophilic member of the genus Spirochaeta. Archives of Microbiology, v. 155, n. 4, p. 396401, 1991. ISSN 1432-072X. Available at: < http://dx.doi.org/10.1007/BF00243461 >.

RALPH, J. et al. Lignins: Natural polymers from oxidative coupling of 4-hydroxyphenyl- propanoids. Phytochemistry Reviews, v. 3, n. 1, p. 29-60, 2004. ISSN 1572-980X. Available at: < http://dx.doi.org/10.1023/B:PHYT.0000047809.65444.a4 >.

RAMANATHAN, V.; FENG, Y. Air pollution, greenhouse gases and climate change: Global and regional perspectives. Atmospheric Environment, v. 43, n. 1, p. 37-50, 1// 2009. ISSN 1352-2310. Available at: < http://www.sciencedirect.com/science/article/pii/S1352231008008583 >.

RAMIREZ, R. S.; HOLTZAPPLE, M.; PIAMONTE, N. Fundamentals of biomass pretreatment at high pH. In: WYMAN, C. (Ed.). Aqueous pretreatment of plant biomass for biological and chemical conversion to fuels and chemicals. Noida, India: John Wiley \& Sons, Ltd., 2013. p.145-167.

RAMOS, L. P. The chemistry involved in the steam treatment of lignocellulosic materials. Quimica Nova, v. 26, n. 6, p. 863-871, Nov-Dec 2003. ISSN 0100-4042. Available at: < <Go to ISI $>$ //WOS:000186718500015 >.

REYSENBACH, A.-L. Thermotogales ord. nov. In: (Ed.). Bergey's Manual of Systematics of Archaea and Bacteria: John Wiley \& Sons, Ltd, 2015. ISBN 9781118960608.

REZENDE, C. et al. Chemical and morphological characterization of sugarcane bagasse submitted to a delignification process for enhanced enzymatic digestibility. Biotechnology for Biofuels, v. 4, n. 1, p. 119, 2011/11/28 2011. Available at: < http://dx.doi.org/10.1186/1754-6834-4-54 >.

RIVARD, C. J. et al. Waste to energy: Nutrient requirements for aerobic and anaerobic digestion. Journal Name: Journal of Environmental Health; (USA); Journal Volume: 52:2, p. Medium: X; Size: Pages: 96-101, 1989.

RIVIERE, D. et al. Towards the definition of a core of microorganisms involved in anaerobic digestion of sludge. Isme j, v. 3, n. 6, p. 700-14, Jun 2009. ISSN 1751-7362. 
ROCHA, G. J. M. et al. Effect of Xylan and Lignin Removal by Hydrothermal Pretreatment on Enzymatic Conversion of Sugarcane Bagasse Cellulose for Second Generation Ethanol Production. Sugar Tech, v. 15, n. 4, p. 390-398, Dec 2013. ISSN 0972-1525. Available at: <<Go to ISI>://WOS:000327935800007 >.

ROLING, W. F. M. The Family Geobacteraceae. In: ROSENBERG, E. (Ed.). The Prokaryotes: Deltaproteobacteria and Epsilonpoteobacteria. 4th. New York: Springer, 2014. p.157-172.

ROMANÍ, A. et al. Experimental Assessment on the Enzymatic Hydrolysis of Hydrothermally Pretreated Eucalyptus globulus Wood. Industrial \& Engineering Chemistry Research, v. 49, n. 10, p. 4653-4663, 2010. ISSN 0888-5885. Available at: < http://dx.doi.org/10.1021/ie100154m >.

ROTARU, A.-E. et al. Direct Interspecies Electron Transfer between Geobacter metallireducens and Methanosarcina barkeri. Applied and Environmental Microbiology, v. 80, n. 15, p. 4599-4605, August 1, 2014 2014. Available at: 〈 http://aem.asm.org/content/80/15/4599.abstract 〉.

ROUCHES, E. et al. Improvement of anaerobic degradation by white-rot fungi pretreatment of lignocellulosic biomass: A review. Renewable and Sustainable Energy Reviews, v. 59, p. 179-198, 6// 2016. ISSN $1364-0321 . \quad$ Available

ROWEL, R. M. Handbook of wood chemistry and wood composites. CRC press, 2005.

RUIZ, H. A. et al. Bioethanol production from hydrothermal pretreated wheat straw by a flocculating Saccharomyces cerevisiae strain - Effect of process conditions. Fuel, v. 95, p. 528-536, 5// 2012. ISSN 0016-2361. Available at: < http://www.sciencedirect.com/science/article/pii/S0016236111006788 >.

SAAKE, B.; LEHNEN, R. Liginin. In: BOHNET, M.;BELLUSSI, G., et al (Ed.). Ullmann's Encyclopedia of Industrial Chemistry. New Yoark: Wiley, 2007.

SAHA, B. C. et al. Hydrothermal pretreatment and enzymatic saccharification of corn stover for efficient ethanol production. Industrial Crops and Products, v. 44, p. 367-372, Jan 2013. ISSN 0926-6690. Available at: <<Go to ISI>://WOS:000315659400053 >.

SAINI, J. K.; SAINI, R.; TEWARI, L. Lignocellulosic agriculture wastes as biomass feedstocks for secondgeneration bioethanol production: concepts and recent developments. 3 Biotech, v. 5, n. 4, p. 337-353, $08 / 21$

05/19/received

08/05/accepted 2015. ISSN 2190-572X

2190-5738. Available at: < http://www.ncbi.nlm.nih.gov/pmc/articles/PMC4522714/ >.

SAKAI, S. et al. Methanolinea mesophila sp. nov., a hydrogenotrophic methanogen isolated from rice field soil, and proposal of the archaeal family Methanoregulaceae fam. nov. within the order 
Methanomicrobiales. International Journal of Systematic and Evolutionary Microbiology, v. 62, n. Pt 6, p. 1389-1395, 2012. ISSN 1466-5026. Available at: 〈http://dx.doi.org/10.1099/ijs.0.035048-0 >.

SAKAKI, T. et al. Saccharification of Cellulose Using a Hot-Compressed Water-Flow Reactor. Industrial \& Engineering Chemistry Research, v. 41, n. 4, p. 661-665, 2002/02/01 2002. ISSN 0888-5885.

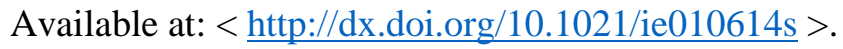

SAMBUSITI, C. et al. A comparison of different pre-treatments to increase methane production from two agricultural substrates. Applied Energy, v. 104, p. 62-70, 4// 2013. ISSN 0306-2619. Available at: < http://www.sciencedirect.com/science/article/pii/S0306261912007799 >.

SÁRVÁRI HORVÁTH, I. et al. Effects of Furfural on the Respiratory Metabolism of Saccharomyces cerevisiae in Glucose-Limited Chemostats. Applied and Environmental Microbiology, v. 69, n. 7, p. 4076-4086, July 1, 2003 2003. Available at: < http://aem.asm.org/content/69/7/4076.abstract >.

SASKA, M.; OZER, E. Aqueous extraction of sugarcane bagasse hemicellulose and production of xylose syrup. Biotechnology and Bioengineering, v. 45, n. 6, p. 517-523, 1995. ISSN 1097-0290. Available at: $<$ http://dx.doi.org/10.1002/bit.260450609 $>$.

SASSNER, P.; GALBE, M.; ZACCHI, G. Techno-economic evaluation of bioethanol production from three different lignocellulosic materials. Biomass and Bioenergy, v. 32, n. 5, p. 422-430, 5// 2008. ISSN 0961-9534. Available at: < http://www.sciencedirect.com/science/article/pii/S0961953407001997 >.

SCHINK, B. Anaerophaga. In: (Ed.). Bergey's Manual of Systematics of Archaea and Bacteria: John Wiley \& Sons, Ltd, 2015. ISBN 9781118960608.

SCHNÜRER, A.; JARVIS, A. Microbiological handbook for biogas plants, Swedish waste management. Swedish gas centre. Sweden. 2010

SCHROYENA, M. et al. Inhibitory effects of p-coumaric acid on the biogas production process, and the interaction with an enzymatic pretreatment. International Conference on Sustainable Solid Waste Management, 2016, Cyprus.

SELIG, M. J. et al. Deposition of Lignin Droplets Produced During Dilute Acid Pretreatment of Maize Stems Retards Enzymatic Hydrolysis of Cellulose. Biotechnology Progress, v. 23, n. 6, p. 1333-1339, 2007. ISSN 1520-6033. Available at: < http://dx.doi.org/10.1021/bp0702018 >.

SENILA, L. et al. The Autohydrolysis of Albies Alba Wood Using Adaptive Neural Fuzzy Interference System Mathematical Modeling. International Journal of Green Energy, v. 11, n. 6, p. 611-624, 2014/07/03 2014. ISSN 1543-5075. Available at: < http://dx.doi.org/10.1080/15435075.2013.777907 >.

SHAO, Q. et al. Hydrogen peroxide presoaking of bamboo prior to AFEX pretreatment and impact on enzymatic conversion to fermentable sugars. Bioresource Technology, v. 142, p. 26-31, 8// 2013. ISSN 0960-8524. Available at: < http://www.sciencedirect.com/science/article/pii/S0960852413007712 >. 
SHEN, G. et al. EFFECT OF HYDROGEN PEROXIDE PRETREATMENT ON THE ENZYMATIC HYDROLYSIS OF CELLULOSE. Journal of Food Process Engineering, v. 34, n. 3, p. 905-921, 2011. ISSN 1745-4530. Available at: < http://dx.doi.org/10.1111/j.1745-4530.2009.00518.x >.

SHEN, X. J. et al. Effects of aluminum chloride-catalyzed hydrothermal pretreatment on the structural characteristics of lignin and enzymatic hydrolysis. Bioresour Technol, v. 206, p. 57-64, Apr 2016. ISSN 0960-8524. Available at: < http://ac.els-cdn.com/S0960852416000444/1-s2.0-S0960852416000444main.pdf? tid=88738638-7826-11e6-b800-

00000aab0f6c\&acdnat=1473601937_af227baceb9b5bcccdb3493b2b8f1f8d >.

SHIMIZU, K. et al. Total utilisation of wood components by steam explosion pretreatment. In: CHICHESTER, H. L. (Ed.). Wood Processing an Utilization, 1989. p.407-412.

SIEBER, J. R.; MCINERNEY, M. J.; GUNSALUS, R. P. Genomic insights into syntrophy: the paradigm for anaerobic metabolic cooperation. Annu Rev Microbiol, v. 66, p. 429-52, 2012. ISSN 0066-4227.

SIMS, R. E. H.; BASSAM, N. E. Chapter 1 - Biomass and Resources. In: SIMS, R. E. H. (Ed.). Bioenergy Options for a Cleaner Environment. Oxford: Elsevier, 2004. p.1-28. ISBN 978-0-08-044351-5.

SINGH, A.; MISHRA, P. Microbial Pentose Utilization: Current Applications in Biotechnology. Elsevier, 1995.

SIRIPATANA, C.; JIJAI, S.; KONGJAN, P. Analysis and extension of Gompertz-type and Monod-type equations for estimation of design parameters from batch anaerobic digestion experiments. AIP Conference Proceedings, v. 1775, n. 1, p. 030079, 2016. Available at: < http://aip.scitation.org/doi/abs/10.1063/1.4965199 >.

SIRIWONGRUNGSON, V.; ZENG, R. J.; ANGELIDAKI, I. Homoacetogenesis as the alternative pathway for $\mathrm{H} 2$ sink during thermophilic anaerobic degradation of butyrate under suppressed methanogenesis. Water Res, v. 41, n. 18, p. 4204-10, Oct 2007. ISSN 0043-1354 (Print)

0043-1354.

SJÖDE, A. et al. The Potential in Bioethanol Production From Waste Fiber Sludges in Pulp Mill-Based Biorefineries. In: MIELENZ, J.;KLASSON, K. T., et al (Ed.). Applied Biochemistry and Biotecnology: Humana Press, 2007. chap. 29, p.327-337. (ABAB Symposium). ISBN 978-1-60327-180-6.

SKIADAS, I. V. et al. Thermal pre-treatment of primary and secondary sludge at 70 degrees $\mathrm{C}$ prior to anaerobic digestion. Water Sci Technol, v. 52, n. 1-2, p. 161-6, 2005. ISSN 0273-1223 (Print)

0273-1223.

SLUITER, A. et al. Determination of Sugars, Byproducts, and Degradation Products in Liquid Fraction Process Samples. National Renewable Energy Laboratory. 2008 
SLUITER, A. et al. Determination of structural carbohydrates and lignin in biomass. National Renewable Energy Laboratory. DOE, USA 2011

SOCCOL, C. et al. Lignocellulosic bioethanol: current status and future perspectives. In: PANDEY, A.;LARROCHE, C., et al (Ed.). Biofuels: Alternative Feedstocks and Conversion Processes. San Diego: Academic Press, 2011 b. p.101-122.

SOCCOL, C. R. et al. Bioethanol from lignocelluloses: Status and perspectives in Brazil. Bioresour Technol, v. 101, n. 13, p. 4820-5, Jul 2010. ISSN 0960-8524.

SOEST, P. J. Nutritional ecology of the ruminant. Cornell University Press, 1994. Available at: < http://books.google.com/books?hl=en\&lr=\&id=mwUu6PL1UgC\&oi=fnd\&pg=PR9\&ots=DOUyB4GbOH\&sig=dQwxX43S5hJiudOwsh38va5dUAM >.

SOMERVILLE, C. et al. Feedstocks for Lignocellulosic Biofuels. Science, v. 329, n. 5993, p. 790-792, August 13, 2010 2010. Available at: < http://www.sciencemag.org/content/329/5993/790.abstract >.

SONG, Y.; LIU, C.; FINEGOLD, S. M. Bacteroides. In: (Ed.). Bergey's Manual of Systematics of Archaea and Bacteria: John Wiley \& Sons, Ltd, 2015. ISBN 9781118960608.

SONG, Z.-L. et al. Pretreatment of Rice Straw by Hydrogen Peroxide for Enhanced Methane Yield. Journal of Integrative Agriculture, v. 12, n. 7, p. 12581266, 2013. ISSN 2095-3119. Available at: < http://dx.doi.org/10.1016/S2095-3119(13)60355-X >.

SONG, Z. et al. Comparison of two chemical pretreatments of rice straw for biogas prodcution by anaerobic digestion. Bioresources, v. 7, n. 3, $2012 \quad 2012 . \quad$ Available at: < http://scholar.google.com/scholar?q=Comparison of two chemical pretreatments of rice straw for biogas prodcution by anaerobic digestion $\& \mathrm{btnG}=\& \mathrm{hl}=\mathrm{en} \&$ num $=20 \&$ as_sdt $=0 \% 2 \mathrm{C} 22>$.

SOROKIN, D. Y. et al. Methanogenesis at extremely haloalkaline conditions in the soda lakes of Kulunda Steppe (Altai, Russia). FEMS Microbiol Ecol, v. 91, n. 4, Apr 2015. ISSN 0168-6496.

STRONACH, S. M.; RUDD, T.; LESTER, J. N. Anaerobic Digestion Processes in Industrial Wastewater Treatment. Springer, 1986. ISBN 978-3-642-71217-3.

STUDER, M. H. et al. Lignin content in natural Populus variants affects sugar release. Proceedings of the National Academy of Sciences, v. 108, n. 15, p. 6300-6305, 2011. ISSN 0027-8424. Available at: < http://dx.doi.org/10.1073/pnas.1009252108 >.

SU, Y. et al. Fractional pretreatment of lignocellulose by alkaline hydrogen peroxide: Characterization of its major components. Food and Bioproducts Processing, v. 94, p. 322-330, 4// 2015. ISSN 0960-3085. Available at: < http://www.sciencedirect.com/science/article/pii/S0960308514000479 >. 
SUN, L. et al. Characterization of microbial community structure during continuous anaerobic digestion of straw and cow manure. Microbial Biotechnology, v. 8, n. 5, p. 815-827, 2015. ISSN 1751-7915. Available at: < http://dx.doi.org/10.1111/1751-7915.12298 >.

SUN, S.-N. et al. Structural characterization of residual hemicelluloses from hydrothermal pretreated Eucalyptus fiber. International journal of biological macromolecules, v. 69, p. 158-164, 2014. ISSN 0141-8130. Available at: < http://dx.doi.org/10.1016/j.ijbiomac.2014.05.037 >.

SUN, S. et al. Improving the enzymatic hydrolysis of thermo-mechanical fiber from Eucalyptus urophylla by a combination of hydrothermal pretreatment and alkali fractionation. Biotechnology for Biofuels, v. 7, Aug 20 2014. ISSN 1754-6834. Available at: < <Go to ISI>://WOS:000340914800001 >.

SUN, S. et al. Systematic evaluation of the degraded products evolved from the hydrothermal pretreatment of sweet sorghum stems. Biotechnology for Biofuels, v. 8, n. 1, p. 1-13, 2015// 2015. ISSN 1754-6834. Available at: < http://dx.doi.org/10.1186/s13068-015-0223-1 >.

SUN, T. S. et al. Hydrothermal treatment and enzymatic saccharification of corncobs. BioResources, v. 9, n. 2, p. 3000-3013, 2014. Available at: < http://scholar.google.com/scholar?q=Hydrothermal treatment and enzymatic saccharification of corncobs\&btnG=\&hl=en\&num=20\&as_sdt=0\%2C22 >.

TABATABAEI, M. et al. Importance of the methanogenic archaea populations in anaerobic wastewater treatments. Process Biochemistry, v. 45, n. 8, p. 1214-1225, 8// 2010. ISSN 1359-5113. Available at: < http://www.sciencedirect.com/science/article/pii/S1359511310001984 >.

TAHERZADEH, M. J.; KEIKHOSRO, K. Pretreatment of Lignocellulosic Wastes to Improve Ethanol and Biogas Production: A Review. International Journal of Molecular Sciences, v. 9, n. 9, 2008. Available at: < http://dx.doi.org/10.3390/ijms9091621 >.

TAKASHIMA, M.; SPEECE, R. E.; PARKIN, G. F. Mineral requirements for methane fermentation. Critical Reviews in Environmental Control, v. 19, n. 5, p. 465-479, 1990/01/01 1990. ISSN 1040-838X. Available at: < http://dx.doi.org/10.1080/10643389009388378 >. Accessed on: 2015/09/08.

TEIXEIRA, R. S. et al. Biomass pretreatment: a critical choice for biomass utilization via biotechnological routes. BMC Proceedings, v. 8, n. 4, p. O34, 2014. ISSN 1753-6561. Available at: < http://dx.doi.org/10.1186/1753-6561-8-S4-O34 >.

TEMIZ, E.; AKPINAR, O. The Effect of Severity Factor on the Release of Xylose and Phenolics from Rice Husk and Rice Straw. Waste and Biomass Valorization, p. 1-12, 2016. ISSN 1877-265X. Available at: $<$ http://dx.doi.org/10.1007/s12649-016-9608-z >.

TIAN, J. H. et al. Occurrence of lignin degradation genotypes and phenotypes among prokaryotes. Appl Microbiol Biotechnol, v. 98, n. 23, p. 9527-44, Dec 2014. ISSN 0175-7598. 
TRAJANO, H. L. et al. The fate of lignin during hydrothermal pretreatment. Biotechnology for Biofuels, v. 6, Aug 1 2013. ISSN 1754-6834. Available at: < <Go to ISI>://WOS:000323166000001 >.

ULBRICHT, R. J.; NORTHUP, S. J.; THOMAS, J. A. A review of 5-hydroxymethylfurfural (HMF) in parenteral solutions. Fundamental and Applied Toxicology, v. 4, n. 5, p. 843-853, 1984/10/01 1984. ISSN 0272-0590. Available at: 〈 http://www.sciencedirect.com/science/article/pii/0272059084901064 >.

UNICA. SOUTH CENTRAL 2015/2016 HARVEST SHOULD REACH 590 MILLION TONS OF PROCESSED CANE, WITH PRIORITY ON ETHANOL PRODUCTION: Brazilian Sugarcane Industry Association. 20152015.

VALO, A.; CARRÈRE, H.; DELGENÈS, J. P. Thermal, chemical and thermo-chemical pre-treatment of waste activated sludge for anaerobic digestion. Journal of Chemical Technology \& Biotechnology, v. 79, n. 11, p. 1197-1203, 2004. ISSN 1097-4660. Available at: 〈 http://dx.doi.org/10.1002/jctb.1106 >.

VAN HAANDEL, A. C.; LETTINGA, G. Anaerobic Sewage Treatment: A Practical Guide for Regions with a Hot Climate. Chichester, UK: Wiley, 1994. ISBN 0471951218.

VAN WALSU, G. P. Severity function describing the hydrolysis of xylan using carbonic acid. Applied Biochemistry and Biotechnology, v. 91, n. 1, p. 317-329, 2001. ISSN 1559-0291. Available at: < http://dx.doi.org/10.1385/ABAB:91-93:1-9:317>.

VANWONTERGHEM, I. et al. Deterministic processes guide long-term synchronised population dynamics in replicate anaerobic digesters. ISME J, v. 8, n. 10, p. 2015-2028, 10//print 2014. ISSN 17517362. Available at: 〈http://dx.doi.org/10.1038/ismej.2014.50 >.

VERGARA-FERNÁNDEZ, A. et al. Evaluation of marine algae as a source of biogas in a two-stage anaerobic reactor system. Biomass and Bioenergy, v. 32, n. 4, p. 338-344, 4// 2008. ISSN 0961-9534. Available at: < http://www.sciencedirect.com/science/article/pii/S0961953407001912 >.

WALLIS, A. F. A.; WEARNE, R. H. Fractionation on the polymeric components of hardwoods by autohydrolysis-explosion-extraction. Appita J., v. 38, p. 432-437, 1985.

WALTER, J. Ecological Role of Lactobacilli in the Gastrointestinal Tract: Implications for Fundamental and Biomedical Research. Applied and Environmental Microbiology, v. 74, n. 16, p. 4985-4996, August 15, 2008 2008. Available at: < http://aem.asm.org/content/74/16/4985.short >.

WALTERS, W. A. et al. PrimerProspector: de novo design and taxonomic analysis of barcoded polymerase chain reaction primers. Bioinformatics, v. 27, n. 8, p. 1159-61, Apr 15 2011. ISSN 1367-4803.

WANG, H. et al. An integrated approach for efficient biomethane production from solid bio-wastes in a compact system. Biotechnology for Biofuels, v. 8, n. 1, p. 62, 2015. ISSN 1754-6834. Available at: < http://www.biotechnologyforbiofuels.com/content/8/1/62 >. 
WANG, W. et al. Performance and microbial community analysis of the anaerobic reactor with coke oven gas biomethanation and in situ biogas upgrading. Bioresource Technology, v. 146, p. 234-239, 10// 2013. ISSN 0960-8524. Available at: <//www.sciencedirect.com/science/article/pii/S0960852413011176 >.

WANG, Y. et al. Effects of volatile fatty acid concentrations on methane yield and methanogenic bacteria. Biomass and Bioenergy, v. 33, n. 5, p. 848-853, 5// 2009. ISSN 0961-9534. Available at: < http://www.sciencedirect.com/science/article/pii/S096195340900018X >.

WANGLiANG, L. et al. Anaerobic Digestion of Yard Waste with Hydrothermal Pretreatment. Applied Biochemistry and Biotechnology, 2014. ISSN 0273-2289. Available at: < http://dx.doi.org/10.1007/s12010-014-0724-6 >.

WARNECKE, F. et al. Metagenomic and functional analysis of hindgut microbiota of a wood-feeding higher termite. Nature, v. 450, n. 7169, p. 560-565, 2007. ISSN 0028-0836. Available at: < http://dx.doi.org/10.1038/nature06269 >.

WEIL, J. et al. Pretreatment of yellow poplar sawdust by pressure cooking in water. Applied Biochemistry and Biotechnology, v. 68, n. 1-2, p. 21-40, 1997/10/01 1997. ISSN 0273-2289. Available at: < http://dx.doi.org/10.1007/BF02785978>.

WENG, J.-K.; CHAPPLE, C. The origin and evolution of lignin biosynthesis. New Phytologist, v. 187, $\mathrm{n}$. 2, p. 273-285, 2010. ISSN 1469-8137. Available at: < http://dx.doi.org/10.1111/j.1469-8137.2010.03327.x $>$.

WHITMAN, W. B.; BOWEN, T. L.; BOONE, D. R. The methanogenic bacteria. In: DWORKIN, M. (Ed.). The Prokaryotes: An evolving electronic resource for the microbiological community. New York: Springer, 2006.

WI, S. G. et al. Lignocellulose conversion for biofuel: a new pretreatment greatly improves downstream biocatalytic hydrolysis of various lignocellulosic materials. Biotechnology for Biofuels, v. 8, n. 1, p. 228, 2015// 2015. ISSN 1754-6834. Available at: < http://dx.doi.org/10.1186/s13068-015-0419-4 >.

WIJEKOON, K. C.; VISVANATHAN, C.; ABEYNAYAKA, A. Effect of organic loading rate on VFA production, organic matter removal and microbial activity of a two-stage thermophilic anaerobic membrane bioreactor. Bioresource Technology, v. 102, n. 9, p. 5353-5360, 5// 2011. ISSN 0960-8524. Available at: < http://www.sciencedirect.com/science/article/pii/S0960852410020663 >.

WILKINS, D. et al. Effects of sludge inoculum and organic feedstock on active microbial communities and methane yield during anaerobic digestion. Frontiers in Microbiology, v. 6, n. 1114, 2015-October-13 2015. ISSN 1664-302X. Available at: < http://journal.frontiersin.org/article/10.3389/fmicb.2015.01114 >. 
WINGREN, A.; GALBE, M.; ZACCHI, G. Energy considerations for a SSF-based softwood ethanol plant. Bioresource Technology, v. 99, n. 7, p. 2121-2131, 5// 2008. ISSN 0960-8524. Available at: < http://www.sciencedirect.com/science/article/pii/S096085240700466X >.

WIRTH, R. et al. Characterization of a biogas-producing microbial community by short-read next generation DNA sequencing. Biotechnology for Biofuels, v. 5, n. 1, p. 41, 2012. ISSN 1754-6834. Available at: < http://dx.doi.org/10.1186/1754-6834-5-41 >.

WOESE, C. R.; FOX, G. E. Phylogenetic structure of the prokaryotic domain: the primary kingdoms. Proc Natl Acad Sci U S A, v. 74, n. 11, p. 5088-90, Nov 1977. ISSN 0027-8424 (Print)

0027-8424.

WONG, M. T. et al. Substrate-Driven Convergence of the Microbial Community in LignocelluloseAmended Enrichments of Gut Microflora from the Canadian Beaver (Castor canadensis) and North American Moose (Alces americanus). Frontiers in Microbiology, v. 7, p. 961, 06/21

01/27/received

06/03/accepted 2016. ISSN 1664-302X. Available at: < http://www.ncbi.nlm.nih.gov/pmc/articles/PMC4914502/ >.

WWF. WWF - World Wildlife Fund for nature, The energy report 100\% renewable energy by 2050. 2011

XIA, Y. et al. Cellular adhesiveness and cellulolytic capacity in Anaerolineae revealed by omics-based genome interpretation. Biotechnology for Biofuels, v. 9, n. 1, p. 111, 2016// 2016. ISSN 1754-6834. Available at: 〈 http://dx.doi.org/10.1186/s13068-016-0524-z >.

XIANG, Q. et al. Heterogeneous aspects of acid hydrolysis of alpha-cellulose. Applied biochemistry and biotechnology, v. $105-108$, p. 505-514, 2003. ISSN 0273-2289. Available at: < http://www.ncbi.nlm.nih.gov/pubmed/12721431 >.

XIAO, L.-P. et al. Impact of hot compressed water pretreatment on the structural changes of woody biomass for bioethanol prodution. Biorsources, v. 6, n. 2, p. 1576-1598, 2011.

XING, D. et al. Ethanoligenens harbinense gen. nov., sp. nov., isolated from molasses wastewater. Int J Syst Evol Microbiol, v. 56, n. Pt 4, p. 755-60, Apr 2006. ISSN 1466-5026 (Print)

1466-5026.

XU, J.; THOMSEN, M. H.; THOMSEN, A. B. Investigation of acetic acid-catalyzed hydrothermal pretreatment on corn stover. Applied Microbiology and Biotechnology, v. 86, n. 2, p. 509-516, 2009. ISSN 1432-0614. Available at: 〈 http://dx.doi.org/10.1007/s00253-009-2340-x >. 
YADVIKA et al. Enhancement of biogas production from solid substrates using different techniques--a review. Bioresour Technol, v. 95, n. 1, p. 1-10, Oct 2004. ISSN 0960-8524 (Print)

0960-8524.

YAMADA, T. Anaerolinea thermolimosa sp. nov., Levilinea saccharolytica gen. nov., sp. nov. and Leptolinea tardivitalis gen. nov., sp. nov., novel filamentous anaerobes, and description of the new classes Anaerolineae classis nov. and Caldilineae classis nov. in the bacterial phylum Chloroflexi. Int J Syst Evol Microbiol, v. 56, 2006// 2006. Available at: < http://dx.doi.org/10.1099/ijs.0.64169-0 >.

YAMADA, T. et al. Bellilinea caldifistulae gen. nov., sp. nov. and Longilinea arvoryzae gen. nov., sp. nov., strictly anaerobic, filamentous bacteria of the phylum Chloroflexi isolated from methanogenic propionate-degrading consortia. Int J Syst Evol Microbiol, v. 57, 2007// 2007. Available at: < http://dx.doi.org/10.1099/ijs.0.65098-0 >.

YAMADA, T.; SEKIGUCHI, Y. Cultivation of Uncultured $<i>$ Chloroflexi $</ \mathrm{i}>$ Subphyla: Significance and Ecophysiology of Formerly Uncultured $\langle\mathrm{i}>$ Chloroflexi $</ \mathrm{i}\rangle$ 'Subphylum I' with Natural and Biotechnological Relevance. Microbes and Environments, v. 24, n. 3, p. 205-216, 2009.

YANG, B. et al. Enzymatic hydrolysis of cellulosic biomass. Biofuels, v. 2, n. 4, p. 421-449, 2011/07/01 2011. ISSN 1759-7269. Available at: < http://www.tandfonline.com/doi/abs/10.4155/bfs.11.116 >.

YANG, B. et al. Unconventional Relationships for Hemicellulose Hydrolysis and Subsequent Cellulose Digestion. In: (Ed.). Lignocellulose Biodegradation: American Chemical Society, v.889, 2004. chap. 6, p.100-125. (ACS Symposium Series). ISBN 0-8412-3876-6.

YANG, B.; WYMAN, C. E. Effect of xylan and lignin removal by batch and flowthrough pretreatment on the enzymatic digestibility of corn stover cellulose. Biotechnology and Bioengineering, v. 86, n. 1, p. 8898, 2004. ISSN 1097-0290. Available at: < http://dx.doi.org/10.1002/bit.20043 >.

BSA treatment to enhance enzymatic hydrolysis of cellulose in lignin containing substrates. Biotechnology and Bioengineering, v. 94, n. 4, p. 611-617, 2006. ISSN 1097-0290. Available at: < http://dx.doi.org/10.1002/bit.20750 >.

YANG, H. Y. et al. H2SO4-Catalyzed Hydrothermal Pretreatment of Triploid Poplar to Enhance Enzymatic Hydrolysis. Industrial \& Engineering Chemistry Research, v. 51, n. 36, p. 11598-11604, Sep 12 2012. ISSN 0888-5885. Available at: < <Go to ISI>://WOS:000308575300002 >.

YASHIRO, Y. et al. Methanoregula formicica sp. nov., a methane-producing archaeon isolated from methanogenic sludge. Int J Syst Evol Microbiol, v. 61, n. Pt 1, p. 53-9, Jan 2011. ISSN 1466-5026.

YI, Z. et al. Pretreatment of lignocellulosic biomass for enhanced biogas production. Progress in Energy and Combustion Science, 2014. ISSN 0360-1285. Available at: < http://dx.doi.org/10.1016/j.pecs.2014.01.001 >. 
YOSHIDA, M. et al. Effects of Cellulose Crystallinity, Hemicellulose, and Lignin on the Enzymatic Hydrolysis of Miscanthus sinensis to Monosaccharides. Bioscience, Biotechnology, and Biochemistry, v. 72, n. 3, p. 805-810, 2008/03/23 2008. ISSN 0916-8451. Available at: < http://dx.doi.org/10.1271/bbb.70689 >.

YOURCHISIN, D. M.; PETER VAN WALSUM, G. Comparison of microbial inhibition and enzymatic hydrolysis rates of liquid and solid fractions produced from pretreatment of biomass with carbonic acid and liquid hot water. Applied Biochemistry and Biotechnology, v. 115, n. 1, p. 1073-1086, 2004. ISSN 15590291. Available at: < http://dx.doi.org/10.1385/ABAB:115:1-3:1073 >.

YU, H.-L. et al. Improvement of the enzymatic hydrolysis of furfural residues by pretreatment with combined green liquor and hydrogen peroxide. Bioresource Technology, v. 147, p. 29-36, 11// 2013. ISSN 0960-8524. Available at: 〈 http://www.sciencedirect.com/science/article/pii/S096085241301242X >.

YUE, Z. B. et al. Enhanced anaerobic ruminal degradation of bulrush through steam explosion pretreatment. Industrial \& ..., 2008. Available at: 〈 http://dx.doi.org/10.1021/ie800202c >.

ZAKARIA, M. R.; HIRATA, S.; HASSAN, M. A. Hydrothermal pretreatment enhanced enzymatic hydrolysis and glucose production from oil palm biomass. Bioresource Technology, v. 176, p. 142-148, 1// 2015. ISSN 0960-8524. Available at: http://www.sciencedirect.com/science/article/pii/S0960852414016290 >.

ZAKRZEWSKI, M. et al. Profiling of the metabolically active community from a production-scale biogas plant by means of high-throughput metatranscriptome sequencing. J Biotechnol, v. 158, n. 4, p. 248-58, Apr 30 2012. ISSN 0168-1656.

ZANIN, G. M. et al. Brazilian bioethanol program. Applied Biochemistry and Biotechnology, v. 84, n. 1, p. 1147-1161, 2000. ISSN 1559-0291. Available at: < http://dx.doi.org/10.1385/ABAB:84-86:1-9:1147 $>$.

ZENG, Y. et al. Lignin plays a negative role in the biochemical process for producing lignocellulosic biofuels. Current Opinion in Biotechnology, v. 27, p. 38-45, 6// 2014. ISSN 0958-1669. Available at: < http://www.sciencedirect.com/science/article/pii/S0958166913006708 >.

ZHANG, J. et al. Understanding changes in cellulose crystalline structure of lignocellulosic biomass during ionic liquid pretreatment by XRD. Bioresour Technol, v. 151, p. 402-5, Jan 2014. ISSN 0960-8524.

ZHANG, Q. et al. Enhancement of methane production from cassava residues by biological pretreatment using a constructed microbial consortium. Bioresource Technology, v. 102, n. 19, p. 8899-8906, 10// 2011. ISSN 0960-8524. Available at: < http://www.sciencedirect.com/science/article/pii/S0960852411008881 >. 
ZHANG, Q. et al. Optimization of thermal-dilute sulfuric acid pretreatment for enhancement of methane production from cassava residues. Bioresource Technology, v. 102, n. 4, p. 3958-3965, 2// 2011. ISSN 0960-8524. Available at: < http://www.sciencedirect.com/science/article/pii/S0960852410019619 >.

ZHANG, Y. H. P.; LYND, L. R. Determination of the Number-Average Degree of Polymerization of Cellodextrins and Cellulose with Application to Enzymatic Hydrolysis. Biomacromolecules, v. 6, n. 3, p. 1510-1515, 2005/05/01 2005. ISSN 1525-7797. Available at: 〈 http://dx.doi.org/10.1021/bm049235j 〉.

ZHAO, C. et al. Physical and chemical characterizations of corn stalk resulting from hydrogen peroxide presoaking prior to ammonia fiber expansion pretreatment. Industrial Crops and Products, v. 83, p. 8693, 2016. ISSN 0926-6690. Available at: < http://dx.doi.org/10.1016/j.indcrop.2015.12.018 >.

ZHAO, X.; ZHANG, L.; LIU, D. Biomass recalcitrance. Part I: the chemical compositions and physical structures affecting the enzymatic hydrolysis of lignocellulose. Biofuels, Bioproducts and Biorefining, 2012. ISSN 1932-1031. Available at: < http://dx.doi.org/10.1002/bbb.1331 >.

ZHENG, M. et al. The Effects of Alkaline Pretreatment Parameters on Anaerobic Biogasification of Corn Stover. Energy Sources, Part A: Recovery, Utilization, and Environmental Effects, v. 32, n. 20, p. 1918-1925, 2010/08/13 2010. ISSN 1556-7036. Available at: < http://dx.doi.org/10.1080/15567030902937119 >. Accessed on: 2015/09/25.

ZHONG, W. et al. Effect of biological pretreatments in enhancing corn straw biogas production. Bioresource Technology, v. 102, n. 24, p. 11177-11182, 12// 2011. ISSN 0960-8524. Available at: < http://www.sciencedirect.com/science/article/pii/S0960852411013654 >.

ZHU, L. et al. Structural features affecting biomass enzymatic digestibility. Bioresource Technology, v. 99, n. 9, p. 3817-3828, 6// 2008. ISSN 0960-8524. Available at: < http://www.sciencedirect.com/science/article/pii/S096085240700586X >.

ZIEMINSKI, K. et al. Effects of hydrothermal pretreatment of sugar beet pulp for methane production. Bioresource Technology, v. 166, p. 187-193, Aug 2014. ISSN 0960-8524. Available at: < <Go to ISI $>$ ://WOS:000338711100024 >.

ZIGANSHIN, A. M. et al. Microbial community structure and dynamics during anaerobic digestion of various agricultural waste materials. Appl Microbiol Biotechnol, v. 97, n. 11, p. 5161-74, Jun 2013. ISSN 0175-7598.

ZINDER, S. H.; ANGUISH, T.; LOBO, A. L. Isolation and characterization of a thermophilic acetotrophic strain of Methanothrix. Archives of Microbiology, v. 146, n. 4, p. 315-322, 1987. ISSN 1432-072X. Available at: <http://dx.doi.org/10.1007/BF00410928 >.

ZINDER, S. H. et al. Methanogenesis in a Thermophilic $\left(58^{\circ} \mathrm{C}\right)$ Anaerobic Digestor: Methanothrix sp. as an Important Aceticlastic Methanogen. Applied and Environmental Microbiology, v. 47, n. 4, p. 796807, April 1, 1984 1984. Available at: < http://aem.asm.org/content/47/4/796.abstract >. 
ZWIETERING, M. H. et al. Modeling of the Bacterial Growth Curve. Applied and Environmental Microbiology, v. 56, n. 6, p. 1875-1881, 1990. ISSN 0099-2240

1098-5336. Available at: < http://www.ncbi.nlm.nih.gov/pmc/articles/PMC184525/ >.

\section{APPENDIX}

Table 10.1 - Batch reactor composition of $\mathrm{H}_{2} \mathrm{O}_{2}$ assisted hydrothermal pretreatment for anaerobic digestion

\begin{tabular}{|c|c|c|c|c|c|c|}
\hline Index & $\begin{array}{l}\text { Reactor } \\
\text { Vol (ml) }\end{array}$ & $\begin{array}{l}\text { Working } \\
\text { Vol (ml) }\end{array}$ & Replication & $\begin{array}{c}\text { Substrate } \\
\left(\mathrm{g} \mathrm{L}^{-1}\right)\end{array}$ & $\begin{array}{c}\text { Inoculum } \\
\left(\mathrm{g} \mathrm{L}^{-1}\right)\end{array}$ & $\begin{array}{l}\text { Nutrient } \\
\text { Sol (mL) }\end{array}$ \\
\hline A-HO & 1000 & 500 & 2 & 2.44 & 21.75 & 475.81 \\
\hline B-HO & 1000 & 500 & 2 & 2.94 & 21.75 & 475.31 \\
\hline $\mathrm{C}-\mathrm{HO}$ & 1000 & 500 & 2 & 3.52 & 21.75 & 474.73 \\
\hline D-HO & 1000 & 500 & 2 & 2.49 & 21.75 & 475.76 \\
\hline E-HO & 1000 & 500 & 2 & 2.41 & 21.75 & 475.85 \\
\hline F-HO & 1000 & 500 & 2 & 2.23 & 21.75 & 476.02 \\
\hline G-HO & 1000 & 500 & 2 & 2.83 & 21.75 & 475.42 \\
\hline $\mathrm{H}-\mathrm{HO}$ & 1000 & 500 & 2 & 2.39 & 21.75 & 475.87 \\
\hline I-HO & 1000 & 500 & 2 & 2.54 & 21.75 & 475.72 \\
\hline $\mathrm{J}-\mathrm{HO}$ & 1000 & 500 & 2 & 2.37 & 21.75 & 475.89 \\
\hline $\mathrm{K}-\mathrm{HO}$ & 1000 & 500 & 2 & 2.85 & 21.75 & 475.41 \\
\hline L-HO & 1000 & 500 & 2 & 2.97 & 21.75 & 475.28 \\
\hline M-HO & 1000 & 500 & 2 & 2.51 & 21.75 & 475.75 \\
\hline $\mathrm{N}-\mathrm{HO}$ & 1000 & 500 & 2 & 2.33 & 21.75 & 475.92 \\
\hline $\mathrm{O}-\mathrm{HO}$ & 1000 & 500 & 2 & 2.50 & 21.75 & 475.75 \\
\hline $\mathrm{P}-\mathrm{HO}$ & 1000 & 500 & 2 & 2.34 & 21.75 & 475.91 \\
\hline
\end{tabular}


Table 10.2 -Batch reactor composition of $\mathrm{H}_{2} \mathrm{SO}_{4}$ assisted hydrothermal pretreatment for anaerobic digestion

\begin{tabular}{|c|c|c|c|c|c|c|}
\hline Index & $\begin{array}{l}\text { Reactor } \\
\text { Vol (ml) }\end{array}$ & $\begin{array}{l}\text { Working } \\
\text { Vol (ml) }\end{array}$ & Replication & $\begin{array}{c}\text { Substrate } \\
\left(\mathrm{g} \mathrm{L}^{-1}\right)\end{array}$ & $\begin{array}{c}\text { Inoculum } \\
\left(\mathrm{g} \mathrm{L}^{-1}\right)\end{array}$ & $\begin{array}{l}\text { Nutrient } \\
\text { Sol }(\mathrm{mL})\end{array}$ \\
\hline A-HSO & 1000 & 500 & 2 & 5.1 & 22.9 & 471.9 \\
\hline B-HSO & 1000 & 500 & 2 & 4.0 & 22.9 & 473.0 \\
\hline C-HSO & 1000 & 500 & 2 & 2.8 & 22.9 & 474.3 \\
\hline D-HSO & 1000 & 500 & 2 & 3.3 & 22.9 & 473.8 \\
\hline E-HSO & 1000 & 500 & 2 & 2.4 & 22.9 & 474.7 \\
\hline F-HSO & 1000 & 500 & 2 & 2.2 & 22.9 & 474.9 \\
\hline G-HSO & 1000 & 500 & 2 & 2.4 & 22.9 & 474.7 \\
\hline $\mathrm{H}-\mathrm{HSO}$ & 1000 & 500 & 2 & 2.2 & 22.9 & 474.9 \\
\hline I-HSO & 1000 & 500 & 2 & 2.7 & 22.9 & 474.4 \\
\hline J-HSO & 1000 & 500 & 2 & 2.6 & 22.9 & 474.5 \\
\hline K-HSO & 1000 & 500 & 2 & 4.1 & 22.9 & 472.9 \\
\hline L-HSO & 1000 & 500 & 2 & 2.1 & 22.9 & 475.0 \\
\hline M-HSO & 1000 & 500 & 2 & 2.4 & 22.9 & 474.6 \\
\hline N-HSO & 1000 & 500 & 2 & 2.4 & 22.9 & 474.7 \\
\hline $\mathrm{O}-\mathrm{HO}$ & 1000 & 500 & 2 & 2.50 & 21.75 & 475.75 \\
\hline $\mathrm{P}-\mathrm{HO}$ & 1000 & 500 & 2 & 2.34 & 21.75 & 475.91 \\
\hline
\end{tabular}


Modified Gompertz fit curves for $\mathrm{H}_{2} \mathrm{O}_{2}$ assisted hydrothermally pretreated samples

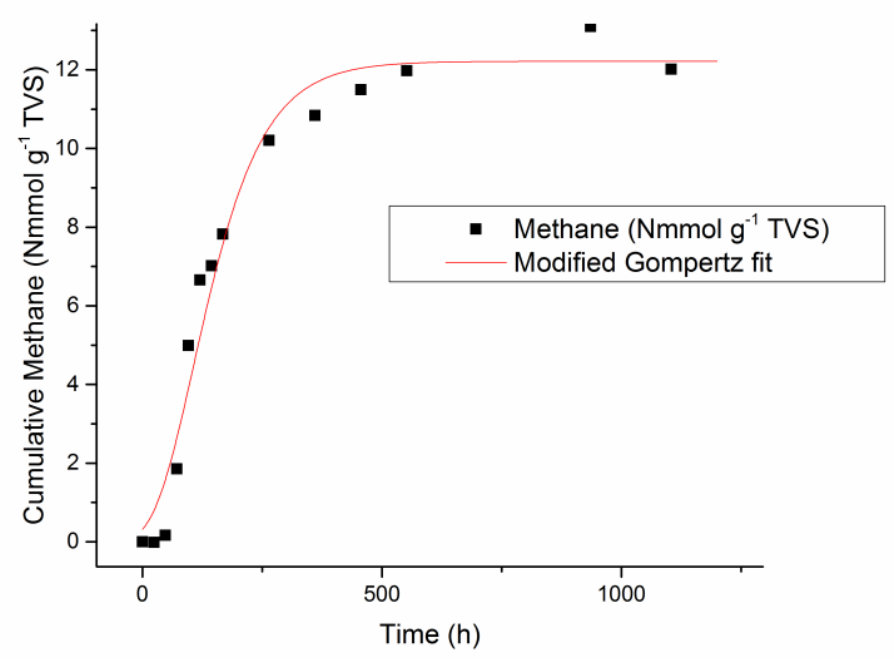

Figure 10.1 - Cumulative methane (Nmmol g ${ }^{-1}$ TVS) production with Modified Gompertz fit for A-HO

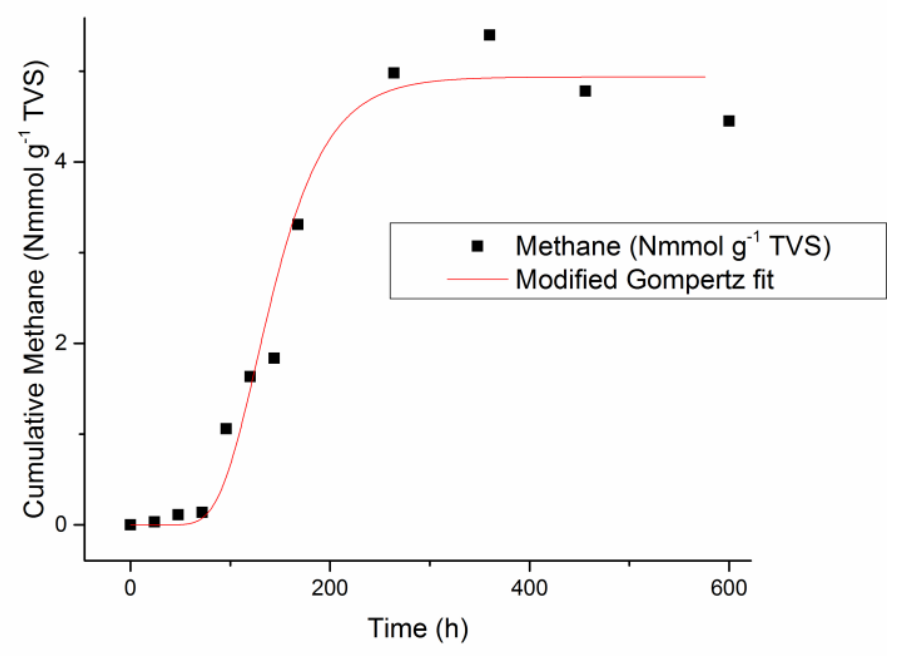

Figure 10.2 - Cumulative methane (Nmmol g ${ }^{-1} \mathrm{TVS}$ ) production with Modified Gompertz fit for $\mathrm{B}-\mathrm{HO}$ 


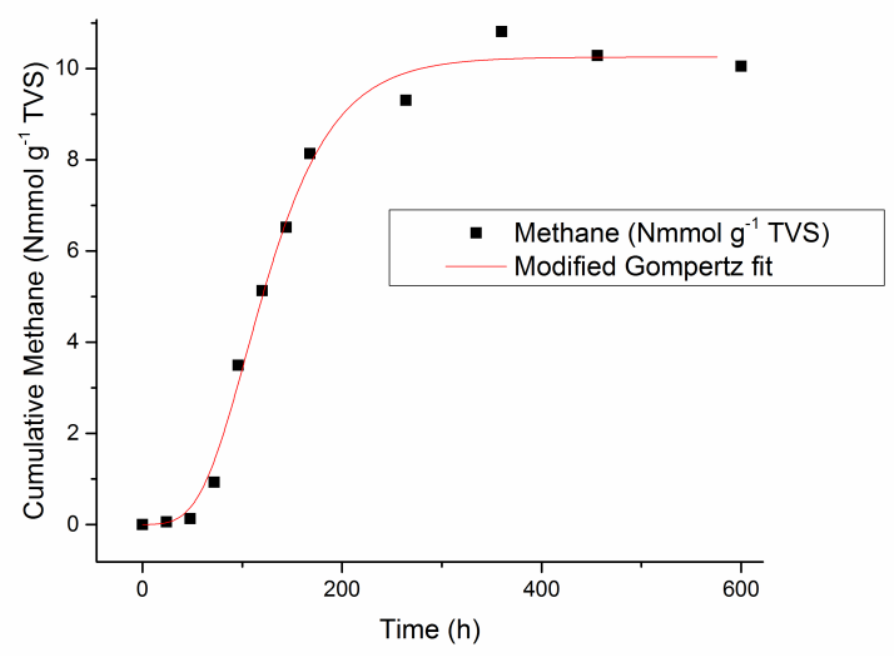

Figure 10.3 - Cumulative methane (Nmmol g ${ }^{-1}$ TVS) production with Modified Gompertz fit for $\mathrm{C}-\mathrm{HO}$

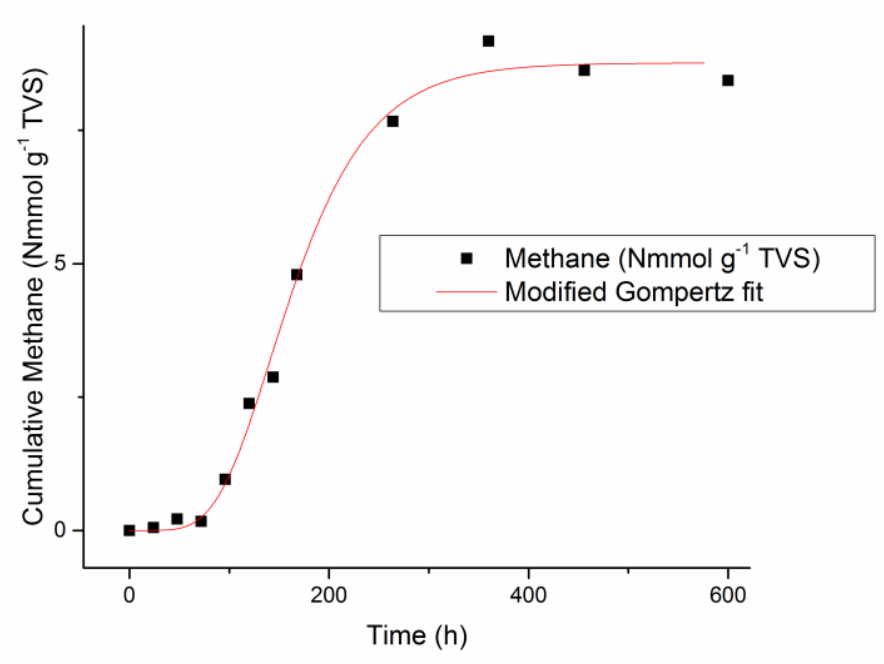

Figure 10.4 - Cumulative methane (Nmmol g ${ }^{-1}$ TVS) production with Modified Gompertz fit for $\mathrm{D}-\mathrm{HO}$ 


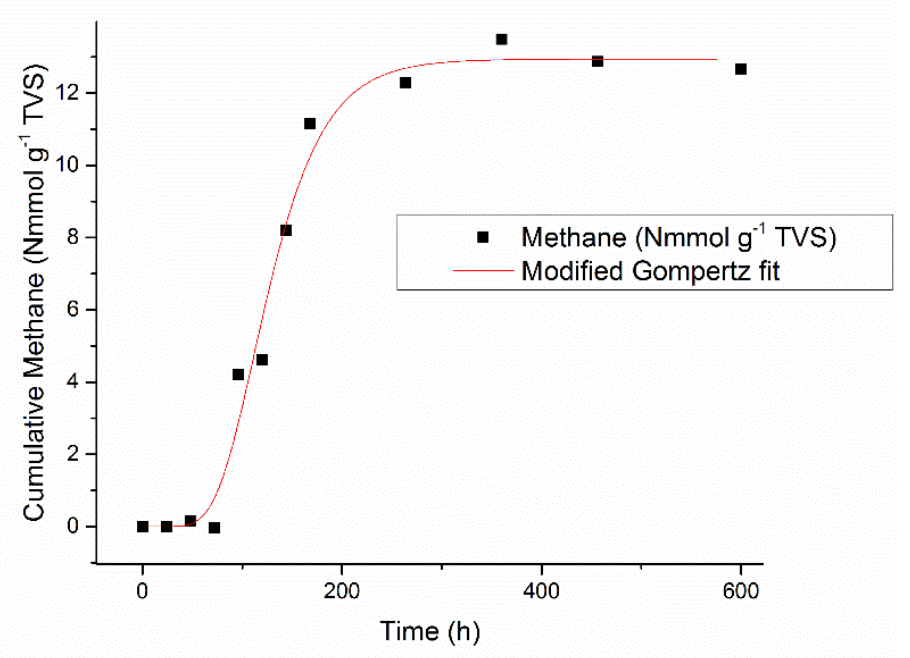

Figure 10.5 - Cumulative methane (Nmmol g ${ }^{-1}$ TVS) production with Modified Gompertz fit for E-HO

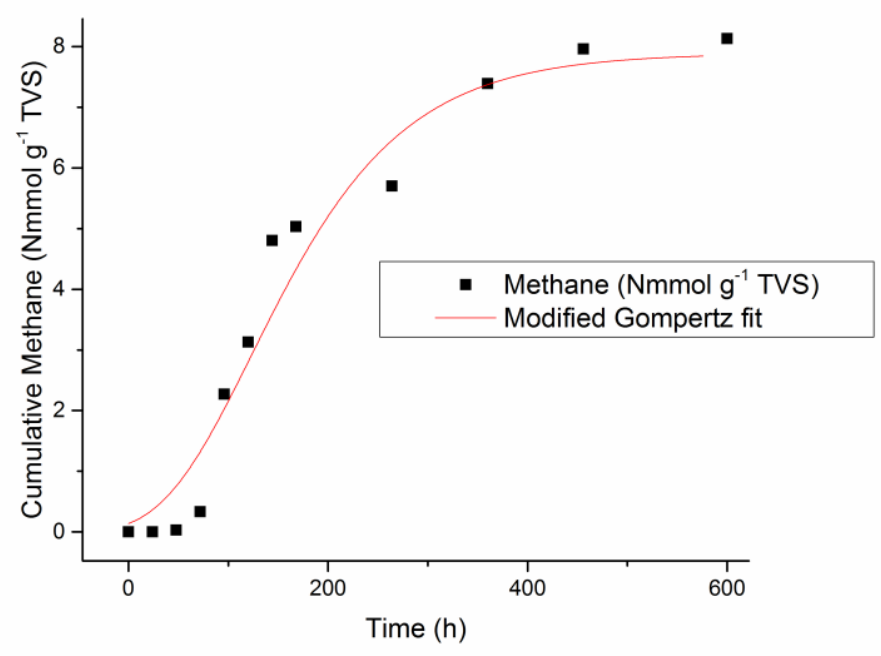

Figure 10.6 - Cumulative methane (Nmmol g ${ }^{-1}$ TVS) production with Modified Gompertz fit for $\mathrm{F}-\mathrm{HO}$ 


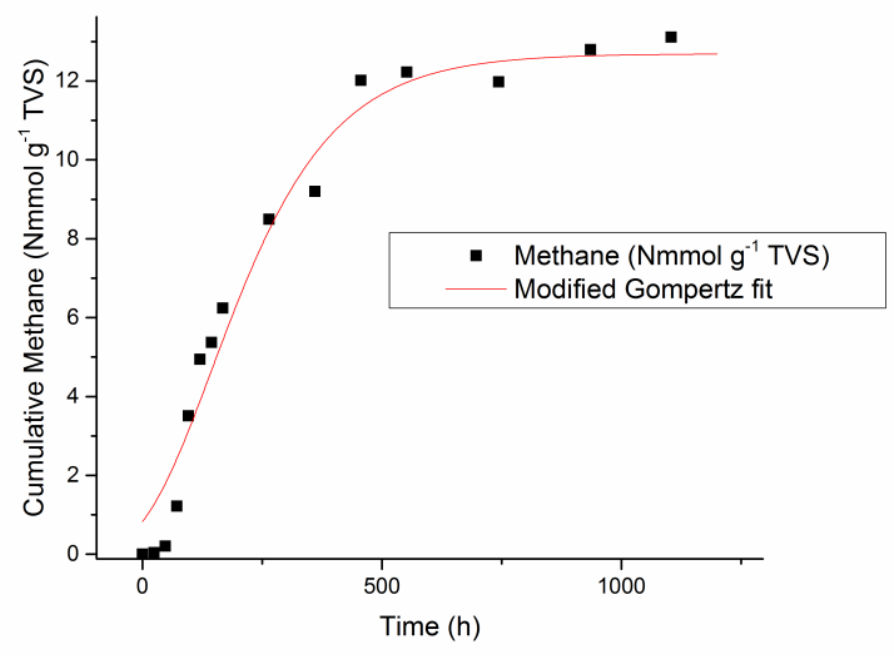

Figure 10.7 - Cumulative methane (Nmmol g ${ }^{-1} \mathrm{TVS}$ ) production with Modified Gompertz fit for G-HO

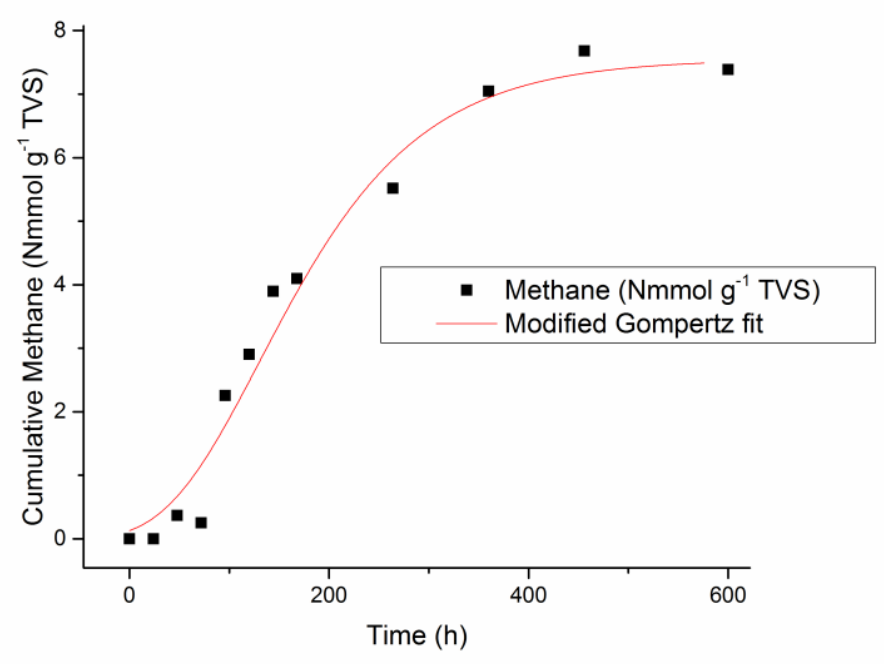

Figure 10.8 - Cumulative methane (Nmmol g ${ }^{-1}$ TVS) production with Modified Gompertz fit for $\mathrm{H}-\mathrm{HO}$ 


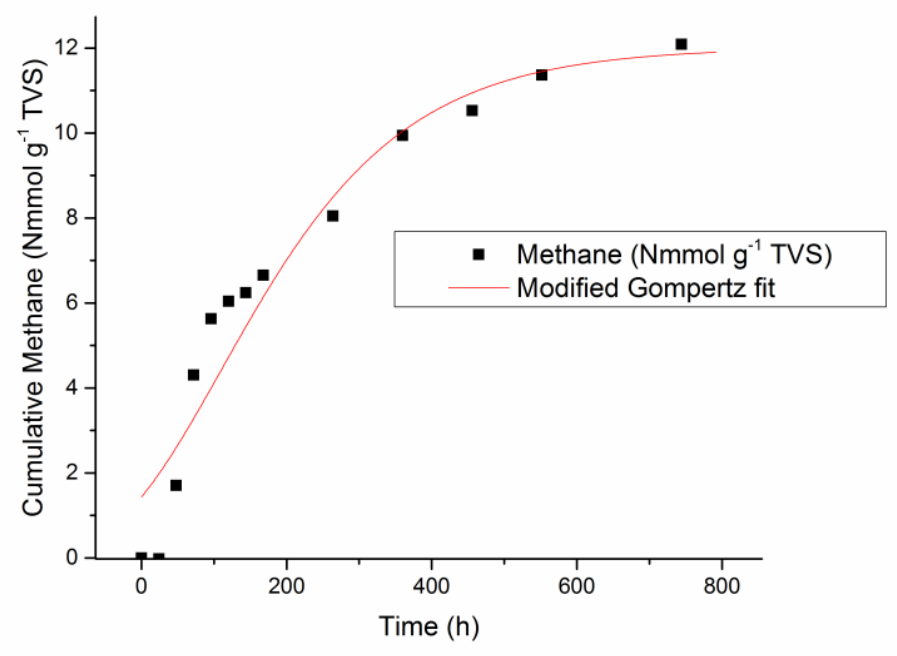

Figure 10.9 - Cumulative methane (Nmmol g-1 TVS) production with Modified Gompertz fit for I-HO

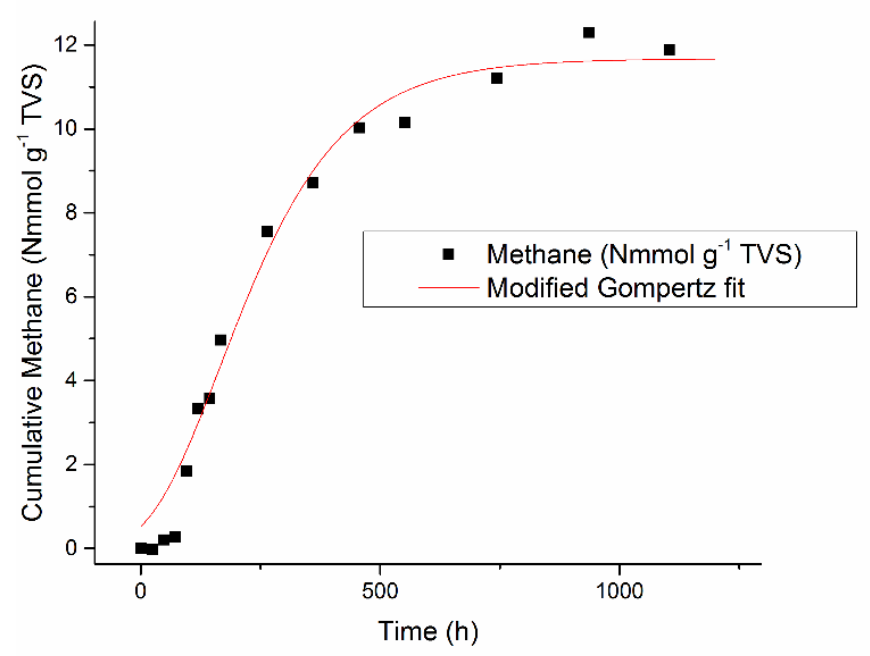

Figure 10.10 - Cumulative methane (Nmmol g ${ }^{-1} \mathrm{TVS}$ ) production with Modified Gompertz fit for J-HO 


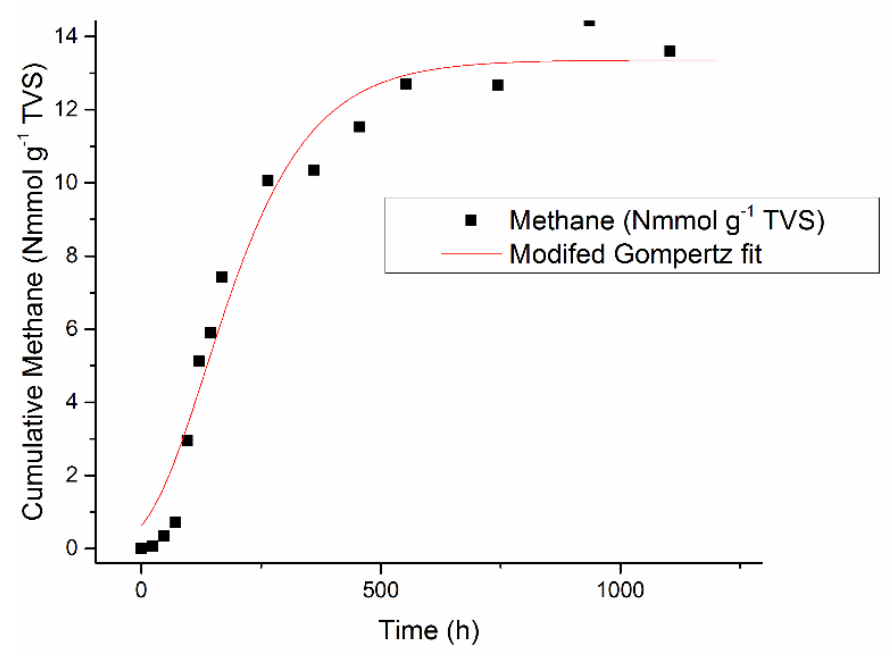

Figure 10.11 - Cumulative methane (Nmmol g${ }^{-1}$ TVS) production with Modified Gompertz fit for $\mathrm{K}-\mathrm{HO}$

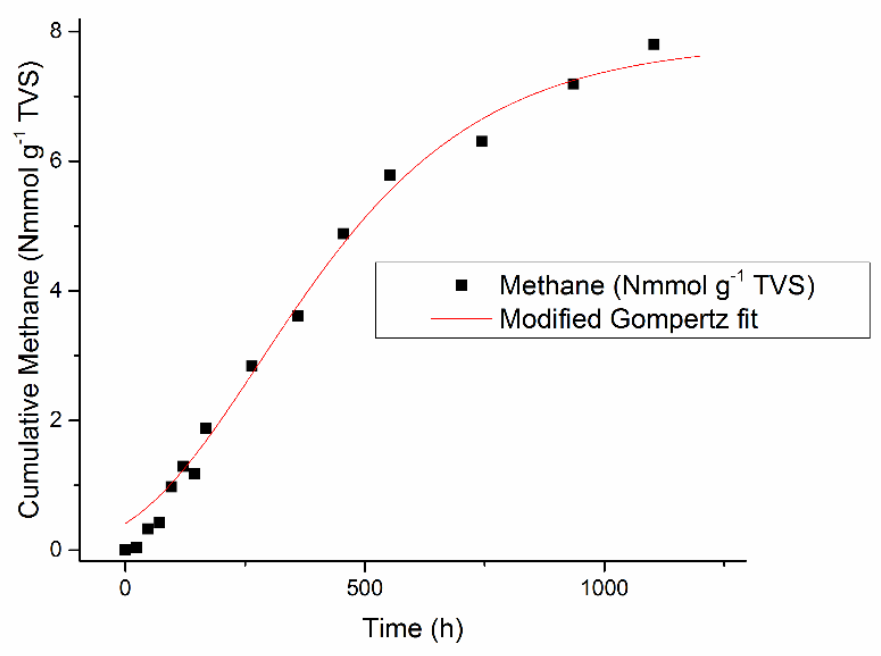

Figure 10.12 - Cumulative methane (Nmmol g${ }^{-1}$ TVS) production with Modified Gompertz fit for $\mathrm{L}-\mathrm{HO}$ 


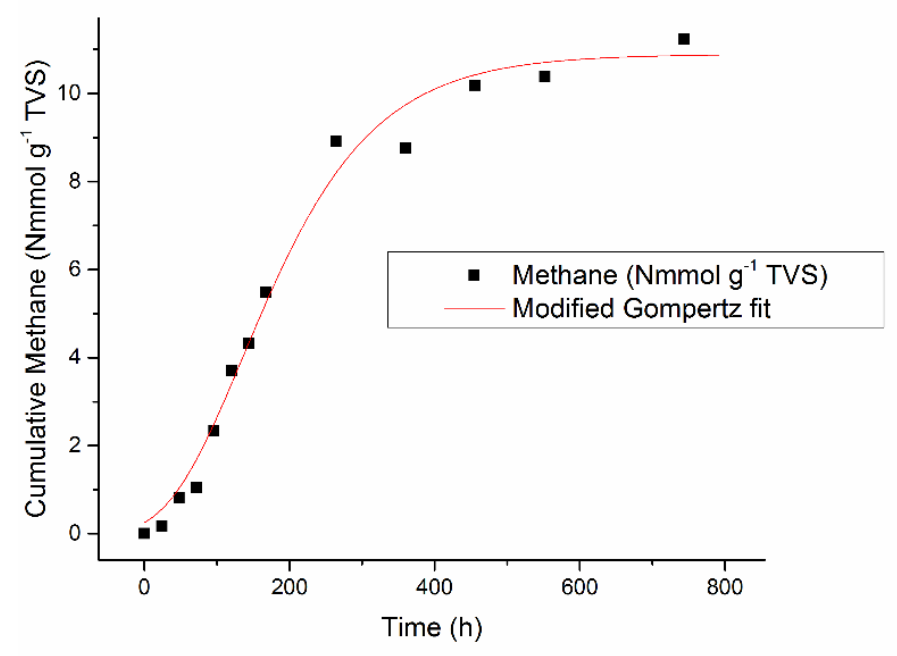

Figure 10.13 - Cumulative methane (Nmmol g- $\mathrm{TVS}^{-1}$ ) production with Modified Gompertz fit for $\mathrm{M}-\mathrm{HO}$

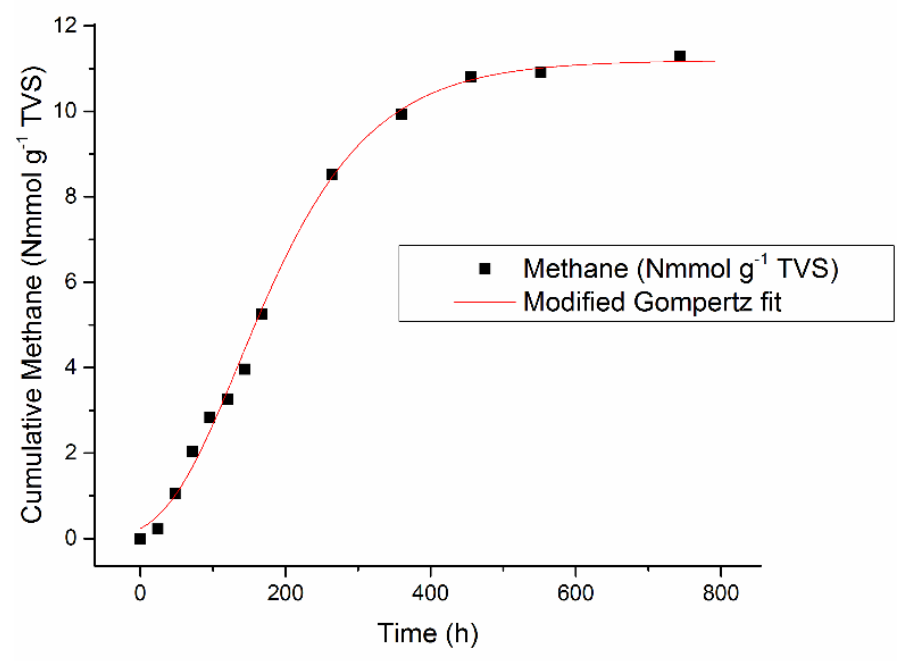

Figure 10.14 - Cumulative methane (Nmmol g ${ }^{-1} \mathrm{TVS}$ ) production with Modified Gompertz fit for N-HO 


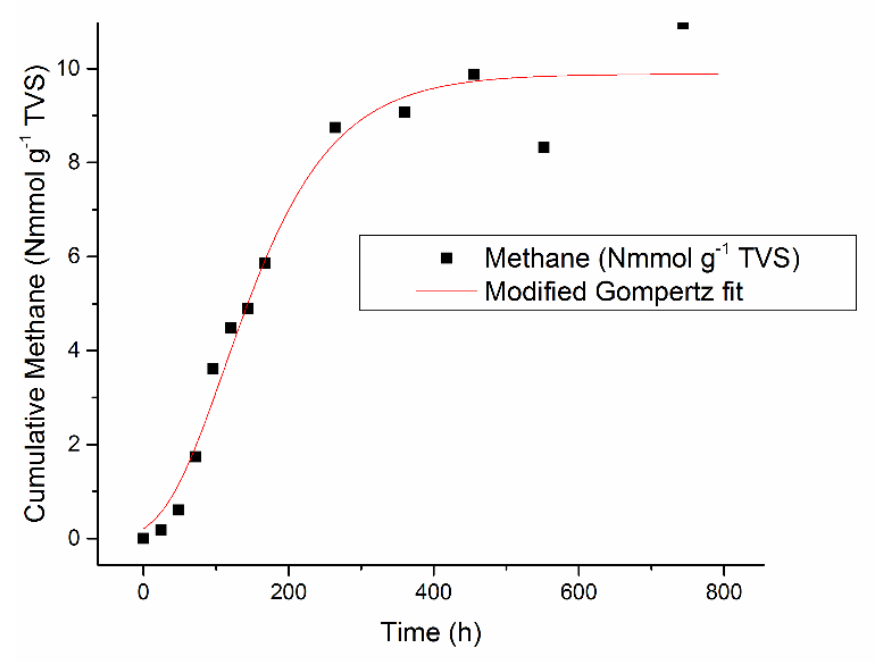

Figure 10.15 - Cumulative methane (Nmmol g ${ }^{-1} \mathrm{TVS}$ ) production with Modified Gompertz fit for $\mathrm{O}-\mathrm{HO}$

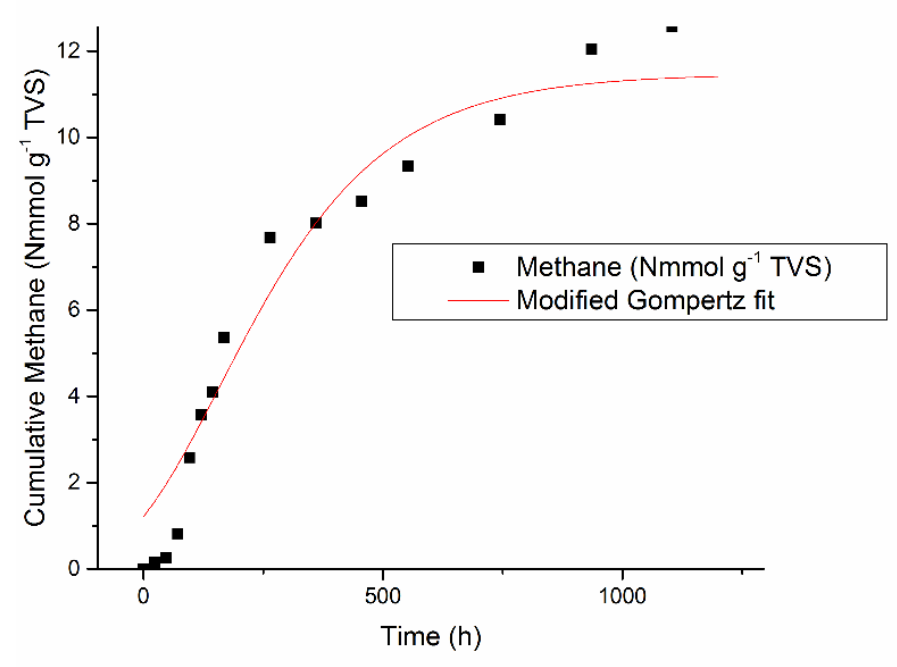

Figure 10.16 - Cumulative methane (Nmmol g ${ }^{-1} \mathrm{TVS}$ ) production with Modified Gompertz fit for $\mathrm{P}-\mathrm{HO}$ 
1 Modified Gompertz fit curves of $\mathrm{H}_{2} \mathrm{SO}_{4}$ assisted hydrothermally pretreated reactors

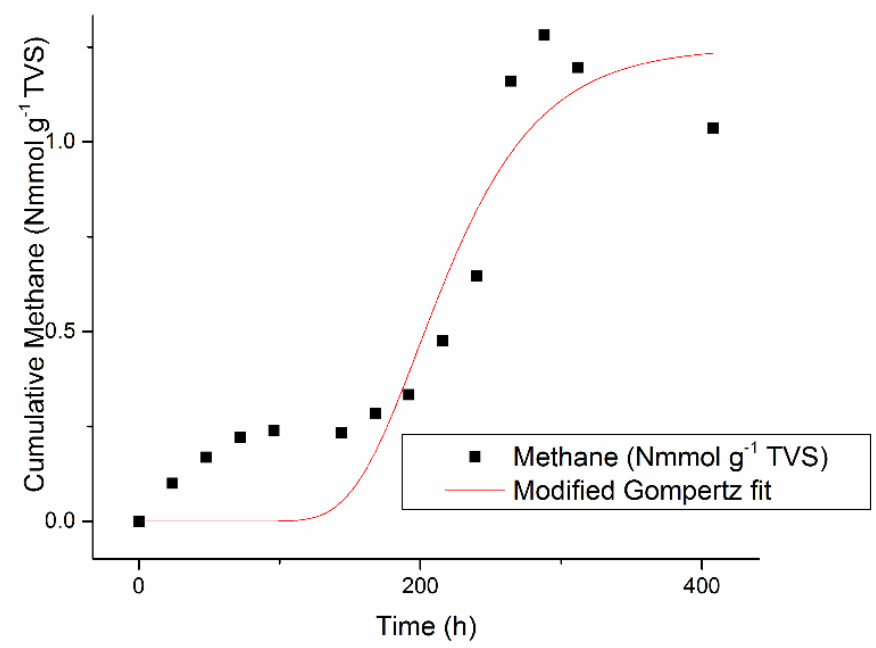

2

3 Figure 10.17 - Cumulative methane (Nmmol g-1 TVS) production with Modified Gompertz fit for 4 A-HSO

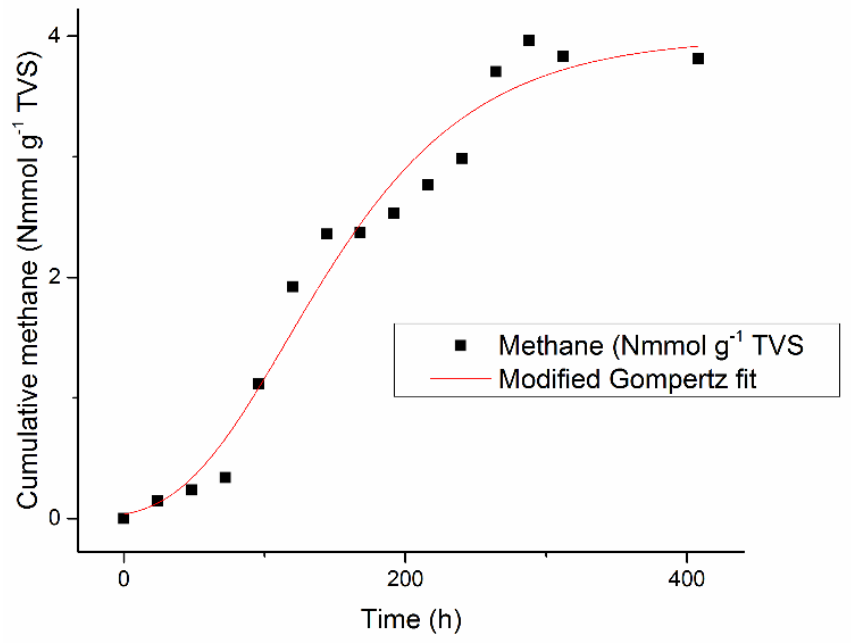

5

6 Figure 10.18 - Cumulative methane (Nmmol g-1 TVS) production with Modified Gompertz fit for 7 B-HSO 


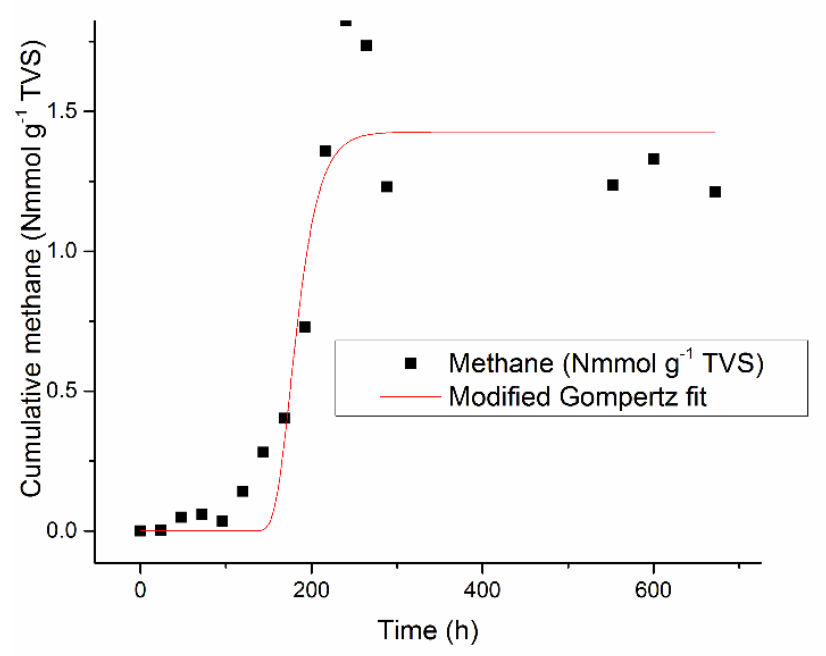

8

9 Figure 10.19 - Cumulative methane (Nmmol g-1 TVS) production with Modified Gompertz fit for 10 C-HSO

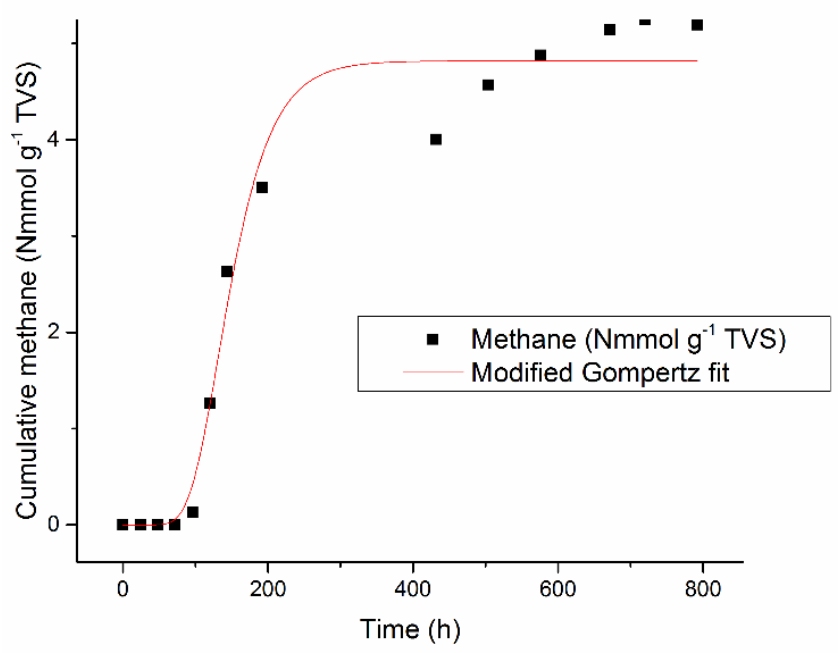

11

12 Figure 10.20 - Cumulative methane (Nmmol g-1 TVS) production with Modified Gompertz fit for 13 D-HSO 


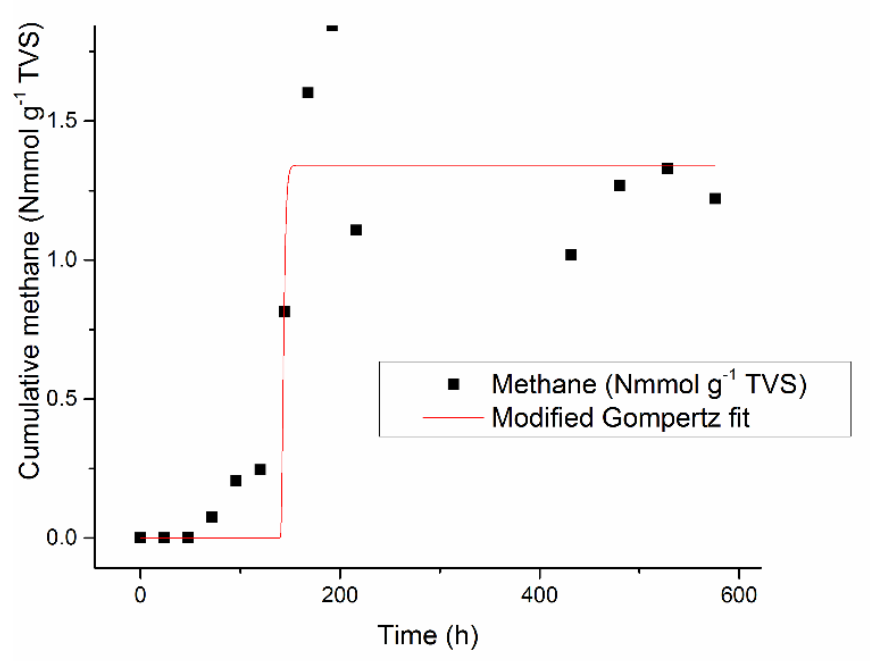

14

15 Figure 10.21 - Cumulative methane (Nmmol g-1 TVS) production with Modified Gompertz fit for 16 E-HSO

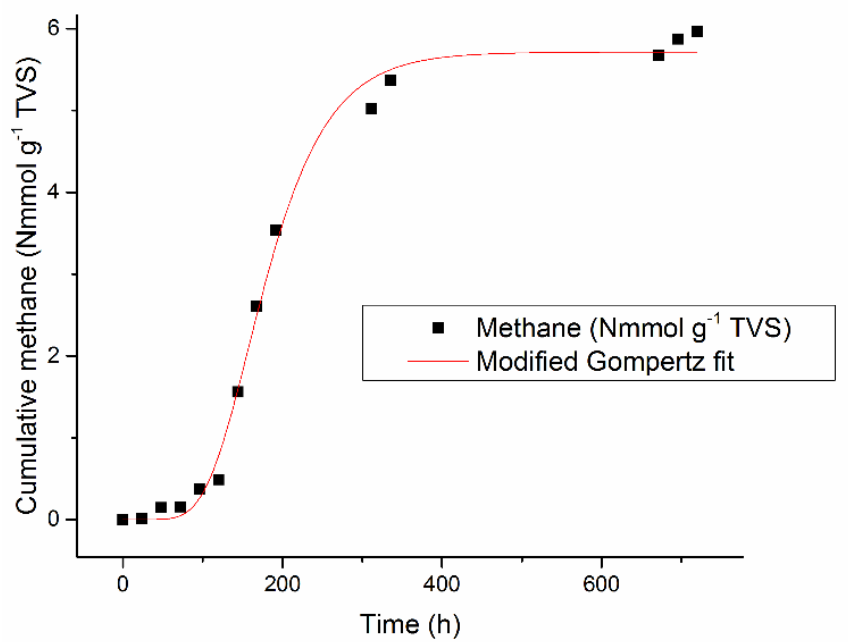

17

18 Figure 10.22 - Cumulative methane (Nmmol g-1 TVS) production with Modified Gompertz fit for 19 F-HSO 


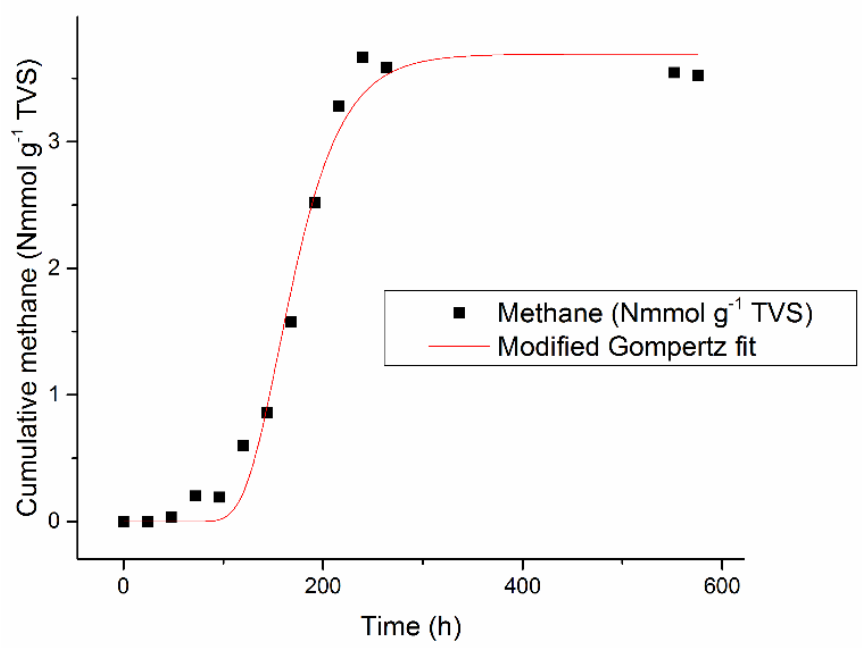

20

21 Figure 10.23 - Cumulative methane (Nmmol g-1 TVS) production with Modified Gompertz fit for 22 G-HSO

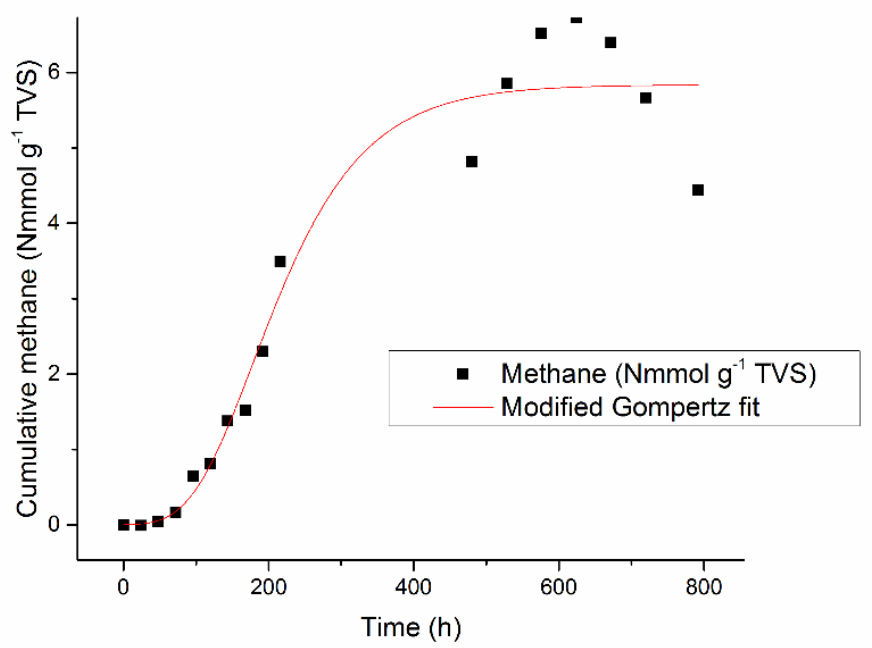

23

24 Figure 10.24 - Cumulative methane (Nmmol g ${ }^{-1}$ TVS) production with Modified Gompertz fit for 25 H-HSO 


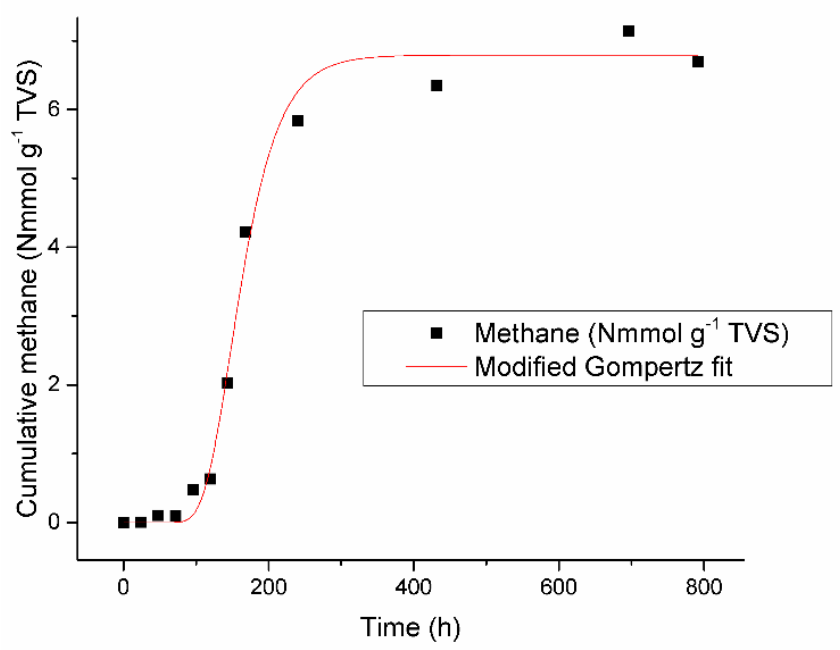

26

27 Figure 10.25 - Cumulative methane (Nmmol g ${ }^{-1}$ TVS) production with Modified Gompertz fit for 28 I-HSO

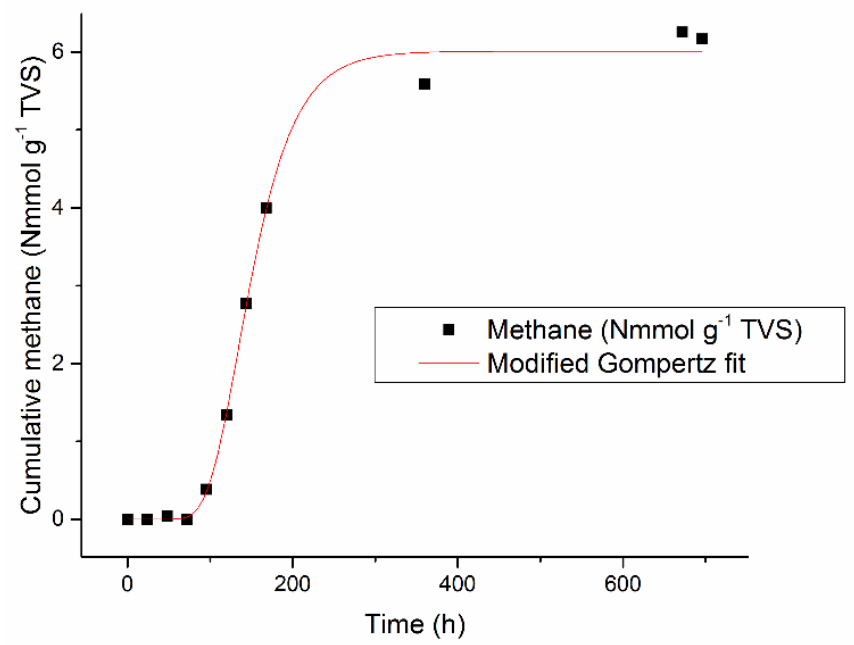

29

30 Figure 10.26 - Cumulative methane (Nmmol g ${ }^{-1}$ TVS) production with Modified Gompertz fit for 31 J-HSO 


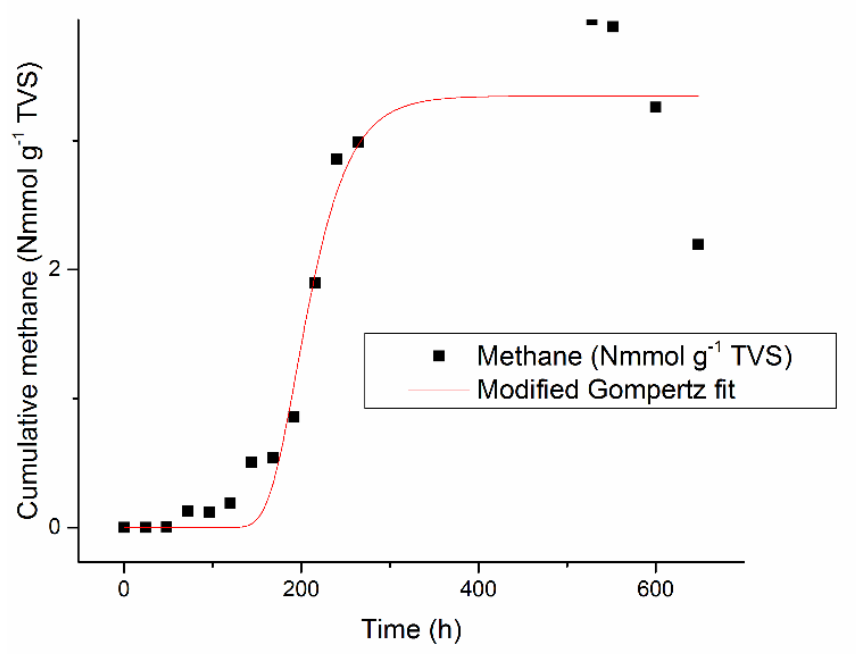

32

33 Figure 10.27 - Cumulative methane (Nmmol g ${ }^{-1}$ TVS) production with Modified Gompertz fit for 34 K-HSO

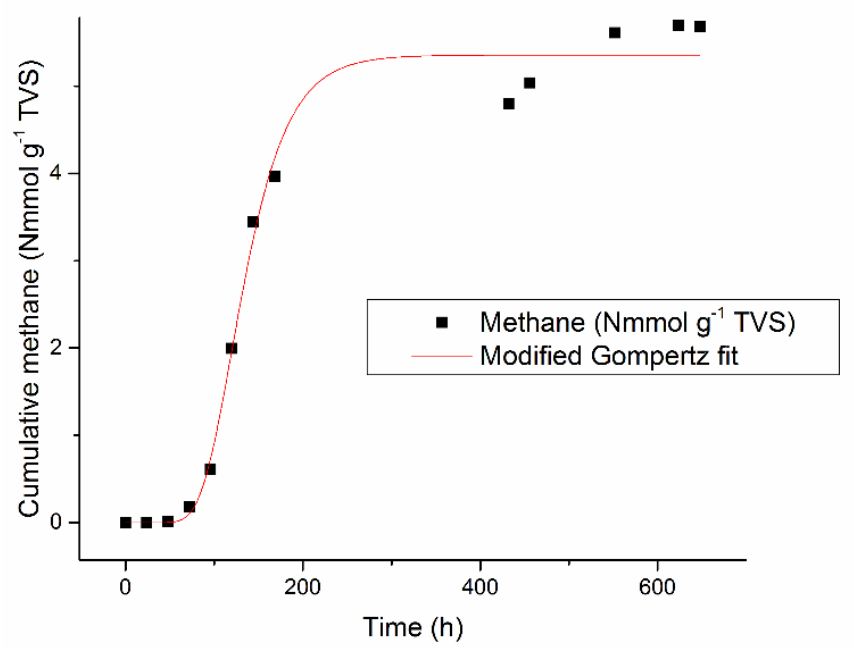

35

36 Figure 10.28 - Cumulative methane (Nmmol g-1 TVS) production with Modified Gompertz fit for 37 L-HSO 


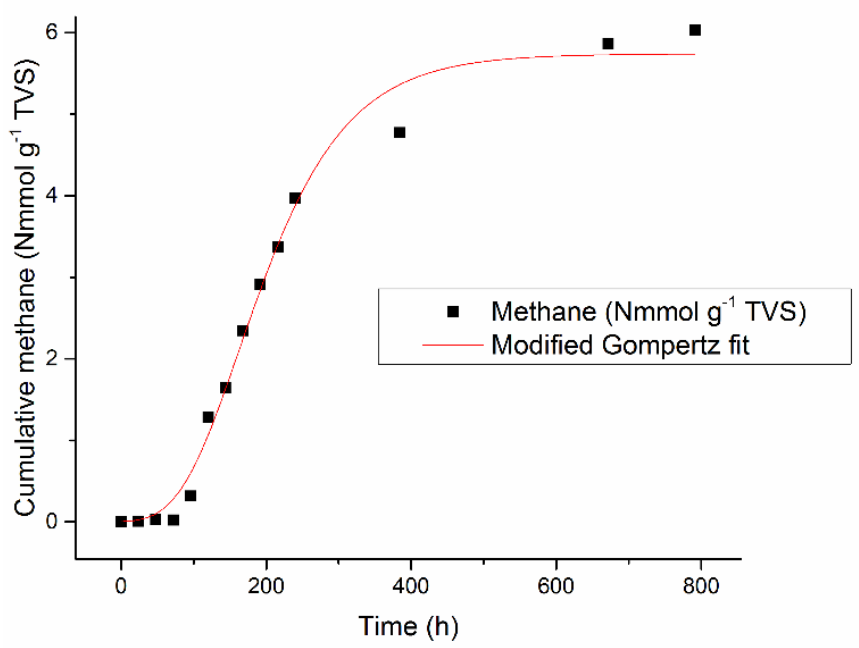

39 Figure 10.29 - Cumulative methane (Nmmol g-1 TVS) production with Modified Gompertz fit for 40 M-HSO

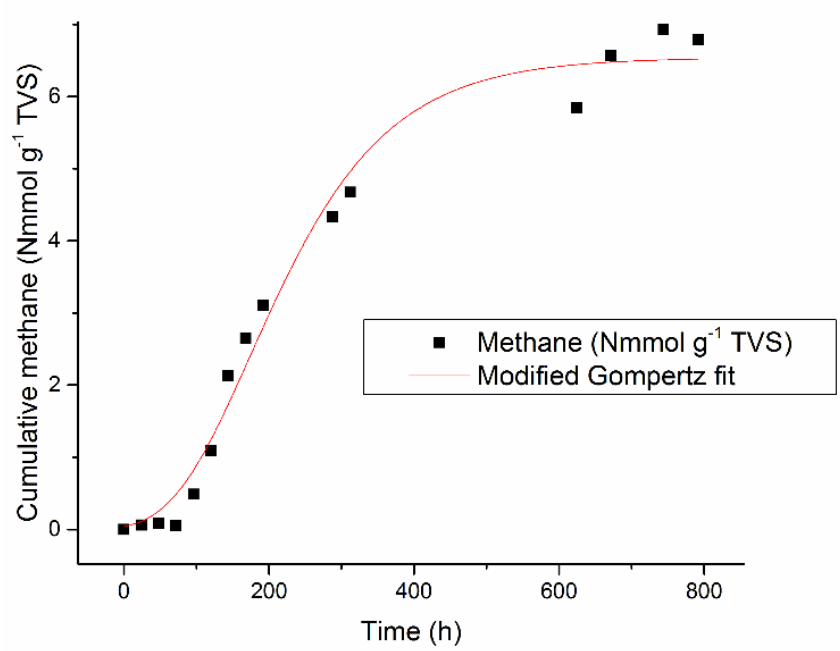

41

42 Figure 10.30 - Cumulative methane (Nmmol g ${ }^{-1}$ TVS) production with Modified Gompertz fit for 43 N-HSO 


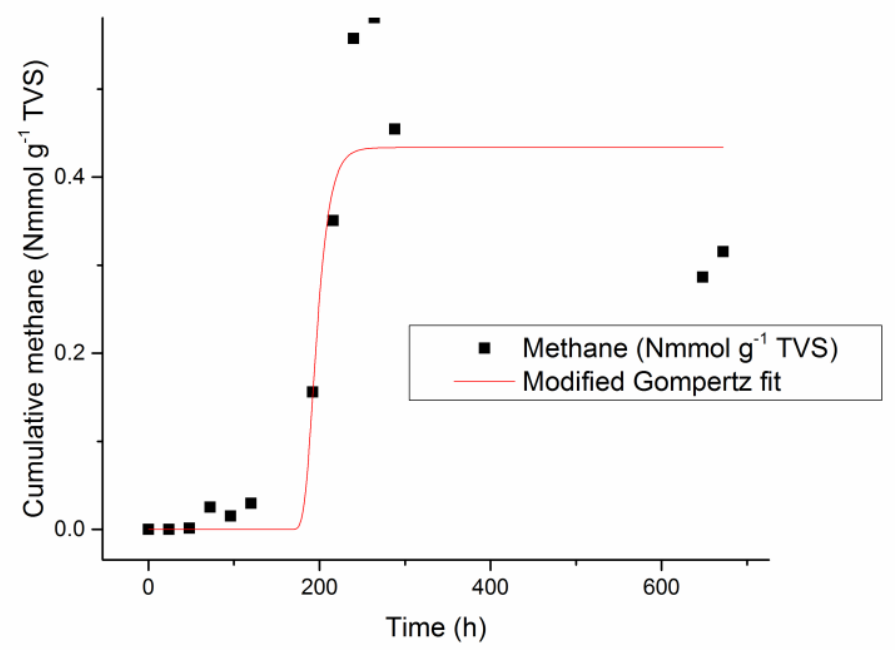

44

45 Figure 10.31 - Cumulative methane (Nmmol g-1 TVS) production with Modified Gompertz fit for 46 O-HSO

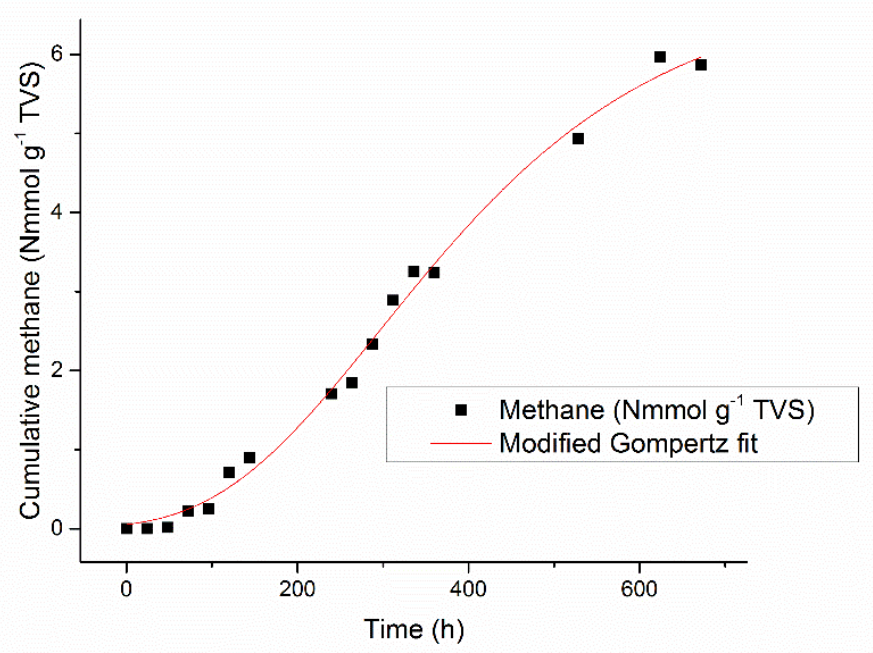

47

48 Figure 10.32 - Cumulative methane (Nmmol g-1 TVS) production with Modified Gompertz fit for 49 P-HSO 